\title{
THE IMPACT OF UNFAMILIAR PROPER NAMES ON ESL LEARNERS' LISTENING COMPREHENSION
}

by

Polina P. Kobeleva

\author{
A thesis submitted to Victoria University of Wellington \\ in fulfilment of the requirements for the degree of \\ Doctor of Philosophy \\ in Applied Linguistics
}

Victoria University of Wellington

2008 


\begin{abstract}
Vocabulary knowledge is a prerequisite to successful comprehension for native speakers and second language learners alike. Proper names, a peculiar and diverse group of lexical items, have long been the focus of discussion in general linguistics but have received practically no attention in second language vocabulary acquisition research. This study is the first attempt to assess whether proper names impact on second language learners' listening ability.
\end{abstract}

First, I examine the question of how proper names can be adequately defined and discuss their semantic, structural, pragmatic and functional properties. I analyze proper names in light of the prototype theory and argue that personal, deity and pet names constitute the core of the proper name category. Names of places and enterprises occupy an intermediate position while names of events and artefacts are considered the least prototypical, i.e. peripheral members of the category.

After identifying essential properties of prototypical proper names, I argue that in a spoken (as opposed to a written) text proper names cannot be considered automatically known items and place high demands on the listeners' cognitive resources. English as a second language (ESL) learners have to bring in a large amount of linguistic and encyclopaedic knowledge in order to cope with proper names in the flow of speech. I propose a 3-level model of such knowledge: recognition $\rightarrow$ categorization $\rightarrow$ referent properties. I then subject this model to empirical testing.

The first experiment shows that among intermediate to advanced ESL learners the proper names recognition rate is around 60\%. It is harder for ESL listeners to recognize proper names when the percentage of difficult common vocabulary in the text is high. The participants' proficiency level and the structure of a specific text were also found to affect the ability to recognize unfamiliar names. Well over a third of proper names are missed, which suggests that in real life listening, ESL learners mistake unknown common expressions for proper names and vice versa.

In the second experiment, the participants' comprehension of a news story is tested under two conditions: Names Known (all proper names are familiar prior to listening) and Names Unknown (all proper names are unfamiliar). Results indicate that the presence of unfamiliar proper names hinders the intermediate to advanced proficiency learners' comprehension of a short news text as measured by immediate free recall and the ability to evaluate proper names related statements. The effect is 
local; it concerns comprehension of details, particularly those details that are associated with processing the proper names themselves. The Names Unknown group produced fewer details and more incorrect inferences in their recalls, scored significantly lower on the measure of proper names related comprehension, and selfreported a lower amount of comprehension. In contrast, the Names Known group produced more details and fewer incorrect inferences in their recalls, scored much higher on the measure of proper names related comprehension, and self-reported a greater degree of comprehension.

The experiment also shows that participants in the Names Unknown treatment were not always able to ascertain from context what the referent of an unfamiliar proper name is, and in cases when they did, they could not extract as much information about the referent as the participants in the Names Known treatment had available. It is evidently unrealistic to expect ESL learners to determine what unfamiliar proper names refer to from context. On average, after 2-3 attempts at listening participants in the Names Unknown group were able to extract just over $40 \%$ of the information about the referents of unfamiliar proper names. Also participants' difficulty ratings of experimental tasks confirmed that the presence of unfamiliar proper names definitely makes the text seem harder to understand.

The last experiment replicated the findings of the previous one on a larger sample. The Names Known group performed significantly better on open-ended questions and true-false-don't know statements. A substantial effect of unfamiliar proper names on the overall comprehension scores was found. Around $17 \%$ of the variance in the scores was accounted for by familiarity/lack of familiarity with proper names. The findings also provide some evidence in support of the claim that a name form that hints at the cognitive category its referent belongs to is less likely to adversely affect comprehension than a form that does not.

Unfamiliar proper names contribute to raising the vocabulary threshold in second language listening, which should be taken into account by teachers, testdevelopers and other TESOL (teaching English to speakers of other languages) professionals. 


\section{Acknowledgements}

As the old saying goes, money does not grow on trees. This sad fact stopped many a good undertaking from happening. First and foremost, I would like to thank the Victoria University Scholarships Committee for granting me the VUW PhD Scholarship and then the VUW PhD Completion Scholarship without which I would not have been able to carry out this project. I am thankful to the Faculty of Humanities and Social Sciences for providing two generous grants that enabled me to attend overseas conferences. Last but not least, I am also very grateful to the School of Linguistics and Applied Language Studies for funding the proofreading and programming work as well as statistical consulting.

Special thanks go to my extraordinary supervisors, Paul Nation and Laurie Bauer for their continuous support, insightful comments, ideas and guidance, and, above all, for believing in me despite the fact that I am such a slow writer and persistently forget to use articles.

I wish I could list the names of every one of some two hundred students who took part in my experiments. This is not possible for ethics reasons but I want you to know that you are truly the main characters of this thesis. Thumbs up! I sincerely hope that your time and effort was spent for the ultimate benefit of all other English learners out there who struggle with unfamiliar proper names just like you and I did. Many thanks to the teachers and programme coordinators who gave up some of their precious time to assist me in advertising the experiments and collecting participants' background information. In Victoria University of Wellington: Angela Joe, Susan Smith, Mary Greenfield, Philippa Larkindale, Sonia Millett, Natalia Peters, Alastair Ker, Gael Liston, Brian King, Ewa Kusmierczyk, Jo Leach, Alison Hoffmann, Jonathan Newton, Margaret Lloyd, Annie Marenghi, Deryn Hardie Boys, Sally Lindfors, Kristen Shann, Kieran File, Prudence Walker, Jenny Simpson and Alison Hamilton-Jenkins. In Massey University: Masako Crawford. In The Campbell Institute CLA: Tim and Julie Brown, Richelle Hewin. In GEOS Wellington Language Centre: Anna Hasper.

I would also like to gratefully acknowledge the help of people whose specialist skills were instrumental in implementing various parts of the project: Anna Adams for proofreading all experimental texts plus purchasing and advice on sound equipment; Edith Paillat for Soloist training and technical assistance in the multimedia classroom; 
Vivien Trott for transcribing Radio New Zealand news broadcasts; Cheryl McGettigan at the VUW IELTS Centre for letting me borrow the IELTS materials and liaising with IDP Education Australia; Chris Andreae for writing the computer programme for my proper names test; Colleen Kelly, Colin Walker and Nokuthaba Sibanda for statistical advice and teaching me how to use SPSS.

Thanks to the wonderful school administration team - Jane Dudley, Sarah Dunstan, Rachel Scholes and Bernie Hambleton - for patiently attending to hundreds of my requests, big and small, and for always being cheerful doing that!

Writing a thesis is largely a solitary activity, and sometimes it makes you feel isolated from the entire world. Thanks to Janet Holmes, there is a fortnightly $\mathrm{PhD}$ group that promotes informal discussion and cooperation among the current postgraduates at the school. These meetings kept me sane and were a great help, especially at the methodology development stage. I'm indebted to the fellow $\mathrm{PhD}$ students for ideas and constructive criticism, for sending me references and web links, and for bringing along delicious cakes and chocolate. In particular, cheers to Stephie for being a role model; to Tina for being my only floormate at uni in the ungodly late hours on weekends and her friendly encouragement; to Agnes for not letting me give up when I almost did; to Sangrawee, Laura, Marianna, Marianne, Sharon and Dongkwang for help with recordings and piloting, and to my officemate Nita for putting up with me on 'whining days'.

Caro, my adventurous Argentinean friend, you always inspired me to aim high. I wish you every success with your own thesis.

Dearest Mum, Dad and Sasha, you are thousands of miles away but your love is with me all the time; without your support I would never have come this far.

... And the Oscar for being THE best and most caring person in the world goes to my fiancé, Andrew Mahoney, who in the course of time has been my personal chef, taxi driver, councellor, employment adviser, cheerleaders' manager, nurse and motivational coach, not to count full-time news announcer, proofreader and research assistant. 


\section{Contents}

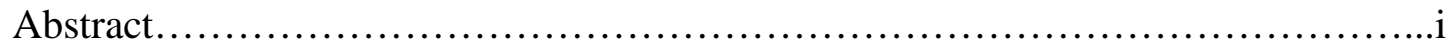

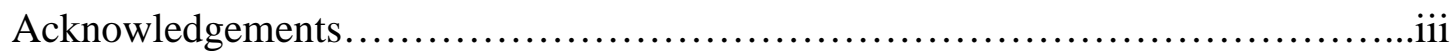

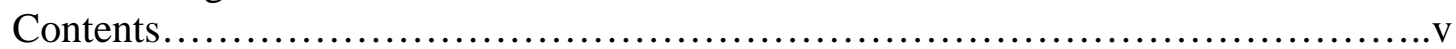

List of tables and figures..................................................... viii

Chapter I. Introduction..........................................................1

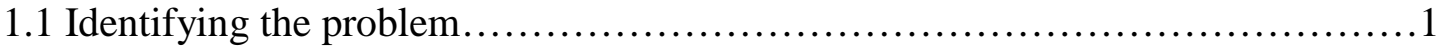

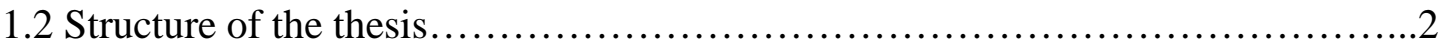

Chapter II. Defining a proper name: the prototype theory $. . . . \ldots \ldots \ldots \ldots \ldots \ldots \ldots \ldots . . .5$

2.1 What is a proper name? Analysis of proposed definitions......................5

2.2 Philosophy of language: Kripke's account of proper names....................11

2.3 Onomastics: name catalogue approach........................................ 15

2.4 Prototype theory: core names and periphery................................20

2.4.1 Personal, deity and animal proper names..........................21

2.4.2 Place names and names of enterprises.............................27

2.4.3 Names of events and artefacts.................................... 30

2.5 Chapter overview.................................................... 32

Chapter III. Defining a proper name: semantic, grammatical, pragmatic and structural properties...............................................................34

3.1 Prototypical proper names in semantics................................... 34

3.1.1 Proper names as referring devices..................................34

3.1.2 Proper names lack intensions....................................... 35

3.1.3 Proper names are definite, specific and non-partitive...................37

3.2 Prototypical proper names in grammar...................................41

3.2.1 Simplicity ..................................................4

3.2.2 Non-predicability..........................................47

3.2.3 Lack of article contrast, number contrast and restrictive modification...50

3.3 Prototypical proper names in pragmatics....................................57

3.4 Functional approach to defining proper names..............................59

3.4.1 Functional definition of proper names adopted in this study...........60

3.4.2 Functional properties comparison: proper names and deictics............61

3.4.3 Functional properties comparison: proper names and definite noun phrases...........................................................63

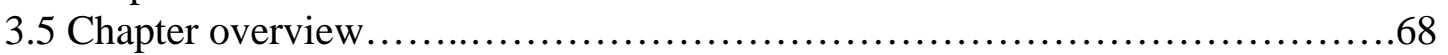

Chapter IV. Proper names in ESL listening.................................69

4.1 Introduction............................................................69

4.2 Can unfamiliar proper names affect ESL learners' listening comprehension?......69

4.3 What knowledge do ESL learners need to have in order to cope with proper names

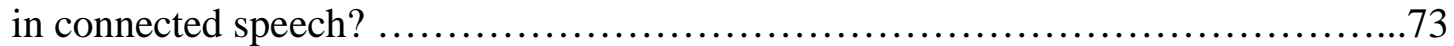

4.3.1 Level 1. A name or not a name? That is the question..................74

4.3.2 Level 2. What kind of referent? .................................... 75

4.3.3 Level 3. Almost Famous? ..............................................76

4.4 What kind of name? All names are equal but some are more equal than others ...78

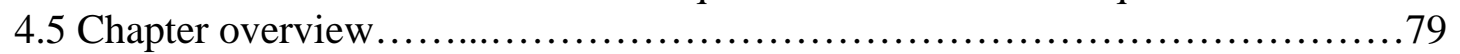

Chapter V. Experiment 1: proper names recognition rate........................81

5.1 Introduction............................................................. 81

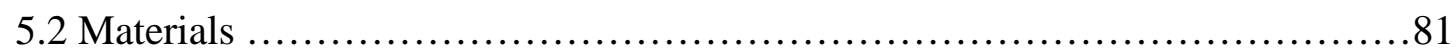

5.2 .1 Text selection................................................. 81 


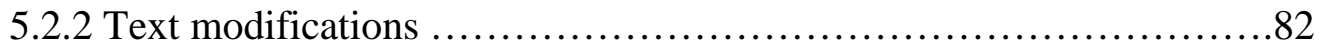

5.2 .3 Audio files ....................................................... 84

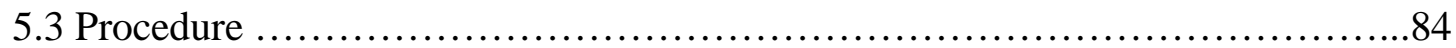

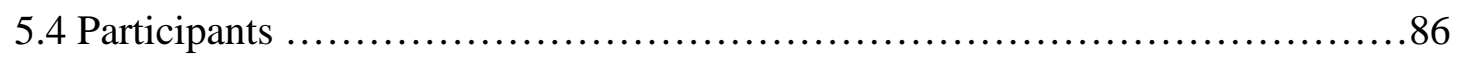

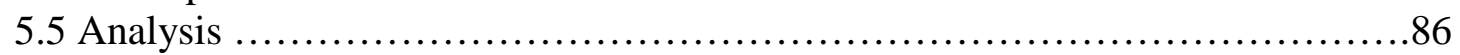

5.5.1 Percentage of proper names recognized $\ldots \ldots \ldots \ldots \ldots \ldots \ldots \ldots \ldots \ldots . . . \ldots 7$

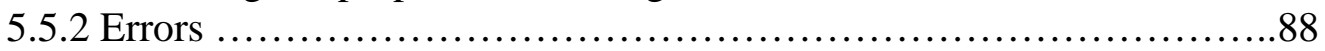

5.5.3 GEE analysis ....................................................

5.5.3.1 Practice effect ......................................91

5.5.3.2 Proficiency effect ....................................92

5.5.3.3 Repeated vs. singly occurring proper names ...............92

5.5.4 Native speaker control group ...................................93

5.6 Summary of Experiment 1 findings ...................................... 94

Chapter VI. Experiment 2: the learners' ability to categorize the referent and the impact of names on listening comprehension......................................95

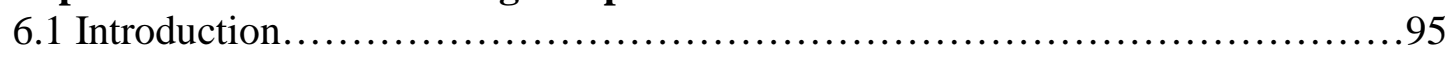

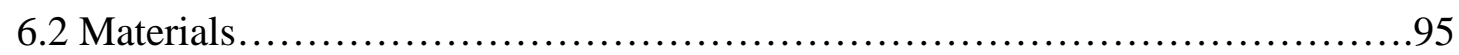

6.2.1 Experimental text...........................................95

6.2.2 Comprehension measures......................................994

6.2.2.1 Recall...............................................994

6.2.2.2 Comprehension questions.............................99

6.2.2.3 Difficulty ratings and PNT .............................100

6.2.2.3.1 Difficulty ratings..............................100

6.2.2.3.2. Computerized proper names test (PNT)...........101

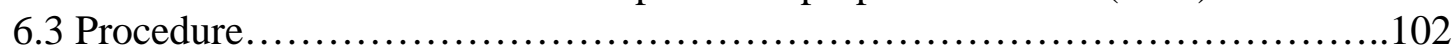

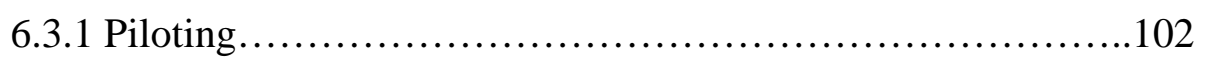

6.3.2 Main phase ............................................103

6.3.2.1 Treatment groups...............................103

6.3.2.2 Preteaching....................................103

6.3.2.3 Listening and comprehension testing.................105

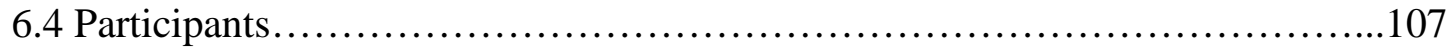

6.5 Results................................................................... 107

6.5.1 Recall protocols................................................ 107

6.5.2 Open-ended questions......................................... 112

6.5.3 Multiple choice questions......................................113

6.5.4 Proper names related statements (true-false-don't know).............114

6.5.5 Proficiency comparison....................................... 115

6.5.6 PNT results ...................................................... 116

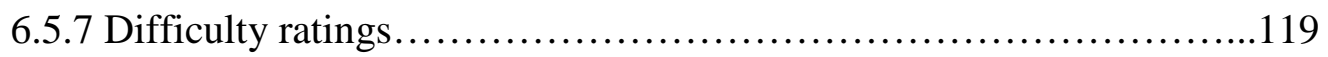

6.6 Summary of Experiment 2 findings..................................... 121

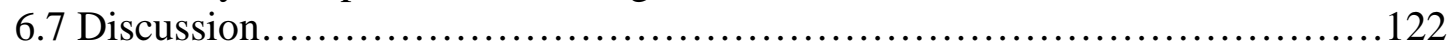

Chapter VII. Experiment 3: replication study with larger sample................126

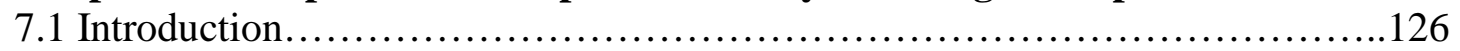

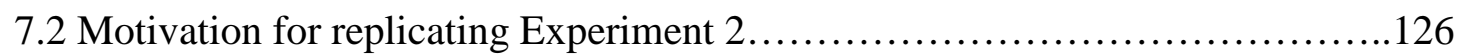

7.2.1 Drawbacks in Experiment 2................................... 126

7.2.2 Procedure modifications in Experiment 3.......................... 127

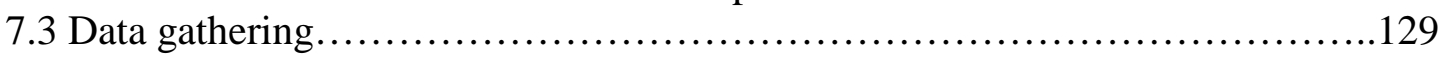

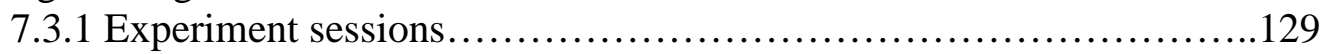

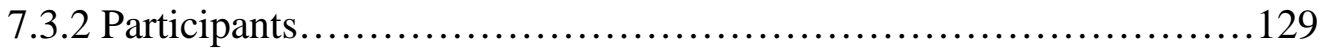

7.4 Results............................................................... 130 
7.4.1 Proper names related statements (TFDN) ........................ 130

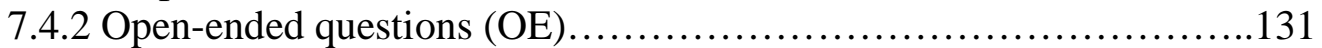

7.4.2.1 Quantitative comparison...............................131

7.4.2.2 Qualitative comparison.................................132

7.4.2.2.1 Question 1....................................133

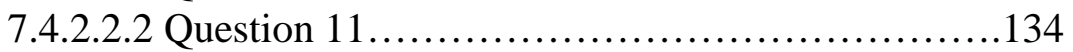

7.4.2.2.3 Question 2...................................134

7.4.2.2.4 Question 4...................................135

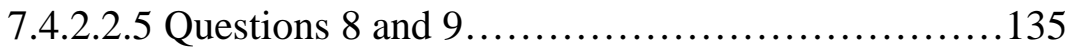

7.4.3 Multiple choice questions (MC) ............................... 136

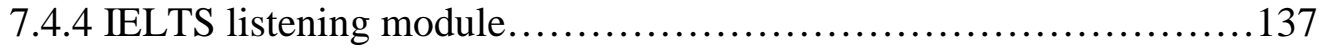

7.4.5 ANCOVA results (TFDN+OE+MC) ............................. 137

7.4.6 Mini proper names test............................................ 139

7.4.6.1 Proper names self report................................139

7.4.6.2 'Tick all options that apply' questions......................141

7.4 .7 Difficulty ratings............................................... 142

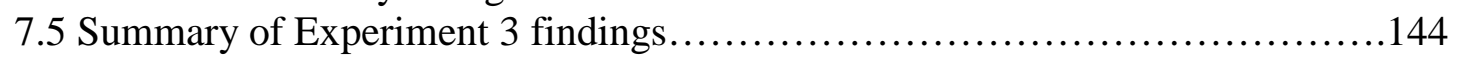

7.6 Discussion............................................................. 143

Chapter VIII. Conclusions....................................................149

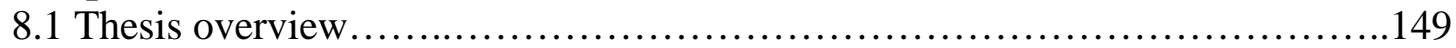

8.2 Implications for ESL pedagogy ...................................... 152

8.3 Limitations of the study and suggestions for future research..................157

Appendix A. Experiment 1. Text topics, origin and speakers......................159

Appendix B. Experiment 1. Number of proper names and text length...............160

Appendix C. Experiment 1. Information sheet................................. 161

Appendix D. Experiment 1. Listening instructions and sequence of text

presentation............................................................... 162

Appendix E. Experiment 1. Participants and their VLT test results..................163

Appendix F. Experiment 1. Number of errors of different types by participant......164

Appendix G. Experiment 2. Listening passage................................. 165

Appendix H. Experiment 2. Open-ended questions ............................ 166

Appendix I. Experiment 2. Multiple choice questions............................ 167

Appendix J. Experiment 2. Proper names related statements........................169

Appendix K. Experiment 2. Difficulty ratings of the experimental tasks, participants'

answer sheet.............................................................. 170

Appendix L. Experiment 2. Participants' scores on open-ended

questions.................................................................. 171

Appendix M. Experiment 2. Participants' scores on multiple choice

questions................................................................ 172

Appendix N. Experiment 2. Participants' scores on proper names related

statements.............................................................. 173

Appendix P. Experiment 2. Participants' difficulty ratings of experimental tasks...174 Appendix Q. Experiment 3. Participants' scores on proper names related

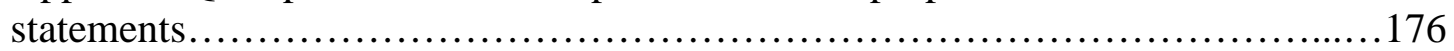

Appendix R. Experiment 3. Participants' scores on open-ended questions...........178

Appendix S. Correct options and distractors in the PNT ......................... 180

Appendix T. Experiments 2 and 3. Cards used in preteaching..................... 183

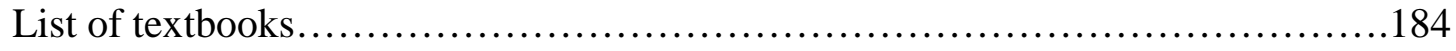

References............................................................. 187 


\section{List of tables and figures}

Table 2.1. Comparison of proper name types outlined in CMS and in Zelinsky's paper

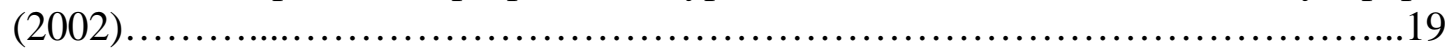

Table 2.2. Proper names of events............................................... 30

Table 2.3. Proper names of artefacts ........................................ 31

Table 3.1. Comparison of proper names and Anderson's 'notional classes' (2007:

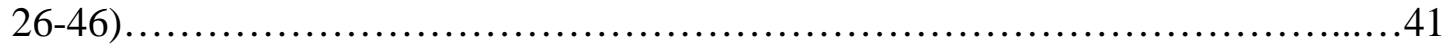

Table 3.2. The notional system of syntactic categories (Anderson, 2007)............49

Table 3.3. Comparison of the functional properties of proper names and deictic expressions................................................................

Table 3.4. Comparison of the functional properties of proper names and definite

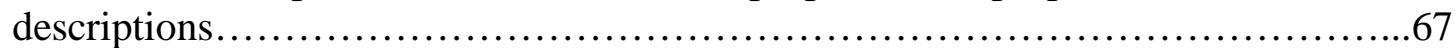

Table 4.1. Knowledge necessary to deal with proper names in spoken texts..........73

Table 4.2. Semantic and contextual types of proper names........................79

Table 4.3. Potential impact of different types of proper names on ESL learners'

listening comprehension......................................................79

Table 5.1. Vocabulary profile: simplified set vs. complicated set. Percentages are for

types, i.e. unique words ................................................. 83

Table 5.2. Vocabulary profile: simplified set vs. complicated set. Percentages are for

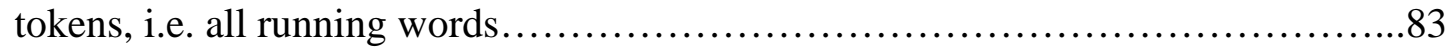

Table 5.3. Average percentage of recognized proper name tokens..................87

Table 5.4. Average percentage of recognized proper name types..................88

Table 5.5. Experiment 1. Examples of different kinds of errors.....................90

Table 5.6. Percentages of partially recognized repeated proper name types by class..90

Table 5.7. Score statistics for Type 3 GEE analysis................................ 91

Table 5.8. Percentage of recognized proper name tokens by batch.................92

Table 5.9. Percentages of proper name tokens recognized by native speakers........94

Table 6.1. Idea units found in recalls (excluding proper names)....................108

Table 6.2. Average per participant frequencies of different idea unit types found in recalls by treatment group..................................................110

Table 6.3. Raw frequencies and percentage of correct idea units in recalls by treatment group with proper names included in the count (as idea units in their own

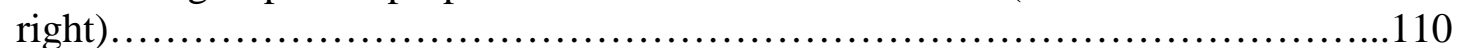

Table 6.4. Raw frequencies and percentage of correct idea units in recalls by treatment group with proper names excluded from the count......................110

Table 6.5. Examples of how the answers to open-ended questions were scored......113 Table 6.6. Mean scores on open-ended questions (out of 33) by treatment group...113 Table 6.7. Mean scores on multiple choice questions (out of 16) by treatment group................................................................... 113

Table 6.8. Mean scores on direct and indirect multiple choice questions by treatment

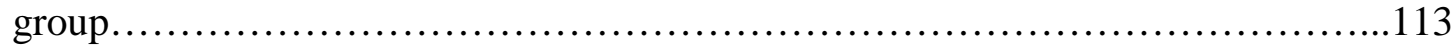

Table 6.9. Mean scores on true-false-don't know statements (out of 14) by treatment group................................................................. 114

Table 6.11. Mean PNT scores by treatment group..............................117

Figure 6.12. Correct answers, incorrect answers and 'missed opportunities'. Comparison of the treatment groups............................................119

Table 6.13. Average per participant difficulty ratings of experimental tasks (on a scale of 7$)$ by treatment group................................................. 120 
Table 7.1. Experiment 3. Participants' first languages (as indicated in the personal

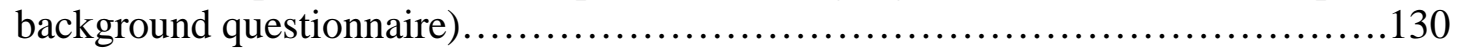

Table 7.2. Experiment 3. Mean scores on true-false-don't know statements (out of 14) by treatment group....................................................... 131

Table 7.3. Experiment 3. Mean scores on open-ended comprehension questions (out of 33) by treatment group.................................................131

Table 7.4. Experiment 3. Percentages of correct responses to each of the open-ended questions by treatment group................................................ 132

Table 7.5. Open-ended questions where the difference between percentages of correct responses between the treatment groups was the largest...........................133

Table 7.6. Experiment 3. Mean scores on multiple choice questions (out of 15) by treatment group.........................................................136

Table 7.7. Experiment 3. Mean IELTS listening module scores (out of 40) by treatment group .........................................................137

Table 7.8. Experiment 3. Mean overall comprehension scores (out of 62) by treatment group.................................................................137

Table 7.9. ANCOVA: dependent variable - overall comprehension scores $(\mathrm{OE}+\mathrm{MC}+\mathrm{TFDN})$, independent variable - treatment group, covariate - listening proficiency (IELTS listening module scores)...............................138

Figure 7.11. Experiment 3. The distribution of participants' overall proper name ratings (out of 70) by treatment group...................................... 139 Figure 7.12. Experiment 3. Mean ratings (out of 7) of particular proper names by treatment group ...........................................................139

Table 7.13. Experiment 3. Mean PNgood scores (out of 20) by treatment group....141

Table 7.14. Experiment 3. Mean PNbad scores (out of 40) by treatment group........141 Figure 7.15. Experiment 3. 'Tick all options that apply' questions. Summary of variables: ticked correct options (PNgood), ticked incorrect options (PNbad) and missed correct options (PNmissed). Comparison of treatment groups...............142 Table 7.16. Experiment 3. Average per participant difficulty ratings of experimental tasks (on a scale of 7) by treatment group......................................142 Table 7.17. Experiment 3. Mean overall difficulty ratings (maximum 35) by treatment group................................................................ 143 Table 7.18. Percentage of information about proper name referents that the participants were able to access. Comparison of Experiment 2 and Experiment 3...146 Table 7.19. Experiment 2. Mean overall comprehension scores (out of 30: $16 \mathrm{MC}+$ 14 TFDN) by treatment group. 


\section{Chapter I. Introduction}

\subsection{Identifying the problem}

Listening comprehension is a vitally important skill for foreign and second language learners, and it is often the hardest one to master. New Zealand welcomes thousands of well-educated migrants from all over the world each year, and, commonly, while attending government-funded English courses many comment that understanding spoken English is one of the most challenging tasks. In recent years, a lot of research effort in applied linguistics has been dedicated to examining various aspects of listening comprehension as a process, as well as ways to facilitate listening comprehension via adequate and effective teaching. Excellent progress has been made in terms of establishing how listening comprehension is different from reading comprehension and what factors affect the second language learners' ability to understand connected speech.

A fruitful area of inquiry concerns the link between comprehension and vocabulary knowledge. In particular, vocabulary knowledge has been recognized as a prerequisite to successful comprehension. However, the vast majority of studies in this area have dealt with written as opposed to spoken texts. At least partially this can be attributed to methodological issues since electronic text processing makes it much easier to manipulate the quality of input (and collect learner vocabulary data) using written material. The present work aims to fill this gap by building on the few available studies which investigate how vocabulary knowledge impacts on English as a second language (ESL) learners' ability to understand spoken texts.

Proper names as a special group of lexical items have long been the focus of discussion in philosophy and linguistics but, surprisingly enough, they are hardly ever touched upon in second language learning and vocabulary acquisition literature. Moreover, on rare occasions when they are mentioned it is normally in order to say that they will not be accorded any further attention. For instance, Wilbur Ames was interested in classifying various clues that help readers to guess the meanings of unknown words from context; in his carefully chosen sample of experimental texts 
proper nouns (perhaps excusably) were 'eliminated from consideration' (1966: 61). To cite a more recent example, Laufer and Nation proposed an improved method to measure lexical richness, i.e. the extent to which ESL writers are using a varied vocabulary. When the new instrument was tested on student compositions, "proper nouns were deleted from the samples' (1995: 315). Although this decision might have been fully licensed by the logic of the research goals, it certainly seems to imply that productive knowledge of proper expressions does not make the learners' vocabulary any richer. In vocabulary threshold studies set up to calculate the minimum percentage of familiar words in a text that still allows to achieve reasonable comprehension, proper expressions have been counted as automatically known items (Hirsh and Nation, 1992; Hu and Nation, 2000).

The implicit assumption that in the course of ESL learners' interlanguage and vocabulary development proper names will somehow 'take care of themselves' does not appear justified. At the very least, it deserves careful evaluation. As a first step in this direction, the present study seeks to determine whether the presence of unfamiliar proper names affects ESL learners' listening comprehension. The outcomes of this research are envisaged to help develop more appropriate ways of dealing with proper names in ESL learning, teaching and testing as well as make existing estimates of the vocabulary threshold more accurate.

\subsection{Structure of the thesis}

This thesis consists of two main parts, theoretical and empirical. The theoretical part, comprising Chapters II-IV, explores the following topics: (1) What are proper names? How can they be adequately defined? (2) What semantico-pragmatic and structural properties are characteristic of proper names? What types of proper names are distinguished? (3) What knowledge do ESL learners need to have in order to understand spoken texts containing proper names?

In Chapter II, some of the numerous definitions of proper names proposed in the literature are reviewed and analyzed in terms of their strong and weak points. I argue in favour of the prototype theory as a productive approach to defining proper names in their enormous variety. Justification is given for placing particular subcategories of proper names in certain positions along the prototypicality scale. The beginning of Chapter III is dedicated to semantic properties of prototypical proper names. Further, salient syntactic patterns and structural types of proper names are 
discussed along with some of their pragmatic features. Finally, I adopt the functional approach to defining proper names and supply my own definition. While no definition of proper names is without limitations, the definition I propose can be considered acceptable for the empirical purposes of this research. In Chapter IV, the focus of discussion is the type of knowledge necessary for ESL learners to successfully cope with proper names in connected speech. I develop a 3-level model of such knowledge: (level 1) recognition $\rightarrow$ (level 2) categorization $\rightarrow$ (level 3) referent properties.

The empirical part of the thesis, Chapters V-VII, describes three experiments that were designed to answer the following research questions:

1. Are ESL learners able to discriminate between unfamiliar proper names and unknown common vocabulary while listening to connected speech?

2. Does the presence of unfamiliar proper names influence ESL learners' comprehension of a short spoken text, and if so, how?

3. While listening to connected speech, are ESL learners able to determine what unfamiliar proper names refer to, and how much information about proper names' referents can listeners get from context?

In the first experiment (Chapter V), I am empirically testing level 1 of the proposed 3-level model, i.e. the ESL learners' ability to recognize unfamiliar proper names in spoken texts. In short news texts, the recognition rate is found to be around $60 \%$. The experiment also addresses the question of how the ability to recognize unfamiliar proper names is related to the percentage of unknown common vocabulary in the input.

In the second experiment (Chapter VI), the participants' comprehension of a news story is assessed under two conditions: Names Known (all proper names are familiar prior to listening) and Names Unknown (all proper names are unfamiliar). The Names Known group performed better on two out of four measures (free recall and true-false-don't know statements). The experiment also deals with level 2 of the proposed model, namely the ESL learners' ability to determine what kind of object an unfamiliar proper name refers to. It is shown that participants in the Names Unknown treatment were not always able to ascertain from context what the referent is, and in cases when they did, they could not extract as much information about the referent as the participants in the Names Known treatment had available. In addition, difficulty ratings of experimental tasks demonstrated that the presence of unfamiliar proper names definitely makes the text seem more confusing to the ESL listeners. 
The third experiment (Chapter VII) was designed as a replication of the second in order to overcome a few design drawbacks and involved a larger sample of participants. The Names Known treatment group performed significantly better on 2 out of 3 measures (open-ended questions and true-false-don't know statements). A highly significant effect of unfamiliar proper names on the overall comprehension scores was found. Around $17 \%$ of the variance in the scores was accounted for by familiarity/lack of familiarity with proper names. The findings also provided some evidence in support of the claim that certain types of proper names affect comprehension more than others. 


\section{Chapter II. Defining a proper name: the prototype theory}

\subsection{What is a proper name? Analysis of proposed definitions}

Proper names are perhaps the only part of language able to arise [sic] substantial interest and emotions in a variety of individuals besides linguists (Berezowski 2001: 7).

Proper names can be viewed from a number of different perspectives. Coming from social psychology, for instance, one may look at the distribution of personal names and what motives lead parents to choose particular ones for the newly born, and at the popularity of certain names as indirect social class markers. Cognitive psychologists will be more interested in how naming expressions are creatively constructed in the human mind and bestowed on new objects or concepts. An anthropologist would wish to investigate naming practices in a given community to gain insights about its culture. Proper names also stand out as an important issue in advertising, marketing, politics, and information and communication technology. Outside linguistics, philosophy and logic are the closest areas of inquiry where proper names have received an enormous amount of attention. So what is a proper name? At first glance it seems a trivial question but when one takes a look at various definitions suggested by numerous scholars so far it turns out that none of them actually gives a satisfactory answer.

Proper name - a noun or a noun phrase whose only function is to pick out some individual person, place or thing. Examples: Lisa, Abraham Lincoln, Spain, the Basque Country, the Golden Gate Bridge, the Roman Empire, the Eighteenth Dynasty. Proper names conventionally take capital letters in English, but some words which are also conventionally capitalized are not proper names, such as Frenchman, Tuesday and November. Proper noun - a noun which is a proper name, such as Susie, Chicago or Finland. Such a noun usually constitutes a noun phrase all by itself (Trask, 1997: 177).

This is a brief description, which 'the person on the street may get along quite nicely with' (Zelinsky, 2002: 245), but it is far from being adequate for academic purposes. 
It is definition by example that basically says, 'A proper name is something like this...' but does not explain why the Eighteenth Dynasty (which by the way can hardly be tagged as either a person, a place, or a thing) is a proper name while Frenchman (who surely qualifies as a person) is not. Would the Shang dynasty count as a proper name or do we have a proper name/noun Shang and a common noun dynasty here since the latter is not capitalized? The definition contains several important bits of information, namely that proper names are noun phrases, that they are capitalized, and that their function is to pick out individual objects. However, should a proper name be a noun or at least a noun-headed structure, does that mean that $O f$ Mice and Men (prepositional phrase) is not the proper name of Steinbeck's renowned novel?

Huddleston also draws a distinction between proper nouns and proper names. A proper noun is a grammatical noun subclass, while a proper name is 'the institutionalized name of some specific person, place, organization, etc. institutionalized by some formal act of naming and/or registration' (1988: 96). This solves our Steinbeck problem: the author has officially named the book before submitting it to the publishers therefore there is no doubt about Of Mice and Men being a proper name. The presence of some explicit act of assigning a name, from christening a baby or registering a new club to choosing what to call your pet lizard is a helpful hint. However, while resolving some difficulties, it leads to others. For a number of words, we cannot trace even a quasi-ceremony of naming yet common sense strongly indicates that they are proper names. The largest country in the world used to be officially called USSR (Union of Soviet Socialist Republics) until 1991 when the 15 republics split and the new state was, again officially, renamed to become Russian Federation. For centuries and centuries though this land has been called Russia. Nobody knows when and how it got to be so called but in the absence of an official naming act Russia appears to be no less a proper name than the former two. Nicknames, both nice and offensive, are another interesting group. Intuitively, they are clear proper names yet it is unlikely that there will be any 'formal act' preceding them at inception. It is hard to imagine somebody saying to a friend: 'Henceforth I shall be calling you Stompie'. On the other hand, a lot of expressions are introduced into the language by a distinct 'naming ritual' which as such does not guarantee their proper name status. The International Union of Pure and Applied Chemistry after much controversy and careful consideration assigned names to 
recently synthesized transuranic elements in the periodic table aiming to pay tribute to their discoverers; however, from the linguistic point of view, meitnerium probably better belongs in one row with gold and iron rather than with Lise Meitner. Huddleston's 'formal act of naming/registration' is what Saul Kripke (1980) called 'initial baptism' about a decade before and what John Austin (1955) pointed out as one of the most salient performative uses of language still earlier. Although a proper name must not necessarily be a word that has been privileged with a "name assigning ceremony', for many subtypes of proper names (e.g. personal names; names of businesses, political parties and other public organizations; brand names, names of movies, TV shows, books etc.) some act of naming, whether formal or informal, does indeed take place.

Coates (2000: 1164) defines proper names as follows: 'A name is a NP expression, in using which the user need not be committed to, and is not presumed to assert, any literal meaning of or any entailments of any word of the lexicon of the language in question homophonous with any part of that expression'. A similar definition was earlier proposed by Gardiner (1957: 43): 'A proper name is a word or group of words recognized as indicating or tending to indicate the object or objects to which it refers by virtue of its distinctive sound alone, without regard to any meaning possessed by that sound from the start, or acquired by it through association with the said object or objects'. The idea of proper names being entirely meaningless does not accord well with every day language experience. This is because we have an intuitive feeling that if there is an expression, be it common or proper, it should mean something. Firstly, it is obvious that swapping a proper name for another proper name changes the communicative value of a sentence: He went to Whitcoulls yesterday. $\neq$ He went to the \$2 Shop yesterday. Secondly, some names appear to be more meaningful than others. Suppose somebody is unfamiliar either with Whitcoulls or the Two Dollar Shop. Judging solely by the sound of the names, s/he will not be able to get any information whatsoever about the former but they will understand that the latter is a shop (and perhaps even infer that things in this shop are going to be cheap). Therefore it is safer to assume that proper names do mean, but in a peculiar way, differently from other vocabulary.

Bussman (1996: 387) defines proper nouns as 'a semantically defined class of nouns that unequivocally identifies objects and states of affairs in a given context. By designating an object or a state of affairs in a given statement, proper nouns replace 
deictic, or pointing, gestures such that direct reference to that object or state of affairs is made. Whether proper nouns have meaning and how they differ from generic names and (definite) descriptions has been open to much debate'. There are two shortcomings to this definition. Firstly, it captures only proper nouns, which as has already been mentioned, are only part of a larger class of proper names. Nevertheless, grammatical research (Hopper, 1990; Gary-Prieur, 1994) shows that in texts even non-nominal and structurally analyzable proper names function as one word and occupy the same slots in a sentence that regular nouns (and pronouns) do. Salient in The article presented the salient facts clearly and concisely behaves differently from Salient (proper name of a publication) in I read about the email upgrade in Salient. Although technically it is still an adjective in the latter example, it has lost its adjectival characteristics and syntactically acts like a standard noun phrase in I read about the email upgrade in the paper. Multiword names, like idiomatic expressions and compounds, are compact units that do not allow interruption by modifiers, appositives, or other material:

(1) Welcome to the fun-loving Chemistry Department.

Welcome to the, I hope you don't mind Boyle puns, Chemistry Department.

(2) *Welcome to the Chemistry fun-loving Department.

*Welcome to the Chemistry, I hope you don't mind Boyle puns, Department. (examples from Carroll, 1985: 150).

Given that even non-nominal and complex proper names still function like single noun lexemes, it could perhaps be possible to generalize Bussman's definition to cover all proper names. Its second major drawback, however, becomes immediately clear. While it points out that proper nouns are peculiar semantically, the explanation of what it is that determines their unique semantics is not that clear-cut and complete. The key point in the definition is that they provide unequivocal identification in a given context by making direct reference to an object; this sheds light on the nature of proper names but poses more questions as well. How is The P/president has decided different from Tanya has decided? Subjects in both sentences seem to unequivocally identify who is being talked about if the context is known/set. Compare I'll look it up in Britannica and I'll look it up on the I/internet. Again the nouns in the two sentences seem to identify a particular information source equally successfully. Does the difference lie in some linguistic mechanism by virtue of which these words refer to certain people and objects? If so what is the mechanism? Why is it that we find 
ourselves inclined to consider P/president or I/internet common words and Tanya or Britannica proper names? To sum up, Bussman asserts that chief foundation for selecting proper names is semantic but because at least some common expressions appear to be able to provide unequivocal identification in a given context, this alone is not sufficient, and we need to know more about how direct reference is achieved.

Let us take a closer look at P/president and Tanya. The first word can indeed definitely point to one particular person, let's say George W. Bush. However, in other contexts it can as easily refer to a president in general, i.e. to 'a person who currently holds or previously held a presidential post at least once in their life at any time in any country' as in Any president would do the same. To use Bussman's words, it can provide unequivocal identification in a given context but it does not need to. In contrast, Tanya can and must only refer to one individual; Any Tanya would do the same sounds unnatural and odd at best. The following definition captures this semantic distinction:

A name is a word or group of words used to refer to an individual entity (real or imaginary); the name singles out this entity by directly pointing to it, not by specifying it as a member of a class. [...] The distinction between names and appellatives (common nouns) is generally clear: names are used in individual reference, appellatives can be used in reference to all members of a class or to any number of them (e.g. river, hill, man, girl, car, table, virtue, and so on)' (Zgusta 2002: 733).

This definition provides a reliable rule of thumb: a common noun denotes an object as a member of a class of similar objects (implies certain characteristics shared by all of them) while a proper name denotes an individual object (and thus does not imply characteristics that it may share with others). Here is a good illustration:

[...] if there are two animals in a cage and one is a tiger, a perfect specimen of a tiger, and the other animal is virtually indistinguishable from it, then the second animal is a tiger. But if there are two animals in a cage and one is Witchgren and the other animal is virtually indistinguishable from it, it does not follow that the second animal is Witchgren (Ziff, 1960: 102-3).

The rule is generally helpful but it runs into problems when one applies it to the socalled uni-designatory, or monoreferential, nouns/noun phrases denoting objects of which there factually happens to be only one in the world or which are held unique within a certain system of cultural assumptions. The classic case is the word $S /$ sun in its most usual sense (not as a synonym of star); other examples are easily found in the domains of geography, history, religion and others: the equator, the South Pole, 
Pleistocene, the cold war, the Renaissance, the antichrist, the Trinity, the I/internet, the sphinx, the mafia (for more, see Coates, 2000: 1161-2). The difficult question is: do such words still denote classes (albeit unusual ones because they comprise just one member) and are thus common, or are they proper names of the individual objects designated? The uncertainty is often manifested in lack of consistency with spelling. There is no visible semantic difference between the cold war and the War on Poverty both denoting distinct one-off historical periods, yet one is written as if it was a common noun phrase, while the other as if it was a name (Chicago Manual of Style, 2003).

Individual reference vs. member of a class reference is a useful logical distinction but is not exhaustive for defining proper names because it does not account for monoreferential common expressions and is of little help with words that denote classes within classes.

Another subtheme of Zgusta's definition is that a name singles out an individual by directly pointing to it. What precisely this direct pointing involves has been the subject of long-standing and ongoing debate in logic and philosophy of language. The advocates of the descriptive theory associated with Frege, Russell and Searle argue that a proper name 'hooks on' to the world through a description (or a set of descriptions) helping people identify what referent to pick. The causal (chain) theory associated with Kripke and dating back to Mill, claims that a proper name is 'attached' to its referent directly without recourse to intermediate description/s. There is a third position first put forward by Kneale (1962) that proper names have peculiar word-reflexive senses consisting of a citation of the expression itself but this view was criticized for circularity and never gained as wide currency as the former two.

The descriptivist approach implies that proper names are meaningful, i.e. that their relation with extralinguistic reality is mediated by senses similar to that of common expressions whereas the direct reference view suggests proper names are meaningless. The theories are in confrontation but what is sadder is that both are unable to handle questions arising when one applies them to language practice. Numerous arguments and objections have been piled on either side but the major dispute is still unresolved. In particular, the ultimate challenge for any descriptivist account is: if proper names are meaningful then what are their meanings? (Napoli, 1997). If proper names are meaningless, then how does a direct reference adherent explain their communicative value? In virtue of what do they refer? (Willems, 2000). 
The direct reference theory can be said to have gained wider popularity among contemporary scholars and I will further dwell on Kripke's account of proper names but it should be noted that the descriptivists have by no means put a full stop on the issue (Liu, 1996; Seuren, 1998: 378-382) and that there is a tendency for convergence as attempts to arrive at a unified explanation are being made.

\subsection{Philosophy of language: Kripke's account of proper names}

Kripke's famous lectures at Princeton University were revolutionary but 'proper names' in his series of talks are not a strictly defined set of expressions:

By name here I will mean a proper name, i.e., the name of a person, a city, a country, etc. It is well known that modern logicians also are very interested in definite descriptions: phrases of the form 'the $x$ such that $\varphi x$ ', such as 'the man who corrupted Hadleyburg'. Now, if one and only one man ever corrupted Hadleyburg, then that man is the referent, in the logician's sense, of that description. We will use the term 'name' so that it does not include definite descriptions of that sort, but only those things which in ordinary language would be called 'proper names' (1980: 24).

Apparently, Kripke is not concerned about what 'things' can actually count as proper proper names from the linguistic point of view. Practically all examples throughout his argument are one-word personal names such as Nixon, Hitler, Gödel. The question he seeks to answer is how they are related to definite descriptions that have the same referent. Refuting the descriptivist position that a proper name is in essence a definite description 'abbreviated or disguised' (ibid. 27), he argues that the meaning of a proper name cannot be equated with a synonymous description (ibid. 30):

If Aristotle meant the man who taught Alexander the Great, then saying 'Aristotle was a teacher of Alexander the Great' would be a mere tautology. But surely it isn't; it expresses the fact that Aristotle taught Alexander the Great, something we could discover to be false. So, being the teacher of Alexander the Great cannot be part of [the sense of] the name.

The radical difference between proper names and definite descriptions in Kripke's view is that the names are rigid designators while the descriptions are not. A name will designate the very same object in all possible worlds where this object exists (or nothing in those worlds where it does not exist). A description can designate different objects in different stipulated possible worlds. For instance, most of the things commonly attributed to Aristotle are things that in some counterfactual world he might not have done. However, Kripke insists, in such a situation we would still 
'describe that as a situation in which Aristotle didn't do them.' (ibid. 61). So the proper name Aristotle designates rigidly, unlike the definite description the teacher of Alexander the Great which will pick out a different individual if we counterfactually stipulate that Aristotle was never involved in pedagogy. Similarly, Kripke criticizes the view that a proper name represents a disjunction (logical sum) of several suitable descriptions because 'when we say counterfactually 'suppose Aristotle had never gone into philosophy at all', we need not mean 'suppose a man who studied with Plato, and taught Alexander the Great, and wrote this and that, and so on, had never gone into philosophy at all', which might seem like a contradiction' (ibid. 57).

According to descriptivist theorists, a proper name is defined by, i.e. means the same as a corresponding description or a family of descriptions. Consequently, it appears that to be able to use the name correctly people must know the description that would uniquely identify its bearer: 'The picture associated with the theory is that only by giving some unique properties can you know what the reference of your name is' (ibid.83). Kripke provides a number of examples to demonstrate that speakers need not necessarily possess such knowledge to make use of the name in communication. Quite commonly, people talk about famous figures - Cicero, Feynman, Einstein, Columbus - with only a vague idea about the deeds or achievements of the persons in question. A 'layman' may not know that Cicero was the man who denounced Catiline and most likely will not be able to state the content of Feynman's theories. An average speaker if asked about these names will probably think something like 'a Roman orator', 'a famous physicist', 'the man who discovered the Theory of Relativity', 'the first European to land in America'. In the first place, this information in many cases is not uniquely identifying: the property of being 'a famous physicist' may be true of several scientists, not just of Feynman. Secondly, even if the definition picks out someone uniquely, it can be circular. Einstein is 'the famous physicist who discovered the Theory of Relativity' but it can easily turn out that the only thing the speaker 'knows' about this theory is that it is Einstein's theory. Thirdly, the speaker's picture of the referent may be nothing but a misconception. In fact, the first European to set foot in America was some obscure Viking, yet it does not oblige us to refer to him each time we are talking about Columbus. Kripke offers several other examples to show that the absence of accurate uniquely identifying knowledge or even patently false beliefs about the referent of the name on the part of the speaker does not preclude them from establishing its reference. The philosopher argues that even if 
someone erroneously believes that Einstein was the inventor of the atomic bomb, they are still talking about Einstein and not about Oppenheimer when using the name Einstein in their speech.

Thus, according to Kripke, a definite description or a cluster of descriptions cannot be equal to the meaning of a proper name. The name and the corresponding description are not synonymous. Rather, people use descriptions to fix the referent, i.e. to initially pick out to which particular individual the name is to refer.

If the picture given by the descriptivist theory is wrong what alternative is Kripke suggesting? He argues, 'for most speakers, unless they are the ones who initially give an object its name, the referent of the name is determined by a 'causal' chain of communication rather than a description' (ibid. 59). A speaker's ability to use a proper name depends on its use by other people in a group sharing the same language, and, crucially, on the history of how the name has reached this speaker. Objects are originally 'baptized' with rigid designators after which those are passed on from link to link down through the community. This chain, or links, is set up roughly in the following way:

An initial 'baptism' takes place. Here the object may be named by ostension, or the reference of the name may be fixed by a description. When the name is 'passed from link to link', the receiver of the name must, I think, intend when he learns it to use it with the same reference as the man from whom he heard it (ibid. 96).

Kripke agrees that the view of proper names as given by the descriptivist theory has its place but it is mainly applicable to cases of 'initial baptisms'. He insists that his own agenda is to present an alternative picture as opposed to a new theory in any rigorous sense. He emphasizes several times that his claims are intuitive and that strict conditions of how the reference of a proper name is accomplished are hard to establish:

In general our reference depends not just on what we think ourselves, but on other people in the community, the history of how the name reached one, and things like that. It is by following such a history that one gets to the reference. More exact conditions are very complicated to give. They seem in a way somehow different in the case of a famous man and one who isn't so famous (ibid. 95).

There are potential blank spots in Kripke's contentious 'new picture' that were picked up by his opponents and critics later on. For instance, he himself admits the possibility of failure somewhere along the 'chain' to keep the reference fixed (for good 
examples, see Liu, 1999: 3-4). He is also aware that 'not every sort of causal chain reaching from me to a certain man will do for me to make a reference':

There may be a causal chain from our use of the term 'Santa Claus' to a certain historical saint, but still the children, when they use this, by this time probably do not refer to that saint (Kripke, 1980: 93).

Practically every time Kripke explains the difference between rigid and non-rigid designation he gives a pair of examples to illustrate the point. It is a proper name on the one side and a descriptive phrase on the other: Napoleon vs. the emperor of the French in the early XIX century, Peano vs. the discoverer of the axioms which characterize the sequence of natural numbers, Hesperus vs. the heavenly body in the yonder position, Nixon vs. the president of the US in 1970. He makes the claim that rigid designation is an essential characteristic of a proper name but not of a description but the question of just how to draw a line between names and descriptions is left open:

It should not be thought that every phrase of the form 'the $x$ such that $\mathrm{F} x$ ' is always used in English as a description rather than a name. I guess everyone has heard about The Holy Roman Empire, which was neither holy, Roman nor an empire... these phrases should be regarded not as definite descriptions but as names. In the case of some terms, people might have doubts as to whether they're names or descriptions; like 'God' - does it describe God as the unique divine being or is it a name of God? But such cases needn't necessarily bother us (ibid. 27).

It is precisely these cases that 'bother' a linguist. Philosophers can get by considering only the most typical of names such as personal names or place names, and contrasting them with freely constructed descriptive phrases. It is fairly easy to see how Hitler is a rigid designator while the man who succeeded in having more Jews killed than anyone else in history is not, but what if there is no conventionalized oneword name corresponding to a singular description (i.e. a description having a unique referent)? In other words, what happens when a description and a name are the same thing? The linguist needs something more 'down-to-earth' than an ability to designate rigidly in stipulated possible worlds as a base to delimit the class of proper names from common vocabulary. Is The Iron Age a name or a description? Can it be a rigid designator of this particular archaeological epoch if in some counterfactual world it were not marked by the spread of iron? Will the phrase pick out 'the same' period or not? To bring it to the bottom-line, what is there but one's own intuition that makes one decide what is possible in a possible world? 
Kripke does not dwell on the notion of 'baptism' but it presupposes some kind of a dubbing ceremony or at least a distinct event of naming. As I mentioned before, it works perfectly well with some types of proper names but not with others. Firstly, there are obviously cases when the initial baptismal act is not traceable (as is the case with most mythological names like Amen-Ra, nicknames, or proper names that originated as descriptions such as Big River). Secondly, a lot of nouns for which we can easily identify the moment of official 'baptizing' are distinctly borderline and do not readily fit into the category of proper names as we normally think of them using common sense (words like quark, names of diseases, drugs, chemical elements) otherwise we may end up saying that pretty much any nouns making up technical terminology are proper names.

To recap, there are two ideas of Kripke's that may be relevant for the problem of defining proper names: (i) proper names are rigid designators that pick out the same object in all possible worlds; (ii) proper names are bestowed on individuals in some kind of 'baptismal act' and are then passed around the community from one speaker to others. Unfortunately, both ideas, as valuable as they are, leave the linguist to look for a more precise foundation for defining proper names.

As this brief analysis of Kripke's work shows, no proper name definition can be transplanted straight from logic or philosophy of language into linguistics. In the next section I will return to a purely linguistic approach to the study of names.

\subsection{Onomastics: name catalogue approach}

Onomastic research traditionally comprises tracing the etymology of proper names and classifying them into groups and types. My aim is to establish how proper names influence comprehension. The etymological aspect of onomastics is not as relevant for the present study since the present study is focused exclusively on the synchronic plane.

Since antiquity it has been a widely spread practice to provide only sketchy definitions of what a proper name is and to support them with lists of illustrative examples. The reason may be that the notion of proper name is intuitively simple but, as witnessed by continuous debates in philosophy, has proved notoriously difficult to formalize. This often leads to a mismatch between a rather loose and narrow definition (if one is offered) and a catalogue of proper names that captures their variety (cf. Trask, 1997; Sloat, 1969; Lyons, 1999: 21). Quite a few taxonomies have 
been proposed to date and they are well worth exploring because they present a panoramic picture of what kind of expressions can count as proper names.

Allerton suggested five main categories and two additional ones that include expressions occupying an intermediate position between proper names and ordinary words (1987: 73-4):

1. Human beings (+ pets and racehorses)

2. Vessels, vehicles and machines

3. Geographical locations (natural and man-invented)

4. Social organizations

5. Publications and works of art

6. Languages and dialects

7. Periods of time (days, months, seasons (?), years (?), festivals)

The proper name status of the last two categories is debatable; nevertheless this concise list gives one an idea of what names are commonly assigned to. The weak point is it does not give much detail about the scope within the categories, and there are missing proper name candidates that come to mind, for instance names of gods or commodities.

Another brief taxonomy is found in Valentine et al. (1996) but unlike Allerton who treats proper names from the sociolinguistic point of view, Valentine's team comes from the field of cognitive psychology with quite different research purposes. In their understanding, 'denotation of unique entities is the key criterion' in defining proper names, and this naturally dictates the set up of the categories:

1. Personal names (surnames, first names, nicknames and pseudonyms)

2. Geographical names (names of cities, countries, islands, lakes, mountains, rivers and so forth)

3. Names of unique objects (monuments, buildings, ships or any other unique object, e.g. Excalibur - the sword)

4. Names of unique animals (e.g. Benji or Bugs Bunny)

5. Names of institutions and facilities (cinemas, hospitals, hotels, libraries, museums or restaurants)

6. Names of newspapers and magazines

7. Titles of books, musical pieces, paintings or sculptures

8. Names of single events (e.g. Kristallnacht) 
The last type is reserved for unique events as opposed to categories of events so words for days of the week, months and recurrent holidays are excluded. The authors also consider brand names as a borderline case. Such words do not denote unique things but it can be argued that 'a brand name designates a unique object that is simply replicated in a number of identical exemplars' (Valentine et al., 1996: 5).

There are also much more extended taxonomies, one proposed by an American onomastic scholar Wilbur Zelinsky (2002), and another found in the latest edition of the Chicago Manual of Style (hereafter CMS). Both of them are intended to be all-inclusive and offer a very detailed and vast overview of various objects and phenomena that receive names. The main drawback, however, is that neither has any strict theoretical position behind it as to how a proper name should be defined.

CMS, for instance, aims to illustrate the conventions of capitalization, use of italics, quotation marks etc. for editors. That is why all sorts of expressions, both capitalized and lower-cased, are piled together indiscriminately under the ambiguous heading 'Names and terms'.

Capitalization is often seen as misleading and not a reliable means of separating proper names from non-proper expressions (Algeo, 1973: 14-9). Nevertheless from a practical point of view, taking orthography as a starting point allows us to cover the largest set of potential proper name candidates. Whereas it is absolutely certain that a lot of non-proper words and phrases can be spelt with initial capitals, we can be confident in claiming that the number of unambiguously proper expressions beginning with lower-case letters in English is negligible. Indeed, decapitalization is a sure sign that a proper name has changed its status and became an eponym, i.e. turned into a common word. In a handful of examples where initial capitals in genuine intact proper names are dropped, it is done for a very peculiar reason and usually for stylistic effect (e.g. overland, leading Australian literary magazine). Gleason pointed out that capitalizing names is in fact an exceptional linguistic phenomenon in that it is one of the very few occasions when written language signals have no counterparts in speech and not vice versa. He holds that the major function of capitalization is 'to mark a class of words - proper nouns' (Gleason, 1965: 186).

What is problematic, however, is the fact that in addition to marking proper names, capitalization may play a whole range of other roles in texts:

- personification as a literary (mostly poetic) device: 
'The Night is Mother of the Day, / The Winter of the Spring' (J.C. Whittier, cited in CMS, 2003: 324);

'A Rock there is whose homely front / The passing traveller slights / And one coy Primrose to that Rock / The vernal breeze invites' (W. Wordsworth, cited in Carney, 1994: 52);

- emphatic intonation conveying irony:

'Ok, so I'm a Bad Mother,' admitted Mary cheerfully. (CMS, 2003: 291);

- division of homonyms:

a stoic attitude (metaphorical use) vs. a Stoic (representative of Stoicism as school of thought), democrat (supporter of democracy in the broadest sense) vs. Democrat (member of a concrete political party);

- lending importance to some words sporadically, honoris causa:

a Committee meeting, a future Convention, the present Administration,

Transformational-Generative grammar (examples from Algeo, 1973: 16);

- marking any words of special note, especially nouns which are the focus of the discussion or have technical meaning (this practice similar to German where all nouns are capitalized was used much more widely in English in the XVIII century but now survives only in legal documents 'perhaps to provide a focus for the reader in long legal sentences' (Peters, 2004: 90)):

'... on the terms of the letter to Shareholders and the Memorandum and Articles of Association of the Company and subject to the proposed dividend being declared by the Directors and approved by the Shareholders and the admission of the New Shares to the Official List by the London Stock Exchange. We are not electing on behalf of any person who is a North American Person (as defined in Appendix II to this letter)' (example from Carney, 1994: 52).

Thus when looking at the stock of upper-case words in English one needs to be extremely careful because a number of common expressions demonstrate confusing spelling patterns, i.e. may be capitalized or lower-cased depending on the circumstances. However, searching for proper names among expressions that are never capitalized (leaving aside the sentence initial position) is undoubtedly pointless.

Numerous accounts of proper names (especially in philosophy) have been based mainly on personal and place names as the purest and least controversial representatives of the class. A number of descriptive onomastic studies have 
successfully expanded this narrow picture (Nuessel, 1992; Eichler et al., 1996). Zelinsky (2002: 249) proposed a broad classification containing over 130 name-types in total. It is arranged around eight chief divisions with further subgroupings that in places go as far as three levels down the hierarchy. The author made an effort to be as comprehensive as possible putting in 'every group of words that reasonable scholars could accept as names'. Although what 'reasonable scholars' should count as a proper name is not theoretically specified, it is helpful to have a thorough overview of what words can be considered names by common consent.

Table 2.1. Comparison of proper name types outlined in CMS and in Zelinsky's paper.

\begin{tabular}{|l|l|}
\hline Chicago Manual of Style (2003) & Zelinsky (2002) \\
\hline A. Personal names & I Deities \\
\hline B. Place names & II Biota \\
\hline C. Names of organizations & III Places \\
\hline D. Historical and cultural terms & IV Events \\
\hline E. Calendar and time designations & V Social entities \\
\hline F. Religious names and terms & VI Enterprises \\
\hline G. Military terms & VII Artefacts \\
\hline H. Ships, trains, aircraft and spacecraft & VIII Unclassified \\
\hline I. Scientific terminology & \\
\hline J. Brand names and trade marks & \\
\hline K. Titles of works & \\
\hline L. Notices and Mottoes & \\
\hline
\end{tabular}

As can be seen, a number of categories in the two typologies cut across one another; there is more overlapping to be seen at lower levels (in subcategories and further subdivisions). Zelinsky's taxonomy is more homogeneous in that it deals exclusively with names albeit their 'nameness' is at the discretion of the author. CMS 'dumps in' everything that can be used to highlight editing rules. That is how notices and mottoes that evidently have nothing to do with proper names end up in the same lot simply because typographically they should be treated similarly to book titles. While Zelinsky's arrangement is more systemic and fitting with the purposes of my research, CMS offers a lot of interesting examples and brings up cases of spelling variation which can be linguistic forms in transition from common descriptive collocations to partially institutionalized names. Therefore I take Zelinsky's framework as a base and fuse in additional elements from CMS when they appear useful.

The merits of proper name taxonomies are that they invoke an intuitive understanding of the notion' and display the diversity of names: 'the strength of this 
approach does not lie in its cold precision and theoretical sophistication, but in its spontaneous presentation of the range of data any more formal definition has to account for (but rarely does)' (Berezowski, 2001: 23). Their foundation though is purely pragmatic which entails certain limitations. Undeniably, humans bestow proper names only on those things that are perceived as 'individuals in their own right', moreover 'of enduring significance as individuals', and that therefore need to be singled out from others (Hall et al., 2004: 7). The question underlying taxonomies is: what kinds of entities deserve (read: are important enough for people) to have a name? Nevertheless it is always possible to start naming new things (imagine somebody wanting to give a proper name to their favourite chair; it does not sound too probable but why not?). There is no guarantee either that all entities of the same kind must take a proper name (every person has a name, but not every animal). If games are assumed to be nameworthy, one is not justified in calling chess a proper name similar to Risk or Cranium. In a nutshell, enumerating the types of objects in the outside world believed by taxonomy compilers to bear proper names, valuable as it is, still does not say what makes a name proper.

\subsection{Prototype theory: core names and periphery}

Tse (2000) identifies two major ways of assigning items into linguistic categories, namely the classical approach and the prototype theory based approach. According to the traditional line started by Aristotle, membership in a category is determined by a strict set of necessary and sufficient features. The latter are binary therefore 'once the boundary between two categories is established, there are no ambiguous cases and all members within each category enjoy equal status' (2000: 491). However, the study of principles of classification in cognitive psychology (Rosch, 1975) reveals that people are very likely to have similar ideas on what are the 'best exemplars' of a given class regardless and despite quite strong disagreement about where the boundaries between neighbouring classes should cut. Unlike the classical member/non-member dichotomy, prototype theory 'allows for a non-discrete continuum space between categories' (Tse, 2000: 493) in viewing them as fuzzily bound groups of similar items extending from the core, or the prototype, out to marginal, peripheral instances.

Ongoing attempts to construct a strict criterial proper name definition, as transpires from the literature, have not been a success. A number of salient characteristics of name expressions were identified but none of them is a hard and fast 
indicator as to whether a certain expression belongs to the class of proper names. The elusive boundary between proper nouns and common nouns is still not found; nor is there a watertight division of composite names and definite descriptions. As Zelinsky puts it, 'the pursuers of their holy grail of an ironclad definition seem no closer to the goal than they were at the outset' (Zelinsky, 2002: 245). He believes it is time for scholars to admit defeat and accept that the boundaries of the category are indeterminate because there will always be a stock of terms that fall 'into the twilight zone' between genuine names and ordinary words (ibid.).

I shall adopt the prototype model because it promises to offer a more constructive way of describing proper names given their immense diversity. First, I consider the whole subcategories of names (taking Zelinsky's typology as a base) to determine which of them constitute the core and which ones lie further towards the outer edge of the proper name class:
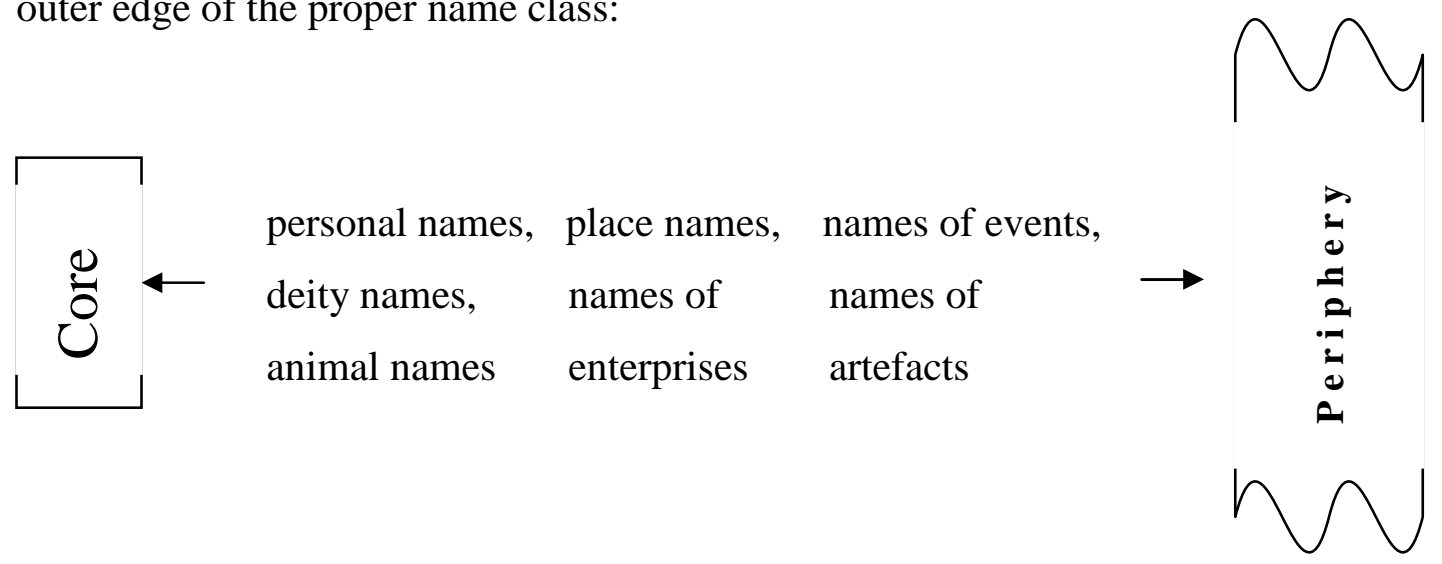

It must nevertheless be stated that such a division is nothing but a rather crude approximation. Pronounced gradience effects can be seen within each subcategory so even the core ones would contain names that vary in their degree of prototypicality. Further I will discuss prototypical proper names in terms of semantics, grammar and pragmatics to allow for assessing individual name forms on a case-by-case basis.

\subsubsection{Personal, deity and animal proper names}

If one looks at what has been considered as the core representative proper names in research to date, each and every source mentions personal and place names:

The main division within the recognized class of proper names is between personal and geographical (place) names (Thrane, 1980: 214).

There is overwhelming cross-linguistic evidence that names are given to people and places (the anthroponyms and toponyms of the onomastic 
tradition) in the first instance, and that other nominations are extensions of this 'convention'.... (Anderson, 2003: 354).

This widely held view has been transferred outside the linguistic field - to media, social and cognitive studies. It is reflected in the corresponding amount of attention received by these types of proper names in linguistic works as well; hence 'the conservative guess that personal and place names account for at least $98 \%$ of the existing literature...' (Zelinsky, 2002: 249).

Although it seems self-evident that personal names and, to a somewhat lesser extent, place names are the central members of the proper name category, a question still remains - why are they thought to be prototypical?

It has been established and borne out by cross-linguistic studies that human languages are largely anthropocentric (Croft, 2003). Given the overall anthropocentricity of human language, it is not surprising that names of people are of primary importance. Accordingly, Anderson claims that the unifying feature of core proper names is their 'anthropocentric origin' (2003: 354-65). The further a proper name moves out of the core the less people-oriented it becomes and, consequently, the more divergently it would behave in terms of morphosyntax. That is what makes even place names less central. Pet animals and familiar inanimate objects that receive proper names are 'anthropomorphised to some extent' (ibid. 357). Other subcategories, for instance ship, river, building and monument proper names are less 'personal' but calling a ferris-wheel the London Eye or a ship Dreadnought still constitutes a figurative act of personification.

There is some evidence that personal names are the most frequent in occurrence among different name types. Tse (2004: 242) extracted 14921 tokens of personal names from a sample of 514691 tokens, which makes up about $2.9 \%$ of the running text while the average coverage by all proper nouns in the BNC corpus she was using is $3.2 \%$. Overall proper noun coverage varies depending on the text genre so it may not be reliable to compare the average figure in the whole corpus with the percentage obtained in Tse's sample. Her sample consisted exclusively of written texts of a certain style, namely newspaper reporting. It is a robust finding that proper nouns are more frequent in writing than in speech, and more frequent in informative writing than in imaginative writing (Francis and Kucera, 1982: 539, 543; Leech et al., 2001: 297, 303). Proper noun coverage in the informative writing section of the BNC is more comparable to Tse's data, and comes to 5.1\% (Leech et al, 2001: 303). Thus, 
roughly, all proper nouns together account for 5.1\% of the running words while personal names make up $2.9 \%$, which means that over a half of all names are names of people, and a smaller fraction is other name subcategories combined. One should be conservative and cautious in interpreting these estimates but they give reason to believe that personal names are indeed the dominant type.

In addition to being very frequent, personal and deity names often serve as a basis from which a lot of other proper name subvarieties can be formed: 'One finds the names of national leaders or of gods assigned to heterogeneous entities like parks, theatres, city extensions, cafes, barber shops, and even pet animals' (Bhat, 1979: 109). Also bridges, stars, ships, streets, weapons, and trees can be named after people (e.g. General Sherman, a giant sequoia claimed to be the largest living tree by volume; see also Lehrer, 1992: 128-9).

Apart from reasoning that personal names make up the core because they are manifestations of language anthropocentricity and occur most frequently, I suggest looking at their functional aspects. Proper names may perform a number of functions not each of which is necessarily fulfilled by every proper name. I argue that the core of the category consists of anthroponyms together with deity names and pet names because these are the only subcategories that, unlike the rest, are capable of realizing all characteristic proper name functions.

In anthropology, two principal functions for people's names have been proposed - categorization and differentiation. Names can be a social classifying device that allows one to make inferences about the name bearer in terms of socioeconomic status, ethnicity, geographical location etc. At the same time they are considered a tool to identify the bearer of the name uniquely in context, i.e. to distinguish him/her from others. Alford demonstrated that the two functions might conflict as 'the more a name differentiates its bearer from other people, the less category information it carries regarding its bearer' (Alford, 1988; cited in Valentine et al., 1996: 16); however both must be fulfilled. Alford examined the degree of given name uniqueness and the naming practices in sixty cultures around the world and reported interesting correlations. In some villages in the Scottish Highlands, for example, as few as three surnames were shared by over three-quarters of inhabitants while their first names often came from a small group of biblical names. Name uniqueness was low; from their names people could be easily classified as Christians and as coming from the area. It was observed that in these communities a lot of 
descriptive by-names, such as Lame Sandy or Robber John, were in circulation as if to 'enhance' the neglected differentiation function. In other cultures given names were practically never repeated. For instance, Northern Yuman Indians had a taboo on using the names of the dead and named each individual according to either unusual circumstances at the time of birth or peculiar behavioral traits in childhood (Kendall, 1980: 263). Consistent with Alford's predictions, high name uniqueness correlated with low incidence of nicknames. Furthermore, people in such societies tended to address each other not by the first name but by a term of kin as if to 'compensate' for lack of categorization.

Alford's conceptualization of name functions applies to entire systems of personal naming in different cultures rather than to separate name forms as peculiar vocabulary items. My question is: can categorization and differentiation as social functions of whole systems of personal names be reinterpreted to stand as communicative functions of proper names of various types as linguistic forms? Alford speaks about social categorization, where for groups of people their position in society may be reflected in a pattern of name distribution at a certain point in time. Linguistic categorization concerns an altogether different matter of whether one can securely pin down what category the referent of an expression belongs to based on the information contained in this expression alone.

I would like to argue that the nature of proper names (including every subcategory here) is such that differentiation is their major integral function in communication. In contrast, categorization is only a random by-product in using names, not their essential role. Thus, if I say Do you know how to get to Shortland Street?, although I am signalling that the referent belongs to the category of streets, it is incidental. The main purpose for using the name is to distinguish this particular street from others. If I now say The acting in Shortland Street is atrocious!, the name would no longer explicitly categorize the referent, however it still fulfils its chief function of distinguishing this particular soap opera from others.

Firstly, some proper names do not have overt categorizing elements. I visited Sydney on my way home, for example, may cause ambiguity, as 'there is no noncontextual way in which the hearer may learn whether I visited a friend or a town' (Thrane, 1980: 214). Secondly, some proper names, if taken literally, would be outright misleading. The fact that the Wellington Botanic Gardens are indeed the gardens having trees, flowers, and all other attributes associated with gardens, does 
not preclude Herbert Gardens being the name of a building in one of Wellington's streets. Similar examples led Coates to conclude that as far as proper names are concerned, 'the implied categorization should always be taken as falsifiable in principle even if not yet falsified' (2006: 365).

Although there has been a lot of debate on whether proper names have meaning and what kind of meaning, most linguists agree that they are noncategorizing*: 'proper names lack classifying, characterising meaning' (Dalberg, 1985: 132); 'proper names are non-categorial signs, which means they do not in any way indicate what kind of thing they are being used to refer to on a given occasion' (Thrane 1980: 214). I would like to rephrase the latter strong statement to read: prototypical proper names are non-categorizing while the more classifying they become, the further away they shift from the core to the outer boundaries.

Lyons (1977: 216-7) holds that names in discourse fulfil two characteristic functions, vocative and referential. The vocative or phatic role is the use of proper names as forms of address when they either constitute a sentence of their own or appear as extrasentential elements to establish social relationships or attract somebody's attention rather than to impart information. Alongside pronoun you, standardized politeness forms (Mr, Ladies and Gentlemen), kinship terms (Auntie, Dad) and some occupational titles (Nurse, Professor), proper names are the most common vocatives: Lynda! Hurry up! Lynda, where did you put my papers? In their referential function, proper names serve as participant arguments in an utterance, i.e. refer to some object or individual: Lynda went for a drive along the coast. It is fairly obvious that a great number of proper names, namely all the ones referring to inanimate objects, normally cannot be used as vocatives: Albert, I'd like to get to know you. *World War II / Open University, I'd like to get to know you. I add 'normally' to allow for a handful of atypical cases that involve addressing places or objects found in literary contexts:

Auckland, you great arsehole,

Some things I like about you

Some things I cannot like. [...]

\footnotetext{
* Even Van Langendonck, a strong proponent of the 'categorical meaning' for proper names concedes that such meaning is only presuppositional: 'My position here will be that proper names have an inherent categorical presupposition without which the use of a proper name is inconceivable. Whenever a proper name is assigned to a referent, this referent belongs to a specific (sub)class of entities. [...] However, since this categorical meaning is a presupposition, things cannot be viewed in terms of necessity,... In other words, presuppositions can be cancelled' (2007: 72-76).
} 
Auckland, even when I am well stoned

On a tab of LSD or on Indian grass

You still look to me like an elephant's arsehole... (Baxter, 1972: 16-18).

They are clearly figurative, stylistically marked uses of proper names creating a personification effect. Another instance is organization names occasionally employed in (formal) letters or emails when the writer does not have a contact person to address their message to: Dear VUWSA, [...]. This usage however is restricted and marginal; writers would usually avoid awkward openings like *Dear Dominion Post/TelstraClear in favour of more human Dear Editor/Sir/Madam or To Whom It May Concern. In all other contexts proper names denoting organizations are not acceptable as vocatives: *VUWSA/Dominion Post/TelstraClear, I'd like to get to know you.

With regards to grouping the personal, and deity and pets' names together, the anthropocentricity of language manifests itself once again in an intimate connection between personal names and the latter two subcategories. In many religious movements living individuals are idolized and become revered as gods so deity and personal proper names coincide in form, e.g. Ti, Do (leaders of Heaven's Gate, see www.heavensgate.com [accessed 14 March 2008]). A few names of gods and goddesses from classical mythology, such as Dionysus, Athena, Demeter (Dimitra), Aphrodite, are still in circulation in modern Greece. As for pets' names, it is quite common to select a personal first name as a name for a cat or a dog (George, Tex) or to name your house pet after a famous person (Cleopatra, Maximillian) (Lehrer 1992: 129).

To recap, I consider names of deities, personal names, and names of pets to be the core, prototypical representatives of the category. Their central status is determined by the following factors: the extent to which they manifest general anthropocentricity of human language, the frequency of occurrence (in the case of personal names), and the ability to fulfil the greatest number of characteristic proper name functions. While the differentiating and referring functions are shared by all proper name subcategories, the ability to perform the vocative role is generally available only to the three subcategories mentioned above. It was also established that differentiation is the major communicative role of all subcategories of proper names in discourse. Although categorization may be achieved through proper name use (and in many cases is), it is not their essential function; the more categorizing a proper 
name is the more description-like it becomes and the further it shifts away from the core to the periphery.

\subsubsection{Place names and names of enterprises}

I put names of places and enterprises in the middle, halfway from the core to the more peripheral types. Firstly, one reason why philosophers, psychologists, and linguists unanimously agree that names of places and enterprises are central may be that, from a purely pragmatic point of view, these subcategories are very predictable, i.e. in terms of the name catalogue approach, once identified, they cover practically all prospective referents. Nobody knows of nameless gods or nameless human beings. Likewise, if there exists a location that is at least slightly important to people or an organization, it is bound to have a proper name. With very few exceptions, everything from a galaxy to a subway station as well as from an international corporation to a tiny firm must have a proper name attached.

Also there is some evidence to believe that names of places and enterprises are more frequent than others (rank second after personal names). In an earlier study Tse extracted a 65-thousand-word sample of proper names from a daily British newspaper and divided them into 12 subcategories. She does not cite the number of items found in each subcategory but she mentions that it is personal names, place names and names of organizations which 'count for the majority of the overall data' (2000: 494). Although it would not be safe to generalize from a single study, it can serve as an acceptable preliminary estimate in the absence of more thorough corpus research that needs to be done.

Next let me explain why I consider place and organization names to be less central than personal (plus deity and pets) names. It has been noted by many scholars that a representative proper name is a brief referring device, ideally consisting of a single noun (Quirk et al. 1985, Allerton 1987, Tse 2000; see 3.2.1 below). Far more complex multiword strings are found among place names and especially enterprise names than in the most prototypical proper name subcategories. In English as in some other languages, personal names consisting of several words are not common. Although individuals usually possess more than one name (i.e. a surname and oftentimes a middle name in addition to a given name) they are usually referred to by means of only one of those. In rare cases a 'first name + family name' pattern is used but, interestingly enough, it still does not quite qualify to be on a par with complex 
proper names. Grammatically, unlike other phrasal names that consist of a head word and its dependents, this construction is unique because 'there is no convincing evidence for treating one element as head' (Payne and Huddleston, 2002: 519). Place names may consist of one word (Mars, Chicago, Miramar), but two-, three- and even multi-word constructions are numerous (Little Rock, Bremerton Naval Base, Smokey Mountains National Park). Simple organization names also occur (Microsoft) yet more often than not they are characteristically multipart (Outsource Solutions, APN Educational Media, International Federation of Civil Aviation).

When a proper name is represented by a multiword sequence, this sequence has to function as a single unit rather than a free syntactic combination of words. For common vocabulary, Bauer (1983: 42-50) proposes the following terminology for the process by which this occurs:

\begin{tabular}{|l|l|l|}
\hline Stage & Description & Example \\
\hline 1 & $\begin{array}{l}\text { A new multiword lexeme is } \\
\text { Noined 'on the spur of the } \\
\text { moment to cover some } \\
\text { immediate need' (p. 45). }\end{array}$ & a call boy \\
\hline 2 & $\begin{array}{l}\text { The formation begins to be } \\
\text { accepted as a known item. Its } \\
\text { potential ambiguity is ignored, } \\
\text { and 'only some of the possible } \\
\text { meanings of the form are used } \\
\text { (sometimes only one)' (p. 48). }\end{array}$ & $\begin{array}{l}\text { meanings 'boy who makes a } \\
\text { call/boy who was called/boy } \\
\text { oho is on call' and any } \\
\text { who calls actors on to the } \\
\text { stage' becomes familiar }\end{array}$ \\
\hline 3 & $\begin{array}{l}\text { '..because of some change in } \\
\text { the language system, the lexeme } \\
\text { has, or takes on, a form which it } \\
\text { could not have if it had arisen by } \\
\text { the application of productive } \\
\text { rules' (p. 48). }\end{array}$ & \\
\hline
\end{tabular}

Lexicalization is the final stage in the historical development of a complex lexeme, which is associated with irregularity at the synchronic plane, i.e. inconsistency with normal current word formation patterns. Bauer's concept of lexicalization is elaborate as he goes on to distinguish its phonological, morphological, semantic, and syntactic types concluding that complex lexemes are often the result of their mixed action. For the purposes of my research, which is not going to focus on the grammar of proper names as such, more general definitions offered by Kastovsky and Lipka are suitable. Thus lexicalization may be regarded simply as the process via which complex units 'become fixed parts of the vocabulary, with formal and/or semantic properties which 
are not completely derivable or predictable from their constituents...' (Kastovsky 1982, cited in Lipka, 1994: 2164). Institutionalization will be viewed as the gradual inclusion of a new item 'into the existing stock of words as a generally acceptable and current lexeme' (Lipka, 1994: 2165).

All definitions quoted above were proposed with common vocabulary in mind; the process looks slightly different for proper expressions:

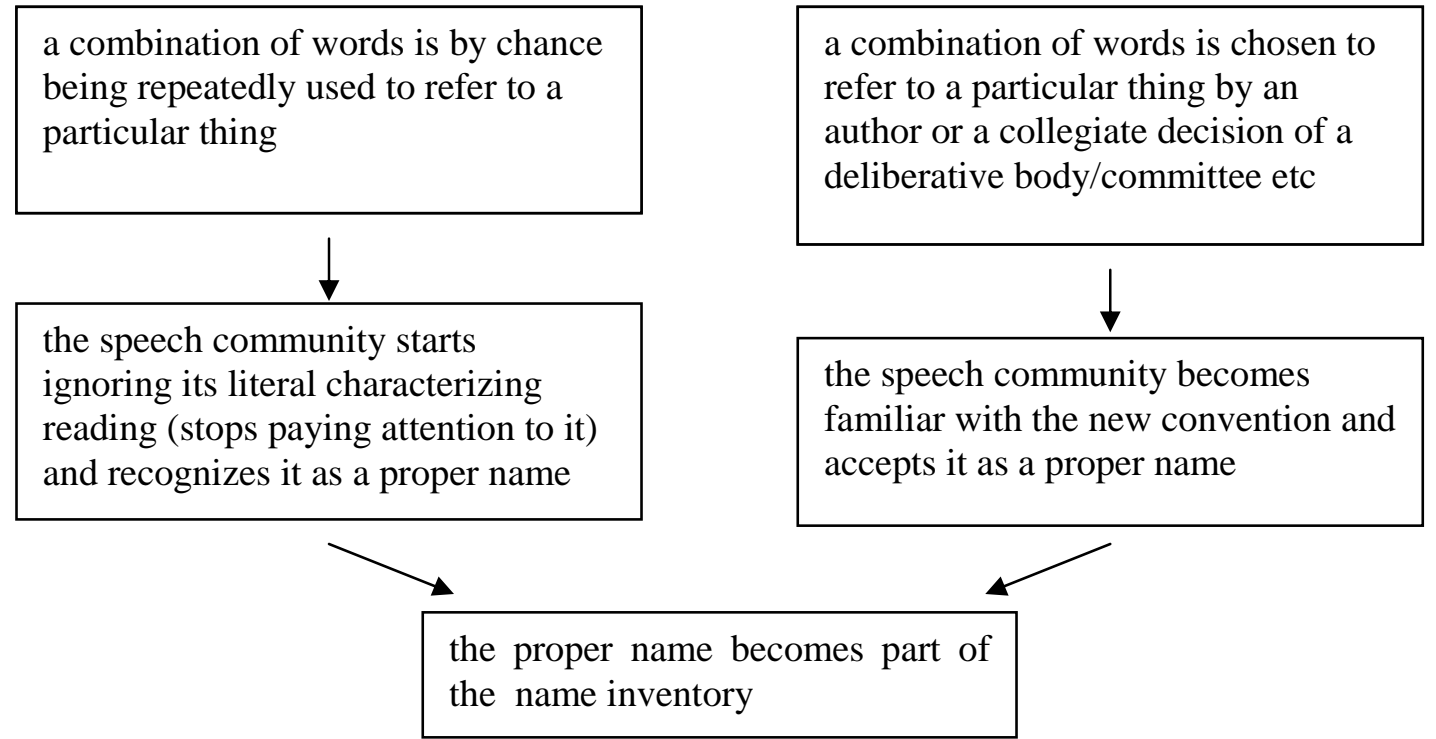

The main point relevant for the present study is that lexicalization is not a prerequisite for a multiword expression to be a proper name; institutionalization is enough. For a unit to be lexicalized it has to lose its motivation (i.e. its meaning should become impossible to ascertain from the meanings of individual parts). All that is needed for an item to get institutionalized is its recognition by a speech community as a recurrent stable whole:

Institutionalized words belong to the norm of the language and are more or less familiar to the members of a certain speech community... A minimal degree of item-familiarity is a necessary requirement for institutionalization (Lipka, 1994: 2166).

While scores of place names and particularly enterprise names have not undergone lexicalization (i.e. remain semantically and/or structurally motivated: Cable Car Museum, Workman Antenna Co, Pak'n Save), what unites them is they became institutionalized. Institutionalization for these particular proper name subcategories is achieved with ease because they appear in atlases, TV and printed commercials as well as on signposts, company letterheads etc. It is also noticeable that a much greater fraction of place and enterprise proper names is descriptive of their referents 
compared to personal and deity and pet proper names. Lack of internal semantic content have been postulated by a number of scholars to be a distinctive feature of core proper expressions. Whenever it is at least partially intact it makes them more prone to take on an unusual categorizing function and to move further out from the core.

\subsubsection{Names of events and artefacts}

I placed these two subcategories at the outmost edge of the proper name class.

Table 2.2. Proper names of events.

\begin{tabular}{|c|c|}
\hline Geological epochs & $\begin{array}{l}\text { the Archean, the Mesoproterozoic, the Paleozoic, } \\
\text { Pleistocene, Holocene (CMS: } 361 \text { ) }\end{array}$ \\
\hline Historical eras & $\begin{array}{l}\text { the Age of Reason, the Augustan Age, the Common } \\
\text { Era, the Dark Ages, the Enlightenment, the Old } \\
\text { Kingdom, the Gay Nineties, the Gilded Age, the } \\
\text { Reformation, the Renaissance (CMS: 340-1) }\end{array}$ \\
\hline Wars, milita & $\begin{array}{l}\text { Crusades, the Sixth Crusade, French Revolution, } \\
\text { Great Sioux War, Gulf War, Korean War, } \\
\text { Napoleonic Wars, Norman Conquest, Russian } \\
\text { Revolution, Seven Years' War, Shays's Rebellion, Six } \\
\text { Days' War, Spanish-American War, Vietnam War, } \\
\text { War of } 1812 \text { (CMS: 354-5) }\end{array}$ \\
\hline Battles & $\begin{array}{l}\text { Battle of Britain, Battle of Bulge, Bunker Hill, the } \\
\text { Blitz, Operation Overlord (CMS: } 355 \text { ) }\end{array}$ \\
\hline Histori & $\begin{array}{l}\text { the Boston Tea Party, the Great Depression, the } \\
\text { Reign of Terror, the Industrial Revolution, the New } \\
\text { Deal (CMS: } 341 \text { ) }\end{array}$ \\
\hline Major & $\begin{array}{l}\text { Washington's Farewell Address, the Gettysburg } \\
\text { Address (CMS: } 341 \text { ) }\end{array}$ \\
\hline Space missior & Project Apollo (CMS: 356) \\
\hline $\begin{array}{l}\text { Hurricanes, typhoons, } \\
\text { floods etc. }\end{array}$ & $\begin{array}{l}\text { El Nino, Hurricane Mitch (CMS: 342), Typhoon } \\
\text { Maemi, Hurricane Pauline, Hurricane Lynda, } \\
\text { Typhoon Pongsana, Tropical Storm Allison, Katrina } \\
\text { (mine) }\end{array}$ \\
\hline Major earthquakes and & the Great Fire of London (CMS: 342) \\
\hline $\begin{array}{l}\text { Tournaments, races, major } \\
\text { sporting events }\end{array}$ & $\begin{array}{l}\text { the Olympic Games, the Olympics, the Winter } \\
\text { Olympics, the World Cup, the Kentucky Derby, the } \\
\text { NBA World Championship Series (CMS: 342) }\end{array}$ \\
\hline $\begin{array}{l}\text { Festivals, special celebrations, } \\
\text { conferences }\end{array}$ & $\begin{array}{l}\text { Christmas (Day), Mother's Day, Kwanzaa, Rosh } \\
\text { Hashanah, New Year's Eve (CMS: 346), Poznan } \\
\text { Linguistic Meeting, Wellington Film Festival (mine) }\end{array}$ \\
\hline
\end{tabular}

The vast majority of proper name forms are low frequency vocabulary items but I suppose that names of events and artefacts are infrequent compared to other proper name subcategories. I am not aware of any documented quantitative data on the 
matter but in my own small corpus of news texts out of 240 names only 15 were of this kind $(\approx 6 \%)$. These two subcategories are, however, extremely variegated (see tables 2.2 and 2.3).

Table 2.3. Proper names of artefacts.

\begin{tabular}{|c|c|c|}
\hline \multirow{3}{*}{$\begin{array}{l}n \\
0 \\
0 \\
0 \\
0 \\
0 \\
0 \\
0\end{array}$} & Ships and boats & $\begin{array}{l}\text { USS SC-530, HMS Frolic, the United } \\
\text { States (CMS: 356) }\end{array}$ \\
\hline & Trains & $\begin{array}{l}\text { Atlantic Express, Dixie Flyer, Cornbelt } \\
\text { Limited, Superchief, Hiawatha (Nuessel, } \\
\text { 1992: 121) }\end{array}$ \\
\hline & Aircraft and spacecraft & $\begin{array}{l}\text { Boeing 747, the Spirit of Saint Louis } \\
\text { (CMS: 356), Challenger (mine) }\end{array}$ \\
\hline \multirow{7}{*}{ 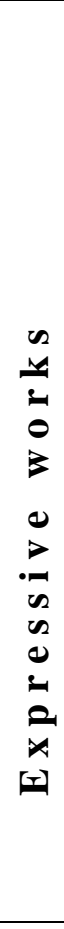 } & Books and periodicals & $\begin{array}{l}\text { A Short History of Nearly Everything, A } \\
\text { Mind of its Own: How Your Mind Distorts } \\
\text { and Deceives, And Quiet Flows the Don, } \\
\text { Scarlet Sails, Inside Out, Journal of } \\
\text { Anthropological Research, The Modern } \\
\text { Language Journal (mine) }\end{array}$ \\
\hline & Articles and chapters & $\begin{array}{l}\text { Naming Processes, On Homonymy } \\
\text { between Proper Name and Appellative } \\
\text { (mine) }\end{array}$ \\
\hline & Poems and songs & Arrow, Because of You (mine) \\
\hline & Orations and sermons & $\begin{array}{l}\text { the Sermon on the Mount, the Lord's } \\
\text { Prayer, the Our Father (CMS: 352) }\end{array}$ \\
\hline & $\begin{array}{l}\text { Musical compositions, albums } \\
\text { and CDs }\end{array}$ & $\begin{array}{l}\text { Don Giovanni, Swan Lake, Moonlight } \\
\text { Sonata, Crowded House, Beautiful } \\
\text { Collision, Innuendo, Birds (mine) }\end{array}$ \\
\hline & Paintings and sculptures & $\begin{array}{l}\text { the Return of the Prodigal Son, Fifteen } \\
\text { Sunflowers in a Vase, the Thinker (mine) }\end{array}$ \\
\hline & Films, radio and TV shows & $\begin{array}{l}\text { About a Boy, Artificial Intelligence, the } \\
\text { Apprentice, Breakfast, NZ Idol (mine) }\end{array}$ \\
\hline & B r & $\begin{array}{l}\text { Jacuzzi, Kleenex, Scrabble, Monopoly, } \\
\text { Xerox, Pyrex, Levi's, Panasonic, Coca- } \\
\text { Cola, Toyota, Anchor (mine) }\end{array}$ \\
\hline
\end{tabular}

In terms of the name catalogue approach, several proper name groups in tables 2.2 and 2.3 above are not fully predictable in that not every event and artefact actually has a proper name. Only a handful of speeches and sermons are honoured with names, and scores of trains, poems, and sport competitions never receive one. Similarly, proper names are given only to major battles and natural disasters while thousands of smaller scale ones remain nameless. Events can be so short lived that their names simply do not have enough time to get institutionalized. For example, a contemporary dance show Feats of Fancy was performed in New Zealand only four times over a period of one week (the last time in The Opera House, Wellington, 1 July 2006). The 
fact that even the proper names of well-known events can be partially institutionalized is reflected in unstable spelling. Compare winter Olympics, Winter Olympics, and winter olympics (all three variants found in the BNC); American Civil War and Spanish civil war (CMS: 355); Battle of Britain and battle of Bunker Hill (CMS: 355).

As can be seen from the tables, there are only a few proper names of events and artefacts that consist of a single proper noun. As a rule, they are multiword, and names of literary works in particular can be quite lengthy. Also, a lot of names in these subcategories are descriptive of their referents, which makes them marginal as they are gradually merging with definite descriptions. What is very atypical for proper names, names of events and artefacts are prone to represent the referent as a member of a class rather than an individual object as in I sold my Toyota and bought a BMW. This webpage gives you information about the past PLMs". Moreover, in certain contexts they can even function as generic expressions, i.e. refer unspecifically to all members of a class together as in Fords are selling well this summer.

Thus I consider names of events and artefacts to be borderline peripheral members of the proper name category because they are: (i) often descriptive; (ii) sometimes only partially institutionalized; (iii) as a rule consist of several words, and, unlike items in other subcategories, can be of considerable length; (iv) low frequency compared to other subcategories; (iv) instead of individualizing the referent, can represent it as a member of a class of similar objects, which is a very atypical function for proper names.

\subsection{Chapter overview}

To sum up the discussion so far, numerous definitions of proper names have been proposed in philosophy of language and linguistics, however none of them is completely satisfactory. I adopt the view that this category of expressions should be treated in terms of the prototype theory rather than a traditional member/non-member opposition. Personal, deity and pet names are considered the core subcategories on the grounds that they are the most anthropocentric, rank first in frequency and are able to perform the full range of proper name functions, namely vocative and referential (differentiating a certain entity from others). Place names and enterprise names are still close to the core but move further out towards periphery because they are not as

\footnotetext{
* PLM stands for the Poznań Linguistic Meeting, an annual conference in Poland.
} 
frequent, and often are not lexicalized. Within these subcategories, there are a lot of multiword names that have been institutionalized but retain their descriptive meaning, which makes them perform a non-characteristic classifying function. With very few exceptions, proper names of places and organizations in English cannot be used as vocatives. Names of events and artefacts are the least prototypical proper names lying at the outer edge of the category.

This division of proper names is only approximate due to the fact that a scale of gradience is found across each subcategory. Although personal names constitute the very core, not all of them are equally prototypical. Individual cases range from totally opaque one-word proper names (Jane) through partially motivated and characterizing (Little Turtle, (Mrs) Darling) to clearly atypical directly descriptive multiword giants (If-Christ-Had-Not-Died-For-You-You-Had-Been-Damned, example from Allan, 2001: 92). Compare Chicago, Little Rock, the North Island, the Great Barrier Reef; Kristallnacht, Easter, Wellington Film Festival, ANZAC Day, Mother's Day and again you find items varying from lexicalized units to full descriptions which, if (they were) not institutionalized as names, could easily pass for freely constructed common phrases. Due to considerable variance within subcategories proper names ought to be treated on a case-by-case basis. In the following chapter I will discuss what can be set out as a prototypical proper name regardless of what subcategory it belongs to. 


\section{Chapter III. Defining a proper name: semantic, grammatical, pragmatic and functional properties}

\subsection{Prototypical proper names in semantics}

Prototypical proper name properties have been identified on different levels, namely in semantics, grammar and pragmatics. As has been noted by many scholars, difficulties with arriving at a uniform definition and inconclusiveness of proper name theory may arise particularly because few expressions score 'ideal' at all levels simultaneously. I start with semantics and elaborate the following points:

- Prototypical proper names are referring expressions;

- $\quad$ prototypical proper names have no sense (i.e. intension);

- prototypical proper names are definite, specific and non-partitive.

\subsubsection{Proper names as referring devices}

Reference is a relation that is made between an etic word (i.e. a word as part of an utterance actually produced by a language user) and an object in the world at large that is being communicated about. Proper names are a primary linguistic means to establish this relation, i.e. they are perfect referring devices. Following Coates (1994), I hold that proper names lie somewhere in between two other kinds of referring expressions in English, namely pronouns and definite common noun phrases.

Pronouns, on one side, require almost no semantic commitment on the part of the speaker and can be used to refer to virtually anything. In Can you see that?, for instance, that can stand for a toe, a point someone is trying to put across, a dinosaur, and what not. Although they possess grammatical meaning (Van Langendonck, 1997: 40), the lexical content of pronouns is close to zero, which allows them to point at an outside world object practically without describing it in any way. In logical terms, their intension (or sense) is minimal while their extension is very broad. ${ }^{*}$ In contrast,

\footnotetext{
* By extension of a word I mean all the things in the real world 'to which it can be correctly applied'. The intension of a word is 'the set of essential properties which determines the applicability' (Lyons, 1977: 158-159). In other words, the intension, or sense, is a set of conditions that must be met in order for a word to be used correctly.
} 
common noun phrases are lexically loaded, and each element 'brings a full semantic contribution to the business of referring' (Coates, 1994: 3370). For example, the ceramic jar with fish-shaped handle and red pattern on the upper edge refers in virtue of the sum of lexical meanings of its constituents. Moreover, it can refer to only a few real world jars that actually live up to the conditions imposed by the description and possess all the qualities mentioned. Therefore in freely articulated common phrases, the intension (sense) is substantial while the extension is proportionately small.

Prototypical proper names are in the middle, i.e. neither completely common phrase like, nor pronoun-like. What unites them with pronouns is lack of semantic commitment on the part of the speaker. When students at Victoria University of Wellington talk about Cotton (Building) they do not communicate that this building has anything to do with cotton. Nobody thinks of buns, ginger bread or cookies when greeting (Mr) Baker, and going to the Embassy ${ }^{*}$ (at least in Wellington, New Zealand) can be associated with movies and popcorn, not consulates or visa officers.

In fact, it is next to impossible to formulate the sense of proper names in the same way it can be obtained for common vocabulary. The strict conditions, or set of essential rules that would govern their application, are hard to determine. Russia cannot have the largest country in the world as its intension because, strangely enough, it can also refer to a chocolate factory situated in the city of Samara as well as the corresponding popular brand of chocolate and at least a dozen hotels scattered around the country. On the other hand, neither popular brand of chocolate nor the chain of hotels will do as its sense because obviously not all the chocolate bars and not all the big hotels are correctly called Russia. When we try to word the intension of a proper name as conditions of correct application, these conditions turn out to be fickle and we come instead to listing the proper name's extralinguistic denotata, i.e. extension.

\subsubsection{Proper names lack intensions}

Thus it has been postulated that proper names (no matter whether they are opaque or seemingly meaningful, i.e. lexically transparent on the surface) are expressions that refer independent of sense:

\footnotetext{
* While there are a number of embassies around Wellington, The Embassy is a recently refurbished movie theatre where the premiere of the second movie in The Lord of the Rings trilogy took place in 2003.
} 
One of the questions that has been most hotly disputed is whether names have a sense. What is probably the most widely accepted philosophical view nowadays is that they may have reference but not sense (Lyons, 1977: 219).

Sense is a property of the emic language expression. All language expressions except proper names have sense (Allan, 1986: 71).

Centrally, properhood has to do with sense. Most linguists agree that proper names have no sense(s) at all (Coates, 2004: 1).

Sense (or intension) is a technical term. It concerns abstract, strictly intralinguistic properties of words as units in the language system (emic words) and should not be confused with their communicative value. Saying that emic proper names do not carry sense is not equal to saying that etic proper names do not contribute any information to the utterances in which they appear*

(1) I've been to the Long Island.

(2) I've been to the South Island.

Of course, (1) and (2) communicate different things, however this difference is not accounted for by the difference in their senses, but merely by the difference in reference. The standard intensions of long, south and even island stop working. Around the world, there exist dozens if not thousands of 'patches of land completely surrounded by water' that are 'not short from end to end' nevertheless none of them can be correctly called The Long Island because this name actually refers to a whole group of islands in Scotland better known as The Outer Hebrides. So I'm taking my holiday on the long island (normal intension) is not equal to I'm taking my holiday on The Long Island (proper name, no intension) because 'I could be visiting several islands, none of which is necessarily long individually, and my words would still not be untruthful or devious' (Coates, 2004: 2). Similarly, the South Island cannot stand for 'an island situated in the south' but only for one of the two main pieces of land in New Zealand.

The idea of proper names not having sense is a hard one to grasp because: (i) we are prone to equate 'sense' to 'meaning' in the every day non-technical sense of the word, i.e. not to distinguish sense and reference as separate building blocks of 'meaning', or communicative value; (ii) since there are a lot more common words in an average speaker's lexicon than proper names and, for the majority of common

\footnotetext{
* My 'emic proper name' / 'etic proper name' distinction corresponds to 'proper name category' / 'proper name as functioning in a sentence' distinction emphasized by Van Langendonck $(1997,1999)$ and Willems (2000).
} 
expressions, communicative value is directly dependent on sense, we tend to assume that this link should always be in place for every word. However, language is extremely versatile and flexible therefore sense and reference do not have to be and are not always 'tied' to each other". Undoubtedly, there are a lot of expressions that have disparate senses but the same reference. 'The marketer of the first successful parking meter' and 'the man responsible for the first great yo-yo fad in the United States' mean very different things but both have Donald F. Duncan as their referent (example from Allan, 1986: 70). By the same token, one should not be surprised to accept that there are expressions that refer to different people or objects, being identical in terms of their lack of sense.

As has been said before, proper names closely resemble pronouns regarding lack of intension. However, unlike pronouns, they are not deictic ${ }^{* *}$ in that their extensional capacity is not unbounded. Proper names cannot point to anything (in context) but are reserved for particular fixed entities. Paradoxically, because their reference is permanent and so specific, they remind us of elaborate common noun phrases with ultra-narrow extensions.

\subsubsection{Proper names are definite, specific and non-partitive}

It is a long established and widely accepted view that proper names are inherently definite (Tse, 2000: 491; Berezowski, 2001: 92-5; Payne and Huddleston, 2002: 517). I draw on the recent work of Anderson (2003, 2004 and 2007) who offered a new perspective on this issue.

Even among genetically related languages much variation is observed in the morphosyntactic structure of proper names, and superficial formal markers of namehood on their own have often been considered an unreliable base for defining proper names (Algeo, 1973; Coates, 2000; Berezowski, 2001). For instance, irregular article choice often seen as such a marker in English would not be applicable to Russian, a language without articles. Prototypical members of the English proper name category normally resist pluralization but this feature is of no use in Mohawk in which most nouns are not marked for plural. Initial capitalization is a conspicuous formal proper name marker in many European languages but there are other one-set

\footnotetext{
* Sense concerns with conditions of truth and falsity which are irrelevant for reference since it is 'measured' differently: it is either successful (established) or not.

** A deictic expression is an expression whose interpretation is relative to the extralinguistic context of the utterance.
} 
writing systems like that of Hebrew or Arabic which do not allow for the uppercaselowercase distinction. Anderson aims to show that in all languages proper names are 'a notionally coherent class of items' (2004: 436). He arrives at establishing the essential properties of proper names by comparing them in great detail with such categories as vocatives, deictics, definites, indefinites, generics etc, noting every small patch of common ground names share with these other classes as well as apparent differences.

Together with deictics, proper names establish the identity of arguments. Both notional classes share the 'semantico-pragmatic property of uniquely identifying, without recourse to description, a particular argument in a particular context' (Anderson, 2004: 440). Moreover, they enable primary identification in the sense that all further references, which Anderson terms 'derived identification', ultimately rely on either deixis or proper name use. Unlike deictic expressions though, names are not dependent on the immediate non-linguistic context. They identify who or what is being talked about without recourse to situational extralinguistic information as long as the act of prior nomination had taken place: '... the use of a name like Basil for identification presupposes that the speaker and addressee have participated, together or separately, in a naming to them, as Basil, of the same entity, and that, if separate namings are involved, they have ascertained that their namings correspond' (ibid. 440).

Lyons distinguished two kinds of nomination: 'by didactic nomination we mean teaching someone, whether formally or informally, that a particular name is associated by an already existing convention with a particular person, object or place' (1977: 217), or, in simple terms, teaching an existing name to someone. Performative nomination is the actual act of christening of some - up to now nameless - entity with a name, i.e. creating a new convention. Performative nomination utterances involve verbs of naming, such as name, call, as in I name this child Basil. Obviously, performative nomination is primary in the sense that any didactic nomination needs to be derived from and is not possible without the latter. Thus for Anderson, didactic nomination is 'an assurance of correspondence' of identity while performative nomination is the process by which 'identity is assigned' (Anderson, 2004: 441). Therefore, he argues, in utterances involving didactic nomination, names still function as arguments whereas in the performative nomination case they do not. 
In Greek when a proper name is used as an argument it is preceded by the definite article. However, with names in vocative function and in performative nomination utterances, the article is absent. The same is observed in some Polynesian languages. Anderson suggests that proper names are not always definite. They are definite only in their argumental uses (whenever they refer to someone, including cases of didactic nomination) but are indefinite in non-argumental (vocative and performative nomination) uses. In argumental uses, their primary role, which they share with deictics, is the ability to enable primary identification.

Definite common nouns and the pronoun one may also act like primary identifiers but this use is subject to contextual limitations:

(1) I prefer the pink ones.

(2) Will you feed the dog?

In these examples, identification is achieved only when it is known that (1) is said by a person choosing floor tiles, and (2) by wife to husband, the joint owner of Bonzo (Anderson, 2004: 443). Besides, definite common expressions may provide incomplete identification:

(3) The author of this pamphlet is a liar.

(4) A boy and a girl came to see Jill. The girl knows Jack.

According to Anderson, the author of this pamphlet in (3) is a case of non-specific identification. The referent of the expression can be represented as 'whoever s/he may be'. Thus what the speaker had in mind is identified for the addressee but not specified. The girl in (4) is what Anderson terms specific non-identification. Here 'the speaker has a specific referent in mind, but does not, or cannot, identify it to the addressee' (ibid. 444). The only thing ascertained is that the referent exists.

Anderson points out that specificity is not a necessary inherent property of definite expressions. In contrast, the salient notional characteristic of proper names is that, similar to deictics, they can only be used to identify specifically. The difference between proper names and deictics is that 'names are homophoric, self-identifying, and deictics are exophoric, extratextually identified' (ibid. 444).

Indefinites can be both specific as a boy, a girl in (4), or non-specific if the existence of the referent is not presupposed or asserted as in Bill longs for a yacht. The function of indefinites, both specific and non-specific, is non-identification. Both specific and non-specific indefinite nouns can imply partitivity, i.e. they are interpreted as referring to only some subset of individuals or some part of the 
substance being described. One more salient notional property of proper names is that partitivity is absent. Unfortunately, Anderson does not supply further illustration for this point, which, in my view, is rather important. Semantic non-partitivity is reflected in the fact the proper names are never given to diffuse substances. For something to receive a name, it has to be (or to be perceived as) a distinct whole, an object separated (or at the very least separable) from others. This semantic property is what sharply contrasts proper names with mass nouns and unites them with countables. It is reflected in the syntactic fact that names cannot take the low-stressed some (as a typical mass noun quantifier): some porridge/sugar, but not *some John/Zimbabwe. If they do, the resulting constructions are semantically bizarre and require special interpretation (Sloat, 1969: 30). Semantic non-partitivity does not imply that proper names are not capable of denoting only a part of something larger (consider, e.g., named rooms or wings within buildings or names of administrative divisions within countries). What it does imply though is that a proper name cannot be attached to some part of a larger object unless this part itself is (perceived as) a distinct whole: 'those objects that cannot be viewed as forming distinct individuals ... appear to have no proper names assigned to them' (Bhat, 1979: 107).

Coming back to Anderson's argument, it is very interesting that he noted and explicated an inconspicuous link between proper names and generic nouns. Generic utterances are utterances with non-specific and nonpartitive arguments as in Lions are extinct. Singular generic nouns and proper names display some common syntactic features due to their shared non-partitivity. This similarity is especially conspicuous in the case of abstract nouns. Abstract mass nouns do not take the definite article in their standard generic uses but become 'straightforwardly countable' (Anderson, 2004: 450) when used nongenerically. Similarly, core names normally do not require an article, but behave differently in atypical, partitive use instances.

\begin{tabular}{|l|l|l|}
\hline & Names & Abstract generic nouns \\
\hline $\begin{array}{l}\text { Primary } \\
\text { non-partitive use }\end{array}$ & Brown is blind. & Love is blind. \\
\hline $\begin{array}{l}\text { Subsidiary (marked) } \\
\text { partitive use }\end{array}$ & Those three Browns you met & $\begin{array}{l}\text { All his girls were one-night } \\
\text { loves. }\end{array}$ \\
\hline
\end{tabular}

Table 3.1 summarizes Anderson's observations on how proper names fit among other notional classes (2003, 2004, 2007: 26-46). He proposes that inherently proper names are neither definite nor indefinite: 'Definiteness is an acquired characteristic which 
enables names to function as arguments and serve an identificatory function' (Anderson, 2003: 352). Following Anderson, I hold that non-argumental proper names (i.e. used as vocatives or in performative nomination utterances) are not definite. On the other hand, argumental proper names are non-deictic homophoric sources of primary identification; they are always definite, always specific, and in the majority of cases non-partitive.

Table 3.1. Comparison of proper names and Anderson's 'notional classes' (2007: 2646).

\begin{tabular}{|l|l|l|}
\hline & $\begin{array}{l}\text { Common ground with proper } \\
\text { names }\end{array}$ & $\begin{array}{l}\text { What is different from proper } \\
\text { names }\end{array}$ \\
\hline vocatives & Normally specific. & In rare cases can be non-specific. \\
\hline deictics & $\begin{array}{l}\text { Definite, specific, enable primary } \\
\text { identification of arguments. }\end{array}$ & $\begin{array}{l}\text { Identification depends on } \\
\text { extratextual context. }\end{array}$ \\
\hline definites & $\begin{array}{l}\text { Definite, may enable primary } \\
\text { identification in context. }\end{array}$ & $\begin{array}{l}\text { Are often partitive, can be non- } \\
\text { identifying and non-specific. }\end{array}$ \\
\hline indefinites & Can be specific. & Always non-identifying, partitive. \\
\hline generics & Non-partitive, self-identifying. & Always non-specific. \\
\hline
\end{tabular}

\subsection{Prototypical proper names in grammar}

The peculiar semantics of proper names is reflected in their grammar so prototypical names would be expected to demonstrate the following morphosyntactic behaviour:

- Consist of one noun (without modifiers);

- are not predicative; cannot be pro-forms in anaphora;

- lack article contrast, number contrast, and restrictive modification.

\subsubsection{Simplicity}

It has been largely unquestioned since ancient times that proper names (alongside pronouns and common nouns) are a noun category (Langendonck, 1997: 39). Formally, this is supported by their positional preferences in text: '.. a proper noun can appear with all the distribution characteristics of the noun in the interior of the N[ominal] S[yntagm]' (Gary-Prieur, 1994: 243, cited in Anderson, 2004: 457). Based on the analysis of the permissible types of common noun phrase structures, Allerton believes that 'proper nouns stand syntactically closest to personal pronouns' (1987: 63). The same thought is expressed by Hopper (1990) who examines how referential devices (namely pronouns, ordinary nouns, and proper names) in a written Malay 
monologue compete with each other in sustaining reference for the postulated reader. He shows that although proper names, like common nouns, can take the article and appear in object and oblique position in a sentence, they exhibit a higher distributional preference for topic/subject slot (and concomitant absence of the article), which aligns them with personal pronouns.

Grammarians usually speak of proper nouns rather than proper names and unfortunately it is not always clear if a given observation would hold true for both. Many scholars use the terms proper name and proper noun interchangeably, which creates terminological confusion. Nicolaisen traces the history of both terms and notes that their usage is full of inconsistencies (1996: 384-6). It is a grave misconception to say that all proper names are proper nouns; however the opposite is undeniably true. Following Coates, I consider proper nouns as a narrower category 'epiphenomenal upon the basic category of proper name-expressions' (2004: 3). In my view, it is justified to claim that the most prototypical proper names are simplex (consist of one noun only), and that phrasal and the more so, non-nominal proper names are further out from the core.

Curiously, direct empirical support for the view that 'a typical proper name consists of a single proper noun' (Tse, 2000: 491) does not come from corpus-based frequency studies but from research in cognitive psychology. American psychologist John Carroll conducted a series of experiments on how people make names for things. He started off with almost no bounds as to what counts as a name 'defining it to be what people create when they are asked to "name" something' (1985: 4). The participants were presented with sets of cards featuring varied pictures and texts: linedrawn real-world scenes involving people in their daily lives, geometric shapes and other symbols (single and in combinations) as well as cookie recipes, role descriptions, and textual specifications of steps in procedures. People were asked to view the cards one at a time and make up a name for each entity. Then they had to judge the name created on two 7-point scales: how good a name it was and how easy it was for them to create.

One can debate whether it is theoretically valid to compare the new 'names' that participants created in this experiment with the established inventory of fully institutionalized proper names in the English language but the results certainly speak in favour of the 'prototypical proper names consist of one noun' view. Firstly, far more simple nominal names were generated than compound names, and absence of 
modification was more common than explicit modifiers of any kind. Besides, lexical modifiers (i.e. single word modifiers or sequences of single word modifiers) occurred much more often than phrasal or clausal ones. Not surprisingly, simple names tended to have more modifiers than compound nominal names because the non-head noun in a compound may be functionally analogous to a modifier. Secondly, practically nobody explicitly used any determiners in their names: 'Perhaps participants treated the names they created as proper names, which often require no explicit marking for definiteness, or perhaps they omitted determiners purely as a behavioural convenience' (Carroll, 1985: 6). Overall, this suggests that there exists a gross 'complexity bound' on name structures and that people predominantly try to create names that are syntactically simple:

Names with no modifiers were also rated as being better names and as easier names to make up. This finding seems to endorse the conventional wisdom that modifiers within name forms are the exception to the rule (Carroll, 1985: 21).

Another interesting discovery was that very few names supplied by the participants ( $1 \%$ out of almost 1600 in total) were coined forms, i.e. containing 'invented' words not in a standard dictionary. People preferred using regular common nouns and phrases built around common nouns instead of crafting novel names:

This suggests that behavioural economy plays a major role in limiting the scope of creative naming. Since speakers of human languages already have a rich fund of existent forms, there is no pressing need to coin new ones. So people apparently don't (ibid. 21).

As Carroll himself acknowledged, the main problematic aspect of his research was representativeness. It is not always the case that someone would construct names while sitting alone in their study. The second experiment addressed this issue and aimed to tackle the process of how names are developed in the course of interaction. Two participants who could not see each other had to communicate and mutually identify an assortment of graphic designs. Each person had a different spatial arrangement of the designs so the goal was to successively isolate designs with referential labels:

The chief question here is how the name - the final brief referential label emerges through the course of the dialogue. Such an analysis may provide hypotheses about how names are functionally descendant from descriptions in ordinary speech. (ibid. 27). 
In the majority of elicited dialogue transcripts there transpired a clear three-stage cycle: at first the participants exchanged descriptive phrases of the type sort of like a flying saucer with something hanging down on the bottom or some kind of crazy thing with three circles. Later when the design became familiar to both, a shorter name was proposed by one of the participants, or in some cases several names were 'trialled'. Finally, some name was ratified and became a permanent conventionalized form of reference throughout the remaining of the conversation (flying saucer).

Carroll looked again at the form of obtained names. Compared to the first experiment, simple forms occurred more often than compounds that made up over $30 \%$ in individual name creating but only $4 \%$ in the communicative situation. Participants generated fewer modified names overall. Absence of modification was again preponderant with lexical modifiers more common than phrasal or clausal ones. No modified compounds were produced. Basically, in regards to structure, the second experiment revealed the same tendencies as were found in the first study but they became even more pronounced.

Besides form, names were analyzed in terms of content. In both experiments, most of them tended to be highly descriptive and categorizing, i.e. rayed circle, diner, peanut molasses munchy etc. In the majority of cases participants evidently took the nature of specific referents into account while generating names for them so that referent type is somehow 'coordinated' with and reflected in the name forms: 'many of the names elicited bear systematic content relations to their referents' (ibid. 17). In the first experiment, for example, compound names were more commonly assigned to fairly complex recipes as opposed to symbols. The vast majority of action-like procedures received nominalized verbs as names (weighing, scheduled painting). Overwhelmingly, there was an apparent link between names and corresponding descriptions produced earlier in the dialogue in experiment two. In over $3 / 4$ of cases, all of the name material was literally present in the initial description; moreover, in $2 / 3$ of cases this material was salient, that is either the only content noun or one of the two content nouns in the description became the name. Even when the name was not literally present in the prior descriptive phrase, quite often it was a synonym of the prominent noun or obviously came out by way of association (looks like a Santa Claus hat -> cap; looks like the throne of a king, ... not a throne -> crown).

At first sight, high descriptiveness of obtained names in Carroll's study as well as of a large number of real institutionalized proper names (Cable Car Museum, 
United Nations, Red Rocks) seems to contradict the assumption that proper names are devoid of sense. However, it should be emphasized that 'descriptive content' and 'sense' although closely interrelated, are not synonymous. For instance, personal pronouns are not descriptive but their minimal senses can be stated: it is a semantic rule that $I$ should refer to the speaker, you to the addressee etc. In contrast, the fact that in principle proper names can reflect the actual qualities of their real world referents is still not enough to pin down their senses (defined as intralingual conditions of applicability). Imagine a painting on the wall, produced by a landscape artist, showing the early hour of morning and the sun rising from the sea. Imagine now that this picture is called Sunrise. There is an obvious content relation between the work of art and its name; the latter is genuinely descriptive. Nevertheless, as a proper name this word does not possess its regular sense as it would have in There was a beautiful sunrise this morning the reason being that sunrise (normal intension) always" points to the appearance of sunlight in the sky while Sunrise (proper name, no intension) in this case only points to a particular arrangement of oil-colours on a piece of canvas. The semantic 'rule of applicability' is not obtainable for Sunrise because as a name it can just as correctly be applied to a novel, a song, or even a brand of margarine (!).

Carroll viewed naming as a problem-solving activity governed by 'rule schemes', i.e. patterns that people regularly opt for which both facilitate and restrict (the scope of) name making. Although virtually any linguistic material can be employed in the construction of a new name (some participants supplied non-nominal names despite the explicit instruction that names can only be nouns or noun phrases), there emerged some stable 'rule-like strategies' that represent 'systematic ways in which the composition of lexical items may suggest properties of their referents':

A rule-scheme differs from a linguistic rule in being less complete, less permanently a part of the language, and more discretionary from a speaker's point of view... Violating linguistic rules makes speech ungrammatical. In contrast, rule-schemes are relatively flexible; they narrow down the space of possibilities instead of making a single prediction.... And rule-schemes can be violated with impunity; if someone really wanted to name a new type of cookie Ronald Reagan, they could. Nevertheless, rule-schemes have structure. People don't mechanically grind out new names, but surely they don't start completely from scratch each time either (ibid. 16).

\footnotetext{
* Saying 'always' I exclude cases of mention when the word is used metalinguistically to refer to itself as in Sunrise has seven letters.
} 
The nature of rule-schemes appears to be twofold as they can be regarded both as a process and a product of name creation. On the one hand, they are strategies that are not applied rigorously in every case but loosely guide the way people go about making names. On the other hand, they are 'structural patterns for name forms codifying systematic contrasts among their referents' (ibid. 156). In this sense, ruleschemes are regularities in the shape of the already created names, which have been prompted by some properties of the extralinguistic entities these names refer to. In particular, rule-schemes as form patterns manifest themselves in common substrings shared by several names. Thus there is a 'rule of thumb' one may use in creating names for cookies on the basis of a recipe text, namely to list all or some of the ingredients and finish with some 'cookie word': drop, cake, ball, roll, crisp, snap, munchy etc. (the $[\ldots+$ 'cookie'] rule-scheme). Similarly, there is a common constituent in the following group of real world proper names: the Podunk University, the Podunk Railroad, the Podunk Expressway, Podunk Park, Podunk Convention Center, which reflects the fact that all of them refer to something located in or near the Podunk area (the ['Podunk' $+\ldots .$. ] rule-scheme).

The problem of representativeness is of course not exhausted. As Carroll himself acknowledges, 'the referent domain of the model situation was extremely nonnatural. People name many things in the course of ordinary life, but they rarely name geometric designs' (ibid. 43). The question is how far spontaneously generated ad hoc 'names' in his study can be comparable to the stock of established proper names in English. No doubt, assigning (new) names and using (already accepted) ones are different matters not to be confused. However, analysis of the name creation process gives a lot of clues about the linguistic nature of proper names for the obvious reason that any name currently in circulation must have been previously adopted by the community in a certain way.

I suggest there are three major sources of proper names: (i) picking an item from an established inventory; (ii) employing a description (i.e. making a name out of common stock vocabulary); (iii) creating a novel phoneme string. Each proper name appears as a result of one or, frequently, a combination of these.

Personal names are the most typical example of the first category. In western culture at least, parents would normally consider a list of available options in some 
suitable publication, decide which is best according to their preferences, and register this name for a child.

Carroll's experiments illustrate the second possible route of proper name formation description -> (abbreviation process) -> name (ibid. 25), where initially standard common noun phrases acquire special proper name status. On a slightly simplified interpretation, when a sentence like After five days of marching, we had to cross a river, the big one, not one of the smaller ones has to be repeated over and over again, the name Big River can emerge (Zgusta, 2002: 733).

Manufacturing new phoneme strings usually occurs in situations where the purpose of originality outweighs other concerns. This may involve acronyming, blending, innovative inflections, and word plays. Carroll analyzed witty - at times on the verge of queer - examples of submissions to the contest in the seventies when readers of an American newspaper were invited to suggest names for the (then) newly built New York Conference and Exposition Center: CCCC (=Crystal Convention Center Complex), Con-Cent (read like 'consent'), Appleorium, Pick-NYC (= 'Pick New York City, it's a picnic!'). Invented phoneme strings are quite commonly found among brand names (Exxon, Kodak), organization names (NASA, FBI), and, probably less commonly, names of characters or imaginary places in films and books (Brubaker).

Proper names can consist of an item chosen from the inventory of already existing names and a descriptive element that shows what category the referent of the proper name belongs to, as in Tarewa Road, Tarewa Park, the Lincoln Tunnel, the Lincoln Monument (examples from Quirk et al., 1985: 288). Novel coined forms can also combine with descriptive elements to make up a complex proper name as in two other examples from the New York competition: Big Apple Fantasiorama, The Excelsior Exposition Center (Carroll, 1985: 128-133).

\subsubsection{Non-predicability}

Another grammatical manifestation of the peculiar semantic nature of proper names is their inability to form predication (Lyons, 1977: 219; Berezowski, 2001: 21; Anderson, 2003: 348-50). The term predication is itself broad and not particularly 
precise $^{*}$, which detracts from its explanatory power. However, basic linguistic intuition surely prompts that the predicate position in an English sentence is hardly ever occupied by a proper name (for sentences of the type This is Polly, see below). Why is this the case? Referring and predication are incompatible in the sense that both cannot be achieved simultaneously by one and the same language expression ${ }^{* *}$. It is impossible to be identifying an object (communicating what it is) and making an assertion or denial (generally communicating something) about this object at the same time. The point of predication is ascribing properties to a referent that has already been identified by some other expression. The crucial corollary of this assumption is that when a word/phrase is used predicatively it does not refer. In order to become predicative the expression (even if it is potentially referential) must 'give up' referring which goes against the most essential function of proper names. When a common noun or noun phrase forms a predication it stops pointing to real world referents but serves instead to evoke their characteristic qualities (and attributes those qualities to other referent/s identified by the subject of the sentence) ${ }^{* * *}$. Proper names are primary referential devices therefore they are practically never able to 'stop referring' in this fashion.

As I already said, the traditional view in grammar has been that proper names are a subclass of noun. Anderson $(1997,2007)$ argues that they constitute a separate category of their own based on syntax distinctive from other word classes. He proposes a notional system of syntactic categories summarized in Table 3.2.

Alongside pronouns and determiners Anderson classifies proper names as determinatives that embody referentiality at its finest. He agrees that the distribution pattern of names may indeed resemble that of nouns but argues that the distinction between nouns and names, i.e. $\{\mathrm{N} ; \mathrm{P}\}$ as opposed to pure $\{\mathrm{N}\}$ in his terminology, should be based on non-predicability. Proper names are never predicative; when they occur in combination with the auxiliary be they do not form a standard nominal

\footnotetext{
* In the logico-linguistic analysis of Aristotle it roughly meant 'what is asserted of a subject' (Cinque, 2003: 399). 'To predicate something of a subject or subjects is to describe it or them as having some property or as standing in some relation' (The Oxford Dictionary of Philosophy. Simon Blackburn. Oxford University Press, 1996. Oxford Reference Online. Oxford University Press. www.oxfordreference.com/views/ENTRY.html?subview=Main\&entry=t98.e1896 [Accessed 14 March 2008]) ** That is on one occasion of use.

*** Compare (1) The carpenter is goofing off. (2) He is a carpenter. In (1) the carpenter identifies an individual, i.e. it refers. In (2) he refers but a carpenter does not because it would not make sense to continue by saying and he works hard but the carpenter tends to goof off (example from Berezowski, 2001: 20).
} 
predicate but become part of an equative construction: This is Basil. Basil is him. Basil is that guy over there. Basil is the one who married Clotilde. According to Anderson, in all these examples, definite phrases on both sides of be are equal so that the subject can be inverted with this, him, that guy over there, the one who married Clotilde. An equative construction is a sentence asserting that two referents are identical (as opposed to ascribing properties to a referent or group of referents in standard predication) so both the subject and the fake 'predicate' refer. It may be argued that equative constructions constitute a peculiar type of predication. This, however, would not harm Anderson's non-predicability proposal. It would just have to take a slightly weaker form: 'A proper name cannot be predicative unless it is part of an equative predication'.

Table 3.2. The notional system of syntactic categories (Anderson, 2007).

\begin{tabular}{|c|c|c|c|c|}
\hline Categories & Type & \multicolumn{2}{|c|}{$\begin{array}{l}\text { Presence of referentiality }\{\mathrm{N}\} \\
\text { and predicability }\{\mathrm{P}\}\end{array}$} & Examples \\
\hline $\begin{array}{l}\text { Functors: elements that express } \\
\text { the functions of arguments }\end{array}$ & $\bar{\sigma}$ & \multicolumn{2}{|c|}{$\begin{array}{l}\{-\} \\
\text { non-referential and } \\
\text { non-predicative }\end{array}$} & $\begin{array}{l}\text { of, } \\
\text { and }\end{array}$ \\
\hline $\begin{array}{l}\text { Determinatives: } \\
\text { pronouns, determiners, names }\end{array}$ & 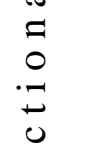 & \multicolumn{2}{|c|}{$\begin{array}{l}\{\mathrm{N}\} \\
\text { referential but } \\
\text { non-predicative }\end{array}$} & $\begin{array}{l}\text { you, } \\
\text { the, } \\
\text { Basil }\end{array}$ \\
\hline $\begin{array}{l}\text { Operatives: elements that } \\
\text { express finiteness when it has } \\
\text { word status (is not absorbed } \\
\text { into the content verb) }\end{array}$ & $\Xi$ & \multicolumn{2}{|c|}{$\begin{array}{l}\{\mathrm{P}\} \\
\text { non-referential but } \\
\text { predicative }\end{array}$} & $\begin{array}{l}\text { has, as in } \\
\text { He has } \\
\text { come. }\end{array}$ \\
\hline Noun & \multirow{3}{*}{$\begin{array}{l}\bar{\sigma} \\
0 \\
\dot{x} \\
0 \\
0\end{array}$} & \multirow{3}{*}{$\begin{array}{l}\text { referential } \\
\text { and } \\
\text { predicative }\end{array}$} & $\begin{array}{l}\{\mathrm{N} ; \mathrm{P}\} \\
\mathrm{N} \text { predominates }\end{array}$ & carpenter \\
\hline ‘Main' verb & & & $\begin{array}{l}\{\mathrm{P} ; \mathrm{N}\} \\
\mathrm{P} \text { predominates }\end{array}$ & come \\
\hline Adjective & & & $\begin{array}{l}\{\mathrm{N}: \mathrm{P}\} \\
\mathrm{N} \text { and } \mathrm{P} \text { are } \\
\text { equally } \\
\text { preponderant }\end{array}$ & industrious \\
\hline
\end{tabular}

Proper names also exhibit a distinctive syntactic pattern in sentences containing anaphora*. They are 'eminently suitable antecedents' (Anderson, 2003: 349) but cannot serve as substitutional elements (pro-forms). For instance, when hearing The girl thought that she was alone, we assume that 'the girl' and 'she' are

\footnotetext{
* Anaphora is the effect of one expression referring to another, most commonly in the preceding text. The former is called substitutional element, or pro-form; the latter is called antecedent. Compare The bird picked the berry because it was hungry and The bird picked the berry because it was ripe. It in both sentences is the pro-form. The bird and the berry respectively are antecedents.
} 
the same person but the effect is instantly ruined if we try to put a proper name, e.g. Elizabeth, in place of she. Similar to pronouns I, you, we and us, "proper names cannot have an anaphoric function' (Thrane, 1980: 223).

\subsubsection{Lack of article contrast, number contrast and restrictive modification}

Quirk et al. (1985) spell out the distinction between proper nouns (which they loosely define as words like Sid, Paris, September, Thursday, Christmas, Vogue) and names (that can consist either of one word or several words). They note that proper nouns are often supplemented by the common stock words to make up a composite name, e.g. Kennedy Airport. The surface structure of a composite name may be syntactically analyzable but the construction still functions as a single unit not permitting interruption by new words or inflectional change: King's College, but not *King's famous College (Quirk et al. 1985: 288). Three major features of proper nouns are: (i) they may be preceded by a definite article, but normally lack article contrast; (ii) they can be singular or plural, but normally lack number contrast; (iii) they can only take non-restrictive modifiers, such as relative clauses, appositions, and a few premodifying adjectives. Unfortunately, the authors do not state explicitly if these observations hold true for proper names (as opposed to proper nouns only). Like Allerton (1987), I am inclined to believe they do:

\begin{tabular}{|c|c|c|}
\hline & Proper nouns & Proper names \\
\hline \multirow[t]{2}{*}{ Article contrast } & $\begin{array}{l}\text { Wellington, but not *the } \\
\text { Wellington, } * a \text { Wellington }\end{array}$ & $\begin{array}{l}\text { Island Bay, but not *the } \\
\text { Island Bay, *an Island Bay }\end{array}$ \\
\hline & $\begin{array}{l}\text { the Crimea, but not } \\
* \text { Crimea, } * \text { a Crimea }\end{array}$ & $\begin{array}{l}\text { the Open University, but } \\
\text { not *Open University, *an } \\
\text { Open University }\end{array}$ \\
\hline \multirow[t]{2}{*}{ Number contrast } & Elbrus, but not $*$ Elbruses & $\begin{array}{l}\text { Southern Cross, but not } \\
\text { *Southern Crosses }\end{array}$ \\
\hline & $\begin{array}{l}\text { the Himalayas, but not } \\
\text { *the Himalaya }\end{array}$ & $\begin{array}{l}\text { the Olympic Games, but } \\
\text { not * the Olympic Game }\end{array}$ \\
\hline Restrictive modification & $\begin{array}{l}\text { Everest, which is on your } \\
\text { right, is magnificent, but } \\
\text { not *Everest which is on } \\
\text { your right is magnificent. }\end{array}$ & $\begin{array}{l}\text { Central Park, which is on } \\
\text { your right, is open, but not } \\
\text { *Central Park which is on } \\
\text { your right is open. }\end{array}$ \\
\hline
\end{tabular}

Quirk et al. (1985: 294-7) divide names into two large groups: those with no article, and the ones with the definite article. Their further subgrouping is pragmatic; they draw attention to common structural patterns but note apparent inconsistency in the article application or omission. In locative names of the type 'proper noun + common 
noun descriptor' the article is usually absent, however exceptions are numerous, the Merrit Parkway and the Albert Hall found alongside Oxford Street and Canterbury Cathedral. The definite determiner is typical in names of theatres and other public facilities yet Covent Garden does not follow suit. Plural names, as a rule, are preceded by the but again Kensington Gardens and some others do not comply with the general pattern. Quirk et al. attribute such inconsistency as well as cases of vacillation (optional article use as in (the) Edgware Road, (the) Hatfield Polytechnic) to the fact that there is no hard and fast boundary between institutionalized names and definite descriptions, which are the frequent etymological predecessors of names. They suggest that there exists a gradient between fully institutionalized names and definite noun phrases produced arbitrarily according to syntactic rules so that some expressions are 'neither completely name-like nor completely description-like, but somewhere between the two' (ibid. 294).

Allerton (1987) follows Quirk et al. (1985) in recognizing simple and complex proper names, i.e. one-word and phrasal units. The former are usually represented by proper nouns. The latter may consist of common nouns and/or proper nouns but must function like a single word rather than a regularly generated noun phrase, which implies being established with 'a partly unpredictable meaning' (Allerton, 1987: 64) and not allowing substitution of constituent words by synonyms. Although the form of complex names may coincide with that of common noun phrases, the former normally lack some of the basic grammatical features of the latter. Allerton reiterates essentially the same points that Quirk et al. had set out: (i) the definite article and the plural morpheme are fixed by the individual name and, unlike in common noun phrases, are not contrastive; (ii) while both restrictive and nonrestrictive modifiers occur with common noun phrases, names normally resist restrictive modification.

There are two broad claims in Allerton's work one of which is especially worthy of attention. Firstly, he claims that name phrases as a special kind of noun phrase are structurally restricted. They make up an open inventory but there are only so many as opposed to virtually innumerable common noun structures that speakers produce to satisfy their communication needs every day:

While common noun phrases, through their choice of determiners, their range of adjectival structures, and so on, are infinitely varied, proper noun phrases form a large but finite set of items, which belong to a limited number of structural types (Allerton, 1987: 67). 
Secondly, he implicitly suggests that limitations on modification as a unique property of names should hold true for all languages:

Common noun phrases in all languages allow modification with articles (where these exist), quantifiers, demonstratives, adjective phrases, restrictive relative clauses, and other modifiers. Proper noun phrases usually allow none of these without losing their properness.

Some languages, of course, lack articles, number and gender; but they still allow quantifiers, demonstratives, possessives and adjectives as specifiers or restrictive modifiers of the noun in a common noun phrase. This alone distinguishes common noun phrases from proper names... (ibid. 64-5).

Names exist in all languages of the world (Hockett, 1958: 311 and 1963: 17) therefore establishing cross-linguistic universals is undoubtedly important. However, as my research is aimed at English learners, the first claim of Allerton's is more interesting. He proposed a structural taxonomy of proper names summarized below (1987: 67-9):

1. Pure proper names

\begin{tabular}{|l|l|}
\hline Structure type & Example \\
\hline a) Single proper noun & Nepal \\
\hline b) The + single proper noun & The Hebrides \\
\hline $\begin{array}{c}\text { c) (Title indicator) }+ \\
\text { one or two proper nouns }\end{array}$ & (Mrs.) Helen Clark \\
\hline
\end{tabular}

2. Mixed proper names

\begin{tabular}{|c|l|}
\hline $\begin{array}{l}\text { a) Proper noun + common noun } \\
\text { in either order }\end{array}$ & $\begin{array}{l}\text { Mexico City } \\
\text { Lake Geneva }\end{array}$ \\
\hline $\begin{array}{l}\text { b) The + (proper noun + } \\
\text { common noun in either order) }\end{array}$ & $\begin{array}{l}\text { The Suez Canal } \\
\text { The (River) Avon }\end{array}$ \\
\hline $\begin{array}{l}\text { c) Proper noun + restrictive } \\
\text { adjective }\end{array}$ & $\begin{array}{l}\text { Latin America } \\
\text { Smith Minor }\end{array}$ \\
\hline $\begin{array}{c}\text { d) Proper noun + the + } \\
\text { adjective/common noun }\end{array}$ & $\begin{array}{l}\text { Peter the Great } \\
\text { John the Baptist }\end{array}$ \\
\hline $\begin{array}{l}\text { e) The }+(\text { adjective) common } \\
\text { noun }+ \text { of }+ \text { proper noun }\end{array}$ & $\begin{array}{l}\text { The Isle of Wight, the United Kingdom of } \\
\text { Great Britain and Northern Ireland }\end{array}$ \\
\hline
\end{tabular}

3. Common-based proper names

\begin{tabular}{|l|l|}
\hline a) Adjective + noun & Green Lane \\
\hline b) Modifier noun + noun & Park Lane, Salt Lake City \\
\hline c) The + adjective + head noun & the White House \\
\hline d) The + modifier noun + noun & the Labour Party \\
\hline
\end{tabular}

4. Coded proper names

\begin{tabular}{|l|l|}
\hline a) acronym/numbers & $I B M$ \\
\hline b) The + acronym/numbers & the M25 [motorway] \\
\hline
\end{tabular}


There are some problematic spots in this classification. In group 3, not all structures of common-based proper names are included: 'single common noun' and 'the + single common noun' are missing (Indigo, a pub in Wellington; the Channel, formed by ellipsis from the English Channel). It should be noted that Allerton provided a caveat that he was only outlining the main subvarieties because theoretically 'any partial or complete common noun phrase could be converted into a proper noun phrase' (1987: 68).

Payne and Huddleston again draw a distinction between proper nouns and proper names. Proper nouns are one-word units specialized in the function of heading proper names. Proper names are 'expressions which have been conventionally adopted as the name of a particular entity - or, in the case of plurals like the Hebrides, a collection of entities' (2002: 515). Both definitions are unsatisfactory. First of all, a proper noun does not need to be a head of a proper name. In the following examples Leeward and Manchester function as dependents: the Leeward Islands, the University of Manchester. One could argue that in the second case we are dealing with a derived proper name (the name of the university derived from the name of the city), and that Manchester at least potentially can be used on its own as head of a one-word proper name phrase. Still, it is impossible to put Leeward into the head position. Payne and Huddleston's definition of a proper noun may be modified to read: a proper noun is a noun that occurs only as part of a proper name, not outside. Unfortunately, however, defining a proper name as something that has been conventionally adopted as a name is not very informative.

As for the form of proper names, the vast majority are noun phrases excluding names of TV programmes, movies, artistic works and the like which can take practically any - sometimes quite whimsical - shape (The Who; Eyes Wide Shut; Rabbit, Run!). Most proper names can either have the syntactic status of full noun phrases or be parts of larger constructions. In the latter case proper names either modify the head of a noun phrase, as in a Thames cruise, or are themselves modified, as in the new Clinton. Proper names with articles normally lose their article when they become parts of larger syntactic units, but not all proper names are able to enter larger structures: both _ Republic of Chad delegates ${ }^{*}$, but not *two Hague councillors (Payne and Huddleston, 2002: 517).

\footnotetext{
* The underscore indicates the absence of the definite article.
} 
The authors make a distinction between primary and secondary uses of names. In their primary uses proper names are inherently definite, which makes the indefinite article impossible, and the definite article unnecessary:

We distinguish, then, between strong proper names like Kim or New York, where there is no determiner, and weak proper names like the Thames or the Bronx, where definiteness is redundantly marked by the definite article the (ibid. 517).

In secondary uses, proper names lose their inherent definiteness and denote a set of objects as opposed to an individual object, for example:

1. a set of bearers of the name: The Georges that you met yesterday are not twins;

2. a set of entities having relevant properties of the bearer of the name: We need another Roosevelt;

3. a set of manifestations of the bearer of the name: This is not the Paris I used to know;

4. a set of products created by the bearer of the name: The gallery has acquired a new Rembrandt;

5. a set of copies/editions of the entity bearing the name: Can I borrow your Herald-Tribune for a minute? (ibid. 521-522).

As can be seen from these examples, proper names in their secondary uses behave just as ordinary countable nouns and allow for full range, common-like selection of determiners and restrictive modifiers. This is why the observations that articles and number inflections with proper names are not contrastive and that the latter reject restrictive modification have often come under attack. The strong version of the critique is found in Berezowski (2001: 44-52) who declares all such claims null and void (unduly in my view) and discards the notion of a proper noun altogether.

The milder version is Sloat (1969) who argues that proper nouns are freely pluralizable and take almost the same range of determiners as common nouns do. $\mathrm{He}$ does not give any formal definition of a proper noun: 'The class to which I wish to give the name PROPER comprises such words as John, Smith, Rover, Chicago, England, Chevrolet (name of man), The Dalles, and so forth' (1969: 26). He claims that proper nouns take the same set of determiners as common countable nouns with the only exception that the definite article does not appear before a singular proper noun unless this noun has undergone restrictive modification (The Smith that I met 
yesterday stopped by) or the article is heavily stressed (Do you really mean you worked with THE John Lennon?). So *The Smith stopped by is unacceptable but this 'trivial' thing put aside, examples like A Smith stopped by, The clever Smith stopped by, The Smiths must breath etc. are all grammatical. According to Sloat, they are not 'semantic anomalies' but cases of standard proper noun behaviour.

Besides overlooking the fact that some singular proper nouns customarily take the (the Hague, the Crimea, the Mississippi), Sloat overstates the similarities between proper nouns and common countable nouns. He is right in criticizing the thesis that proper nouns may not be used with contrastive determiners under any circumstance but his position falls victim to the opposite extreme. He espouses the view that was later expressed with such wit by Algeo: 'Given any proper noun in English - from Aaron to Zurich - English speakers are free to talk about "an Aaron" and "the Zurichs that never were".' (1973: 21).

In my view, it is an exaggeration to claim that proper names select determiners as freely as common countables do. Chomsky's early reservation that the use of proper nouns in constructions like the England I know or a different John Smith is restricted (1965: 217), is correct in the sense that such uses are by far less common than, let's say, John Smith lives in England. Let's look again at the Payne and Huddleston's 'secondary uses' rubric and at the examples offered by Sloat. They are indeed perfectly grammatical but they are not the kind of sentence in which most proper names would be expected to appear regularly. These are clearly marked, not standard uses. Saying that proper names are freely pluralizable and unrestricted in regard to the choice of determiners and modifiers is equal to saying that two possessive pronouns in English can freely be found together preceding the head noun. Let's imagine I lose the swipe card allowing access to the building where I work and have to get a replacement. By chance, a few days after I got a new card I find my old one and decide to give it to Mum to save myself having to come down from level 23 to let her in when she comes to pick me up. We can further imagine that when she calls me at work I might say 'Please go straight to the office, do you have my card?' and it will be perfectly natural for her to smile and answer 'Yes, I've got $\underline{\mathrm{MY}}$ your card'. As we see, two possessives can in fact occur with one head noun but the point is usually they do not. Similarly, proper names normally do not require number contrast or a contrastive determiner to successfully perform their chief function of identifying specific individuals. Only in a handful of 'out of the ordinary' situations is 
their morphosyntactic capacity stretched to accommodate the demands of peculiar extralinguistic circumstances. The conclusions I come to are as follows:

1. Proper names take articles however in the majority of uses their determination is idiomatic, i.e. 'does not represent a semantic choice' (Allerton, 1987: 64).

2. Proper names in the majority of uses are not contrastive for number.

3. Proper names' ability to undergo restrictive modification is limited.

Berezowski criticizes these points because they 'are merely tendencies and counterexamples are easy to find' (2001: 45). It is true that there are counterexamples but one cannot deny that they are a minority and, as Allerton rightly noted, do not represent the basic usage for proper names (1987: 65). The existence of singularia tantum ${ }^{*}$ and pluralia tantum ${ }^{* *}$ does not compel anyone to think that ordinary English nouns do not inflect for number. So why should examples like both Georges in the class or a London I remember make us throw away three valid observations about the grammatical behaviour of names that capture the leading tendencies?

I agree nevertheless that the division between proper and common nouns as based solely on the forementioned formal criteria is too fluid to be acceptable. The definition of a proper name cannot in principle be worked out from the notion of a proper noun. First, a solid understanding of properness, or nameness if you like, has to be established on some other foundation (most likely semantico-pragmatic, or as I suggest, functional). After that we can view proper nouns as a subtype of nouns that function exclusively within proper expressions.

Three positions can be found in literature concerning the London of my childhood and other examples of this kind. Some scholars presume that a proper name gets reclassified as a common word, i.e. stops being a proper name (Quirk et al., 1985; Willems, 2000). Others think that in these cases nothing changes, i.e. London remains just as good a proper name as it is in other contexts (Sloat, 1969; Algeo, 1973; Berezowski, 2001). Still others (myself including) believe that in such sentences London is still a proper name but less prototypical than in London is a capital of England (Payne and Huddleston, 2002; Anderson, 2003). Anderson, for example,

\footnotetext{
*Latin 'singulars only': i.e. nouns that only have a singular form, e.g. physics, linguistics.

** Latin 'plurals only': i.e. nouns that have only a plural form, e.g. scissors, trousers.
} 
calls the London of my childhood and the like 'derived names' because they have lost one of the essential features of core proper names, namely non-partitivity.

\subsection{Prototypical proper names in pragmatics}

Several researchers believe the difference between proper names and other nominals does not lie in their morphological, syntactic or semantic properties, but in their pragmatic status (Huddleston, 1988; Berezowski, 2001; Coates, 2000, 2004 and 2006). For instance, Berezowski states: 'proper names constitute a pragmatically defined group of expressions which have been bestowed on any entities in properly performed acts of naming' (2001: 59). Following Austin's speech act theory (1962), Berezowski claims that acts of naming can be 'validly performed only by individuals who are vested with appropriate authority and observe all requisite formalities' (Berezowski, 2001: 217-8). The source of such authority depends on the type of referent. Thus human beings are named by their parents or pastor, animals and vehicles by their owner, streets and squares by the city council, companies by courts or registrars depending on the legal system, movies by producers, buildings by developers and so on. However, the author adds, the range of duly authorized individuals and prescribed settings furnishing the act of naming is much wider than christening babies or naming ships recognized in the original formulation by Austin. Alongside officially pronounced naming formulae or decisions made by national or municipal deliberative bodies, a speech act of naming can take the form of general consent of all interested parties thus becoming casual and indirect.

I agree with the pragmatists' position in principle because most proper names indeed have properly authorized name givers. However proper names that, similar to common expressions, possess descriptive content reveal a weak point of this theory. Descriptive proper names on the one hand and freely constructed definite common noun phrases on the other can only be distinguished by their origin. Thus the point of being able to trace this rooted-in-the-proper-speech-act-of-naming origin becomes crucial since it is the only means by which one can tell the two apart. If consent of all interested parties is considered to be a valid act of naming, the whole notion of a specialized speech act is reduced to essentially two things: (i) the intention of a speaker (i.e. name author or name originator) to make this or that expression a proper name; and (ii) the acceptance of the newly 'ordained' name by the speaker's 
immediate circle of interlocutors. Chasing down this original intention and the following 'ratification' by those who happened to be around at the moment the intention was verbalized is not always possible, which leaves a linguist looking at the synchronic use of the expression rather helpless and doubtful. All the theory has to say on tricky borderline cases thus boils down to stating that if the first human to call the north pole the North Pole intended the phrase as a name and that was followed by approval from the people they were communicating to, then the speech act had indeed been performed and we deal with a legitimate proper name. If this same individual did not harbour such an intention but was merely describing what s/he meant then, alas, it is a common noun phrase. The problem is that this person (if someone manages to find them) most probably passed away and would not be able to explain their true intention even if they had ever had it registered and remembered.

The problem of 'gauging' the invisible intentions of the speaker was emphasized by Coates. He holds that the class of proper names cannot be fully circumscribed because some expressions fluctuate between being names and nonnames:

[...] there are two different modes of reference: in context, speakers may use an expression either with semantic reference, that is with the senses of the constituent words intact, or with onomastic reference, that is with the senses of the words cancelled or suspended. Any expression may in principle refer in either mode; an expression which is used to refer onomastically is a proper name... (2004: 1)

[...] I should like to claim that namehood is pragmatic in nature, and that, in principle, any referring expression consisting of ordinary words of the speaker's language may be used to REFER ONOMASTICALLY... (2000: 1166)

Coates argues that in the present state of our knowledge and technology there is no empirical way to test under which of the two modes of reference the speaker was operating:

One literally cannot know, in any secure sense, whether in using a fully articulated NP the user intended onomastic reference or not, unless the user offers an explicit epistemological confession (2000: 1167).

Since one and the same noun phrase may be both common and proper depending on the intentions of the speaker on a particular occasion of use, proper names are not a delimitable category of expressions. 


\subsection{Functional approach to defining proper names}

The name simply distinguishes a certain company from others (Coates, 1994: 3370).

The question 'What is a proper name?' is answerable in principle, on the emic level (namely that of linguistic categories) although sometimes it cannot receive a definitive answer for a given etic expression. This state of affairs is not surprising because the boundaries of other linguistic categories are no less fluid. For instance, rice is commonly considered a mass noun however it can temporarily turn into a countable: It takes a hardy rice to grow here (example from Sloat, 1969: 30). Pronouns sometimes surface as nouns: Is it a he or a she? (example from Langendonck, 1997: 38). Some words take on either a nounal or an adjectival status: The new policy mostly affected the poor vs. This is a poor policy. Lexemes like go (which are especially numerous in English) function as nouns or verbs: Let's give it a go vs. I'll go with you. In certain circumstances even conjunctions can be construed as nouns: The decision is final and I don't need any more buts. Therefore the presence of borderline cases that fluctuate between proper and non-proper does not mean that proper names are not definable as a word class:

... the fact that names and other words seem to resemble chameleons changing their status time and again, can give rise to the conviction that the notion of proper name and of word-class in general, cannot be pinpointed, and hence may be irrelevant. In other words, following this reasoning could ultimately lead to the abolition of all word-classes (Langendonck, 1997: 38).

I fully agree with Hopper who holds that grammatical categories are labile in the sense that much depends on their actual deployment in discourse. Similarly to all others, the category proper name is not fixed and bounded but 'emergent', i.e. 'functionally relativized to discourse context' (1990: 161). Hopper suggests that a better term is categoriality, the degree to which an expression conforms to a prototype. In certain contexts items are accorded full categoriality while in others their categoriality will be lessened.

Of course the crucial question is how to determine the prototype given that the actual usage is so variable. As has been shown above, the prototype can be semantic (notional), formal (morphosyntactic), or pragmatic (rooted in the social conventions of language use). I suggest that the prototype is first and foremost functional. I think language as a system works similarly to the human brain showing phenomenal 
interconnectivity. It means that normally each segment performs one chief function but when needed can instantly 'adopt an extra qualification' and substitute for any number of other segments. Similarly, each linguistic category is responsible for a certain communicative function being at the same time very flexible, i.e. able to take on an alternative function/s.

The reason why there exist troublesome borderline items is simple. The default 'one category-one function' division is not absolute so quite often the same language expression can be performing more than one role. Whenever it is doing solely its main communicative 'job' it appears as a prototypical instance of the category. If two or more functions are involved but one of them is dominant we assign the expression to the category that corresponds to its leading function. In such a case the categorical status remains clear although the expression in question appears less prototypical. Finally, there are expressions where the ratio of a 'main' function to a 'secondary' one is close to 50:50, which makes their categoriality uncertain. These are the cases that linguists argue about and struggle to classify.

\subsubsection{Functional definition of proper names adopted in this study}

So what we need to define proper names as a category, is to understand their primary communicative function and to establish what other functions they can adopt (and hence what other categories they may be confused with), i.e. to identify their closest functional 'neighbours'.

Intuitively, the chief proper name function is clear to everyone, and there is evidence from cognitive psychology that children grasp it as early as at the age of two (Hall et al., 2004: 6). Both 5-year-olds and adults give strikingly similar explanations why some things have proper names: 'because they need to be singled out from others' (ibid. 28). In more sophisticated academic terms, ‘... proper names are assigned to objects only when they have to be constantly distinguished from other individual objects, and have to be individually referred to on different occasions' (Bhat, 1979: 107). So I define proper names as words or institutionalized word groups whose primary function in communication is referring to a particular fixed entity and differentiating it from others. Proper names are not the only linguistic means of referring to specific entities and share this ability with other types of expressions as shown in the diagram: 

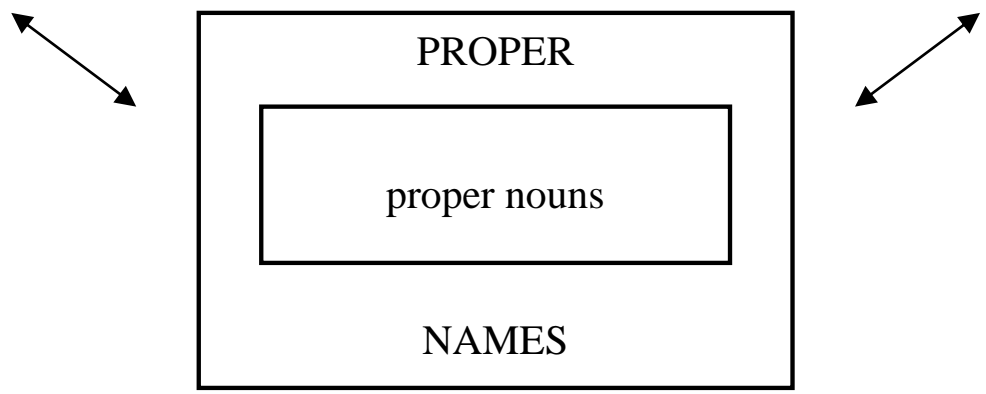

\subsubsection{Functional properties comparison: proper names and deictics}

Similarities between deictics and proper names are so conspicuous that it led some authors to think that proper names are actually a subclass of deictic expressions (Récanati, 1993: 140-143). Although functionally proper names indeed share a lot with deictics, I believe that there are weighty reasons to treat them as two separate categories. The main property they share is the ability to identify who or what is being talked about, i.e. both are primary referential devices. I have already pointed out the major difference between deictics and proper names in the discussion of prototypical name semantics (see 3.1.3 above). I will repeat it here and add two others not previously emphasized.

The reference of a deictic expression is totally dependent on the extralinguistic context and is easily shifted from one referent to another. Although the reference has to comply with the minimal sense of the expression in question, it is essentially temporary, i.e. operative only in a particular situation. For example, using you I can refer to my brother, to my mother five minutes later, to a classmate at university, to an assistant in the shop etc. The reference of a proper name is not regulated by sense (defined as conditions of correct usage) but is definitely fixed. There is a convention associating the name with a certain referent, and this association, once it has been established, is permanent. It is an interesting and very debatable point whether conventions pairing names with their referents are linguistic or purely social in nature (see Récanati, 1993: 143-146) but what is crucial is that as soon as somebody learns such a convention they no longer need the extralinguistic context to interpret utterances containing the name:

(1) Can you please lock the door?

(2) Can Jeremy please lock the door? 
It is impossible to determine the reference of you in (1) if the situation of the utterance is not known. However if Jeremy has been previously introduced to someone they will be able to interpret (2) without any extratextual information. So the chief function of deictics is to provide temporary specific reference while proper names' reference is specific but also fixed.

It can be argued that 'knowing who Jeremy is' does in some sense resemble knowing the context. Récanati says (1993: 143):

Two different individuals, for example, may be called 'John Smith', 'Ralph Banilla' or 'Aristotle'. What is referred to by a particular use of the name depends on which convention happens to be invoked, and which convention happens to be invoked depends on the context of utterance. In some contexts, the relevant convention is the convention of using 'Aristotle' to name a philosopher, whereas in other contexts it is the convention of using 'Aristotle' to name a shipowner. Therefore a proper name is referentially context-dependent, exactly as an ordinary indexical.

Récanati is using the term 'indexical' as a full synonym of 'deictic'. He claims that proper names are a type of deictic expressions but I cannot subscribe to his view because there are two separate kinds of 'context' that have to be distinguished. Deictics are immediately situational: they freely change the target referents and can do so as quickly as every minute. On the contrary, proper names are permanently attached to their respective referents and this is not invalidated by the fact that many men are called John. Nevertheless proper names may be considered contextdependent in the sense of their localness. A given name usually circulates in a relatively small community of speakers who have sufficient interest in its bearer. Depending on the type of referent a proper name can be spread within a smaller or a larger group of people (cf. Telecom, a transnational giant, and Trademark Residential $L t d$, a tiny privately owned NZ company) but is normally restricted to this particular group. Of course, there is no limit as to how far the speakers' erudition can go, given that globalization and advanced communication technologies nowadays allow for the phenomenally fast spread of information around the world. However, compared to other classes of words, proper names are the most regionally bound. If someone lives permanently in Wellington, most likely they will know the referents of Lambton Quay and Dominion Post. It is not as probable though that they should know the name of the mayor of Christchurch, or the main street in Kurow. It is certainly not surprising that out of the 25 most frequent city names in the British National Corpus, 17 that made it to the top should be places within the UK. As Carney (1994: 444) notes, 'the 
names found in any given sample are bound to be more peculiar to that sample than ordinary words.' A competent speaker of English has to know all the deictics but is familiar with only a fraction of proper names existing in the language as a whole. Apart from famous names, the vast majority belongs to the microlevel of local 'contexts' so that the set of proper names known to one community or even to one person is different from the sets known to others.

Another significant functional difference between names and deictics is that the latter are not descriptive: deictic expressions refer to some 'piece of reality' practically without revealing what it is like. Proper names are also prototypically nondescriptive, however, unlike deictics, they can (and often do) adopt a descriptive function.

Calendrical terms (days of the week and months) have often been considered proper names albeit with an acknowledgement that they are less central than other proper name subtypes. Following Anderson (2003), I consider such words to be hybrids, forms combining the features of proper names and deictics. Similar to names, they are able to refer with a high degree of specificity. However, they are evidently deictic in relying on the immediate extralinguistic context for successful interpretation. Since they possess stable senses and are definitely not local (in the sense adopted above), I suggest it is more sensible to treat them as items lying outside the proper name class.

Table 3.3. Comparison of the functional properties of proper names and deictic expressions.

\begin{tabular}{|l|l|}
\hline Proper names & Deictics \\
\hline \multicolumn{2}{|l|}{ the main communicative function is to provide definite specific reference } \\
\hline do not have senses & have minimal senses \\
\hline $\begin{array}{l}\text { reference is fixed by a convention } \\
\text { associating the name with its bearer }\end{array}$ & $\begin{array}{l}\text { reference has to comply with the } \\
\text { minimal sense but is completely } \\
\text { context-dependent }\end{array}$ \\
\hline provide permanent reference & provide temporary reference \\
\hline $\begin{array}{l}\text { 'local', the vast majority known only to a } \\
\text { small community or even a part of the } \\
\text { community }\end{array}$ & $\begin{array}{l}\text { very frequent, all known to each and } \\
\text { every language user }\end{array}$ \\
\hline can be descriptive & are not descriptive \\
\hline
\end{tabular}

\subsubsection{Functional properties comparison: proper names and definite noun phrases}

Another class of expressions that can perform functions similar to those of proper names is definite descriptions, i.e. the-determined common noun phrases. I have 
already dwelt on some differences and similarities between these two classes (see 3.1.3 above). I will summarize them here and add a few more observations.

Most importantly, the chief communicative function of definite descriptions is to classify and describe an object or state of affairs; they may but do not have to refer. The underlined part in Our new marketer turned out to be the star of the talent show is not referring but serves to describe the qualities of the person in question and classifies him/her as a talented amateur performer. When definite descriptions do fulfil a referring function, the reference they provide is incomplete and contextdependent, or may even be intentionally unspecific. For instance, in Has the star of the talent show already left? the intended referent will only be clear to somebody who was present at the show or somehow knows a lot about it. In The star of the talent show - as judged by the audience - will be given a gift voucher, the referent is not specified because it is not known yet (see also Anderson's examples in 3.1.3).

The main communicative function of proper names is referring; moreover, they always provide individuating/individual reference, i.e. distinguish a particular referent from the others. The reason it is extremely difficult in some cases to establish whether an expression is a definite description or a proper name is there are a lot of names that, despite not having sense in the technical meaning of the word, are to some extent descriptive of their referents. Definite descriptions primarily describe but may refer to a specific entity as their secondary function while proper names are predominantly a means of highly specific referring but can also describe.

The discussion of descriptive content in names has always been an extremely troublesome exercise for scholars. Lehrer (1992: 127), among many others, observes: 'The line between a pure description and a proper name based on a description is subtle and difficult to draw [...]'. According to Carroll, 'There are no existent theoretical criteria for "namehood" or "descriptionhood." Indeed, there are few wellarticulated pretheoretical criteria. We can merely use our informal pretheoretical notions to define these terms...' (1985: 29). These intuitive notions seem to suggest that the difference between using proper names and describing is that a description must be literal and precise whereas a name may convey information about the properties of the referent to varying degrees yet this connection is less binding: '...one can use the brief form flying saucer as a name, escaping the claim that the referent is a flying saucer - a claim that could not be avoided if the same phrase were used as a literal description' (Carroll, 1985: 42). 
Berezowski (2001: 82-92) divided proper names into three groups according to their descriptive content, in particular proper names which:

1. 'have not been descriptive of their referents ever since they were bestowed on them' (NGC 342, Mitch, Market Garden [military operation]);

2. 'were initially intended to describe their referents in one way or another but lost their meaning after the context of their use changed enough for the original properties of the referents no longer to apply' (Pearl Harbour, the Bay of Pigs, Little Rock [no longer places known for pearl fishing, colonies of pigs or a little rock]);

3. 'originated as descriptive designations of their referents and have not shed their meaning yet or never will' (New York Public Library [located in New York and open to the public], Charles the Bald [a hairless king of the Francs], the North Pole).

I believe that the descriptiveness scale for proper names needs to be more detailed. Also Berezowski's classification is not entirely consistent because some examples in (2) and (3) contain both descriptive (bay, public, library, bald) and non-descriptive (pigs, New York, Charles) elements. I suggest amending it in the following way:

1. Fully non-descriptive proper names

2. Partially non-descriptive proper names

3. Partially descriptive proper names

4. Fully descriptive proper names

Group 1 is synchronically opaque proper names that consist either of proper nouns (Tanya, Wellington) or common elements none of which is descriptive of the referent (New World [supermarket], Little Rock [city], Embassy [cinema]). I also assign acronym proper names to this type. Although acronyms (IBM, SPCA, CEED) signal to a competent language user that there must be full noun phrases they were derived from (which are descriptive and may be known to the user), these forms as such, in and of themselves, do not describe the referent in any way.

Group 2 is probably the most controversial and I understand that "partially non-descriptive' is not the best term but I will use it until a more suitable one is found. It is for proper names that do reflect the qualities of the referent in some way but none of the elements can be considered true of the referent. For example, Ginger as a name of a light yellowish-brownish cat describes its colour but ginger $\neq$ cat. Similarly, the Beehive [the offices of the members of the New Zealand government] definitely hints 
at the shape of the respective building yet the literal meaning of beehive is not applicable. Other examples of forms where there is a connection between the referent qualities and the name but the latter is not literally descriptive are: All Day Breakfast [cafe], Workman Antenna Co [company providing aerial installation services], Crystal Palace [big exhibition hall made of glass], the Greens [party whose agenda it is to keep the world clean and green], Crazy Faces [face-shaped biscuits], World of Warcraft [computer game with opposing warring factions]. Works of art or, more generally, expressive works often have names that qualify as partially non-descriptive, e.g. The Thinker [Rodin's famous sculpture of a thinking man sitting on a rock], the Flight of the Bumble Bee [fast-paced musical piece that imitates the sound of a bumble bee in flight], Fifty First Dates [comedy about a guy wooing a girl who has short-term amnesia and never remembers him in follow-up dates], Flatland [book written on behalf of a creature who lives in a two-dimensional world].

Group 3 comprises proper names which, at the synchronic level, have at least one element that is literally true of the referent, while the rest are non-descriptive. New Zealand Symphony Orchestra, for instance, has a descriptive element symphony orchestra (since the name refers to an actual symphony orchestra) and a nondescriptive element New Zealand. There are numerous names of this kind (the descriptive elements are highlighted): Charles the Bald, New York Public Library, Mexico City, Stewart Island. The non-descriptive element can be either a proper noun or a common word as in the Bay of Pigs, the Cape of Good Hope, Medobble Bodonadbl [oney Waterfalls] .

Group 4 consists of proper names that are the closest to definite descriptions where all elements are descriptively true of the referent: the North Pole, the South Island, Red Rocks, Cable Car Museum, Ice Age, Independence Day, the Second World War, Grand Canyon, the United Nations Organization, the Language Learning Centre.

This classification is not without its faults one of them being that the exact position of a proper name along the scale may be uncertain (the Democratic Party can go either to group 4 if one believes that the agenda of this particular party is genuinely

\footnotetext{
* The referent is a set of beautiful small waterfalls near Pyatigorsk, Russia, which was allegedly named this way because wild bees used to live all around the area and honey would literally drop in the water. The bees are now long gone, and tourists never suspect a link between the waterfalls and honey until told this story by a guide.
} 
democratic or to group 3 otherwise) but it is sufficient to demonstrate that there is a wide range of proper names in regards to their descriptiveness.

The line between definite descriptions and group 4 proper names is not clearcut but in most cases it is possible to make a judgement based on their functional properties. Proper names are first and foremost standardized labels differentiating one referent from the rest. They are 'frozen', i.e. allow neither substitution of constituents by synonyms nor parts regrouping. Descriptions, on the other hand, primarily serve to convey information about the referent qualities, and this information can be expressed freely in a variety of ways. Compare the following examples:

(1) Red rocks were glistening under the morning sun.

(2) Let's hike to Red Rocks", it's a beautiful spot.

(3) Compared to peaches and oranges, a quince is not a juicy fruit.

(4) The kid sure needed a cheering up treat. 'Hey, buddy, want a slushy or a Juicy Fruit $^{* *}$ ?'

Red cliffs easily replaces red rocks in (1) but not in (2); and juicy fruit can be freely changed to succulent fruit or soft fruit in (3) but not in (4).

Table 3.4. Comparison of the functional properties of proper names and definite descriptions.

\begin{tabular}{|l|l|}
\hline Proper names & Definite descriptions \\
\hline do not have senses & have well-established determinate senses \\
\hline $\begin{array}{l}\text { the main communicative function is to } \\
\text { distinguish this particular referent from } \\
\text { the rest }\end{array}$ & $\begin{array}{l}\text { the main communicative function is to } \\
\text { classify and describe the (qualities of the) } \\
\text { referent }\end{array}$ \\
\hline may or may not describe & may or may not refer specifically \\
\hline $\begin{array}{l}\text { institutionalized, do not allow } \\
\text { substitution of constituents by synonyms, } \\
\text { parts regrouping or insertion of additional } \\
\text { elements }\end{array}$ & $\begin{array}{l}\text { freely constructed, allow substitution of } \\
\text { constituents by synonyms, parts } \\
\text { regrouping and insertion of additional } \\
\text { elements }\end{array}$ \\
\hline
\end{tabular}

Proper names normally produce an effect of unique identification. There may be several different entities called Russia (country, hotel, brand of chocolate) (i.e. Russia as an emic expression is multi-designatory), however when the name is actually used in speech it unmistakably identifies one and only one of these entities (i.e. Russia as an etic expression is always uni-designatory). There is a small group of nouns in

\footnotetext{
${ }^{*}$ The site of the seal colony and a popular destination for hikers near Wellington, New Zealand.

** Brand of chewing gum.
} 
English that are also uni-designatory because they denote factually unique entities, i.e. those occurring only in a single specimen in the world (equator, internet).

Although it is debatable, I believe it is best to treat such nouns as non-names. The chief function of proper names is to distinguish a particular referent from the others (Russia distinguishes Russia from other countries (or from other hotels or brands of chocolate respectively), Abra-kebabra distinguishes Abra-kebabra from other Turkish restaurants, the North Pole distinguishes the North Pole from the South Pole etc.), consequently if there are no 'others' there is no need for differentiation. Similarly to other common definite noun phrases, the dominant function of unidesignatory nouns seems to classify and describe the referent.

\subsection{Chapter overview}

The degree of prototypicality can vary among proper name forms within the same subcategory. The characteristic proper name properties regardless of subcategory have been identified in semantics, grammar, and pragmatics. Semantically, prototypical proper names are primary referring devices. They have no intension (i.e. sense in the strict terminological sense of the word). They are definite in their referential (as opposed to vocative) uses, always specific and in the majority of uses non-partitive. The peculiar semantic nature of proper names is reflected in their morphosyntax. Grammatically, the core names consist of a single noun without modifiers and follow the same distributional patterns as nouns and personal pronouns. Prototypical proper names are not predicative (apart from equative constructions) and cannot be proforms in anaphora. They also lack article contrast and number contrast, and resist restrictive modification. Pragmatically, prototypical proper names are bestowed on entities in an official act of naming or registration that can be validly performed only by individuals who are vested with appropriate authority and observe the necessary formalities.

I suggest that proper names can be defined on the basis of their functional properties. A proper name is a word or an institutionalized word group whose primary function in communication is referring to a particular fixed entity and differentiating this entity from others. Functionally close categories of expressions, which, similarly to proper names, are used to achieve specific referring, are deictic pronouns and definite descriptions (including uni-designatory nouns). Proper names are capable of adopting additional functions such as describing or referring unspecifically. 


\section{Chapter IV. Proper names in ESL listening}

\subsection{Introduction}

In the previous chapters I have shown that proper names are a peculiar and diverse group of lexical items. However, to date they have not received much attention in second language vocabulary studies. Firstly, unlike general high frequency words, they do not provide significant text coverage therefore, it is concluded, they are not important for the ESL learners to know: 'whenever somebody learns a proper name of an entity his or her gain is typically limited to mastering a foolproof ability to refer to only one person or object (i.e. the one he or she has been introduced to), whereas learning a new non-name gives the speaker a tool to refer to any number of referents...' (Berezowski, 2001: 66). Secondly, some authors hold that knowledge of proper names is encyclopaedic rather than linguistic (Napoli, 1997). No ESL learner can claim that they have mastered English if they do not understand common words, for instance man or town. In contrast, such expressions as Ato Wudneh or Timaru are optional in the sense that one can be a competent English user without knowing them. This gives rise to an absurd opinion that proper names fall outside the scope of (second) language education.

To my knowledge, the problem of whether proper names can cause ESL learners any difficulties has never been assessed. The goal of this chapter is (i) to show that, as far as second language listening is concerned, the "proper names will take care of themselves' view is not to be taken for granted; and (ii) to begin investigating what kind of impact unfamiliar proper names can have on ESL learners' listening comprehension.

\subsection{Can unfamiliar proper names affect ESL learners' listening comprehension?}

Understanding both written and spoken texts can be affected by a large number of factors, from background knowledge of the subject (Markham and Latham, 1987), to the position of comprehension questions in relation to the text (i.e. whether the questions precede, follow, or are integrated into the text) (Sherman, 1997; Wu, 1998; 
Hung, 2007), through to availability of discourse organization clues (Jung, 2003) or visual support (Arcario, 1990: 113-117), to name only a few. However, it has long been established that both for native speakers and second language learners, vocabulary knowledge is the main variable affecting comprehension (Laufer and Sim, 1985a and 1985b; Kelly, 1991; Nuttall and Alderson, 1996: 62-77; Buck, 2001: 54, 58). To put it simply, the more words you know, the more you are likely to understand. The vast majority of studies to date have focused on reading comprehension, however listening comprehension is also increasingly attracting research interest.

None of the factors mentioned above can compensate for the lack of vocabulary knowledge. It is incredible that changing the fraction of unfamiliar words in a text by as little as $1 \%$ makes it much harder to understand even when one is dealing with a text written in their native language: '... (a) when the material being read is relatively easy, then close to $0 \%$ of the words will be unknown; (b) when the material is relatively hard then around $2 \%$ or more of the words will be unknown; and (c) when the difficulty level of the material is approximately equal to the ability level of the individual, then around 1\% of the words will be unknown' (Carver, 1994: 432).

Extensive research has also been conducted on the link between reading comprehension and vocabulary knowledge of ESL learners. Until fairly recently it was believed that $95 \%$ of the running words in a text must be known for the reader to be able to guess the rest from context (Liu and Nation, 1985) and achieve reasonable comprehension (Laufer, 1989; Laufer, 1992). However, Hu and Nation (2000) demonstrated that even $95 \%$ coverage is usually not enough. They replaced various proportions of words in a short story with nonsense words. Each group of advanced ESL learners read one of the four versions of the story where $80 \%, 90 \%, 95 \%$ or $100 \%$ of the running words were familiar. None of the participants understood the story at $80 \%$ coverage. Although some readers at $90 \%$ and $95 \%$ levels were able to gain adequate or close to adequate comprehension, they were still a small minority. At $100 \%$ coverage, most learners gained adequate comprehension. Applying a regression model to the data allowed $\mathrm{Hu}$ and Nation to calculate the effect of coverages other than those directly measured in the experiment: 'The results suggest that for this kind of reading [i.e. unassisted reading of a short fiction text - addition mine] learners need to know at least $98 \%$ of the running words in the text. That is, the density of unknown words should be around one in fifty' (2000: 423). Thus, the currently accepted view is 
that $98 \%$ of the words in a text ought to be known for an ESL reader to achieve good comprehension (Nation, 2006).

In some studies the assumption has been that proper names are easily picked up 'on the spot', and therefore can be equated with known words:

There are strong reasons for considering proper nouns as words that do not require previous learning. First, the text reveals what we need to know about them as the story progresses. [...] Second, their form (an initial capital letter) and their function clearly signal they are proper nouns (Hirsh and Nation, 1992: 691).

I agree that proper expressions are unlikely to disrupt comprehension in reading, particularly in short novels that were the subject of Hirsh and Nation's study, however this does not guarantee that the same should hold true for listening.

Listening and reading modalities, while sharing some cognitive mechanisms, nevertheless have a number of distinct differences. First language research shows that for adults, reading usually produces better comprehension than listening (Sanders, 1973; Walker, 1976; Kintsch and Kozminsky, 1977). In some second language studies, reading was also found to be more efficient (i.e. allowed participants to understand more than listening) (Lund, 1991; Hirai, 1999).

Very few studies have looked at how vocabulary knowledge and second language listening comprehension are related: 'The question of how much lexis is necessary to listen to and comprehend texts in L2 remains largely unaddressed in the literature' (Bonk, 2000).

Nevertheless, it has been shown that acceptable comprehension requires substantial familiarity with text vocabulary. Kelly (1991) analyzed a large sample of errors made by 38 advanced L1 French learners of English and a French-speaking English teacher. Participants were required to transcribe and translate extracts from the $\mathrm{BBC}$ radio news broadcasts. The researcher then categorized the errors under three headings: perceptual, lexical and syntactical. Perceptual errors occurred where a part of the recording was not clearly audible; they could have legitimately been made by a native speaker. Lexical errors were associated with unfamiliar words/collocations or ignorance of a particular meaning in familiar lexical items. Syntactical errors were cases when transcribers produced forms that did not fit the sentence grammatically. As it turned out, lexical errors were the most frequent. Then the researcher divided all errors again, this time into two groups: (1) errors that affected comprehension only minimally; and (2) errors that obscured the meaning considerably. Lexical errors 
accounted for $65.5 \%$ of cases where comprehension was severely impaired. Kelly concluded that insufficient vocabulary knowledge is 'the main obstacle to listening comprehension with advanced foreign language learners' (1991: 147).

Bonk (2000) went on to show that at other proficiency levels reasonable comprehension is likely to occur only if over $90 \%$ of the words in the text are familiar. Four listening passages with increasing amounts of low-frequency vocabulary were developed and played to 59 L1 Japanese English students. Comprehension was measured by L1 recall protocols. Each protocol was assigned a holistic rating on the scale from 1 to 4 . Next, protocols were divided into two groups, namely the inferior comprehension group (ratings 1-2) and the good comprehension group (ratings 3-4). Familiarity with text vocabulary was measured by a dictation, which is a rather generous test since participants could have guessed the spelling of some words they did not know based solely on their sound shape. A significant correlation was found between comprehension (quality of recall) and familiarity with vocabulary (dictation scores): ‘...Good comprehension seldom occurred with textlexis familiarity levels lower than 75 percent, but occurred frequently at 90+ percent levels. This pattern was observed equally for learners of high, middle, or low secondlanguage listening proficiency' (Bonk, 2000: 14).

It is likely that the relationship between the amount of un/familiar lexis and comprehension is more complicated in listening compared to reading. Sometimes ESL listeners do not seem to be able to achieve adequate comprehension even while reporting familiarity with up to $100 \%$ of words in the text (Olsen and Huckin, 1990; Bonk, 2000).

According to the Brown Corpus, depending on text genre, proper expressions can make up from $2.3 \%$ to over $9 \%$ of the running words " (Francis and Kučera, 1982: $539,543)$. Let us take $4-5 \%$ as an average. ESL learners usually face big linguistic deficits, i.e. their vocabulary knowledge is far lower than the necessary $90 \%$ threshold to begin with. I conclude that if the assumption that in connected speech proper names are automatically dealt with 'on the spot' is wrong, then a further 4-5\% drop in the amount of known words can significantly reduce ESL listeners' chances of adequate comprehension.

\footnotetext{
* In reality these figures may be slightly higher due to limitations of tagging conventions in language corpora. In the Brown Corpus, the relevant tag covers only proper nouns as opposed to a wider class of proper names, so such names as the Great Smoky Mountains are left out.
} 


\subsection{What knowledge do ESL learners need to have in order to cope with proper names in connected speech?}

Evidently, an ESL learner has to bring in and utilize a large amount of knowledge in order to make sense of spoken texts containing proper names. I propose a progressive three-level model of such knowledge. Firstly, a learner has to establish whether the lexical item they have encountered is a proper name or a common expression. Secondly, they must work out what kind of referent this proper name refers to. Thirdly, sometimes the text will draw on additional extralinguistic information about the characteristics of some particular referent.

Table 4.1. Knowledge necessary to deal with proper names in spoken texts.

\begin{tabular}{|l|l|}
\hline $\begin{array}{l}\text { Level } 1 \\
\text { recognition }\end{array}$ & Is this item a proper name or an ordinary expression? \\
\hline $\begin{array}{l}\text { Level } 2 \\
\text { categorization }\end{array}$ & $\begin{array}{l}\text { What kind of an object does this proper name refer to (a person, } \\
\text { a spelling competition, a building, a book, a race horse etc.)? }\end{array}$ \\
\hline $\begin{array}{l}\text { Level } 3 \\
\text { referent properties }\end{array}$ & $\begin{array}{l}\text { What further information about the particular characteristics } \\
\text { of this referent does the text draw on (colour, size, value etc.)? }\end{array}$ \\
\hline
\end{tabular}

It seems likely that to achieve adequate comprehension of an average text, an ESL listener will usually need knowledge at least at level 2. Listening comprehension as a construct is not rigid (Buck, 2001: 94-115). 'Understanding the text' can imply different things depending on the target quality and depth of understanding. As a rule, proper names would not be crucial for grasping the main ideas expressed in the text but serve to add detail. Therefore level 1 can suffice to get the gist of a text provided that it does not prevent the listener from identifying the main characters or the topic of the text. For example, a conversation between friends discussing plans for the evening can be considered partially understood if the listener got the message that they decided to watch a rugby game but could not deduce from the proper names whether the group was going to a bar or to a stadium. Normally, level 3 knowledge would not be required to achieve reasonable overall comprehension but sometimes it can become critical for precise understanding, for instance, if the listener is not able to tell the gender of the main character and this is important in the story or in rare cases when proper names are used figuratively. A fuller description of the model is presented below. 


\subsubsection{Level 1. A name or not a name? That is the question...}

The first thing that an ESL learner has to do is to recognize a name as a name in the input. As mentioned by Hirsh and Nation above, this should be fairly easy in reading English since in print proper names are made salient by initial capitals (1992: 691). However, it may become more tricky in listening. In an action study, Tatsuki investigated comprehension 'hot spots' in movies, namely the parts where her students felt lost and compelled to view several times. Based on three years of student logs, she identified several factors that repeatedly contributed to creating such 'hot spots'. One of them was that learners mistook unfamiliar proper names for common vocabulary and vice versa (Tatsuki, 1998). There are two main reasons to account for that: (i) English as well as many other languages 'has no phonologically defined class of names' (Algeo, 1973: 18); (ii) although peculiar semantically, proper names can coincide in form with common expressions.

It is a well-known fact that proper names may contain sound strings that do not comply with the general sound patterns of a language. A lot of names of foreign origin resist the diachronic sound change for much longer than ordinary words and, as a result, have idiosyncratic, unpredictable pronunciations. Some authors suggest that 'names in fact do not even have to be well-formed morphemes of the language: Vlasic, Zwicky, Dvorak can be used by English speakers despite their non-canonical sequences' (Lass, 1973: 395-396). However, even if pronunciations of some names diverge from typical phoneme sequences, it should be borne in mind that there are thousands of common words which are similarly non-canonical. Arguably, ChâtelGuyon would not sound any different from papier-mâché if neither word is familiar to the listener. In terms of surface structure, accentuation, number of syllables and the like, there are no radical systematic phonological differences between names and nonnames (Cutler et al., 1990). Also there are scores of proper names that originated in the English language and are therefore regular (i.e. close to common expressions) in regard to their phonetic patterns.

As shown in 3.2.3, proper names can consist of proper nouns (Paris, John), or a combination of proper nouns and ordinary words (St Peter's Square, $\underline{\text { Kennedy }}$ Airport), or of ordinary words alone (New World, Challenger). In the latter case, what it means for ESL listeners is that in terms of form, proper names and common noun

phrases appear exactly the same. To be sure, there is a considerable semantic difference between them (see 3.1), namely once a common phrase is institutionalized 
as a name, its constituent words stop bearing sense (in the strict terminological sense of the word):

In order to be denoted by an ordinary word, e.g. by a common name such as 'table', an object must possess certain characteristics associated with this word. Thus an object will not fall under the denotation of the word 'table' unless it has the characteristics of a table. I am not free to call any object I want a 'table': certain conditions have to be satisfied. But I am free to confer any proper name I want on my cat. I may call her 'Table' if I so wish... (Récanati, 1993: 136)

In other words, Big River does not have to be a river or anything big when it is the proper name of a creek behind one's batch, and shopping at New World does not bring up mental images of some new civilizations. On the surface however, Table, Big River, New World and table, big river, new world sound identical so it would take processing time to realize if an item is a proper name or not. In principle, any common word or phrase can be potentially used as a proper name so the listener must successfully pinpoint the difference in meaning between He closed the shop earlier on Mother's Day and He did the dishes - it made his mother's day.

\subsubsection{Level 2. What kind of referent?}

Let us assume that despite possible pitfalls described above, our ESL learner has successfully identified a proper name in the spoken text. This still does not guarantee that they will be able to understand what they hear. The major task for the listener is to determine what kind of object this proper name refers to, whether it is a brand of shoes, a TV programme, or a newly discovered galaxy. Most probably, it will be either a person or a place (since personal names and place names appear to be the most frequent), however if one compiles a list of all the types of objects in the outside world that can bear proper names, the figure, as I mentioned before, comes to a staggering 130 (Zelinsky, 2002; see 2.3).

Sortal terms, or classifiers ${ }^{*}$, are words that can help listeners to assign the referent of a proper name to a certain cognitive category. Classifiers may be either explicit (part of the name), e.g. river in the Snake River, airport in Kennedy Airport, or implicit (not used but understood), e.g. 'country' in Portugal or 'board game' in Cranium (Berezowski, 2001: 59, 90). Proper names that lack transparent classifiers are numerous, e.g. Novocherkassk [city], Harem [café], Te Anau [town], Te Papa

\footnotetext{
" Quirk et al. call them descriptors (1985: 288).
} 
[museum], Dell [brand] etc. There are also names with misleading 'classifiers', e.g. the Lone Star is a Wellington pub while The Pole Star is a star.

It was established in Chapter II that the main communicative function of proper names is differentiation, or, as some authors put it, individuation (see 2.4.1). Categorization is incidentally achieved by some proper name forms but it is not their essential function. For instance, when somebody says Kirk Building they are, of course, assigning the referent to the category of buildings, but it is done 'in passing'; it is not the main motivation for the utterance. Rather, the speaker is aiming to make it clear to the listeners what particular thing they are talking about, i.e. to distinguish Kirk Building from Murphy Building or any other nearby structures. Consequently, proper names often shed their explicit categorizing element (i.e. university, building in Victoria University of Wellington, Kirk Building) when the speaker is familiar with the respective referent. Everyone who lives in Wellington is likely to refer to Victoria University with a short form Victoria, and any student on campus talks simply about going to Kirk. For an outsider-listener though, who is not familiar with the name, it is not obvious that Kirk is a building; it may as well be a lawn, a lecture theatre, a separate wing in a building, or a named computer lab (for more on short forms substituting full names, see Carroll, 1985: 144-7).

In many proper name forms there are no overt markers that will give the recipient an idea of what category the referent belongs to. In such cases, ESL learners rely solely on context to determine the type of referent, which is manageable in reading (where they can always go back to the relevant part of the text to search for clues) but would be very challenging in listening due to the volatile, transitory nature of the input.

\subsubsection{Level 3. Almost Famous?}

Finally, I'd like to dwell on a distinctive group of proper names, namely those of famous persons or figures of historical significance, well-known places, worldfamous works of art etc. which at a given period of time can be said to enjoy international appreciation. It may seem that these expressions should be the easiest for ESL learners to handle since by definition they are supposed to be familiar rather than unfamiliar. Nevertheless they too can pose difficulties for listeners because: (i) the forms of a proper name in L1 and in English, though usually similar, are not identical; (ii) the class of famous names is fuzzy; (iii) this is practically the only group of names 
that can be used figuratively, i.e. not to refer to a particular object, but to invoke its salient characteristics.

For the most part, the forms of a famous proper name in L1 and in English would be similar or at least would have something in common. However, from the phonetic point of view, the match is far from full, and in some cases the English form is so 'disguised' that it makes the L1-English transfer time consuming or may even block it. For instance, for an L1 Russian listener Aristotle [ærı`'totl] will be an easy name to recognize since the Russian pronunciation [arıs'to:tıl'] is not too different. Socrates though will involve higher processing costs because the link between Russian [sak`ra:t] and English [`sokrətı:z] is less straightforward.

I have assumed above that the ESL learner is familiar with some renowned referent and the corresponding proper name in their mother tongue but in reality it may not always be the case. The concept of 'being famous' is fuzzy in that some proper names can be common knowledge in one culture, but less well known in another. Even individuals sharing the same cultural background vary greatly in their interests, type of education, travel experiences etc. For instance, I like to think that I am familiar with most of the great classical composers, but my knowledge of famous rock bands is rather limited. In other words, in dealing with this type of proper names ESL listeners are directly and entirely dependent on extralinguistic world knowledge (level 3 knowledge in my model).

This is especially obvious in rare cases when proper names are used figuratively. For example, to interpret such a sentence as Stockholm is the Venice of the North the listener needs to know not only that Venice is a proper name as well as that it is the name of a city, but exactly what properties Venice has (that it is considered one of the most beautiful cities in the south of Europe, is original in terms of architecture, and has numerous waterways). Clark and Gerrig (1983) conducted an interesting study investigating what the recipient's mental process of arriving at the right interpretation may look like for such sentences. It involves recalling a whole bundle of information about the referent and then sifting through it in search for the bit appropriate in the given context in order to establish what was intended by the author of the message. For instance, when someone hears She asked me to do a Napoleon for the camera they need to: (i) remember who Napoleon was; (ii) recall his biography (ruled France, crowned himself, laid siege to Moscow, was exiled to Elba); (iii) out of all the acts associated with Napoleon choose those that would fit in this 
context (frown, crown oneself, pose with your hand in your jacket); (iv) determine what specific act the speaker had in mind - posing with one hand tucked inside the jacket à la Napoleon (Clark and Gerrig, 1983: 592-594).

More recently, Wee provided an insightful analysis of metaphorically used proper names. He points out two different kinds of name-based metaphors. On the one hand, there are 'cases where names are conventionally associated with specific meanings' (2006: 358) as in Cambodia has become Vietnam's Vietnam. That Vietnam stands for 'a disastrous military operation' is already a convention established through repeated usage over time. On the other hand, there are nonce constructions where what a source proper name invokes must be 'inferred locally' as in I don't want to sit next to Allen Iverson (ibid. 357). This is said by Ross in the TV sitcom Friends in reference to Monica who recently had her hair braided in cornrows. It makes sense only with the knowledge that Allen Iverson is a famous basketball player and wears his hair in cornrows. What is important, the name Allen Iverson is not normally linked to 'someone with cornrows' hence 'an online, highly context-specific interpretation is needed here, rather than the accessing of any conventionalized association' (Wee, 2006: 358).

Obviously, figurative uses of proper names, especially the latter kind, will be extremely difficult for ESL listeners to handle due to the lack of relevant background knowledge.

\subsection{What kind of name? All names are equal but some are more equal than others...}

It is reasonable to suppose that certain types of proper names will affect ESL learners' listening comprehension more than others. For instance, it is likely that it makes a big difference for listeners whether the name form contains a transparent classifier or not. Various contextual environments where proper names occur should also be taken into account. Proper names can appear in combination with descriptive appositives (e.g. Thorn EMI, the music and rental group) and in the so-called close apposition structures (e.g. the god Jupiter, the city of London, Nixon the president), which makes the reference explicit even if the listener is not familiar with the name itself. Bjørge (2003) has termed this phenomenon explicitation. Thus according to the type of context, proper names can be either explicitated or non-explicitated. Perhaps if a name form hints at the cognitive category that its referent belongs to (either because it 
contains a transparent classifier or through explicitation) it will be less likely to adversely affect comprehension than a form that does not. This proposal is summarized in tables 4.2 and 4.3.

Table 4.2. Semantic and contextual types of proper names.

Semantic types:

- transparent classifier (Kennedy Airport [airport]; Kirk Building [building]; Scary Movie [movie]; Bluenote Bar [bar])

- misleading classifier (King Country [district]; Quotable Value [company]; Courtenay Place [street], the Lone Star [bar])

- no classifier = implicit classifier (Pyatigorsk [city]; Porirua [city]; Bahrain [country]; James Cook [person/hotel])

Contextual types:

- repeated in the text

- mentioned only once

- explicitated (defined by descriptive apposition/s or other words in the immediate context: Detective Senior Sergeant Neil Grimstone, the town of Talafar, the bus company Stagecoach, the Warehouse store, the vaccine Vaccigrip, aged care groups including Age Concern and Grey Power...)

- no explicitation (names with transparent classifiers are never explicitated)

Table 4.3. Potential impact of different types of proper names on ESL learners' listening comprehension.

Minimal impact on listening comprehension

Transparent classifier (Kirk Building)
$\left.\begin{array}{l}\text { No classifier, explicitated } \\ \text { (Kirk, one of the busiest buildings on campus ...) } \\ \text { No classifier, no explicitation (Kirk) } \\ \text { Misleading classifier (Herbert Gardens [building]) }\end{array}\right\} \begin{aligned} & \text { types of proper } \\ & \text { names }\end{aligned}$

Maximum impact on listening comprehension

\subsection{Chapter overview}

This chapter has shown that ESL learners have to possess several specific competencies and a large amount of knowledge, both linguistic and encyclopaedic, in order to cope with proper names in spoken texts. They must be able to recognize the 
unfamiliar name as a proper name in the flow of speech in the first instance, to successfully determine from context what kind of object it refers to, and in some cases to retrieve the corresponding $\mathrm{L} 1$ form as well as the relevant extralinguistic information about the referent that the text draws on. In addition, proper names are immensely diverse with regard to their semantic and contextual characteristics, which makes it reasonable to suppose that certain types would have a stronger potential to influence comprehension compared to others. The assumption that proper names can be equated with known items may be considered reasonable for reading material but is not likely to hold for spoken texts. The impact of unfamiliar proper names on ESL learners' listening comprehension requires careful assessment.

In the following chapters, I am going to empirically test level 1 and level 2 of the proposed 3-level model. I am also hoping to gather some evidence in support of the view that certain types of proper names are more likely to affect listening comprehension compared to others. For the time being I will not deal with level 3. No doubt, it is worth investigating in the future but fortunately for ESL learners, figurative uses of proper names are by far less common than their normal referential uses, therefore levels 1 and 2 shall be a priority. 


\section{Chapter V. Experiment 1: proper names recognition rate}

\subsection{Introduction}

In this chapter I will present Experiment 1 which was designed to answer the following research questions: (i) Are ESL learners able to discriminate between unfamiliar proper names and unknown common vocabulary while listening to connected speech? (ii) How is the ability to recognize unfamiliar proper names related to the percentage of unknown common vocabulary in the input? First, the choice of experimental materials and considerations underlying their development will be explained. Second, the data gathering procedures and the participants will be described. This chapter will conclude with the analysis of the collected data.

\subsection{Materials}

\subsubsection{Text selection}

Modified news stories were chosen to serve as input in the experiment because: (i) news texts contain a fair number of proper names; and (ii) listening to the news is an authentic task for ESL learners as this is something that they may need to do in real life. Twenty four news reports were sourced mainly from language corpora. I took the majority of texts from the Wellington Corpus of Spoken New Zealand English (WSC, 16 in total), and added a few from the broadcast news section in the spoken component of the British National Corpus (BNC, 4 in total). Four more texts were transcripts of news updates broadcast by Radio New Zealand between 14 March and 5 September, 2005. The texts were selected with the following considerations in mind: (i) there is a wide range of topics so that the participants with extensive expert knowledge in a certain area would not gain a significant advantage; (ii) the content is not likely to be familiar to the participants; and (iii) there are no less than ten proper names present in the story (proper name types). The possibility of learners having prior knowledge of some of the content was a major concern in preparing the 
materials. While it was not feasible to control it in the strict sense (i.e. to eliminate the chances of a story being familiar to a participant altogether), steps were taken to minimize the risk as far as possible. Firstly, the majority of texts came from 'local news' unlikely to have reached English learners living outside New Zealand and Britain. Secondly, most news items were well out of date (the WSC texts were collected between 1990-1994, and the BNC texts between 1985-1994 respectively). For more details, see Appendix A.

\subsubsection{Text modifications}

In developing the materials, I assumed that all participants would have sound knowledge of the first 2000 most frequent words of English. This assumption was based on the understanding that participants would be recruited from the Victoria University of Wellington English Proficiency Programme, i.e. an academic English course that does not cater for beginners but for learners at the intermediate to advanced levels of proficiency (see 5.4 below). Two versions of the same set of news texts were prepared: the simplified version and the complicated version. In the simplified version, low-frequency vocabulary except proper names was taken out or replaced by the first 2000 high-frequency words where appropriate. Some difficult grammatical structures were also broken up into parts or substituted by easier constructions. The aim was to make the amount of non-proper expressions unknown to the participants as low as possible. In the complicated version, all low-frequency vocabulary remained intact and, where possible, some of the simple high-frequency words were replaced by the more difficult low-frequency words.

Tables 5.1 and 5.2 compare the vocabulary composition between the simplified set and the complicated set. Note that these percentages are not precise. They were obtained by running all text files though the Range programme (Heatley, Nation and Coxhead, 2002). The programme does not recognise the difference between intermediate as a common expression and Intermediate as part of a proper name (as in Waimea Intermediate School). The 'Not in the lists' category is ambiguous: it contains both proper names and low-frequency non-proper expressions. As can be seen from the tables, the simplified texts contain more of the highfrequency vocabulary, while the complicated texts contain more of the academic as well as other low-frequency vocabulary. 
Table 5.1. Vocabulary profile: simplified set vs. complicated set. Percentages are for types, i.e. unique words.

\begin{tabular}{|l|l|l|}
\cline { 2 - 3 } \multicolumn{1}{c|}{} & $\begin{array}{l}\text { Average \% across } \\
\text { Simplified texts }\end{array}$ & $\begin{array}{l}\text { Average \% across } \\
\text { Complicated texts }\end{array}$ \\
\hline $\begin{array}{l}\text { The 1st 1000 most frequent } \\
\text { words of English }\end{array}$ & 60.71 & 43.53 \\
\hline $\begin{array}{l}\text { The 2nd 1000 most frequent } \\
\text { words of English }\end{array}$ & 12.55 & 10.31 \\
\hline Academic Word List & 0.47 & 7.49 \\
\hline Not in the lists & 26.27 & 38.67 \\
\hline
\end{tabular}

Table 5.2. Vocabulary profile: simplified set vs. complicated set. Percentages are for tokens, i.e. all running words.

\begin{tabular}{|l|l|l|}
\cline { 2 - 3 } \multicolumn{1}{c|}{} & $\begin{array}{l}\text { Average \% across } \\
\text { Simplified texts }\end{array}$ & $\begin{array}{l}\text { Average \% across } \\
\text { Complicated texts }\end{array}$ \\
\hline $\begin{array}{l}\text { The 1st 1000 most frequent } \\
\text { words of English }\end{array}$ & 80.1 & 69.34 \\
\hline $\begin{array}{l}\text { The 2nd 1000 most frequent } \\
\text { words of English }\end{array}$ & 6.37 & 5.42 \\
\hline Academic Word List & 0.39 & 4.06 \\
\hline Not in the lists & 13.14 & 21.18 \\
\hline
\end{tabular}

The original news reports were cut down so that both simplified and complicated texts comprised around 150 running words each. It was hoped that if the passages were short, the participants would be able to maintain close attention throughout the listening task. It was also desirable to eliminate text length as an additional variable to account for. Ten proper name types per text were kept. Any extra ones appearing in some of the original texts were removed. The number of proper name tokens across the news items varied from 10 to 22 (see Appendix B). A native speaker of English was employed to proofread the modified texts.

Finally, all proper names had to be replaced by non-existent ones invented by the researcher, in order to make sure that none of them are known to the participants prior to the experiment. In creating the made-up names, I consistently applied the following rules: (i) the number of syllables in the target name should stay the same as in the source name; (ii) the target name should imitate the phonotactics of the source name as far as possible, but the source name must not be identifiable from the target name; (iii) where the source name does not consist of proper nouns exclusively but contains common words, the latter should be either preserved (Oxford University $\rightarrow$ 


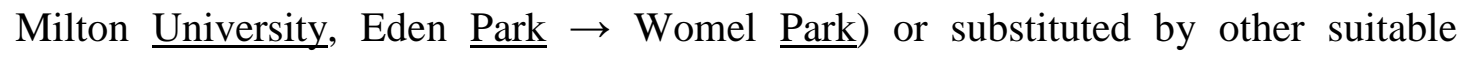

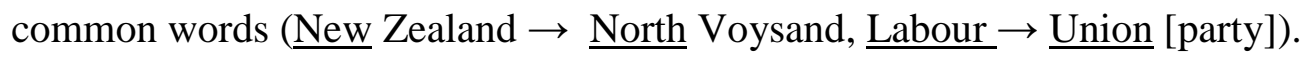

\subsubsection{Audio files}

Eight native speakers of English ( 3 male, 5 female) and in a few cases the researcher (a fluent non-native speaker) recorded the texts using the open source sound editing software Audacity. For all stories, the same speaker/s recorded the simplified and the complicated versions. Fortunately, people from five different countries took part in the process, and thus supplied a variety of English accents in the experimental input. Everybody was asked to read the passage at their normal pace, and to have a bit of practice prior to recording so that the made-up names sound natural (are not marked by hesitations or pauses). In some recordings, the speech tempo appeared too fast, which could be overwhelming for intermediate proficiency ESL learners. Using Audacity, the tempo was reduced to ensure that all texts are well within the participants' listening skills. The complete audio files for the experiment were structured as follows: (i) introductory tone; (ii) news item; (iii) pause; (iv) introductory tone; (v) the same news item sentence by sentence with 2.5 second pauses (filled with clicks) between the sentences. The sole purpose of introductory tones was alerting the participants that the listening passage is about to begin. The click-filled pauses were required mainly to facilitate data interpretation but they also provided extra thinking time for the participants.

\subsection{Procedure}

The experiment was conducted with each participant individually over two 2-hour long sessions that progressed as follows:

\section{Session 1}

1. Introductory part

a) The participant reads the information sheet 'What is a proper name?' (see Appendix C). The researcher assists, answers questions, and explains further if necessary.

b) The participant reads a short sample text and is asked to underline proper names. The researcher checks their work and makes sure the participant understands what proper names are. 
c) The researcher models the experimental procedure and makes sure that the participant understands what to do. The participant is asked to listen to a news story and, on a second (sentence by sentence) listening, to press a button each time they think they heard a proper name (see Appendix D [a]). The participant has a practice run with the sample audio file 1 . The participant has another practice run with the sample file 2.

\section{Main part}

a) The participant listens to the first six experimental texts (25-30 minutes). The researcher reminds the participant to listen out for the proper names and saves the data after each text.

b) The participant takes a 10-minute break and is offered tea and sweets.

c) The participant listens to the next six experimental texts (25-30 minutes).

\section{Session 2}

1. Introductory part

The participant quickly looks through the information sheet ("What is a proper name?') and has one practice run with the sample audio file 3.

2. Main part

a) The participant listens to the next six experimental texts.

b) The participant takes a ten-minute tea break.

c) The participant listens to the last six experimental texts.

d) The participant fills out the personal details and English learning background questionnaire.

Introductory instruction was informal so that the participants feel at ease from the start of the experiment. Plenty of training on the procedure was necessary to ensure that the lack of experience with this kind of recognition task did not distort their performance. Half of the participants listened to the Simplified version of the odd-numbered texts and to the Complicated version of the even-numbered texts. The other half heard the Complicated version of the odd-numbered texts and the Simplified version of the even-numbered texts. The sequence of presenting the versions, however, was kept the same: simplified-complicated-S-C-S-C etc. so all participants always started with a simplified text at the beginning of both sessions and after both breaks, and always finished listening with a complicated text (see Appendix D [b]). Participants were given a choice to listen either through speakers or earphones; all of them opted for the speakers. While listening, participants looked at the 
computer screen where they could see the spectrogram and the progress of the recording as well as red flags appearing whenever the button was pressed. Their responses to each text were saved in a separate Audacity file.

\subsection{Participants}

Eighteen students (5 male, 13 female) in a 12-week English for academic purposes course at Victoria University of Wellington took part in the study. Aged 18 to 31, they were intermediate to advanced proficiency learners as confirmed by the programme placement tests. On the Vocabulary Levels Test ${ }^{*}$ in particular, the majority of participants scored over 25 and none lower than 21 (out of 30) at the 2000 word level. The vast majority also gave over 20 correct answers and none lower than 18 correct answers (out of 30) at the 3000 word level. Vocabulary test results show that all participants had a good receptive knowledge of the first 2000 most frequent words of English. Students were recruited from three separate classes (two intermediate proficiency classes and one advanced class). Participation was voluntary and did not connect in any way to classroom activities. The main motivation for the students appeared to be improving their listening skills although they also received gift vouchers at the end of the experiment. Most participants were from Asia; eight different L1 backgrounds (as indicated in the post-experimental questionnaires) were represented in the sample (for details, see Appendix E). Also three native speakers of English ( 2 female, 1 male) served as a control group. One of them was an academic, another one a university administrative staff member (both in their early fifties), and the third one was a schoolgirl aged 14 .

\subsection{Analysis}

The analysis of the collected data will be organized around the following questions:

1. What percentage of proper names was recognized in simplified and complicated texts?

2. How many errors did participants make while listening to simplified and complicated texts? What kind of errors occurred?

3. Other findings (GEE analysis)

\footnotetext{
*For a description of this test see either: Beglar and Hunt, 1999; Schmitt, Schmitt and Clapham, 2001; Nation, 2001; Nation and Gu, 2007.
} 
4. What differences in performance were there between the ESL participants and the native speakers control group?

\subsubsection{Percentage of proper names recognized}

Proper names recognition rate can be stated in terms of name tokens or name types. A token is an individual occurrence of a proper name in the running text. A type is a class of tokens sharing the same formal features. For example in Edge's entertainment director, Terry Jarvis, says Edge will use this cash to expand, there are three proper name tokens (Edge's, Terry Jarvis, Edge) and two proper name types (Edge, Terry Jarvis). Each participant had to recognize 241 types. This included either 120 in simplified texts and 121 in complicated texts (sequence A participants) or 121 in simplified and 120 in complicated respectively (sequence B participants). A total of 4338 proper name types were processed. Sequence A comprised 375 tokens; sequence B comprised 376 tokens (due to the fact that some texts had a different number of tokens in simplified and complicated versions). A total of 6759 proper name tokens were processed.

Table 5.3. Average percentage of recognized proper name tokens.

\begin{tabular}{|l|l|l|l|}
\hline Condition $\rightarrow>$ & $\begin{array}{l}\text { Simplified } \\
(\mathrm{S})\end{array}$ & $\begin{array}{l}\text { Complicated } \\
(\mathrm{C})\end{array}$ & $\begin{array}{l}\text { Difference } \\
\text { between S and C }\end{array}$ \\
\hline $\begin{array}{l}\text { Overall (average } \\
\text { across all participants) }\end{array}$ & $64.11 \%$ & $61.36 \%$ & $2.75 \%$ \\
\hline Class 1 (upper intermediate) & $61.52 \%$ & $59.48 \%$ & $2.04 \%$ \\
\hline Class 2 (advanced) & $70.93 \%$ & $68.53 \%$ & $2.4 \%$ \\
\hline Class 3 (low intermediate) & $54.39 \%$ & $49.84 \%$ & $4.55 \%$ \\
\hline
\end{tabular}

As can be seen from the table, slightly more proper names were recognized in simplified texts but, contrary to expectations, this difference is small and not statistically significant. However, there is a clear connection between the ability to recognize proper names and the participants' overall language proficiency. The higher the proficiency, the more proper names are recognized under both (simplified and complicated) conditions. Also the difference between the two conditions is more pronounced for the lower proficiency class.

The percentage of recognized proper name types would vary according to what exactly is understood by 'recognized' (see table 5.4). 
Table 5.4. Average percentage of recognized proper name types.

\begin{tabular}{|l|l|l|}
\hline Condition -> & Simplified & Complicated \\
\hline $\begin{array}{l}\text { A type is counted as recognized if the participant has } \\
\text { correctly identified at least one token. }\end{array}$ & $70.45 \%$ & $67.54 \%$ \\
\hline $\begin{array}{l}\text { A type is counted as recognized if the participant has } \\
\text { correctly identified at least 50\% of the tokens. }\end{array}$ & $67.87 \%$ & $65.51 \%$ \\
\hline $\begin{array}{l}\text { A type is counted as recognized if the participant has } \\
\text { correctly identified all tokens. }\end{array}$ & $57.35 \%$ & $54.73 \%$ \\
\hline
\end{tabular}

The most sensible option seems to set the cut-off point at $50 \%$.

Combining the figures on proper name tokens and proper name types, I conclude that on average, adult ESL learners of intermediate to advanced proficiency are able to recognize six unfamiliar proper names out of ten while listening to short news passages. Interestingly, the ability to recognize unknown proper names does not appear to deteriorate by much if the amount of unknown common vocabulary in the text increases.

These findings allow different interpretations. On the one hand, the $60 \%$ recognition rate is good news for ESL teachers and learners. It means that in the majority of cases proper names 'stand out from the crowd' and they are identifiable in the spoken text, largely regardless of how difficult this text is in terms of the general vocabulary load. On the other hand, students did not recognize well over a third of proper names, let alone understand what they refer to, which might detract considerably from the overall comprehension of the passage. It appears that the ability to recognize unfamiliar names depends on the structure of a specific text as well as the position and the shape of the names themselves rather than on the amount of unknown common vocabulary.

\subsubsection{Errors}

Although the percentages of recognized proper names did not differ greatly between the simplified and complicated versions, the experiment demonstrated that it was harder for the participants to do the recognition task with complicated texts. This is shown by the number of errors that participants made during listening. By an error I mean an instance of a participant pressing the button when there was no proper name in the input. Overall, participants made 108 errors (an average of 6 per person) in the simplified condition and 262 errors (an average of 14.56 per person) in the complicated condition. The mean number of errors per participant differed 
significantly under the simplified and complicated conditions (two-sample unequal variances $t$-test, $\mathrm{p}<0.001)$.

Upon examining the context in which the errors occurred, they were classified into several types (see table 5.5 for examples):

1. Unknown word (UW) errors - the button was pressed after a difficult word that the participant presumably did not know.

2. Incorrect prediction (IP) errors - the button was pressed after a (part of a) sentence where a proper name would be possible but was not present in the actual text. These could also be called task interference errors because a number of them were caused by the fact that participants adopted strategic ways of coping with the particular task they were required to do. For example, they soon learnt that place names often appear after the preposition in and started pressing the button whenever they encountered this preposition. Also participants would sometimes mistakenly press the button when they heard such words as person, city, company, college because they were taught to listen out for names of people, places, and organizations.

3. Random (R) errors - the button was pressed after a fragment of speech where no difficult low-frequency words were present and a proper name would not fit the context.

4. Mixed (M) errors - clearly non-random errors where either UW or IP factors or both could have triggered the wrong guess.

Regarding the errors, participants' performance on the simplified and complicated texts differed not only quantitatively but also qualitatively. The fraction of random errors was much higher under the simplified condition $(53.7 \%$ compared to $17.2 \%$ in complicated texts), whereas the fraction of unknown word errors was much higher under the complicated condition (46.9\% compared to $4.6 \%$ in simplified texts). The mean number of all non-random errors (UW, IP and M) per participant in the simplified texts was 2.8 compared to 12.05 in the complicated texts. The mean number of non-random errors per participant between the two conditions differed significantly (two-sample unequal variances $t$-test, $\mathrm{p}<0.001$ ). For more details, see Appendix F.

Since participants made errors and made more of them in the complicated condition, I assumed that as regards name recognition, the learners were guessing their way through. In order to test this prediction, I isolated all repeated proper names 
and looked for cases of partial recognition. Partial recognition means a proper name type where a participant identified only $50 \%$ of the tokens or less, for example one of two or one of three. I hypothesized: (1) that this would indicate participants' uncertainty about the status of an expression, and (2) that there should be more instances of partial recognition in the complicated texts. The first hypothesis was confirmed. There was indeed a considerable amount of guessing going on; on the whole, over $14 \%$ of repeated proper names were recognized only partially. Moreover, partial recognition correlated with language proficiency, i.e. the students in the lower proficiency classes were guessing more than the students in the higher proficiency classes. The second hypothesis was not confirmed. Overall more partial recognition occurred in the complicated condition, however the difference was small and not significant (see table 5.6).

Table 5.5. Experiment 1. Examples of different kinds of errors.

\begin{tabular}{|c|c|c|}
\hline $\begin{array}{l}\text { Error } \\
\text { type }\end{array}$ & Context & $\begin{array}{l}\text { Where the button was } \\
\text { pressed }\end{array}$ \\
\hline \multirow[t]{2}{*}{ UW } & $\begin{array}{l}\ldots \text { in a huge ticker tape parade dedicated to the } \\
\text { victory ... }\end{array}$ & 'ticker tape parade' \\
\hline & $\begin{array}{l}\text { A random killer shot seven customers at } \\
\text { Mydback's Sathnow Shopping Plaza, and an } \\
\text { eighth was hacked to death with a machete. }\end{array}$ & 'machete' \\
\hline \multirow[t]{2}{*}{ IP } & $\begin{array}{l}\text { Health officials will meet representatives of the } \\
\text { Faish manufacturer, Masofi Lasteur, to demand } \\
\text { answers over a faulty vaccine the company } \\
\text { released. }\end{array}$ & $\begin{array}{l}\text { 'health officials', } \\
\text { ‘company' }\end{array}$ \\
\hline & $\ldots$ an engine failed and the pilot crashed. & 'pilot' \\
\hline $\mathrm{R}$ & Turning them on means turning our shoppers off. & 'them on' \\
\hline \multirow[t]{2}{*}{$\mathrm{M}$} & The villain was a cab driver who held a licence. & $\begin{array}{l}\text { 'villain' - either UW or IP } \\
\text { [mistook it for a personal } \\
\text { name that would fit the } \\
\text { context] }\end{array}$ \\
\hline & $\begin{array}{l}\text { Codney Dale took pot shots at people in the } \\
\text { suburbs, killing an old woman. }\end{array}$ & $\begin{array}{l}\text { 'suburbs' - either UW or } \\
\text { IP [mistook it for a place } \\
\text { name after 'in'] }\end{array}$ \\
\hline
\end{tabular}

Table 5.6. Percentages of partially recognized repeated proper name types by class.

\begin{tabular}{|l|l|l|}
\hline & Simplified & Complicated \\
\hline Class 1 & $13.71 \%$ & $15.82 \%$ \\
\hline Class 2 & $12.66 \%$ & $12.50 \%$ \\
\hline Class 3 & $18.35 \%$ & $16.77 \%$ \\
\hline Overall & $14.12 \%$ & $14.39 \%$ \\
\hline Mean number of types per participant & 11.28 & 11.5 \\
\hline
\end{tabular}




\subsubsection{GEE analysis}

In addition to descriptive statistics the data were analyzed using the SAS procedure GENMOD. The model employed was a logistic regression that incorporates repeated measures and uses the generalized estimating equations (GEE) methodology to fit the data. The percentage of proper names recognized was the response. The explanatory variables (factors affecting proper names recognition) were:

- $\quad$ subject group (the model assumed that participants from different classes might perform differently);

- batch (participants did the task over two sessions, each of which in turn consisted of two parts separated by a break therefore the data were divided into four batches corresponding to the four on-task periods);

- type of proper name (repeated vs. singly occurring proper names);

- condition (simplified vs. complicated texts).

Interactions both between group and type as well as between group and condition were considered, but only the group by type interaction was retained in the model. Only batch had a significant effect on the percentage recognized $(\mathrm{p}<0.001)$, but marginally significant differences between the groups $(p=0.09)$ as well as a marginally significant group by type interaction $(\mathrm{p}=0.07)$ were found.

Table 5.7. Score statistics for Type 3 GEE analysis.

\begin{tabular}{|l|l|l|l|}
\hline source & DF & Chi-square & Pr $>$ ChiSq \\
\hline group & 2 & 4.91 & 0.0860 \\
\hline batch & 3 & 12.21 & 0.0067 \\
\hline type & 1 & 0.40 & 0.5259 \\
\hline condition & 1 & 1.95 & 0.1621 \\
\hline group*type & 2 & 5.37 & 0.0683 \\
\hline
\end{tabular}

\subsubsection{Practice effect}

Overall the accuracy of proper name recognition increased over time with the odds of recognizing a $\mathrm{PN}$ in the fourth batch 1.65 times higher than in the first batch. In particular, there was a big improvement in participants' performance from batch 1 to batch 2 , a very slight decrease to batch 3 , and a small improvement to batch 4 (percentages of recognized proper name tokens per batch are presented in Table 5.8). Thus, most of the learning occurred between part 1 and part 2 of the first experimental session, and participants retained what they had learnt about the task till the second session. Most importantly, participants practically mastered the task by the end of part 
1 of the first session so most of the data were not biased by the fact that the participants were not familiar with this kind of task before the experiment.

\begin{tabular}{|l|l|l|l|l|l|l|}
\hline Parameter & Estimate & $\begin{array}{l}\text { Standard } \\
\text { Error }\end{array}$ & \multicolumn{2}{l|}{ 95\% Confidence Limits } & $\begin{array}{l}\text { Wald } \\
\text { Statistic }\end{array}$ & p-value \\
\hline Batch 1 & -0.5005 & 0.1126 & -0.7212 & -0.2797 & -4.44 & $<.0001$ \\
\hline Batch 2 & -0.0825 & 0.0898 & -0.2585 & 0.0936 & -0.92 & 0.3584 \\
\hline Batch 3 & -0.1753 & 0.0761 & -0.3245 & -0.0261 & -2.30 & 0.0213 \\
\hline Batch 4 & 0.0000 & 0.0000 & 0.0000 & 0.0000 &. &. \\
\hline
\end{tabular}

Table 5.8. Percentage of recognized proper name tokens by batch.

\begin{tabular}{|l|l|l|l|l|}
\hline \multirow{2}{*}{ Condition } & \multicolumn{4}{|l|}{ Average percentage of recognised proper name tokens (across 24 texts) } \\
\cline { 2 - 5 } & Batch 1 & Batch 2 & Batch 3 & Batch 4 \\
\hline Simplified & $59.73 \%$ & $64.26 \%$ & $64.24 \%$ & $68.37 \%$ \\
\hline Complicated & $57.14 \%$ & $62.78 \%$ & $60.53 \%$ & $65.01 \%$ \\
\hline
\end{tabular}

\subsubsection{Proficiency effect}

The GEE analysis showed that the advanced proficiency class had the highest probability of recognising proper names that occurred singly, the upper intermediate class had the next highest probability and the low intermediate class had the lowest probability. The odds of the advanced proficiency class recognising a proper name were twice as large as the lower intermediate and 1.6 times larger than the upper intermediate class. The odds of the upper intermediate class recognising a proper name were 1.2 times larger than the low intermediate class.

\begin{tabular}{|l|l|l|l|l|l|l|}
\hline Parameter & Estimate & $\begin{array}{l}\text { Standard } \\
\text { Error }\end{array}$ & \multicolumn{2}{|l|}{ 95\% Confidence Limits } & $\begin{array}{l}\text { Wald } \\
\text { Statistic }\end{array}$ & p-value \\
\hline Group 0 & -0.6936 & 0.2668 & -1.2164 & -0.1708 & -2.60 & 0.0093 \\
\hline Group 1 & -0.4766 & 0.2275 & -0.9225 & -0.0307 & -2.09 & 0.0362 \\
\hline Group 2 & 0.0000 & 0.0000 & 0.0000 & 0.0000 &. &. \\
\hline
\end{tabular}

\subsubsection{Repeated vs. singly occurring proper names}

The majority of proper name types in the experimental texts were represented by one token (i.e. occurred only once); $32.78 \%$ (79 of 241 types) were repeated. The GEE analysis showed marginally significant group by type effects. Interestingly, group 1 participants (upper intermediate class) were significantly more likely to recognize a proper name if it was repeated $(\mathrm{p}=0.022)$. This was also true, although to a lesser extent, for group 2 (advanced class). However, for participants from the lower proficiency group 3 (low intermediate class), the effect was reversed. They were less likely to recognize a proper name if it was mentioned in the text multiple times. The 
odds of the upper intermediate class recognizing a repeated proper name were 1.25 times larger than a singly occurring proper name; the odds of the advanced proficiency class recognizing a repeated proper name were 1.08 times larger than a singly occurring proper name; and the odds of the low intermediate class recognizing a singly occurring proper name were 1.24 times larger than a repeated proper name.

\begin{tabular}{|l|l|l|l|l|l|l|}
\hline Parameter & Estimate & $\begin{array}{l}\text { Standard } \\
\text { Error }\end{array}$ & \multicolumn{2}{|l|}{$\begin{array}{l}\text { 95\% Confidence } \\
\text { Limits }\end{array}$} & $\begin{array}{l}\text { Wald } \\
\text { Statistic }\end{array}$ & p-value \\
\hline Type multi & 0.0753 & 0.0488 & -0.0203 & 0.1709 & 1.54 & 0.1226 \\
\hline Type single & 0.0000 & 0.0000 & 0.0000 & 0.0000 &. &. \\
\hline $\begin{array}{l}\text { Group*type 0 } \\
\text { multi }\end{array}$ & -0.2890 & 0.1077 & -0.5001 & -0.0780 & -2.68 & 0.0073 \\
\hline $\begin{array}{l}\text { Group*type 0 } \\
\text { single }\end{array}$ & 0.0000 & 0.0000 & 0.0000 & 0.0000 &. &. \\
\hline $\begin{array}{l}\text { Group*type 1 } \\
\text { multi }\end{array}$ & 0.1469 & 0.0842 & -0.0182 & 0.3120 & 1.74 & 0.0811 \\
\hline $\begin{array}{l}\text { Group*type 1 } \\
\text { single }\end{array}$ & 0.0000 & 0.0000 & 0.0000 & 0.0000 &. &. \\
\hline $\begin{array}{l}\text { Group*type 2 } \\
\text { multi }\end{array}$ & 0.0000 & 0.0000 & 0.0000 & 0.0000 &. &. \\
\hline $\begin{array}{l}\text { Group*type 2 } \\
\text { single }\end{array}$ & 0.0000 & 0.0000 & 0.0000 & 0.0000 &. &. \\
\hline
\end{tabular}

The only explanation for this quite unexpected finding would be that the low proficiency students were struggling to understand and lost track in some of the stories. They simply did not comprehend enough to be able to successfully identify repeated names. Comprehension was not formally tested, and this assumption is based solely on my observations during the experiment and participants' comments. However, the finding suggests that for lower proficiency learners, repeated proper names 'resembled' the common vocabulary more than the singly occurring ones, and so were harder to discriminate.

\subsubsection{Native speaker control group}

Considering that all proper names were made up, the main purpose of the control group was to check whether the experimental task was doable in principle as well as to compare the native speakers' performance with that of the ESL participants. The results show that dealing with artificial names is unlikely to have compromised the participants' recognition ability. On average, native speakers recognized $95 \%$ of the proper name tokens; the adults recognized $96 \%$ each, and the teenager recognized 
93\%. A few tokens that were missed are probably due merely to lapses of concentration.

Table 5.9. Percentages of proper name tokens recognized by native speakers.

\begin{tabular}{|l|l|l|l|}
\hline Condition & Emma $^{*}$ & Richard & Annie \\
\hline Simplified & $96.40 \%$ & $95.15 \%$ & $94.74 \%$ \\
\hline Complicated & $95.59 \%$ & $97.65 \%$ & $92.16 \%$ \\
\hline
\end{tabular}

Unlike the ESL participants, the native speakers: (i) recognized the vast majority of names regardless of condition (simplified or complicated); (ii) did not guess (no partial recognition); (iii) did not appear to become better at the task over time (no practice effect); and (iv) made practically no errors. Very few errors that occurred were of either R (random) or IP (incorrect prediction) type.

\subsection{Summary of Experiment 1 findings}

The main Experiment 1 findings can be summarized as follows:

1. ESL learners of intermediate to advanced proficiency are able to recognize an unfamiliar proper name in a short listening passage approximately 6 times out of 10

2. The ability to recognize proper names increases proportionately to the overall language proficiency.

3. The ability to recognize proper names appears to depend more on the structure of a specific text as well as on the position and shape of the names rather than on the percentage of unknown common vocabulary in that text.

4. Nevertheless it is evidently harder for ESL learners to recognize proper names in texts containing a lot of unfamiliar common vocabulary than in simple texts. This is shown by a greater amount of errors and guessing (partial recognition) while listening to complicated texts.

5. A great number of proper names are missed and there are significantly more unknown word errors in complicated texts, which suggests that in real life listening, learners can mistake unknown common words for proper names and vice versa.

6. Repeated proper names are better recognized provided that overall text comprehension is reasonably high.

\footnotetext{
*All names of participants in this thesis are pseudonyms.
} 


\section{Chapter VI. Experiment 2: the learners' ability to categorize the referent and the impact of proper names on listening comprehension}

\subsection{Introduction}

Experiment 1 dealt with the first level of knowledge ESL learners need to possess in order to successfully cope with proper names in spoken texts, namely recognition. The next level involves the ability to determine what kind of entity a proper name refers to, i.e. assigning its referent to a certain cognitive category. In this chapter, I will present Experiment 2 aimed at empirically testing this second level of knowledge, categorization. I will also deal with the central problem of the whole thesis, i.e. whether the presence of unfamiliar proper names impacts on ESL listening comprehension. The experiment was designed to answer the following research questions: (1) Does the presence of unfamiliar proper names influence ESL learners' comprehension of a spoken text, and if so, how? (2) While listening to connected speech, how well are ESL learners able to determine what proper names refer to, and how much information about proper names' referents can listeners get from context? First, I will introduce the experimental text and testing materials as well as justification for the particular tasks chosen for the experiment. Then the data gathering procedures and participants will be described. Finally, I will present the results and discuss possible ways of interpreting the findings.

\subsection{Materials}

\subsubsection{Experimental text}

The listening passage, Murder, was one of the simplified news stories used in the previous experiment: 149 words long including 10 proper name types (17 tokens). All proper names were artificial and thus could not have been known to the participants prior to the experiment. The passage did not contain any low-frequency common 
vocabulary and conformed to what can be called a standard 'story grammar', i.e. had a clear plot line developing in chronological order.

One of the challenges in testing listening is there is no strict criterion for measuring text interpretation 'since interpretations may differ between individuals according to a multiplicity of cognitive and affective factors' (Brindley, 1998: 173). Various legitimate understandings of the same input may be possible, none of which is necessarily 'less correct' (Sarig, 1989). Language testing experts recommend that listening tests should primarily target explicit propositional content (literal meanings) as opposed to implied meanings that require extensive inferencing and are thus open to individual variation: '... the default construct should test only those things for which there is clear and unequivocal linguistic evidence in the text' (Buck, 2001: 121). For these reasons, a highly factual news story was chosen for the experiment which left little room for alternative interpretations (see Appendix G).

The passage was dense in terms of informational load and contained practically no redundancies (repetitions of the same information). However, it was very short in order to minimize memory effects on participants' performance. One minute long file was recorded by a male New Zealand English speaker. Another 30second-long file (different text, same speaker) was created to serve as a sound check, i.e. to make sure the participants could hear the recording well.

\subsubsection{Comprehension measures}

Measures of listening comprehension included: (i) immediate oral recall (story retell); (ii) general comprehension questions (open-ended and multiple choice); and (iii) proper names related statements (true-false-don't know format).

\subsubsection{Recall}

Free recall has been advocated by many scholars as an integrative measure of comprehension, superior to discrete-point formats such as sentence verification, comprehension questions or cloze (Berkemeyer, 1989; Bernhardt 1991; Heinz, 2004). It is non-invasive, sensitive, arguably authentic (approximating the natural, real life processing tasks), and more learner-centred than other comprehension assessment methods. 
It is common knowledge that traditional short-answer and multiple choice questions 'impose' a certain view of the text on the learner by giving away clues that interfere with the meaning construction process, often in unpredictable ways:

... when questions are administered, an additional interaction takes place among texts, reader, questioner, and among the questions themselves. In other words, questions form another "text" for comprehension. It is, therefore, extremely difficult to pinpoint how a reader encodes information apart from the additional [italics in the original] input he or she receives from questions. In other words, a free recall measure provides a purer measure of comprehension... (Bernhardt, 1991: 200).

Also immediate recall is sensitive; it 'allows misunderstandings and gaps in comprehension to surface; a feature that other methods of evaluation cannot offer' (Berkemeyer, 1989: 131). Recall protocols are a very rich source of data. Presumably, they tap into the complex process of understanding, shedding light on how the message contained in the text was being put together (Bernhardt, 1983). Heinz (2004) argues that the recall task is authentic, as it resembles what people may often do in everyday life:

Who has not experienced being asked by an acquaintance if he or she had read an article in some newspaper or magazine? [...] Children often cannot wait to relate to their parents stories they read or that were read to them in school. The retelling of what someone has read [or heard - addition mine] is, in fact, a daily occurrence, one in which human beings engage naturally and readily in the course of conversation.

Thus the ecological validity of recall is more than satisfactory.

Researchers consider that comprehension is a multilevel constructive process, and that learning new information is influenced by the information that heen previously stored in memory. Therefore an individual's knowledge base as well as their own peculiar ways of interacting with a given text play a major role. In sharp contrast to the standardized formats, the learner-generated recall protocol brings the researcher closer to the individual, i.e. reveals how this particular learner arrived at the text message.

Immediate recall has been extensively used to assess L1 and L2 reading comprehension (Kameenui, Carnine and Freschi, 1982; Wixson, 1986; Bernhardt, 1991) and, more recently, listening comprehension (Bernhardt and James, 1987; Long, 1990; Lund, 1991; Schmidt-Rinehart, 1994; Jung, 2003). However, while the 
procedure became increasingly popular in second language acquisition research, several weak points were noted.

Lee (1986) found that there is a significant difference in quantity of idea units recalled depending on whether the learners use the first or the target language. Learners using their L1 recall more of the passage than those using L2. Thus, the results can be 'muddied' by the limited L2 production ability unless participants are allowed to recall in their mother tongue.

Riley and Lee (1996) demonstrated that operationalizing comprehension as merely the quantity of information recalled is problematic. Some learners produce a long string of incidental details but fail to express the essence of the text. Yet they may receive a higher score than their peers who successfully grasped the main ideas. Riley and Lee compared the recall with the summary writing task and showed that the task type affects the quality of protocols. The recall, where students are asked to write everything they can remember, was found to encourage them to focus on details. The authors suggest that this is an artificial 'byproduct of the task' and not a reflection of a naturally flowing comprehension process (1996: 176-7). On the other hand, while the length of the output was not affected, 'subjects writing summaries tended to produce more of the important information and to write a more coherent reconstruction of the passage...' (ibid. 184).

Another disadvantage of the recall procedure is that it taxes memory. Readers or listeners may not necessarily be able to remember everything they have understood. A recent study by Chang compared L2 readers' performance on immediate recall with that on a translation task. The latter 'yielded significantly more evidence of comprehension' (Chang, 2006: 537), which indicates that heavy demands on memory in the recall task do hinder the learners' ability to exhibit their comprehension to the full.

Oral recalls have been employed in L1 research with school children, however in most L2 comprehension studies the recall is carried out in writing. Unfortunately, participants in my experiment had to recall in English (L2), which is a rather demanding task. In order to elicit as much output as possible, it was decided to use oral recall but allow students to write during planning time. 


\subsubsection{Comprehension questions}

Most scholars take the so-called multimeasure approach to assessing listening comprehension, namely use several techniques to gain insights into this complex and invisible process. A large body of literature is dedicated to specific test item types, however more often than not there is little consensus among researchers because each type has its own advantages and disadvantages (Weir, 1988 and 1993; Bernhardt, 1991: 195-200; Brindley, 1998: 177-179; Buck, 2001: 134-148). Unfortunately, any test of listening comprehension involves language skills other than listening comprehension as such. Consequently, combining various response formats helps obtain more representative results.

Three sets of items were developed for the experiment:

- 11 open-ended questions that required a short answer without a specified word limit;

- 16 multiple choice questions that consisted of a stem, a correct option and two distractors;

- 14 statements that participants had to evaluate as 'true' or 'false' or 'I don't know'.

Open-ended and multiple choice questions did not contain any proper names and did not require the knowledge of proper names to be answered correctly. The statements were designed to test comprehension of ideas directly related to proper names and could not be evaluated correctly unless the listener understood the names themselves, i.e. what the names referred to in the story (see Appendix H, I and J).

Open-ended questions were written to cover the whole text but 'give away' as little content as possible. They were not piloted.

Multiple choice questions consisted of two kinds, direct and indirect. They were pre-tested with four L1 English speakers to get rid of poor items and fine-tune the wording. The answers to direct questions $(1-4,6-8,14)$ were explicitly stated in the text; indirect questions involved either paraphrase or inference $(5,9-13,15-16)$. Including indirect questions was an attempt to accommodate the view that 'questions classified according to different levels of cognitive processing yield different levels of performance' (Shohamy and Inbar, 1991: 25) as well as Kameenui, Carnine and Freschi's finding that the effect of pretaught unfamiliar vocabulary on comprehension manifests itself only on inferential as opposed to literal questions (1982: 378-9). 
However, given the absence of low-frequency vocabulary and the highly factual text, the difference between direct and paraphrase questions was not large, and very few inference items were possible.

Open-ended and multiple choice questions were to be answered in writing. In contrast, the main consideration in testing proper names related comprehension was to avoid revealing the graphic form of the names to the participants. The true-false-don't know format was chosen mainly because it was the only format suitable for oral presentation. The statements were piloted with the same four native English speakers.

It is not recommended to base more than one comprehension question on the same unit of input information (Buck, 2001: 138). Although open-ended and multiple choice items often tapped the same content in the passage, it is extremely unlikely that this could have confused the learners. Firstly, the two sets of questions were presented as distinctly different activities separated from each other by another task (see 6.3.2.3 below). Secondly, open-ended questions that involve both retrieval and production are proven to be harder than recognition-based multiple choice items (Shohamy, 1984; Berne, 1993). Since open-ended questions preceded multiple choice ones, it is safe to assume that the two sets did not interfere.

\subsubsection{Difficulty ratings and PNT}

\subsection{Difficulty ratings}

The presence of unfamiliar proper names was not expected to have a strong effect on comprehension; after all, proper names make up only a small proportion of the text (see section 4.2 above for figures from language corpora, the experimental text in this study contained $12 \%$ of proper name tokens or $11 \%$ of proper name types). Difficulty ratings were used to determine if unfamiliar proper names would make the text seem harder for the listeners to understand. Participants were asked to indicate on a 7-point scale (i) how much of the text content they understood; and how difficult it was for them: (ii) to retell the story; (iii) to answer multiple choice questions; (iv) to evaluate the true-false-don't know statements; and (v) to do the computerized proper names test. These ratings were not a comprehension measure as such but were aimed to establish whether the learners perceived the experimental tasks as harder to do when unfamiliar proper names were present (see Appendix K). 


\subsection{Computerized proper names test (PNT)}

The computerized proper names test (PNT) was designed to determine how well the students could process the proper names themselves as opposed to the content of the story. The test consisted of 10 sections corresponding to the 10 proper name types found in the experimental listening passage. The PNT was programmed as a Java application. Each section was linked to an audio file containing the relevant proper name, which automatically played once at the beginning of the section. Later throughout the section, participants had an option of repeating the sound file as many times as they wished by clicking on the 'Play audio clip' button that appeared alongside each question. The audio files were created by cutting out the portions of the original recording of the story, so the proper names sounded exactly the same as in the listening passage. Only one question at a time was displayed on the screen. The paper version of the test was piloted with two fellow $\mathrm{PhD}$ students as well as three English Proficiency Programme students. It became clear that people tended to skip the open-ended questions and go straight to the easier multiple choice questions. Therefore in the electronic version the participants could not proceed to the next question until they answered the current one; nor were they able to go back to the previous questions and view or change their answers. In addition to the current question, the answer options and the 'Play audio clip' button, on the screen the participants could see the bars indicating the test progress, i.e. how many sections as well as how many questions in the current section had been completed.

Each section of the PNT comprised four questions. The structure and the order of the questions were the same in every section.

Questions 1-3 all aimed to establish whether the participant understood what the referent of a given proper name was but their degree of difficulty varied. Question 1 was the hardest because it required the participant to supply their own answer and thus tested the declarative knowledge of the proper name. The participant could choose only one out of three answers.

What does this name refer to?

a. This name refers to: (the participant was to type in the answer)

b. I'm not sure but maybe this name refers to: (the answer)

c. I don't know

Question 2 offered six options and the participant was required to tick as many as they considered correct. In reality, only one, two, or three options could be correct but the 
participants did not know there was a limit. All distractors were closely related to the relevant portion of the text as well as to the correct option/s.

(The participant hears: 'Nangatuo'). What does this name refer to? One or several answers may be correct!
a. geographical area
b. boyfriend
c. mountain in New Zealand
d. North Island boundary
e. region in New Zealand
f. New Zealand students

Question 3 was the easiest and provided only one correct option and two completely unrelated distractors.

(The participant hears: 'Nangatuo'). What does this name refer to?

Choose one answer only!
a. student group
b. geographical location
c. political party

Question 4 further clarified the depth of referent familiarity the participant was able to achieve during listening.

Can you describe this name in more detail?

a. Yes, I learnt this from the story: (the answer)

b. No, I don't remember any other information.

Thus questions 1 and 4 were identical in all sections while questions 2 and 3 contained different options depending on which proper name was tested. The full list of correct options and distractors for questions 2 and 3 can be found in Appendix S.

\subsection{Procedure}

\subsubsection{Piloting}

Fourteen Victoria University of Wellington English Proficiency Programme students took part in piloting, which was aimed at (i) working out a comfortable timeline for the experiment; and (ii) trialling the instruments. Participants were invited to individually attend two 1 hour long sessions at the researcher's office. At the first session the researcher pretaught all proper names from the listening passage. Then the participant listened to story A, did the comprehension test and the oral recall followed 
by the computerized proper names test. The second session was almost identical, except the participant did not receive names preteaching and listened to a different text (story B). The outcomes of the pilot study can be briefly summarized as follows:

1. Comparing comprehension scores between two stories was found unreliable because the difference in comprehension could be attributed to the different text topics and structure.

2. It was found that the recall task had to be done prior to comprehension questions otherwise the measures interfered with each other.

3. The preteaching procedure was modified to become longer and to include more practice carried out by the participants themselves rather than being entirely teacher-focused.

4. Out of 14 volunteers only 10 were able to attend both sessions; it was decided that the experiment had to be shorter to make it possible to complete it in one sitting.

\subsubsection{Main phase}

\subsubsection{Treatment groups}

The main experiment was carried out in a group setting in a room in which the necessary multimedia resources had been installed. Participants were randomly assigned to one of the treatment groups: Names Known or Names Unknown. After filling in consent forms, the Known group stayed with the researcher and received thorough preteaching of all proper names from the listening passage. Meanwhile, the Unknown group was taken by an assistant to a different classroom where the students had afternoon tea and an informal chat. Thus the Known group became familiar with the proper names prior to listening whereas the Unknown group heard the names for the very first time while they listened.

\subsubsection{Preteaching}

The goal of the preteaching was to familiarize the Names Known group with the form (both receptive and productive) and the referents of the proper names. However, the researcher was careful not to reveal what role the referents played in the story. For example, the participants learnt that Rati was a girl's name and that Milton was a city name but they were not told that Rati lived and studied in Milton. The 30 minute long 
preteaching was accompanied by a PowerPoint presentation and carried out in the following manner:

1. Participants repeated proper names (displayed on the screen) after the researcher.

2. The participants silently read a list of proper names with explanations (descriptions of what the names refer to), while the researcher was handing out practice packs. The packs consisted of ten $9 \mathrm{~cm} \times 2 \mathrm{~cm}$ cards showing a proper name on one side and the corresponding brief description of its referent on the reverse side as well as ten $21 \mathrm{~cm} \times 13 \mathrm{~cm}$ laminated pictures featuring the referents of the proper names. Each picture had a $10 \mathrm{~cm} \times 7 \mathrm{~cm}$ clear pocket attached at the back. Throughout preteaching the researcher recycled the descriptions of the referents but never gave out any more information other than that on the cards (see Appendix T). Each participant received an individual practice pack.

3. The participants arranged the pictures on their desk and had one minute to match the cards, description side up, with the pictures. After they finished the researcher showed the correct answers on the screen.

4. The participants removed the cards from the pictures and put them in a pack. Then the participants had two minutes to match the cards with the pictures again, this time name side up. They could peek at the description if they did not remember what the name referred to but were encouraged to try and remember without looking first. The participants were also encouraged to say the name out aloud while putting the corresponding card on the picture. After they finished the researcher showed the correct answers on the screen.

5. The participants gathered the name cards in a pack again. Then they studied the cards for three minutes. The students were told to look at the description side and try to remember the name and say it out aloud. If they could not remember they were encouraged to look at the corresponding picture first to see if that would help them to retrieve the name. If they still did not remember they could peek at the name side of the card.

6. The participants put the cards aside and took a mini test of the receptive proper names knowledge. The researcher would say a name out aloud, and the participants were asked to point to the corresponding picture in front of them. Then the researcher would hold up the relevant picture so that the students could check if their answer was correct. 
7. The researcher spoke for approximately five minutes explaining how to group the proper names so that they are easier to remember and illustrating everything with diagrams and pictures on the screen (e.g. 'There are three personal names, the female names both start with ' $R$ '. All the place names refer to places in the UK, except one, which refers to a place in New Zealand' etc).

8. By this stage the vast majority of the participants already knew most of the proper names. The students were asked to study the cards (description -> name) one last time. While going through the cards, if they thought that they knew the name they were told to put the card into the clear pocket at the back of the corresponding picture, name side up. Then the participants were to focus on the remaining names that they had not yet memorized. They continued until they were confident putting all the cards in the clear pockets.

9. The researcher showed all ten pictures on the screen and named them aloud. The participants shuffled their pictures and tested each other working in pairs: student A would hold a picture up and student B would name it; after all ten pictures were named, the students shuffled the pictures again and changed over.

10. The participants put the pictures aside and did the final mini test of the productive proper names knowledge. The researcher would show a picture on the screen and the participants would name it out aloud (in unison).

\subsubsection{Listening and comprehension testing}

After preteaching the two treatment groups came together (the assistant brought the Names Unknown group back). The researcher presented a brief plan of the activities to follow.

\begin{tabular}{|l|l|}
\hline First 10 participants & $\begin{array}{l}\text { The remaining } 40 \\
\text { (majority of participants) }\end{array}$ \\
\hline Listen & Listen \\
\hline Plan $\rightarrow$ retell & Listen 2 \\
\hline Multiple choice questions & Open-ended questions \\
\hline Listen 2 & Plan $\rightarrow$ retell \\
\hline True-false-don't know statements & Multiple choice questions \\
\hline PNT & Listen 3 \\
\hline Difficulty ratings & True-false-don't know statements \\
\hline & PNT \\
\hline & Difficulty ratings \\
\hline
\end{tabular}


The first 10 participants listened to the Murder story once, had some planning time, did their retelling, and then completed the rest of the experiment. All subsequent participants listened to the story twice, then answered open-ended questions, then had some planning time, did their retelling, and then completed the rest of the experiment. A second go at listening and open-ended questions was added to elicit more output because the L2 recall task proved to be too challenging, and the majority of the first 10 participants produced only 2 to 3 sentence retells.

Listening and retelling were carried out via the Soloist software. At first the participants listened to the sound check file to make sure that the equipment was working properly, to get used to the speaker's voice and to adjust the volume to a comfortable level. Immediately after that, they listened to the experimental text. All instructions were given orally in English: 'You will hear a short news story. Try to understand as much as you can. Pay attention to the main ideas. If you do not understand everything, it is OK. Don't panic, just keep listening and try to understand. You will hear the story only once [the first 10 participants] / two times [the rest of the participants]. After you listen you will be asked to retell the story'.

After listening, participants received a recall sheet [the first 10] or open-ended questions and the recall sheet a few minutes later [the rest]: 'Now you have five minutes to remember the story. Write notes or a short plan or a full summary anything that will help you to retell the story. Grammar and spelling are not important. Focus on the meaning and try to remember as many main ideas and details as you can'. The researcher used the 'flexible duration' tactic, i.e. although she gave the students the impression that there was a time limit (to set the pace), she did not stop the task until the vast majority of people finished. Everybody began retelling at the same time after the prompt: 'Speak to the microphone and retell the story. Imagine that you have a friend who did not hear the news. You need to tell your friend what happened. You can read from your notes but you can also change or add anything you want. Try to remember and say as much as you can. When you finish, please take off your headphones and quietly wait for others to finish'. After everybody finished, the participants' recordings were saved as mp3 files.

Then the participants answered multiple choice questions. Following that, they listened to the Murder story again [the second time for the first 10 students, the third time for the rest]: 'You will hear the same news story one more time. Try to understand as much as you can. Pay attention to details - times, places, who went 
where, and things like that. After you listen you will need to answer some more comprehension questions'. Then the participants received the true-false-don't know answer sheet, and evaluated proper names related statements that the researcher delivered orally. Each statement was pronounced clearly and slowly, and repeated twice.

Following comprehension questions, the participants were asked to do the computerized proper names test (PNT, see 6.2.2.3.2). In the last few minutes of the experiment the participants filled in the language learning and personal background questionnaire as well as the difficulty ratings of the experimental tasks.

\subsection{Participants}

The experimental procedure was repeated several times, with different numbers of students participating in each of the six 1.5 hour long sessions (March-May 2007). People from different classes could come to the same session. Unfortunately, this meant that it was unrealistic to match proficiency levels between the two treatment groups on the spot. 20 volunteers were recruited from 6 EPP* $^{*}$ classes, 25 volunteers from 3 ELTO $^{* *}$ classes, and 5 from the Bachelor of Education TESOL exchange programme. In total, 50 students took part - 25 in the Names Known treatment and 25 in the Names Unknown treatment. The age of the participants was between 18-49, with an average of 28 years old. Sixteen of them were male, thirty four female. Fifteen L1 backgrounds were represented in the sample: Chinese - 10 participants; Spanish - 10 participants; Vietnamese - 6 participants; Korean and Lao - 4 participants each; Khmer and Malay - 3 participants each; Japanese and Thai - 2 participants each; German, French, Mongolian, Indonesian, Tokelauan and Persian 1 participant each.

\subsection{Results}

\subsubsection{Recall protocols}

Participants' recordings were transcribed and coded by the researcher. The coding was a considerably simplified version of the system first developed by Johnson (1970) whereby each idea unit in a text is assigned a weighting of 1-4 based on its

\footnotetext{
${ }^{*}$ English Proficiency Programme, Victoria University of Wellington

*** English Language Training for Officials, programme sponsored by NZ Aid, administered by

VicLink, Victoria University of Wellington
} 
importance to the content of the text as a whole. Three changes to Johnson's procedure were made: (1) A category label rather than a weighting was assigned to each idea unit since the researcher was more interested in the qualitative difference in the retells between the treatment groups rather than in obtaining the finite score for each participant. (2) Labels were assigned only to those idea units that were found in the retells and not in the original text. This was done to save time because a lot of the original idea units never appeared in the recall protocols. (3) Since the text was very short it was decided to distinguish only main ideas and details as opposed to the first most important $25 \%$ of the idea units, the second $25 \%$ etc. as proposed by Johnson.

Table 6.1. Idea units found in recalls (excluding proper names).

\begin{tabular}{|l|l|}
\hline Idea units found in recalls & Label \\
\hline Mention of age (either the girl's or the man's or both) & detail \\
\hline The girl was killed/murdered & main idea \\
\hline Mention that they were students (the girl or the man or both) & detail \\
\hline They were boyfriend and girlfriend & main idea \\
\hline The man was charged (in court) & main idea \\
\hline They last saw each other (at the railway station) & detail \\
\hline It was in April & detail \\
\hline The man was arrested & main idea \\
\hline The police questioned the man & detail \\
\hline He was questioned a lot (or for a long time) & detail \\
\hline The man will go to court & detail \\
\hline It will happen in May & detail \\
\hline The police say this case is unusual & detail \\
\hline The police don't know all the facts & detail \\
\hline The girl's body was found & main idea \\
\hline It was found in her flat & detail \\
\hline The girl lived (/shared the flat) with 3 others & detail \\
\hline The girl's mother (says) & detail \\
\hline The man asked the girl to marry him & main idea \\
\hline The girl said she wasn't ready & main idea \\
\hline
\end{tabular}

Proper names were not counted as details but separately on their own. The final coding template consisted of six categories:

1. PNgood, the number of proper names used correctly (i.e. in reference to an appropriate entity, such as a city name used to refer to a city; minor pronunciation errors were disregarded as long as it was clear what proper name the participant intended to say). Example: Raiti and Jasse met at Loottingrey.

2. PNbad, the number of proper names used incorrectly (i.e. in reference to an inappropriate entity, such as a city name used to refer to a region; or in cases 
where the name was so distorted that it was unclear what the participant intended to say). Examples: He was arrested by the police of Loottingrey Valley. Toh [=Nangatuo?] student thought this. [It is unclear if Toh refers to the person or the region].

3. MIgood, the number of correct main ideas present in the retelling, e.g. A girl student was murdered.

4. DEgood, the number of correct details present in the retelling, e.g. Now the boy is going to be in a court.

5. INFgood, the number of correct inferences in the retelling, i.e. propositions not present in the text itself but reasonable given the content of the text. Examples: Her mother Rean is sad. So the police think this is motive for the boy killed the girl.

6. INFbad, the number of incorrect inferences in the retelling. Two kinds of incorrect inferences were found but they were combined into one category. For most of the wrong inferences, the source sentence was easily identifiable. Examples: In the end Rati's mother Rean said that they can get married with each other. She [the girl] asked him to get married and he refused. Rean, Rati's mother, isn't ready to make comments yet. (Source text: Rati's mother Rean says Tanner had asked her daughter to marry him but she told him that she wasn't ready). There were also few cases where it was not clear what part of the text had triggered the incorrect inference. Examples: Rati had some problems of her car in there. This story talk of murder, may be it's on Monday.

No inter-rater checks were performed, however, to ensure consistency, the researcher repeated the coding three times (two weeks apart from each other), first without looking at their previous work and then comparing the new figures with the old. A few discrepancies were noted and resolved either by careful reconsideration or discussion with colleagues. The results by treatment group are presented in tables 6.2, 6.3 and 6.4 .

The overall length of story reconstructions produced by the students did not differ between the treatment groups. The Names Known retells ranged from 17 to 154 words long, the Names Unknown - from 12 to 133 words, with an average of around 66 words per retell in both treatments. 
Table 6.2. Average per participant frequencies of different idea unit types found in recalls by treatment group.

\begin{tabular}{|l|l|l|}
\hline Type of idea units & $\begin{array}{l}\text { Names Known } \\
\text { Group (N=25) }\end{array}$ & $\begin{array}{l}\text { Names Unknown } \\
\text { Group (N=25) }\end{array}$ \\
\hline PNgood (out of 10) & 4.84 & 0.64 \\
\hline PNbad & 0.36 & 0.08 \\
\hline MIgood (out of 7) & 3.00 & 2.92 \\
\hline DEgood (out of 18) & 3.64 & 3.28 \\
\hline INFgood & 0.72 & 0.56 \\
\hline INFbad & 0.92 & 1.44 \\
\hline PNgood + DEgood & 8.48 & 3.92 \\
\hline Running words & 66.84 & 66.28 \\
\hline
\end{tabular}

Table 6.3. Raw frequencies and percentage of correct idea units in recalls by treatment group with proper names included in the count (as idea units in their own right).

\begin{tabular}{|l|l|l|}
\hline & $\begin{array}{l}\text { Names Known } \\
\text { (all participants) }\end{array}$ & $\begin{array}{l}\text { Names Unknown } \\
\text { (all participants) }\end{array}$ \\
\hline $\begin{array}{l}\text { Correct idea units: } \\
\text { Cincl }_{\text {PNgood+MIgood+DEgood+INFgood }}\end{array}$ & 305 & 185 \\
\hline $\begin{array}{l}\text { Total idea units: } \mathrm{T}_{\text {incl }}=\text { PNgood+PNbad } \\
+ \text { MIgood+DEgood+INFgood+INFbad }\end{array}$ & 337 & 223 \\
\hline $\begin{array}{l}\text { Proportion of correct idea units: } \\
\mathrm{C}_{\text {incl }} / \mathrm{T}_{\text {incl }} \text { *100 }\end{array}$ & $91 \%$ & $83 \%$ \\
\hline Confidence interval & $87-93 \%$ & $78-87 \%$ \\
\hline
\end{tabular}

Table 6.4. Raw frequencies and percentage of correct idea units in recalls by treatment group with proper names excluded from the count.

\begin{tabular}{|l|l|l|}
\hline & $\begin{array}{l}\text { Names Known } \\
\text { (all participants) }\end{array}$ & $\begin{array}{l}\text { Names Unknown } \\
\text { (all participants) }\end{array}$ \\
\hline $\begin{array}{l}\text { Correct idea units: } \\
\mathrm{C}_{\text {excl }}=\text { MIgood+DEgood+INFgood }\end{array}$ & 184 & 169 \\
\hline $\begin{array}{l}\text { Total idea units: } \\
\mathrm{T}_{\text {excl }}=\text { MIgood+DEgood+INFgood+INFbad }\end{array}$ & 207 & 205 \\
\hline $\begin{array}{l}\text { Proportion of correct idea units: } \\
\mathrm{C}_{\text {excl }} / \mathrm{T}_{\text {excl }} \text { *100 }\end{array}$ & $89 \%$ & $82 \%$ \\
\hline Confidence interval & $84-93 \%$ & $77-87 \%$ \\
\hline
\end{tabular}

The Names Known group made good use of proper names; on average, 5 correct names per recall were present, with some participants producing as many as 7-9. The Names Unknown group hardly used proper names in their recalls. The inability to produce the unfamiliar names seemed to be an inconvenience for these participants. They appeared to feel the need to refer to specific people and places but 
did not have the means to do so: Someone killed somebody. Someone is about twenty years old, and another one is [...]. And... another guy, I don't remember that guy's name but another guy is also kill another person. Her body was founded in somewhere outside somewhere and he [...].

Some students resorted to using the names they already knew to substitute for the unfamiliar ones they could not catch from the story, e.g. Milton University was labelled Nelson University, and Otago University, and Rati was referred to as Mary, Rita, Niranga and even Sarah. Here are more examples of the same nature: Milton [city] -> Nelson, Melbourne; Milton University -> Marsden University, Argyle St -> Ngaio St; Nangatuo -> Wanganui; Rati Maclean -> Rita Madeleine. This suggests that recognition mechanisms for proper names and common vocabulary are probably similar, i.e. L2 listeners are constantly matching the new input against the familiar word forms already stored in their mental lexicon.

The numbers of main ideas and correct inferences participants produced were similar in both treatments with the Names Known group only ever so slightly outperforming the Names Unknown group, which shows that both groups successfully grasped the gist of the story.

The Names Known group recalled more details than the Names Unknown group. The difference is small but this finding is interesting considering that one could have legitimately counted correctly recalled proper names as additional details. When PNgood and DEgood categories are combined, the difference becomes much more conspicuous.

The Names Known group made fewer incorrect inferences. Again the difference is small, however, it suggests that the listeners who were familiar with the names could form a more precise understanding of the text. On the other hand, their peers who did not know the names had more trouble grasping the details and were forced to compensate for that by inventing the non-existent ones. This is corroborated by the fact that the Names Unknown group seemed to be less confident while retelling: I'm not sure if it's the girl or the [?] is murder. May be this is name or... $\underline{I}$ don't know. And perhaps that is the motivation of murder, I think. Although all students hesitated and made a lot of pauses, only the participants in the Names Unknown group directly expressed uncertainty in what they were saying as illustrated in the examples above. As shown in tables 6.3 and 6.4, a consistently higher 
percentage of correct idea units is observed in the Names Known condition regardless of whether proper names are included or excluded from the count.

Summing up, no differences between the two treatments were found as far as comprehension of main ideas is concerned. Both groups of students were able to follow the general content of the story. On the other hand, lack of proper names knowledge affected comprehension of details detrimentally. The Names Known group was able to recall more details and made fewer incorrect inferences than the Names Unknown group. The percentage of correct idea units in the recalls was higher when students were familiar with the proper names. The observed differences between the two treatments were modest.

The findings should be interpreted cautiously. One of the serious shortcomings of the data gathering method was that students had to recall the story in English (L2). Firstly, it could be that they understood much more than their production skills allowed them to express. Secondly, using L1 could have revealed either smaller or bigger differences between the treatment groups. There is definitely enough evidence to suggest that unfamiliar proper names place high demands on L2 listeners' cognitive resources. With only limited processing time available, participants in the Names Unknown group focused on the more important information and were unable to simultaneously pay attention to proper names as well as expendable, subsidiary details.

\subsubsection{Open-ended questions}

Data from open-ended questions was analysed as follows. First, responses to the first question given by all participants were typed up. Then the researcher compared the responses and gave each one a rating from 0-3: incorrect answer/no answer $=0$; correct imprecise answer $=1$; more precise partial answer $=2$; precise full answer $=3$. Then the same procedure was repeated with the rest of the questions. Two weeks later the researcher rerated the answers without looking at her previous work and then compared the two ratings. They were identical. A week later the researcher rerated the answers one more time to ensure consistency. Again no discrepancies were found. After that, the researcher entered the ratings of all the answers for each participant, and summed them to obtain the participants' overall scores. Examples of how the rating was done can be found in table 6.5 . 
Forty participants answered open-ended questions. Results are presented in table 6.6. For individual scores see Appendix L.

Participants' scores in the Names Known condition were higher. The difference between the groups did not approach statistical significance but there was a trend in the expected direction (Mann Whitney U, 2-tailed, $\mathrm{p}=0.155$ ). This should be interpreted with caution since the sample size was small.

Table 6.5. Examples of how the answers to open-ended questions were scored.

\begin{tabular}{|l|l|}
\hline Question 7. What does the police & Question 9. Who lived in the student flat? \\
think about this case? & Rati/girl and 3 flatmates = 3 \\
It is unusual/it is strange = 3 & Rati (Maclean) and flatmates = 2 \\
It is rare $=2$ & Rati (Maclean) $=1$ \\
It's interesting/they need to know & three of Rati's friends $=1$ \\
all the facts $=1$ & the boy/Jase $=0$ \\
It is usual/not uncommon/hard $=0$ & \\
\hline
\end{tabular}

Table 6.6. Mean scores on open-ended questions (out of 33) by treatment group.

\begin{tabular}{|c|c|c|c|c|c|c|}
\hline group & Mean & $\mathrm{N}$ & $\begin{array}{c}\text { Std. } \\
\text { Deviation }\end{array}$ & Median & Minimum & Maximum \\
\hline Names Knc & 17.47 & 19 & 8.1 & $\overline{14}$ & 6 & 30 \\
\hline Names Unknown & 13.9 & 21 & 8.3 & 14 & 0 & 27 \\
\hline
\end{tabular}

\subsubsection{Multiple choice questions}

All fifty participants answered multiple choice questions. Results are presented in tables 6.7 and 6.8. For individual scores see Appendix M.

Table 6.7. Mean scores on multiple choice questions (out of 16) by treatment group.

\begin{tabular}{|l|c|c|c|r|r|r|}
\hline group & Mean & N & $\begin{array}{c}\text { Std. } \\
\text { Deviation }\end{array}$ & Median & Minimum & Maximum \\
\hline Names Known & 10.76 & 25 & 2.728 & 11 & 5 & 15 \\
Names Unknown & 10.52 & 25 & 2.874 & 11 & 5 & 15 \\
\hline
\end{tabular}

Table 6.8. Mean scores on direct and indirect multiple choice questions by treatment group.

\begin{tabular}{|l|l|l|l|}
\hline \multicolumn{2}{|l|}{$\begin{array}{l}\text { Direct multiple choice } \\
\text { questions (8 in total) }\end{array}$} & \multicolumn{2}{l|}{$\begin{array}{l}\text { Indirect multiple choice } \\
\text { questions (8 in total) }\end{array}$} \\
\hline Names Known & Names Unknown & Names Known & Names Unknown \\
\hline Mean=5.64 & Mean=5.4 & Mean=5.12 & Mean=5.12 \\
\hline $\mathrm{SD}=1.5$ & $\mathrm{SD}=1.7$ & $\mathrm{SD}=1.7$ & $\mathrm{SD}=1.9$ \\
\hline
\end{tabular}

The difference between the treatment groups was not statistically significant. The means for indirect and direct questions did not differ significantly between the 
treatment groups either. This result was not surprising considering that multiple choice questions were written in such a way that they did not require any knowledge of proper names to be answered correctly.

\subsubsection{Proper names related statements (true-false-don't know)}

All fifty participants evaluated the proper names related (true-false-don't know) statements. Results are in table 6.9. For individual scores see Appendix N.

Table 6.9. Mean scores on true-false-don't know statements (out of 14) by treatment group.

\begin{tabular}{|l|r|l|r|r|r|r|}
\hline Group & Mean & N & $\begin{array}{c}\text { Std. } \\
\text { Deviation }\end{array}$ & Median & Minimum & Maximum \\
\hline Names Known & 9.68 & 25 & 1.819 & 10 & 7 & 13 \\
Names Unknown & 6.08 & 25 & 2.379 & 6 & 1 & 10 \\
\hline
\end{tabular}

Participants in the Names Known group performed better and were able to evaluate the statements a lot more accurately than the Names Unknown group. The mean score per participant differed significantly under the Names Known and Names Unknown conditions (Mann Whitney U, p<0.000).

Ranks

\begin{tabular}{|l|r|r|r|}
\hline Group & \multicolumn{1}{|c|}{ N } & Mean Rank & Sum of Ranks \\
\hline Names Known & 25 & 35.12 & 878 \\
Names Unknown & 25 & 15.88 & 397 \\
\hline
\end{tabular}

This finding confirms that intermediate to advanced ESL learners cannot always pick up idea units associated with unfamiliar proper names on the spot while listening. Even after 2-3 attempts at listening, participants in the Names Unknown treatment were not able to establish connections between several proper names encountered in the story and their respective referents as successfully as people in the Names Known group. Names related idea units may not be crucial for reasonable overall comprehension, however neither they are something that ESL listeners get hold of automatically or effortlessly.

The strength of association test showed that $45 \%$ of the variance in scores can be attributed to treatment group, i.e. familiarity or lack of familiarity with proper names $\left(\eta^{2}=0.4502\right)$. This is considered a high strength of association although there is still $55 \%$ of variance to be accounted for by other factors. I discuss this issue in the next section. 


\subsubsection{Proficiency comparison}

Comprehension of connected speech is affected by a number of factors, which could be roughly divided into two categories, namely text-based and listener-based. Textbased factors include text genre and length (Shohamy and Inbar, 1991; Freedle and Kostin, 1999), complexity of its syntactic structure (Blau, 1982; Buck 2001: 150), amount of low-frequency or other unfamiliar vocabulary, acoustic qualities of the recording or the speaker's voice (Whitson, 1972, cited in Kelly, 1991; AndersonHsieh and Koehler, 1988; Blau, 1990; Griffiths, 1992) and so on. Listener-based factors include but are not limited to background knowledge of the subject (Long, 1990; Schmitt-Rinehart, 1994), affective state (Elkhafaifi, 2005; Matsuura, 2007), general language proficiency level (Hirai, 1999), and, in particular, listening ability (Chiang and Dunkel, 1992). While text-based factors in the present study were controlled, listener-based factors were not.

Overall language proficiency is arguably the most important listener-based factor affecting comprehension. Unfortunately, neither general nor listening proficiency was directly measured during the experiment. It was decided to make a rough estimate concerning proficiency on the basis of all information about the participants that the researcher could gain access to.

The proficiency variable was operationalized as follows:

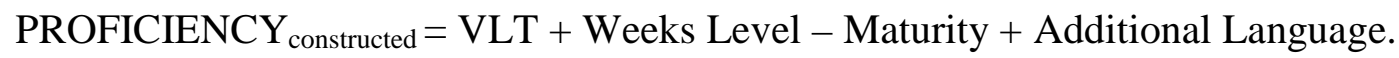

VLT is the total score each participant achieved on their placement Vocabulary Levels Test. Making a judgement concerning proficiency based on a single vocabulary test cannot be considered reliable but, unfortunately, this was the only common denominator and point of comparison for participants from different classes. Students took the VLT prior to the commencement of their respective VUW courses; the VLT scores were obtained from their teachers (with the students' consent).

Weeks Level is an artificial variable based on the number of weeks each participant spent in New Zealand prior to the experiment (as indicated in the personal background questionnaire). The values were assigned as follows: $0=8$ weeks or less in New Zealand, 3 = 9-20 weeks in New Zealand, 6 = over 20 weeks in New Zealand. The decision to assign values in this manner was arbitrary but the rationale was that the longer a participant had been in an English speaking country the better their English was likely to be. 
Maturity is an artificial variable based on the participants' age (as indicated in the personal background questionnaire) and the idea that younger students could be learning English slightly faster than mature students. Values were assigned as follows: $0=$ below 30 years old, $2=30$ or older.

Additional Language is a variable based on whether participants could speak other languages in addition to English and their native language (as indicated in the personal background questionnaire): $0=$ no additional language $/ \mathrm{s}, 2=$ speaks additional language/s. The rationale was that knowing additional language/s might increase one's proficiency in English.

After proficiency scores were calculated as described above, they were compared between the Names Known group and the Names Unknown group by means of the Mann Whitney $U$ test. No statistically significant difference in proficiency was found between the treatment groups (2-tailed, $\mathrm{p}=0.778$ ).

\subsubsection{PNT results}

The PNT tested comprehension of the proper names themselves as opposed to the content of the experimental text. It consisted of ten sections, one for each proper name found in the story, and asked the following questions about each proper name: (1) open-ended 'what does this name refer to?'; (2) multiple choice 'tick all options that apply'; (3) multiple choice 'one correct option'; and lastly (4) 'can you add any more details?' (for details, see 6.2.2.3.2). All saved PNT files were processed manually. The researcher carefully read through the answers and recorded the following scores for each participant:

PntOEgood - the number of open-ended PNT questions answered correctly.

PntOEbad - the number of open-ended PNT questions answered incorrectly.

PntOEzero - the number of open-ended PNT questions the participant could not answer (i.e. chose to click 'I don't know'). There were ten open-ended questions (one for each proper name), so PntOEgood + PntOEbad + PntOEzero $=10$

Multiple choice 'tick all that apply' questions provided six options, with the number of correct options ranging from one to three (and the participants did not know how many were correct). In total, there were 18 correct options and 42 incorrect options in all ten questions of this kind.

PntMCgood - the number of correct options ticked (out of 18).

PntMCbad - the number of incorrect options ticked (out of 42). 
PntMCmissed - the number of correct options the participant missed,

PntMCmissed $=18-$ PntMCgood .

PNToneoption - the number of correctly answered multiple choice 'one correct option' questions (out of 10).

PntDEgood - the number of correctly answered 'can you provide more details?' questions.

PntDEbad - the number of incorrectly answered 'can you provide more details?' questions.

PntDEnoinfo - the number of 'can you provide more details?' questions the participant could not answer (i.e. chose to click 'I don't remember any other information'). PntDEgood + PntDEbad + PntDEnoinfo $=10$

Table 6.11. Mean PNT scores by treatment group.

\begin{tabular}{|l|l|l|}
\hline Type of PNT score & $\begin{array}{l}\text { Mean, } \\
\text { Names Known }\end{array}$ & $\begin{array}{l}\text { Mean, } \\
\text { Names Unknown }\end{array}$ \\
\hline PntOEgood (out of 10) & 7.32 & 3.16 \\
\hline PntOEbad & 1.24 & 2.68 \\
\hline PntOEzero & 1.44 & 4.16 \\
\hline PntMCgood (out of 18) & 12.52 & 6.8 \\
\hline PntMCbad (out of 42) & 2.36 & 6.4 \\
\hline PntMCmissed (out of 18) & 5.48 & 11.2 \\
\hline PNToneoption (out of 10) & 9.72 & 8.52 \\
\hline PntDEgood (out of 10) & 4.88 & 1.6 \\
\hline PntDEbad & 0.56 & 1.32 \\
\hline PntDEzero & 4.56 & 7.08 \\
\hline
\end{tabular}

Table 6.11 shows that the Names Unknown group performed considerably worse than the Names Known group on all types of PNT questions. The largest differences were observed for open-ended and multiple choice 'tick all that apply' questions. The latter finding is particularly noteworthy. While an ability to answer open-ended questions only reflects declarative knowledge of proper names, which may not be necessary for successful comprehension, multiple choice 'tick all that apply' questions specifically target receptive knowledge. Difficulty in answering this latter type of question indicates that the Names Unknown group was indeed not able to determine what unfamiliar names refer to, as opposed to knowing but not being able to demonstrate their knowledge.

All types of participants' PNT responses can be reduced to three main kinds, namely correct answers, incorrect answers and 'missed opportunities'. The latter 
consists of missed correct options in 'tick all that apply' questions as well as those open-ended and 'can you provide more details?' questions in the PNT that the participant chose not to answer. Perhaps, it would be justified to simply count 'missed opportunities' as incorrect answers, however a more lenient policy was adopted. I treated them separately on the grounds that saying 'I don't know' or 'I don't remember', while showing lack of confidence, still does not quite amount to giving the wrong answer.

The overall number of correct answers across all types of PNT questions was calculated for each participant: PNTgood $=$ PntOEgood + PntMCgood + PNToneoption + PntDEgood. Comparison of the resulting scores between the Names Known group and the Names Unknown group revealed a highly significant difference (Mann Whitney U, p<0.000).

Ranks

\begin{tabular}{|l|l|r|r|}
\hline Group & N & Mean Rank & Sum of Ranks \\
\hline Names Known & 25 & 36.22 & 905.5 \\
Names Unknown & 25 & 14.78 & 369.5 \\
\hline
\end{tabular}

The Names Known group provided significantly more correct answers than the Names Unknown group.

Secondly, the overall number of 'missed opportunities' was calculated for each participant: PNTmissed $=$ PntOEzero + PntMCmissed + PntDEnoinfo. Again, upon comparison of the resulting scores between the Names Known and the Names Unknown treatments, a highly significant difference between the groups was found (Mann Whitney U, p<0.000).

\section{Ranks}

\begin{tabular}{|l|c|r|r|}
\hline Group & N & Mean Rank & Sum of Ranks \\
\hline Names Known & 25 & 14.58 & 364.5 \\
Names Unknown & 25 & 36.42 & 910.5 \\
\hline
\end{tabular}

The Names Unknown group missed significantly more correct options (in 'tick all that apply' questions) and opportunities to give an answer (in open-ended and 'can you give any more details?' questions) compared to the Names Known group. A separate test was also performed with the number of missed correct options in 'tick all that apply' questions only as the dependent variable, and again, a highly significant difference between the groups was found (Mann Whitney U, 2-tailed, $\mathrm{p}<0.00$ ). 
The overall PNT results are visually summarized in figure 6.12 .

Figure 6.12. Correct answers, incorrect answers and 'missed opportunities'. Comparison of the treatment groups.

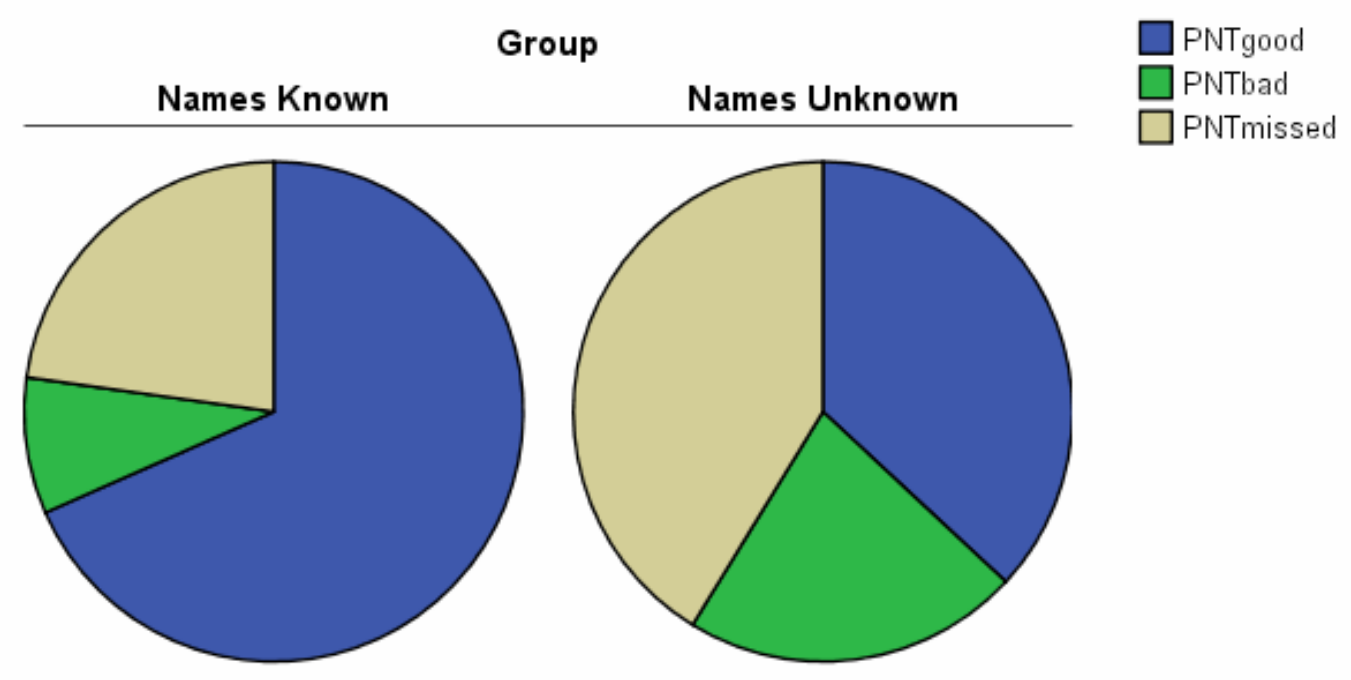

Note: PNTbad $=$ PntOEbad + PntMCbad + $(10-$ PNToneoption $)+$ PntDEbad

Let us now come back to the question of how much information about the referents of unfamiliar proper names, intermediate to advanced proficiency ESL listeners were able to derive from context. In the PNT, the maximum possible number of correct answers was 48. The mean number of correct answers the Names Unknown group supplied was 20.08. Therefore, on average, listeners in the Names Unknown treatment were able to extract $41.83 \%$ of information about the referents of unfamiliar proper names after listening to the experimental text at least 2 times, compared to $71.75 \%$ in the Names Known treatment (the mean number of correct answers 34.44).

These findings show that after 2-3 attempts at listening the participants in the Names Unknown group were not always able to determine what unfamiliar proper names refer to. Although they gained some information about proper names' referents from context, it was not nearly as much as the Names Known group had available.

\subsubsection{Difficulty ratings}

On the 7-point scale, ' 1 ' represented 'extremely difficult' and '7' represented 'very easy'. The higher the rating assigned by a participant to an experimental task, the easier they perceived that task to be. On the other hand, the lower ratings correspond to the tasks that were perceived as more difficult. 
Firstly, averages per participant for all types of ratings were calculated. Results are shown in table 6.13. For individual participant's ratings see Appendix P. Table 6.13. Average per participant difficulty ratings of experimental tasks (on a scale of 7) by treatment group.

\begin{tabular}{|l|l|l|l|}
\hline Rating type & $\begin{array}{l}\text { Names } \\
\text { Known, } \\
\text { Group }(\mathrm{N}=25)\end{array}$ & $\begin{array}{l}\text { Names } \\
\text { Unknown, } \\
\text { Group }(\mathrm{N}=25)\end{array}$ & $\begin{array}{l}\text { Difference } \\
\text { between } \\
\text { the groups }\end{array}$ \\
\hline $\begin{array}{l}\text { 1. Perceived amount of } \\
\text { comprehension }\left(\mathrm{DR}_{\text {compreh }}\right)\end{array}$ & 4.32 & 3.36 & 0.96 \\
\hline 2. Retelling task & 3.92 & 3.08 & 0.84 \\
\hline 3. Multiple choice questions & 4.56 & 3.96 & 0.6 \\
\hline 4. True-false-don't know & 4.48 & 2.76 & 1.72 \\
\hline 5. PNT & 4.96 & 3.2 & 1.76 \\
\hline $\begin{array}{l}\text { 6. Sum of all ratings }\left(\mathrm{DR}_{\text {total }}\right) \\
\text { (maximum 35) }\end{array}$ & 22.24 & 16.36 & 5.88 \\
\hline
\end{tabular}

All experimental tasks were rated as easier to do by the Names Known group and as harder to do by the Names Unknown group. As expected, the biggest difference in perceived task difficulty between the two treatment groups was observed for the PNT and proper names related statements (true-false-don't know), followed by the perceived amount of comprehension. The difference was less pronounced for the retelling task and multiple choice questions.

Secondly, all five types of ratings supplied by each participant were summed up. The resulting overall individual ratings $\left(\mathrm{DR}_{\text {total }}\right)$ were considered continuous data and compared between the treatment groups using the Mann Whitney U test. A highly significant difference between the Names Known group and the Names Unknown group was found $(\mathrm{p}<0.000)$.

\section{Ranks}

\begin{tabular}{|l|r|r|r|}
\hline Group & \multicolumn{1}{|c|}{ N } & Mean Rank & Sum of Ranks \\
\hline Names Known & 25 & 33.44 & 836 \\
Names Unknown & 25 & 17.56 & 439 \\
\hline
\end{tabular}

Thirdly, of particular interest was the $\mathrm{DR}_{\text {compreh }}$ rating, which reflected the participants' self-perceived success in comprehension (i.e. the amount of text understood). The rating of ' 1 ' corresponded to 'I understood nothing' while the rating of ' 7 ' corresponded to 'I understood everything'. Frequencies of particular responses, from ' 2 ' to ' 6 ', were tabulated across treatment groups (in this sample participants avoided ratings of ' 1 ' and ' 7 '). 


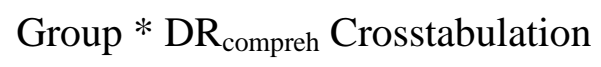

\begin{tabular}{|c|c|c|c|c|c|}
\hline \multirow[b]{2}{*}{ Group } & \multicolumn{5}{|c|}{$\mathrm{DR}_{\text {compreh }}$} \\
\hline & '2' & '3' & '4' & '5 & '6’' \\
\hline Names Known & 2 & 1 & 11 & 9 & 2 \\
\hline$\%$ Within Group & $8 \%$ & $4 \%$ & $44 \%$ & $36 \%$ & $8 \%$ \\
\hline Names Unknown Count & 6 & 8 & 7 & 4 & 0 \\
\hline$\%$ Within Group & $24 \%$ & $32 \%$ & $28 \%$ & $16 \%$ & $0 \%$ \\
\hline
\end{tabular}

The Names Known group tended to give responses at the higher end of the scale (i.e. reported understanding more of the story) while the Names Unknown group tended to give responses at the lower end of the scale (i.e. reported understanding less of the story). The chi-square test showed that there was a statistically significant association between the frequency of particular $\mathrm{DR}_{\text {compreh }}$ responses and treatment group (Fisher's exact test, 2-sided, $\mathrm{p}=0.013$ ).

To sum up, although difficulty ratings are likely to reflect students' selfperceptions of own English proficiency, their past personal experiences with various task formats etc., these findings clearly indicate that the presence of unfamiliar proper names made the experimental text and associated comprehension tasks seem harder to the participants in the Names Unknown group. This is indirect evidence that the presence of unfamiliar proper names indeed makes spoken input harder for ESL learners to handle.

\subsection{Summary of Experiment 2 findings}

The experiment showed that the presence of unfamiliar proper names hinders the intermediate to advanced proficiency learners' comprehension of a short news text as measured by the immediate free recall and the ability to evaluate proper names related statements. The effect is local; it concerns comprehension of details, particularly those details that are associated with processing the proper names themselves. The Names Unknown group produced fewer details and more incorrect inferences in their recalls and scored significantly lower on the measure of proper names related comprehension (true-false-don't know). They also perceived the experimental tasks as hard and selfreported a lower amount of comprehension. In contrast, the Names Known group produced more details and fewer incorrect inferences in their recalls and scored much higher on the measure of proper names related comprehension. They perceived the 
experimental tasks as easier to do and self-reported a higher amount of comprehension.

The results indicate that the Names Known group were able to form a more precise understanding of the passage content than the Names Unknown group. However, the ability to comprehend main ideas was unaffected; both treatment groups successfully grasped the gist of the story. No statistically significant differences on multiple choice or open-ended comprehension questions were found. For open-ended questions, there was a trend in the expected direction, but it is hard to interpret given the small sample size.

The PNT revealed that it is unrealistic to expect ESL learners to determine what unfamiliar proper names refer to from context. On average, after 2-3 attempts at listening participants in the Names Unknown group were able to extract only $\approx 42 \%$ of the information about the referents of unfamiliar proper names encountered in the experimental text.

\subsection{Discussion}

It has been firmly established in the literature that lexical knowledge is a crucial factor affecting both reading and listening comprehension (Stahl and Fairbanks, 1986; Taglieber, Johnson and Yarbrough, 1988; Kelly, 1991; Bonk, 2000; Burns, Dean and Foley, 2004). This study confirms that, similarly to common vocabulary, unfamiliar proper names influence the ESL learners' ability to understand connected speech. On the one hand, Experiment 2 may be subject to the same objection as Experiment 1: in real life listening, it is rare for all encountered proper names to be unknown to the listener therefore their overall impact on comprehension could be smaller. On the other hand, the effect might not have fully manifested itself in the present experiment due to (i) the shortcomings of the methodology; and (ii) the fact that comprehension was tested under much more favourable conditions than in real life.

Firstly, pretaught proper names cannot be equated with known. Although the preteaching was thorough, this one-off intervention could not have substituted for a gradual learning process whereby a new expression becomes solidly engrained in the learner's mental lexicon. In a meta-analysis of 52 studies, Stahl and Fairbanks found a strong correlation between the time allocated for new vocabulary instruction and the subsequent effect of this pretaught vocabulary on reading comprehension. They caution that 'words need to be learned thoroughly in order to contribute to passage 
comprehension' (1986: 101). In the present study, most participants assigned to the Names Known treatment did really well during preteaching. However, they still made mistakes in proper names usage in their retells (and in the PNT), which indicates that their recently acquired knowledge of the new proper names was still rather unstable.

Secondly, the between-participants design requires a careful match of treatment groups with regards to English proficiency, age, gender, length of stay in an English speaking environment and other variables. Due to time and privacy constraints it was not feasible to achieve a perfect match. Based on all the accessible information, the researcher assumed that the treatment groups were comparable, however several contaminating factors could not be avoided: (i) the participants came from different classes so the effects of previous instruction were not controlled; (ii) the students took part in the experiment at different times throughout their course but their VLT test was taken back at the beginning of the programme; and (iii) even if a vocabulary test is accepted as an indicator of general English proficiency (which, in itself, is rather problematic), general proficiency scores did not necessarily reflect the participants' listening ability. A prospective replication study in the future should better control for proficiency, and possibly include a general test of listening comprehension within the experimental procedure so that it can serve as a more reliable point of reference for between-groups comparisons.

Thirdly, the participants came from various L1 backgrounds, which precluded the use of L1 in the recall task. It would be desirable (i) to determine whether the findings can be replicated using L1 recalls; and (ii) rerun the experiment with other kinds of listening input altering the text genre and the fraction of unfamiliar proper names.

What could also have masked the effect of unfamiliar names in the present experiment, is the fact that comprehension was tested under the most favourable conditions: (i) the participants had 2-3 attempts at listening; (ii) the text was very short; (iii) the text was narrative rather than expository; (iv) apart from proper names, the text did not contain any low-frequency vocabulary; and (v) the test of proper names related comprehension came last in the sequence. Berne showed that 'additional exposure to the listening passage improves listening comprehension performance significantly, irrespective of pre-listening treat[e]ment' (1995: 316). Considering the participants' fairly high English proficiency, this gives grounds to claim that if the effect of unfamiliar proper names on comprehension is present even 
under such supportive conditions it can only be stronger in real life listening. An interesting follow-up would be to have a proper names related measure first (prior to other tasks) and determine if this changes the size of the effect.

Proper names cover only a small percentage of a given text so their impact on L2 listening comprehension is necessarily smaller than that of common expressions. Therefore it came as no surprise that the effect emerged only on some measures and not on others. Overall, the results of the present experiment parallel the earlier findings concerning common vocabulary.

Wixson investigated the effect of preteaching common words of central and non-central importance within a text on L1 reading comprehension. She found that 'preteaching unfamiliar vocabulary can have a direct effect on students' understanding of specific ideas within a text' (1986: 327), i.e. when the central words were pretaught the children in her experiment understood more ideas related to the central words and vice versa. When pretaught the non-central words, the children understood more ideas related to the non-central words. The effect reported in the present study is similarly local, i.e. 'concentrates' around the idea units associated with the pretaught (or not pretaught) proper names.

Wixson (1986) and Stahl and Fairbanks (1986) demonstrated that wordspecific measures designed to evaluate understanding of parts of the text directly related to the instructed vocabulary are more sensitive and produce larger effects than general comprehension measures that do not involve the pretaught words. Likewise, the proper names related comprehension measure in this study yielded a significant difference between the treatment groups. As for the general comprehension measures, they can be ranked from the hardest (L2 recall) through medium (open-ended questions) to the easiest (multiple choice questions). A notable difference was only observed on the more conservative (recall and open-ended questions) measures.

Kameenui, Carnine and Freschi found that preteaching unfamiliar common vocabulary enhanced comprehension but only as measured by inferential questions. In their study, the effect did not show on literal questions (1982: 379). This finding was not replicated for proper names in the present experiment: no effect was observed regardless of question type (open-ended, multiple choice indirect or multiple choice direct). Several explanations can be suggested for this difference in results. Firstly, neither open-ended nor multiple choice questions in this study required the knowledge of proper names to be answered correctly so the Names Unknown group 
was able to successfully compensate for the lack of such knowledge. Secondly, due to the factual nature of the text, the inferential questions were rather contrived, which made the difference between direct and indirect multiple choice questions not as tangible. Thirdly, it may be the case that the listening input was a little too easy for the participants' proficiency level. Assuming that inferential questions are more difficult than the literal ones, it can be argued that our results actually conform to a pattern similar to Kameenui, Carnine and Freschi's, namely that the effect of (be it common or proper) unfamiliar expressions on comprehension emerges only on the more conservative measures.

This experiment demonstrated that at least at the intermediate to advanced level of proficiency, the effect of unfamiliar proper names on L2 listening comprehension is local, i.e. concerns only the ability to understand details, in particular idea units directly associated with proper names themselves. Comprehension of main ideas is unaffected. However, as ratings of perceived task difficulty show, unknown proper names make the listening input seem more confusing to L2 listeners, which has clear implications for ESL teaching and testing. In an ESL classroom, if the aim is listening for gist, proper names should not be a concern and, in fact, it would be beneficial to include practice with texts containing unfamiliar names, in order for the learners to develop the skill of coping with challenging input despite the presence of unknown elements. On the other hand, if the aim is detailed, close to $100 \%$ understanding, then proper names will be a burden, especially if there are many; they should either be known or at least pretaught. In a testing situation, it is best to avoid unfamiliar proper names because they may cause unwarranted additional anxiety and reflect negatively on the learners' performance. 


\section{Chapter VII. Experiment 3: replication study with larger sample}

\subsection{Introduction}

In this chapter I will present Experiment 3, which was designed as a replication of Experiment 2. Firstly, I will discuss the motivation for replicating the previous experiment. Secondly, I will explain what modifications and additions to the experimental procedure were made and the rationale behind these changes. Next, participants, data gathering, and findings will be described. Finally, I will compare the results of the two experiments and discuss how the new findings can help refine answers to the research questions posed in the original experiment.

\subsection{Motivation for replicating Experiment 2}

Research questions posed in Experiment 2 remained the same in Experiment 3:

1. Does the presence of unfamiliar proper names influence ESL learners' comprehension of a spoken text, and if so, how?

2. While listening to connected speech, how well are ESL learners able to determine what proper names refer to, and how much information about proper names' referents can listeners get from context?

While the data obtained in Experiment 2 allowed me to answer both research questions satisfactorily, a few drawbacks were noted in the experiment design, which could undermine the validity of the conclusions and prompted the need for a replication study.

\subsubsection{Drawbacks in Experiment 2}

Three related sets of weaknesses were identified in the original experiment design, namely problems with some of the measures, pitfalls in the ordering of experimental tasks, and sampling issues. 
In the between-participants designs, it is important to ensure that treatment groups are comparable, and that performance on the dependent variable is not contaminated by extraneous factors. In Experiment 2, the treatment groups might not have been equal in terms of the participants' listening ability. Listening proficiency was not measured but replaced post factum by a constructed overall English proficiency measure, which in itself could hardly be considered reliable. Therefore, the listening proficiency variable, extraneous to the design, could not be properly controlled. One of the comprehension measures, free recall, also proved problematic because recalls had to be carried out in English as opposed to the participants' L1 (see 6.2.2.1 above).

With as many as four measures ${ }^{*}$ aimed at the same construct (listening comprehension), some ordering issues arose. For example, although care was taken to write open-ended questions that would 'give away' as little of the experimental text as possible, it turned out that in a few cases answering those questions did influence participants' subsequent recalls. However, without the structural support of openended questions prior to the recall, some participants were unable to produce more than 2-3 sentences.

Lastly, a sample of below 30 participants in each treatment precluded the use of parametric statistical tests, and the sample size for open-ended questions in particular was too small. Also, since the experiment sessions were held outside regular class time (some as late as at $5 \mathrm{pm}$ ), it was probably the case that only the most motivated students among all those who were approached, decided to take part. The fact that the sample was 'tied' to a certain profile of learner makes the findings less generalizable.

\subsubsection{Procedure modifications in Experiment 3}

Taking the weak points of Experiment 2 into account, improvements were made to the Experiment 3 procedure.

The free recall measure was left out, which eliminated the ordering issues and made more time available for including a quality listening proficiency measure. The researcher opted to use the International English Language Testing System (IELTS) practice listening module to gauge participants' comprehension ability (IELTS

\footnotetext{
*Free recall, open-ended questions, multiple choice questions and true-false-don't know statements.
} 
Specimen Materials April 1995). It was written by professional test-developers and trialled on thousands of people making it more reliable than a 'home-made' test the researcher could create alone. The IELTS listening module contained 40 items based on 8 spoken texts of various genres and levels of difficulty, and took 30 minutes to complete. An additional advantage to using the IELTS materials was that it made the experiment more attractive to the institutions where participants could be recruited (since many ESL students in New Zealand would sooner or later be required to sit the IELTS exam), which ultimately allowed to increase the number of participants. Current IELTS specimen materials are generally available to the public for purchase. The specimen test of 1995 was chosen over the 2003 one, to make sure that participants did not have any prior exposure to the version of the test to be used in the experiment.

The measure of proper names related comprehension (true-false-don't know) was moved from the end of the task sequence to the beginning. This somewhat improved the ecological validity of the experiment as it removed the need to repeat listening to the experimental text a third time preceding this measure.

According to Shohamy and Inbar, comprehension questions can roughly be divided into global, local and trivial (1991: 29). While global and local questions are valuable in assessing listening comprehension, trivial questions cause confusion and 'should not be asked on LC [listening comprehension] tests' (ibid. 36). One of the multiple choice questions ${ }^{*}$ in the present study clearly matched Shohamy and Inbar's definition of 'trivial', therefore in was excluded in Experiment 3.

The PNT was replaced with a shorter pen and paper test, which included: (i) the self-report section where participants had to indicate on a 7-point scale how well they understood what the proper names in the experimental text referred to; and (ii) the slightly modified 'tick all options that apply' questions from the original PNT (ten in total, each corresponding to the ten proper names in the text). Questions of this type proved to be the best discriminators in the PNT in Experiment 2 so they were retained in Experiment 3 with the number of correct options increased from 18 to 20. The main motivation for the substitute was to allow recruiting more participants. The pen and paper test could be administered anywhere as opposed to the original PNT that required a classroom with multimedia resources. The proper names preteaching was

\footnotetext{
* The guy was ___ years old.
(a) 22
(b) 19
(c) 25 
also slightly modified so that it could be done without the PowerPoint presentation (the researcher manually showed the pictures to the participants).

\subsection{Data gathering}

Apart from modifications discussed above, Experiment 3 was carried out in practically the same manner as Experiment 2 (see 6.3.2 above).

\begin{tabular}{|l|l|}
\hline Experiment 2 procedure & Experiment 3 procedure \\
\hline $\begin{array}{l}\text { Preteaching (Names Known } \\
\text { group) or tea and informal chat } \\
\text { (Names Unknown group) }\end{array}$ & $\begin{array}{l}\text { Preteaching (Names Known } \\
\text { group) or tea and informal chat } \\
\text { (Names Unknown group) }\end{array}$ \\
\hline Listen & Listen \\
\hline Listen 2 & Listen 2 \\
\hline Open-ended questions & True-false-don't know statements \\
\hline Plan $\rightarrow$ retell & Open-ended questions \\
\hline Multiple choice questions & Multiple choice questions \\
\hline Listen 3 & Pen and paper proper names test \\
\hline True-false-don't know statements & Difficulty ratings \\
\hline PNT & IELTS listening module \\
\hline Difficulty ratings & \\
\hline
\end{tabular}

\subsubsection{Experiment sessions}

Ten 1.5-hour long experiment sessions were carried out within the participants' regular class time in their usual classrooms (October 2007-January 2008). The experiment was still advertised as entirely voluntary, however all students who attended their English class on the day of the session chose to take part. The teachers were never present at the experiment. It was hoped that listening proficiency levels in the two treatment groups would be comparable since (i) only one class at a time was invited to participate; and (ii) students were randomly assigned to the Names Known or the Names Unknown treatment.

\subsubsection{Participants}

One hundred and ten students took part in the experiment, 55 in the Names Known treatment group and 55 in the Names Unknown group. They came from ten different classes: (1)-(5) Victoria University EPP* - 15, 13, 14, 13, and 15 participants respectively; (5) Victoria University PreEPP - 9 participants; (6) VicLink ELTO**

\footnotetext{
*English Proficiency Programme

** English Language Training for Officials
} 
10 participants; (7) The Campbell Institute CLA - 7 participants; (8) GEOS Wellington Language Centre - 5 participants; and (9) Massey University EAP $^{* * * *}-9$ participants. Participants were aged from 17 to 46 years old, with a mean age of 26.4 . Most students were in their early twenties with $72.7 \%$ below 30 . Prior to the experiment, participants spent 1 to 520 weeks in an English speaking environment. The mean was not an appropriate measure of central tendency in this case because there was a small number of people who had already lived in New Zealand for several years. The median was $20(\approx 5$ months $) ; 76.4 \%$ of participants arrived in New Zealand less than 32 weeks ( $\approx 8$ months) before the experiment. Exactly half, 55 participants were male and 55 female. $26.4 \%$ of students reported knowing a language/s in addition to English and their L1. Twenty first languages were represented in the sample (see table 7.1).

Table 7.1. Experiment 3. Participants' first languages (as indicated in the personal background questionnaire).

\begin{tabular}{|l|l|}
\hline First language & $\begin{array}{l}\text { Number of } \\
\text { participants }\end{array}$ \\
\hline Chinese & 28 \\
\hline Arabic & 18 \\
\hline Vietnamese & 12 \\
\hline Japanese & 11 \\
\hline Korean & 10 \\
\hline German, Thai & 4 each \\
\hline Spanish, Indonesian, Khmer & 3 each \\
\hline Lao, Italian, French, Burmese & 2 each \\
\hline Dari, Hindi, Mongolian, Portuguese, Russian, Turkish & 1 each \\
\hline
\end{tabular}

\subsection{Results}

\subsubsection{Proper names related statements (TFDN)}

Mean scores on the measure of proper names related comprehension, true-false-don't know format, are presented in table 7.2. For individual participant scores see Appendix Q.

A larger sample allowed the use of parametric tests for comparing the treatment groups. The Names Known group performed significantly better (equal variances independent samples $t$-test, 2-tailed, $\mathrm{p}<0.00)$ :

\footnotetext{
*** English for Academic Purposes
} 


\begin{tabular}{|c|c|c|c|c|c|}
\hline \multirow[b]{2}{*}{$\mathrm{t}$} & \multirow[b]{2}{*}{$\mathrm{df}$} & \multirow{2}{*}{$\begin{array}{c}\text { Mean } \\
\text { Difference }\end{array}$} & \multirow{2}{*}{$\begin{array}{l}\text { Std. Error } \\
\text { Difference }\end{array}$} & \multicolumn{2}{|c|}{$\begin{array}{c}95 \% \text { Confidence Interval } \\
\text { of the Difference }\end{array}$} \\
\hline & & & & Lower & Upper \\
\hline 7.823 & 108 & 3.036 & .388 & 2.267 & 3.806 \\
\hline
\end{tabular}

Table 7.2. Experiment 3. Mean scores on true-false-don't know statements (out of 14) by treatment group.

\begin{tabular}{|l|r|r|r|r|r|r|}
\hline Group & $\mathrm{N}$ & Median & Minimum & Maximum & Mean & $\begin{array}{c}\text { Std. } \\
\text { Deviation }\end{array}$ \\
\hline Names Known & 55 & 9 & 4 & 13 & 8.95 & 1.995 \\
Names Unknown & 55 & 6 & 2 & 11 & 5.91 & 2.075 \\
\hline
\end{tabular}

Participants in the Names Unknown treatment could not understand idea units related to the proper names as well as the participants in the Names Known group.

The strength of association test showed that $36 \%$ of the variability in participants' scores in this sample was accounted for by group, i.e. familiarity or lack of familiarity with proper names $\left(\eta^{2}=0.3616\right)$.

\subsubsection{Open-ended questions (OE)}

\subsubsection{Quantitative comparison}

Mean scores on the measure of general comprehension, short answer format, are presented in table 7.3. For individual participant scores see Appendix R.

Table 7.3. Experiment 3. Mean scores on open-ended comprehension questions (out of 33) by treatment group.

\begin{tabular}{|l|r|r|r|r|r|r|}
\hline Group & $\mathrm{N}$ & Median & Minimum & Maximum & Mean & $\begin{array}{c}\text { Std. } \\
\text { Deviation }\end{array}$ \\
\hline Names Known & 55 & 13 & 1 & 30 & 13.84 & 7.241 \\
Names Unknown & 55 & 8 & 0 & 26 & 8.64 & 5.310 \\
\hline
\end{tabular}

Participants performed considerably better in the Names Known condition compared to the Names Unknown condition. A highly significant difference between the treatment groups was found (independent samples unequal variances $t$-test, 2 -tailed, $\mathrm{p}<0.00)$ :

\begin{tabular}{|c|c|c|c|c|c|}
\hline \multirow[b]{2}{*}{$\mathrm{t}$} & \multirow[b]{2}{*}{$\mathrm{df}$} & \multirow{2}{*}{$\begin{array}{c}\text { Mean } \\
\text { Difference }\end{array}$} & \multirow{2}{*}{$\begin{array}{l}\text { Std. Error } \\
\text { Difference }\end{array}$} & \multicolumn{2}{|c|}{$\begin{array}{l}95 \% \text { Confidence Interval } \\
\text { of the Difference }\end{array}$} \\
\hline & & & & Lower & per \\
\hline 4.295 & 99.051 & 5.2 & 1.211 & 2.797 & 7.603 \\
\hline
\end{tabular}


The strength of association test showed that $16 \%$ of the variance in participants' scores in this sample was accounted for by group, i.e. familiarity or lack of familiarity with proper names $\left(\eta^{2}=0.1569\right)$.

\subsubsection{Qualitative comparison}

While by this stage it is clear that unfamiliar proper names do affect listening comprehension, the question of how, i.e. in what way their influence is manifested has been addressed only partially. A qualitative analysis of participants' responses to open-ended questions was conducted in order to pinpoint where exactly the differences between the treatment groups lie in regards to the participants' mental reconstructions of the story content as a reflection of the underlying comprehension process.

The first matter worth exploring was whether all open-ended questions contributed equally to the difference in the participants' scores. Table 7.4 shows percentages of correct responses to each of the 11 open-ended questions (out of the maximum score possible for each question).

Table 7.4. Experiment 3. Percentages of correct responses to each of the open-ended questions by treatment group.

\begin{tabular}{|l|l|l|l|}
\hline Question & Names Known & $\begin{array}{l}\text { Names } \\
\text { Unknown }\end{array}$ & $\begin{array}{l}\text { Difference } \\
\text { between groups }\end{array}$ \\
\hline Q1 & $70 \%$ & $27 \%$ & $44 \%$ \\
\hline Q2 & $53 \%$ & $29 \%$ & $24 \%$ \\
\hline Q3 & $76 \%$ & $76 \%$ & $0 \%$ \\
\hline Q4 & $55 \%$ & $35 \%$ & $20 \%$ \\
\hline Q5 & $15 \%$ & $8 \%$ & $6 \%$ \\
\hline Q6 & $15 \%$ & $13 \%$ & $2 \%$ \\
\hline Q7 & $16 \%$ & $15 \%$ & $1 \%$ \\
\hline Q8 & $42 \%$ & $27 \%$ & $15 \%$ \\
\hline Q9 & $28 \%$ & $16 \%$ & $12 \%$ \\
\hline Q10 & $25 \%$ & $19 \%$ & $6 \%$ \\
\hline Q11 & $67 \%$ & $22 \%$ & $44 \%$ \\
\hline $\begin{array}{l}\text { Average } \\
\text { all questions }\end{array}$ & $42 \%$ & $26 \%$ & $16 \%$ \\
\hline
\end{tabular}

As can be seen from the table, some questions contributed to the observed difference in scores considerably more than others. For question 3 , there was no difference between the treatment groups at all; for questions 5-7 and question 10 the difference appeared negligible. Table 7.5 shows which remaining questions differed the most between the treatment groups. Note that the majority of questions where the 
difference in responses between the groups was large are the 'who' questions (question 8 can be considered a 'who' question to an extent since the expected answer was 'Rati's body'). Thus, what proved the most difficult for the participants in the Names Unknown condition, was establishing a framework for the story, i.e. 'who is who' and what connections different characters had with each other.

Table 7.5. Open-ended questions where the difference between percentages of correct responses between the treatment groups was the largest.

\begin{tabular}{|l|l|}
\hline Question & $\begin{array}{l}\text { Difference in percentage } \\
\text { of correct responses } \\
\text { between the groups }\end{array}$ \\
\hline Q1: Who were the main characters in the story? & $44 \%$ \\
\hline Q11: Who told the police about the killer's motive? & $44 \%$ \\
\hline Q2: How did the main characters know each other? & $24 \%$ \\
\hline Q4: Who was arrested and why? & $20 \%$ \\
\hline Q8: What did the police find at the student flat? & $15 \%$ \\
\hline Q9: Who lived in this flat? & $12 \%$ \\
\hline
\end{tabular}

Next, it was decided to qualitatively analyse the incorrect responses to questions listed in table 7.5 in order to find out: (i) whether there were any discernible patterns (i.e. similar incorrect answers given by several participants); (ii) whether any such patterns differed between the Names Known and the Names Unknown groups; and (iii) whether any of the incorrect responses or patterns of responses in the Names Unknown group could be attributed to the lack of proper names knowledge.

\subsection{Question 1}

There were no incorrect responses among the Names Known participants, i.e. all their zero scores for this question corresponded to 'no answer supplied'. Out of six incorrect responses in the Names Unknown group, four formed a clear pattern and could be attributed to the presence of unfamiliar proper names.

Question: Who were the main characters in the story?

\begin{tabular}{|l|l|}
\hline Participant & Response \\
\hline OKZ & 'Mr Mclain' \\
\hline YKA & 'Murder[er] (Mclane), victim (Jessie), victim's mother' \\
\hline BIR & '19 years old student - murder[er]; 22 years old man - victim' \\
\hline ROD & 'The guy accused by police as murder[er] and the dead guy' \\
\hline
\end{tabular}

Evidently, these participants confused the two main characters, Rati Maclean (19 years old girl $=$ victim $)$ and Jase Tanner $(22$ years old guy $=$ alleged murderer $)$. The fourth participant mistakenly inferred that both characters were men. 


\subsection{Question 11}

All incorrect responses were remarkably similar. Apparently, participants did not catch that it was the mother of the victim who disclosed information about the possible motive of the murder to the police (which was mentioned in the story only briefly), and instead made the wrong but plausible inference that it was the victim's friend/s. Here are some examples.

Question: Who told the police about the killer's motive?

\begin{tabular}{|l|l|}
\hline Participant & Response \\
\hline WEI & 'The friend of the girl' \\
\hline KNS & 'Girl's three friends' \\
\hline JJC, SNE & 'Her flatmate' \\
\hline BPH & 'A friend of victim' \\
\hline
\end{tabular}

This pattern can definitely be ascribed to the presence of unfamiliar names since the majority of even the lowest proficiency participants in the Names Known condition had no difficulty answering this question. Only two incorrect responses were produced by the Names Known group and thirteen by the Names Unknown group.

\subsection{Question 2}

On the whole, the Names Known group gave four incorrect responses while the Names Unknown group gave eleven. Most incorrect responses, three in the Names Known and seven in the Names Unknown condition, appeared to have the same origin. Probably, participants could not gather what was the nature of the relationship between the two main characters but having heard 'students' and 'flat' inferred that the murderer and the victim were flatting together.

Question: How did the main characters know each other?

\begin{tabular}{|l|l|}
\hline Participant & Response \\
\hline CRD, THI & 'They are flatmates' \\
\hline JJC & 'They live together' \\
\hline OKZ & 'They are neighbour each other' \\
\hline ELL & 'Same flat' \\
\hline
\end{tabular}

This pattern may or may not be ascribed to the presence of unfamiliar proper names. On the one hand, it is possible that the long address that came straight after the girl's name in the passage was what trapped the listeners and made them miss the crucial bit of information, namely that it was the girl who lived in the flat, not both the girl and the alleged murderer. On the other hand, it could be that participants got confused 
because the text said the girl was sharing the flat 'with three other students' and the murderer was a student as well. The fact that a few participants in the Names Known treatment made the same mistake does not allow discarding either of the alternatives.

\subsection{Question 4}

Out of ten incorrect responses produced by the Names Unknown group, eight had much in common. The three incorrect responses produced by the Names Known group were idiosyncratic and did not conform to the pattern. While the correct answer was 'Jase Tanner, because he was suspected of killing his girlfriend' some participants inferred either that the girlfriend herself or one of Jase Tanner's friends was arrested.

Question: Who was arrested and why?

\begin{tabular}{|l|l|}
\hline Participant & Response \\
\hline DAL & $\begin{array}{l}\text { 'One of the four classmates, he was a boy for } \\
\text { questioning' }\end{array}$ \\
\hline RAT, NAC & 'The girl was arrested' \\
\hline AYE & $\begin{array}{l}\text { 'Rati was arrested by the police because two students } \\
\text { had been murder[ed] and he was a friend with them' }\end{array}$ \\
\hline DMR & 'Rita Mclain' \\
\hline
\end{tabular}

The majority of wrong inferences in this question seemed to have the same basis as those in question 1 (see above), namely the failure to establish who the main characters were and what roles they played in relation to each other. As in question 1, this pattern of responses can definitely be attributed to the presence of unfamiliar proper names.

\subsection{Questions 8 and 9}

In question 8, no patterns were identifiable. Two incorrect responses came from the Names Known group and five from the Names Unknown group. The expected answer was 'Rati's body / the girl's body / the body of the victim'.

Question: What did the police find at the student flat?

\begin{tabular}{|l|l|l|l|}
\hline \multicolumn{2}{|l|}{ Names Known } & \multicolumn{2}{l|}{ Names Unknown } \\
\hline TOU & 'The map' & MHY & 'Police find out what frightened people' \\
\hline MDP & $\begin{array}{l}\text { 'Suspect thing } \\
\text { (something } \\
\text { related } \\
\text { to murder)' }\end{array}$ & KNS & 'The man's motive' \\
\cline { 3 - 4 } & KEA & 'Police realize that three boys are sharing the flat' \\
\cline { 2 - 4 } & CIS & 'A thing which used by killing' \\
\hline
\end{tabular}


Two wrong answers (KEA and CIS) can be attributed to the lack of proper names knowledge, which again evidently reflects the participants' confusion as to who the characters were and how they interacted with each other.

As for question 9, it generated the greatest number of wrong answers, fourteen in the Names Unknown group and eleven in the Names Known group. The majority of incorrect guesses in the Names Unknown group (nine in total) appeared to have a common source. Participants inferred by mistake that it was the man (i.e. the alleged murderer) who lived in the flat where the body was found.

Question: Who lived in the student flat?

\begin{tabular}{|l|l|}
\hline Participant & Response \\
\hline SHE & 'The boyfriend' \\
\hline KEA & 'Three boys' \\
\hline LKS & 'Jasse Tanner and his three flatmates' \\
\hline MHY & 'Jason' \\
\hline
\end{tabular}

This pattern is again evidently related to the problem of identifying the main characters in the story and can be accounted for by the lack of familiarity with proper names. The fact that most incorrect inferences in the Names Known group were of a different nature supports this conclusion: here participants mistakenly speculated either that Rati (the victim) and Jase (the murderer) lived together or that Rati lived in the flat with her mother.

\subsubsection{Multiple choice questions (MC)}

Mean scores on the second measure of general comprehension, multiple choice format, are presented in Table 7.6.

Table 7.6. Experiment 3. Mean scores on multiple choice questions (out of 15) by treatment group.

\begin{tabular}{|l|r|r|r|r|r|r|}
\hline \multicolumn{1}{|c|}{ Group } & N & Median & Minimum & Maximum & Mean & $\begin{array}{c}\text { Std. } \\
\text { Deviation }\end{array}$ \\
\hline Names Known & 55 & 10 & 4 & 15 & 10.05 & 2.606 \\
Names Unknown & 55 & 10 & 3 & 14 & 9.56 & 2.379 \\
\hline
\end{tabular}

As can be seen from the table, the performance of the Names Known group was very similar to that of the Names Unknown group. No statistically significant difference between the means of the two groups was found (equal variances independent samples $t$-test, $\mathrm{p}=0.3$ ). It shows that both groups successfully understood the majority 
of idea units in the experimental text regardless of whether proper names were familiar or unfamiliar.

\subsubsection{IELTS listening module}

Comparison of the mean listening proficiency scores between the treatment groups showed that the Names Known group's listening ability was slightly higher than that of the Names Unknown group (table 7.7).

Table 7.7. Experiment 3. Mean IELTS listening module scores (out of 40) by treatment group.

\begin{tabular}{|l|r|r|r|r|r|r|}
\hline Group & N & Median & Minimum & Maximum & Mean & $\begin{array}{c}\text { Std. } \\
\text { Deviation }\end{array}$ \\
\hline Names Known & 55 & 23 & 14 & 37 & 23.22 & 5.792 \\
Names Unknown & 55 & 21 & 4 & 34 & 20.65 & 7.176 \\
\hline
\end{tabular}

The difference appeared to be marginally significant (equal variances independent samples $t$-test, 2-tailed, $\mathrm{p}=0.042$ ). Thus, the treatment groups could not be considered entirely equal in terms of listening ability and this was taken into account in further analysis. Overall, participants' listening proficiency varied widely, from extremely low (scores 4 to 10) to quite advanced (scores above 30).

\subsubsection{ANCOVA results (TFDN+OE+MC)}

In order to determine whether the presence of unfamiliar proper names has an effect on listening comprehension over and above that of proficiency, an overall comprehension score was calculated for each participant by summing up their scores on all comprehension measures (true-false-don't know statements, open-ended questions and multiple choice questions, table 7.8). After that ANCOVA was used to isolate the effect of unfamiliar proper names on comprehension from proficiency effects (table 7.9).

Table 7.8. Experiment 3. Mean overall comprehension scores (out of 62) by treatment group.

\begin{tabular}{|l|l|r|r|r|r|r|}
\hline Group & $\mathrm{N}$ & Median & Minimum & Maximum & Mean & $\begin{array}{c}\text { Std. } \\
\text { Deviation }\end{array}$ \\
\hline Names Known & 55 & 32 & 9 & 57 & 32.8364 & 10.07521 \\
Names & 55 & 24 & 7 & 45 & 24.1091 & 7.71884 \\
Unknown & & & & & \\
\hline
\end{tabular}


Table 7.9. ANCOVA: dependent variable - overall comprehension scores $(\mathrm{OE}+\mathrm{MC}+\mathrm{TFDN})$, independent variable - treatment group, covariate - listening proficiency (IELTS listening module scores).

\begin{tabular}{|l|r|r|r|r|r|r|}
\hline Source & \multicolumn{1}{|c|}{$\begin{array}{l}\text { Type III } \\
\text { Sum of } \\
\text { Squares }\end{array}$} & \multicolumn{1}{c|}{ df } & \multicolumn{1}{c|}{$\begin{array}{c}\text { Mean } \\
\text { Square }\end{array}$} & F & Sig. & $\begin{array}{c}\text { Partial } \\
\text { Eta } \\
\text { Squared }\end{array}$ \\
\hline Corrected Model & $4777.656^{\mathrm{a}}$ & 2 & 2388.828 & 42.489 & .000 & .443 \\
Intercept & 1202.872 & 1 & 1202.872 & 21.395 & .000 & .167 \\
IELTS & 2683.110 & 1 & 2683.110 & 47.723 & .000 & .308 \\
Group & 1211.814 & 1 & 1211.814 & 21.554 & .000 & .168 \\
Error & 6015.762 & 107 & 56.222 & & & \\
Total & 99970.000 & 110 & & & & \\
Corrected Total & 10793.418 & 109 & & & & \\
\hline
\end{tabular}

a R Squared $=.443$ (Adjusted R Squared $=.432$ )

After the listening proficiency variable is controlled, the effect of treatment group on overall comprehension scores is still highly significant $(\mathrm{p}<0.00)$. Around $17 \%$ of remaining variance in the scores can be attributed to treatment group, i.e. to whether the proper names in the text were familiar or unfamiliar.

\subsubsection{Mini proper names test}

\subsubsection{Proper names self report}

This was a new task introduced in Experiment 3 (not used in Experiment 2). Participants indicated on a 7-point scale how well they understood what the proper names in the experimental text referred to. For each of the ten proper names encountered in the story participants had to answer the question 'Do you know what this name refers to?'; the rating of ' 1 ' corresponded to 'I don't know' and the rating of '7' to 'I know'. This was done as a whole class activity. The researcher pronounced each name twice and gave the participants 20-30 seconds to make their choice.

First, all ten ratings were summed and the overall ratings per participant were calculated. Results are presented in figure 7.11. The Names Known group rated almost all proper names as 'known' (ratings of '7', occasionally '6', and in very rare cases ' 5 ') hence the vast majority of overall ratings are close to 70 ( 7 x 10 proper names). The Names Unknown group gave various ratings from ' 1 ' to ' 7 ' depending on which proper name it was and how well they caught it during listening. This pattern was exactly what the researcher expected since the Names Known group had 
learnt all the names prior to listening while the Names Unknown group had to deal with them on the spot and guess from context.

Figure 7.11. Experiment 3. The distribution of participants' overall proper name ratings (out of 70) by treatment group.

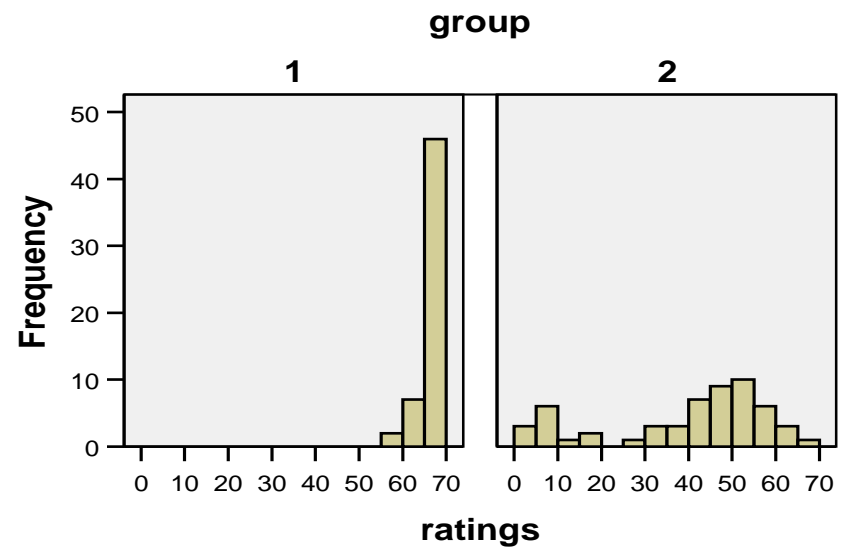

Note: 1 = Names Known group, 2 = Names Unknown group

Next, the mean ratings of separate proper names were analysed. Results are presented in figure 7.12 .

Figure 7.12. Experiment 3. Mean ratings (out of 7) of particular proper names by treatment group.

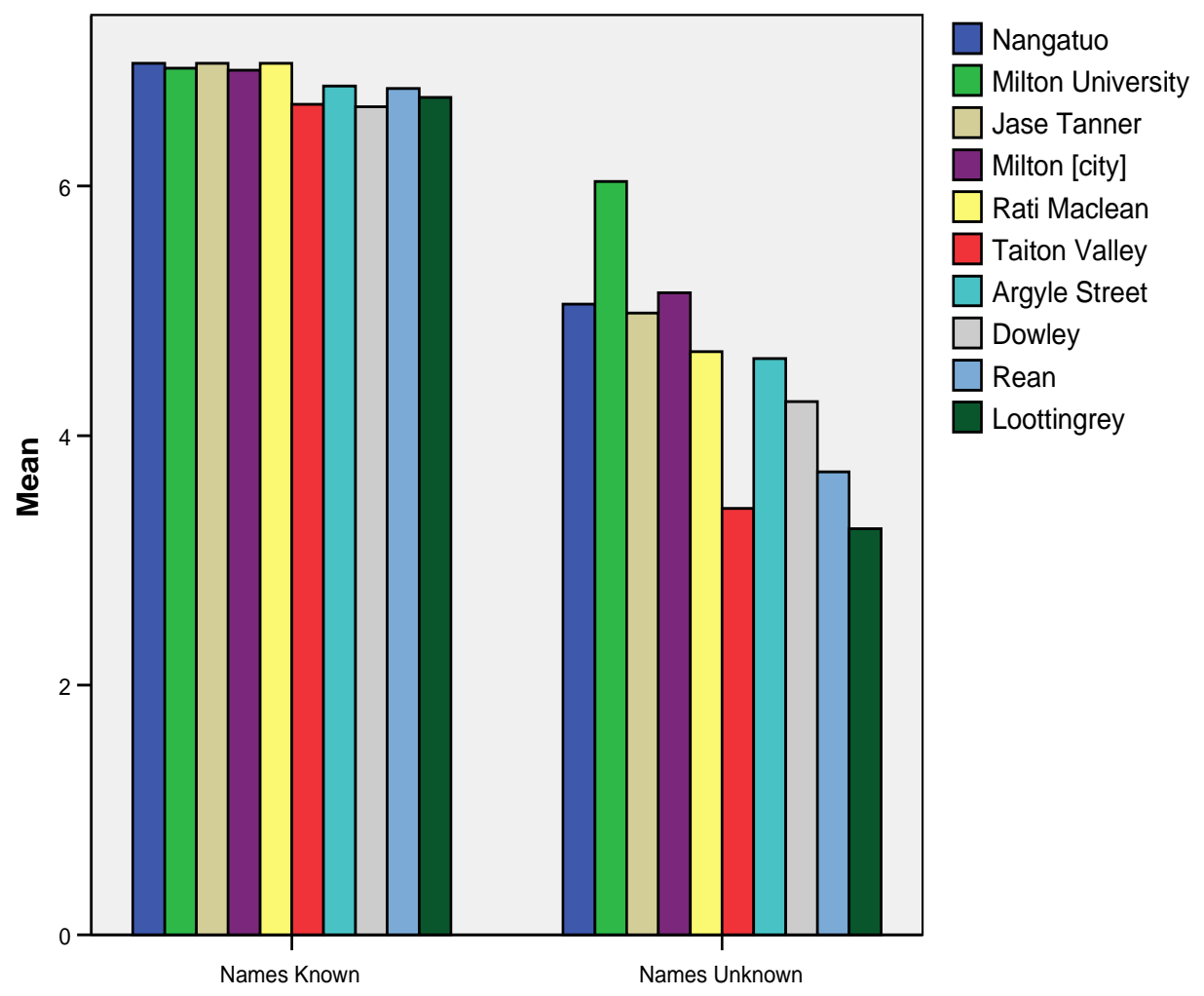


In addition to the obvious fact that the ratings from the Names Unknown group are generally lower, it appears that the first half of the proper names" was rated as "better known' by both treatment groups compared to the second half ${ }^{* *}$. In order to explain this pattern, both the form of the names and their relative importance in the content of the story need to be taken into account. Jase Tanner and Rati Maclean were the names of the main characters; the former was repeated three times and the latter, five times in the text. Milton University was also a salient name since the murder case involved students, and this was mentioned several times throughout the text. Milton [city] was probably reported as 'known' because of its phonetic resemblance to Milton University. There is no apparent reason why Nangatuo received higher ratings, however two possibilities can be suggested. It might have happened because Nangatuo was the very first proper name the listeners encountered (both in the story and in the test). Alternatively, maybe its distinctive Mäori sound made it more memorable.

In any case, all the names that received low ratings (the second half) were unimportant in relation to the content of the text as a whole.

A connection also emerged between the form of the proper names and the ratings they received from the Names Unknown group. Both in the first half and in the second half, the tallest bars correspond to the names with transparent classifiers (Milton University and Argyle Street). This lends some support to the claim that proper names containing a descriptive element that categorizes the referent are less likely to cause comprehension difficulties for ESL learners. If we accept this claim, then one may wonder why Taiton Valley was given low ratings despite having a transparent classifier. There is, however, a simple and plausible explanation for this apparent discrepancy. It has long been established that second language learners' performance is affected by the frequency of vocabulary items they encounter (Laufer and Nation, 1995; Waring and Takaki, 2003). Street and university are among the first thousand of the most frequent words of English while valley is much lower in frequency (Heatley, Nation and Coxhead, 2002).

\footnotetext{
* The first half $=$ the first 5 proper names: Nangatuo, Milton University, Jase Tanner, Milton [city], and Rati Maclean.

** The second half $=$ the last 5 proper names: Taiton Valley, Argyle Street, Dowley, Rean and Loottingrey.
} 


\subsubsection{2 'Tick all options that apply' questions}

Similarly to the PNT, three separate scores were recorded for each participant: PNgood (the number of ticked correct options), PNbad (the number of ticked incorrect options), and PNmissed (the number of missed correct options, PNmissed = 20 - PNgood). The mean PNgood scores are presented in table 7.13.

Table 7.13. Experiment 3. Mean PNgood scores (out of 20) by treatment group.

\begin{tabular}{|l|c|r|r|r|r|r|}
\hline Group & N & Median & Minimum & Maximum & Mean & $\begin{array}{c}\text { Std. } \\
\text { Deviation }\end{array}$ \\
\hline Names Known & 55 & 15 & 6 & 20 & 13.84 & 3.799 \\
Names Unknown & 55 & 9 & 3 & 16 & 8.96 & 3.350 \\
\hline
\end{tabular}

The PNgood scores appeared normally distributed. The $t$-test was used to compare the performance of the Names Known and the Names Unknown group. The Names Known group performed much better and ticked significantly more correct options than the Names Unknown group (equal variances independent samples $t$-test, 2-tailed, $\mathrm{p}<0.00)$.

\begin{tabular}{|c|c|c|c|c|c|}
\hline & & & Mean & Std. Error & \multicolumn{2}{|c|}{$\begin{array}{c}\text { Confidence Interval of } \\
\text { the Difference } \\
\mathrm{t}\end{array}$} & $\mathrm{df}$ & Difference & Difference & Lower & Upper \\
\hline 7.134 & 108 & 4.873 & .683 & 3.519 & 6.227 \\
\hline
\end{tabular}

The mean PNbad scores are presented in table 7.14.

Table 7.14. Experiment 3. Mean PNbad scores (out of 40) by treatment group.

\begin{tabular}{|l|c|r|r|r|r|r|}
\hline Group & $\mathrm{N}$ & Median & Minimum & Maximum & Mean & $\begin{array}{c}\text { Std. } \\
\text { Deviation }\end{array}$ \\
\hline Names Known & 55 & 2 & 0 & 12 & 2.91 & 2.222 \\
Names Unknown & 55 & 7 & 1 & 22 & 8.05 & 4.474 \\
\hline
\end{tabular}

The distribution of PNbad scores appeared to deviate from normal. The Mann Whitney $U$ test was used to compare the performance of the Names Known and the Names Unknown group. The Names Known group performed much better and ticked significantly less incorrect options than the Name Unknown group (Mann Whitney U, $\mathrm{p}<0.00)$.

Ranks

\begin{tabular}{|l|c|r|r|}
\hline Group & N & Mean Rank & Sum of Ranks \\
\hline Names Known & 55 & 34.13 & 1877 \\
Names Unknown & 55 & 76.87 & 4228 \\
\hline
\end{tabular}


Participants in the Names Unknown treatment were able to extract $44.8 \%$ of information about the unfamiliar proper names' referents from context. Participants in the Names Known treatment managed to utilize $69.2 \%$ of information about the referents of the proper names pretaught to them prior to listening. The results from 'tick all options that apply' questions are summarized in figure 7.15.

Figure 7.15. Experiment 3. 'Tick all options that apply' questions. Summary of variables: ticked correct options (PNgood), ticked incorrect options (PNbad) and missed correct options (PNmissed). Comparison of treatment groups.

\begin{tabular}{lll} 
group & & $\square$ PNgood \\
Names Known & Names Unknown & $\square$ PNbad \\
\hline PNmissed
\end{tabular}

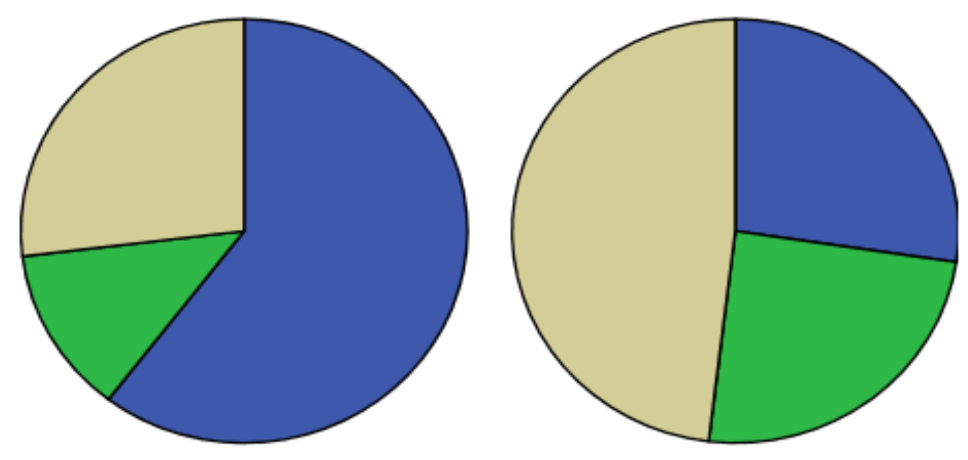

\subsubsection{Difficulty ratings}

Averages per participant for all types of ratings were calculated first. Results are presented in table 7.16 .

Table 7.16. Experiment 3. Average per participant difficulty ratings of experimental tasks (on a scale of 7) by treatment group.

\begin{tabular}{|l|l|l|l|}
\hline Rating type & $\begin{array}{l}\text { Names } \\
\text { Known, } \\
\text { Group }(\mathrm{N}=55)\end{array}$ & $\begin{array}{l}\text { Names } \\
\text { Unknown, } \\
\text { Group (N=55) }\end{array}$ & $\begin{array}{l}\text { Difference } \\
\text { between } \\
\text { the groups }\end{array}$ \\
\hline $\begin{array}{l}\text { 1. Perceived amount of } \\
\text { comprehension (DR }\end{array}$ & 4.11 & 3.24 & 0.87 \\
\hline 2. True-false-don't know & 3.73 & 3.18 & 0.55 \\
\hline 3. Open-ended questions & 3.53 & 2.82 & 0.71 \\
\hline 4. Multiple choice questions & 4.75 & 3.76 & 0.99 \\
\hline 5. Mini proper names test & 4.91 & 3.00 & 1.91 \\
\hline
\end{tabular}


As can be seen from the table, all experimental tasks were rated as easier to do by the Names Known group and as harder to do by the Names Unknown group. The largest difference in perceived task difficulty between the two treatment groups was observed for the mini proper names test and, surprisingly, multiple choice questions, closely followed by the perceived amount of comprehension. Contrary to expectations, the difference was less pronounced for the open-ended questions and true-false-don't know (i.e. proper names related statements).

Next, all five types of ratings supplied by each participant were summed. The resulting overall individual ratings $\left(\mathrm{DR}_{\text {total }}\right)$ were considered continuous data. The mean overall individual ratings are shown in table 7.17.

Table 7.17. Experiment 3. Mean overall difficulty ratings (maximum 35) by treatment group.

\begin{tabular}{|l|c|r|r|r|r|r|}
\hline Group & $\mathrm{N}$ & Median & Minimum & Maximum & Mean & $\begin{array}{c}\text { Std. } \\
\text { Deviation }\end{array}$ \\
\hline Names Known & 55 & 20 & 10 & 31 & 21.0182 & 5.36619 \\
Names Unknown & 55 & 15 & 5 & 29 & 16.0000 & 5.22104 \\
\hline
\end{tabular}

The mean overall ratings were compared between the Names Known and the Names Unknown conditions. A highly significant difference between the treatment groups was found (independent samples equal variances $t$-test, 2 -tailed, $\mathrm{p}<0.00$ ).

\begin{tabular}{|c|c|r|r|rr|}
\hline & & & Mean & Std. Error & \multicolumn{2}{|c|}{$\begin{array}{c}\text { S5\% Confidence Interval } \\
\text { of the Difference }\end{array}$} \\
$\mathrm{t}$ & $\mathrm{df}$ & Difference & Difference & \multicolumn{1}{c|}{ Lower } & Upper \\
\hline 4.971 & 108 & 5.01818 & 1.00955 & 3.01708 & 7.01928 \\
\hline
\end{tabular}

As in the previous experiment, the $\mathrm{DR}_{\text {compreh }}$ rating, which reflected perceived success in comprehension, was examined separately. Recall that the higher ratings corresponded to the higher fraction of the experimental text that the participants subjectively judged as 'understood'. Frequencies of particular responses, from ' 1 ' to '7', were tabulated across treatment groups.

Group * $\mathrm{DR}_{\text {compreh }}$ Crosstabulation

\begin{tabular}{|c|c|c|c|c|c|c|c|}
\hline \multirow[t]{2}{*}{ Group } & \multicolumn{7}{|c|}{$\mathrm{DR}_{\text {compreh }}$} \\
\hline & ' 1 ' & '2' & ' 3 ' & '4' & 5 ' & '6' & '7' \\
\hline Names Known Count & 0 & 7 & 8 & 20 & 12 & 8 & $\overline{0}$ \\
\hline$\%$ within group & $.0 \%$ & $12.7 \%$ & $14.5 \%$ & $36.4 \%$ & $21.8 \%$ & $14.5 \%$ & $.0 \%$ \\
\hline Names Unknown & & & & & & & \\
\hline Count & 2 & 15 & 13 & 20 & 4 & 0 & 1 \\
\hline$\%$ within group & $3.6 \%$ & $27.3 \%$ & $23.6 \%$ & $36.4 \%$ & $7.3 \%$ & $.0 \%$ & $1.8 \%$ \\
\hline
\end{tabular}


$72.7 \%$ of responses in the Names Known group were ' 4 ' or higher compared to only $46 \%$ in the Names Unknown group. 31\% of responses in the Names Unknown group were ' 2 ' or lower compared to only $12.7 \%$ in the Names Known group. For the Names Known group, there were more responses towards the higher end of the scale (i.e. participants reported understanding more of the story) while for the Names Unknown group, the majority of responses lay at the lower end of the scale (i.e. participants reported understanding less of the story). The chi-square test showed that there was a highly significant association between the frequency of particular $\mathrm{DR}_{\text {compreh }}$ responses and treatment group (Fisher's exact test, 2-sided, $\mathrm{p}=0.001$ ).

\subsection{Summary of Experiment 3 findings}

In this experiment, the presence of unfamiliar proper names was found to affect listening comprehension of a short news text by low intermediate to advanced ESL learners. The Names Known treatment group performed significantly better than the Names Unknown treatment group on two out of three comprehension measures, truefalse-don't know (i.e. proper names related statements) and open-ended questions. No difference was observed on the multiple choice questions.

Although the treatment groups were not quite equal in terms of listening proficiency at the time of testing, the effect of unfamiliar proper names on comprehension was highly significant even after the proficiency variable was controlled. $17 \%$ of variance in the overall comprehension scores (TFDN + OE + MC) was still accounted for by the familiary or lack of familiarity with proper names encountered in the experimental text.

The conclusion that the presence of unfamiliar proper names can hinder comprehension was also supported by the qualitative analysis of incorrect responses to open-ended questions and participants' difficulty ratings of experimental tasks. The qualitative findings suggest that the unfamiliar names make it harder for ESL listeners to establish the framework of the story, i.e. to identify the main characters and the roles they played in relation to each other. As for the difficulty ratings, participants in the Names Known group rated all comprehension tasks as easier to do, and their perceived amount of comprehension ratings in particular were higher than those in the Names Unknown group. On the other hand, the Names Unknown group rated all 
comprehension tasks as harder to do and self-reported a lower amount of comprehension.

The results of the mini proper names test indicate that while listening to connected speech, ESL learners (Names Unknown group) were able to derive over $40 \%$ of information about the referents of unfamiliar proper names from context, however they were not able to identify all the referents successfully.

\subsection{Discussion}

Let us compare the findings of the present experiment (Experiment 3) to those of the previous experiment (Experiment 2) and review the answers to the research questions in light of the combined evidence.

The measure of proper names related comprehension (true-false-don't know) yielded similar results in both experiments. Idea units associated with proper names were found to be readily accessible to the listeners in the Names Known group, but not to the listeners in the Names Unknown group. A highly significant difference between the treatments was observed. The effect was smaller in Experiment 3 (36\%) compared to Experiment 2 (45\%). This difference can be explained by considering (a) the sample sizes and (b) interference from other measures. Firstly, there is usually more variability in smaller samples, and the number of participants in Experiment 2 was over 2 times lower than in Experiment 3. Secondly, in Experiment 2 the truefalse-don't know task came last in the sequence whereas in Experiment 3 it was done first thing after listening. In Experiment 2, by the time the true-false-don't know task was administered, the participants' 'picture' (i.e. interpretation) of the text had already been entirely finished and 'frozen' after all the preceding comprehension tasks. Therefore some true-false-don't know statements might have come as an unexpected surprise and 'shook the picture', i.e. made the participants question their established understanding of the story. In Experiment 3, no preceding measures interfered with the task, and 'picture creating' was still in progress. For this reason, I consider the figure obtained in Experiment 3 to be more reliable.

The first general comprehension measure, open-ended questions, showed that the presence of unfamiliar proper names affects not only names-related idea units but the quality of comprehension on the whole. In Experiment 2, although the Names Known group's scores were higher, the difference between the treatments narrowly missed statistical significance. In Experiment 3, the difference between the treatment 
groups was highly significant. The pattern of results was the same in both experiments. The fact that the difference was less pronounced in the earlier experiment is most probably due to the smaller sample size. The qualitative analysis of the wrong answers allowed pinpointing where exactly comprehension was disrupted and in some instances the disruption could be accounted for by the presence of unfamiliar proper names.

The second general comprehension measure, multiple choice questions, produced exactly the same results in both experiments. No effect of proper names on the participants' performance was found. This finding is not surprising. On the one hand, multiple choice questions were purposefully written in such a way that they did not require any knowledge of the proper names to be answered correctly. On the other hand, it can be that for this particular sample of participants this type of question was not sensitive enough. Overall, the students' English proficiency was high, $76.4 \%$ of them achieved an IELTS score of 18 or higher, while the multiple choice format is generally considered the easiest among various test item types (Shohamy, 1984).

The mini proper names test demonstrated that although ESL listeners can pick some information about the referents of unfamiliar proper names from context, the amount of information they are able to derive is far below the amount accessible to the listeners who are familiar with the names. While it was not expected that the results of the computerized PNT in Experiment 2 and the pen and paper mini test in Experiment 3 would be directly comparable, they turned out surprisingly close.

Table 7.18. Percentage of information about proper name referents that the participants were able to access. Comparison of Experiment 2 and Experiment 3.

\begin{tabular}{|l|l|l|}
\hline & PNT (Experiment 2) & Mini test (Experiment 3) \\
\hline Names Known & $71.75 \%$ & $69.2 \%$ \\
\hline Names Unknown & $41.83 \%$ & $44.8 \%$ \\
\hline
\end{tabular}

The PNT should probably be considered more reliable since it included a variety of question types, allowed the participants to work at their own pace and to listen to the sound of the tested proper names as many times as they wished. The mini test included only one type of question ('tick all options that apply') and did not allow much thinking time (was done as a group activity). However, it appears that the testing method did not greatly affect the outcomes. I conclude that on average, intermediate to advanced ESL listeners are able to pick about $40 \%$ of the information about the referents of unfamiliar proper names from context. 
Difficulty ratings of the experimental tasks revealed that the presence of unfamiliar proper names definitely makes the text seem more confusing to the ESL listeners. Both in Experiment 2 and in Experiment 3, participants rated all experimental tasks as easier to do when proper names were familiar and as harder to do when the names were unfamiliar. The only difference concerned the true-falsedon't know task, which in Experiment 3 received lower ratings from both treatment groups compared to Experiment 2. Most likely, this is again a reflection of the change in the order of the tasks in Experiment 3 (see above). Importantly, the DR (perceived amount of comprehension) ratings were very similar in both experiments. Participants self-reported understanding more of the text when the proper names were familiar and less of the text when the names were unfamiliar.

ANCOVA allowed the researcher to determine the effect of familiarity with proper names on comprehension over and above that of the participants' listening proficiency. After the listening proficiency variable was controlled, 17\% of variance in the overall comprehension scores was still attributable to treatment group, i.e. to familiarity or lack of familiarity with proper names. While ANCOVA was not applicable to Experiment 2, and the overall comprehension scores could not be calculated the same way they were calculated in the latest experiment ${ }^{*}$, the researcher summed up the multiple choice and the true-false-don't know scores from Experiment 2 and ran an ANOVA on the resulting figures just for the sake of a rough comparison of the two experiments. The means of these 'truncated' overall comprehension scores from Experiment 2 (out of 30: 16 multiple choice questions +14 true-false-don't know statements) are presented in table 7.19.

Table 7.19. Experiment 2. Mean overall comprehension scores (out of 30: $16 \mathrm{MC}+$ 14 TFDN) by treatment group.

\begin{tabular}{|l|c|r|r|r|r|r|}
\hline Group & N & Median & Minimum & Maximum & Mean & $\begin{array}{c}\text { Std. } \\
\text { Deviation }\end{array}$ \\
\hline Names Known & 25 & 20 & 13 & 27 & 20.44 & 3.831 \\
Names Unknown & 25 & 17 & 8 & 24 & 16.60 & 4.481 \\
\hline
\end{tabular}

A significant effect of treatment group on overall comprehension was obtained $(\mathrm{F}=10.606, \mathrm{p}=0.002)$, and the strength of association test showed that $18 \%$ of variability in the scores could be attributed to the familiarity or lack of familiarity with proper names $\left(\eta^{2}=0.181\right)$. One should bear in mind the weaknesses in the

\footnotetext{
* This was not possible since the first 10 participants did not do the open-ended questions.
} 
Experiment 2 design and the fact that the two data sets are not strictly comparable, nevertheless similar figures across different samples allow us to have more confidence in the Experiment 3 findings.

Let us sum up the answers to the research questions. Unfamiliar proper names do impact on the intermediate to advanced ESL learners' comprehension of a short spoken news text as measured by open-ended questions and proper names related statements (true-false-don't know). Chiefly, it is the comprehension of details, particularly the idea units closely associated with the unfamiliar proper names themselves that is affected. Additionally, when proper names are unknown, it appears to make it harder for the listeners to identify the characters of the story and the roles the characters play in relation to each other. The presence of unfamiliar names has not compromised the ESL listeners' ability to understand main ideas as shown by the free oral recall and multiple choice questions results. Note, however, that the text in the present experiments was very short, factual, and did not contain any low frequency vocabulary apart from proper names. The outcomes would probably be different for an unsimplified, longer expository text, which is a matter to explore in a future study.

While listening to connected speech, ESL learners are able to determine what some unfamiliar proper names refer to. However, far from all proper names are successfully matched with their referents. The ability to establish what unfamiliar proper names refer to seems to depend on the importance of a particular name to the content of the passage as a whole as well as on the form of the name, specifically on whether it contains a transparent classifier. On average, intermediate to advanced ESL listeners can derive $40 \%$ of the information about unfamiliar proper names' referents from context. 


\section{Chapter VIII. Conclusions}

\subsection{Thesis overview}

Let us revisit the chief theoretical points and empirical findings presented and discussed above. As was established in Chapter II, there is no strict criterial definition of proper names universally accepted in the current literature; they are an immensely diverse category of expressions including over a hundred pragmatic and around fifteen structural subcategories.

Proper names were analyzed in light of the prototype theory rather than the classical member/non-member dichotomy. I consider personal, deity and pet names to be the core representatives of the category 'proper name' since they are capable of fulfilling both the vocative and the referential functions, are the most frequent and the most anthropocentric. Names of places and enterprises are still close to the core but are not as frequent, cannot be used as vocatives, and often consist of several words. They are pragmatically predictable and well institutionalized, however a lot of them retain descriptive meanings and perform a non-characteristic classifying function. Proper names of events and artefacts are the least prototypical representatives of the category since they are often multiword, descriptive, pragmatically unpredictable, and sometimes not fully institutionalized. Unlike items in other subcategories, they regularly appear partitive and can be used in generic utterances, which is an extremely unusual function for proper names.

The degree of prototypicality may vary among proper names even within the same subcategory. In Chapter III, essential properties of a prototypical proper name regardless of what subcategory it belongs to were discussed. Such properties have been identified in semantics, grammar, and pragmatics. Semantically, prototypical names are referring expressions; have no sense (intension); are definite, specific and non-partitive. Grammatically, the core names consist of a single noun without modifiers; are not predicative and cannot be pro-forms in anaphora; lack article contrast, number contrast, and restrictive modification. Pragmatically, prototypical proper names are bestowed on objects in an official act of naming or registration that 
can be validly performed only by authorized individuals who observe all the necessary formalities.

I suggested that proper names can be defined on the basis of their functional properties. In my view, a proper name is a word or institutionalized word group whose primary function in communication is referring to a particular fixed entity and differentiating it from others. Functionally, proper names stand close to deictic pronouns and definite descriptions.

In Chapter IV, a preliminary evaluation of whether the unfamiliar proper names may affect listening comprehension in ESL learning contexts was made. Equating proper names with known vocabulary items appeared reasonable for reading material, however processing names in connected speech was shown to be much more demanding. ESL listeners have to possess specific skills and a large amount of linguistic and encyclopaedic knowledge in order to cope with unfamiliar proper names in spoken texts.

First, learners must be able to recognize the unfamiliar proper name as a proper name in the flow of speech, which is not an easy task given that there are no phonetic features that distinguish unknown names from unknown common expressions. Next, learners need to successfully determine from context what kind of object the proper name refers to, which is manageable in reading but is considerably more difficult in listening since the latter is transitory and does not give the recipient of the text much thinking time. In cases where proper names are used figuratively, listeners have to retrieve the corresponding L1 form as well as the relevant extralinguistic information about the referent that the metaphor is based on. Thus, three levels of knowledge were postulated that would allow an ESL learner to cope with proper names in spoken texts: (level 1) recognition $\rightarrow$ (level 2) categorization $\rightarrow$ (level 3) referent properties. A hypothesis was also suggested that if a proper name form provides a clue as to what cognitive category the referent belongs to (either via a transparent classifier or explicitation) it will be less likely to adversely affect comprehension than a form that does not.

In the first experiment, the recognition level was empirically tested. The findings indicate that ESL learners of intermediate to advanced proficiency are able to recognize an unfamiliar proper name in a short listening passage approximately six times out of ten. The recognition rate was measured under two conditions, simplified (text) and complicated (text). It was evidently harder for ESL listeners to recognize 
proper names in complicated texts containing unfamiliar common vocabulary than in simplified texts. Participants made significantly more non-random errors in the complicated condition. However, percentages of successfully identified proper names did not differ significantly between the two conditions. On the one hand, the ability to recognize proper names appears to depend on the structure of a specific text as well as on the position and shape of the particular proper names therein. On the other hand, since the same texts were used in the simplified and complicated sets, the contrast between the treatments themselves might not have been as striking as was hoped for. Anyhow, on average around $40 \%$ of the proper names are missed regardless of the common vocabulary load, which means that in real life listening ESL learners do mistake unknown common expressions for proper names and vice versa.

The second experiment demonstrated that the presence of unfamiliar proper names hinders the intermediate to advanced proficiency learners' comprehension of a short news text as measured by immediate free recall and the ability to evaluate proper names related statements. The effect concerned comprehension of details, particularly those details that were associated with processing the proper names themselves. Comprehension was tested under two conditions, Names Known (all proper names pretaught in advance) and Names Unknown (all proper names unfamiliar prior to listening). The Names Known group scored significantly higher on the measure of proper names related comprehension (true-false-don't know) and produced more details, fewer incorrect inferences, and overall more correct idea units in oral recalls compared to the Names Unknown group. Participants in the Names Known treatment successfully used proper names in their recalls and rated all experimental comprehension tasks as easy to do. In the Names Unknown treatment the percentage of correctly recalled idea units was lower and thus comprehension of the text less precise. Participants hardly ever used proper names in their recalls, perceived all experimental tasks as harder to do and self-reported a lower amount of comprehension. Both treatment groups appeared to have successfully grasped the gist of the story. No statistically significant difference on multiple choice questions was found. The mean difference on open-ended questions narrowly missed statistical significance probably due to the small sample size.

The computerized proper names test showed that ESL learners, at least at the intermediate to advanced proficiency level, were able to determine from context what some unfamiliar proper names refer to, however the learners could not match all 
proper names with their referents successfully. On average, after 2-3 attempts at listening participants in the Names Unknown treatment were able to extract just over $40 \%$ of the information about the referents of unfamiliar proper names encountered in the experimental text.

The last experiment was a replication of the previous one using the improved procedure and a larger sample. The findings were largely similar. The Names Known treatment group performed significantly better than the Names Unknown group on two out of three comprehension measures, namely proper names related statements (true-false-don't know) and open-ended questions. Although the treatment groups were not considered entirely equal in terms of the participants' listening proficiency, unfamiliar proper names had a marked effect on overall comprehension even after the proficiency variable was controlled. Around $17 \%$ of the variance in scores was attributed to the familiarity or lack of familiarity with proper names. The qualitative analysis of incorrect responses to open-ended questions indicated that the presence of unfamiliar proper names made it harder for ESL listeners to establish the framework of the text, i.e. to identify the characters and the roles they played in relation to each other. Also the proper name self-report ratings provided some evidence in support of the claim that proper names containing a descriptive element categorizing the referent are less likely to cause comprehension difficulties for ESL listeners. The ability to establish the referent appeared to depend not only on the availability of a transparent classifier but on the importance of a particular name in the content of the passage as a whole as well as on familiarity with the classifier itself.

\subsection{Implications for ESL pedagogy}

I believe I have succeeded in showing that proper names place high demands on the ESL learners' cognitive resources and that, as far as the vocabulary threshold in second language listening is concerned, proper names contribute to raising it and thus cannot be considered automatically known items without a learning burden.

However, the findings from all three experiments suggest that the relationship between unfamiliar proper names and listening comprehension is bilateral. On the one hand, proper names knowledge makes bottom-up processing easier and aids comprehension. On the other hand, as the learners' proficiency increases and their listening skills improve, both recognizing unfamiliar names and establishing their referents from context becomes easier. For example, in Experiment 1 the proper 
names recognition rate in the advanced class was higher than in the intermediate classes both for simplified and complicated texts. Thus, better overall comprehension also helps to deal with unfamiliar proper names more efficiently.

In conclusion, let me reiterate some implications of the findings for TESOL professionals. I will briefly discuss:

- whether it is worthwhile teaching proper names;

- how names can be approached while teaching listening and speaking; and

- what role unfamiliar names play in language testing.

I will also suggest a few simple classroom activities that can be set up to increase name awareness among ESL learners.

As a rule, low frequency expressions do not warrant spending classroom time on their direct teaching: if learners are unlikely to come across the taught words again, the returns from such an exercise will be minuscule (Nation, 2001). However, proper names differ from ordinary low frequency vocabulary in one important respect. Chances are some of them will be encountered again, at least for the duration of the students' stay in a particular area (the location of their English course). The majority of proper names are 'local' (in the sense adopted in 3.4.2 above). When people move from one place to another, unfamiliarity with the names - which are common knowledge for long-term residents - is often a big contributor to culture shock. Even native speakers of English who come to New Zealand from Britain or the USA may initially feel like a 'fish-out-of-water', and the same certainly applies to ESL learners. Gaining at least receptive knowledge of the core group of proper names widely used by the local community would boost the learners' confidence.

I am not advocating giving students lists of proper names to study and memorize. However, it would be beneficial if the teacher briefly commented on the referents of the names encountered in class and encouraged students to learn as much as they can about the place where they study, i.e. its distinguished people, historic and modern buildings, music and other forms of art, dominant companies, major attractions, popular restaurants, shopping centres, events etc.

Teachers, resource and particularly test developers need to bear in mind that proper names increase the difficulty level of listening materials, especially if the percentage of names in the text is high (by high I mean anything above 4-5\%). ESL listeners cannot be expected to guess what the referents of unfamiliar proper names 
are from context. As Experiments 2 and 3 showed, in the best of circumstances their guesses are successful only around $40 \%$ of the time.

Depending on the learners' proficiency and the characteristics of the text, in some cases proper names can significantly decrease comprehension. Firstly, according to Buck 'texts with fewer things or people to be distinguished tend to be easier than texts with more things to be distinguished' (2001: 150). As the qualitative analysis of participants' answers to open-ended questions in Experiment 3 showed, unfamiliar proper names do precisely that - add extra 'things to be distinguished'. Secondly, additional unknown elements may simply make the ESL listener panic: participants in my experiments invariably judged all comprehension tasks as harder to do when unfamiliar names were present.

I suggest that teachers need to be flexible when setting up listening tasks and use different techniques depending on what depth of understanding the learners are supposed to achieve. If the instructional goal is listening for the main point, most likely proper names will not affect the outcomes of the activity. It would be good to give students plenty of practice on texts that contain unfamiliar names so that they can develop strategies for dealing with input that is only partially comprehensible. However, if detailed and precise understanding is required, then it is unrealistic to expect ESL learners to be able to cope with unfamiliar proper names 'on the spot' without assistance and/or preparation; either the assessment has to be adjusted or proper names can be pretaught.

Proper names should also be taken into account when designing the language support section for speaking tasks, in particular, tasks aimed at enhancing fluency. If learners are to use recently encountered proper names in their speech, pronunciation help will be necessary.

The presence of unfamiliar proper names definitely makes the spoken text seem more confusing to ESL listeners. Therefore, in a testing situation, especially in high stakes placement tests, the impact of unfamiliar proper names must be estimated thoroughly. Unless the context and the form of the names absolutely guarantee easy referent identification, it is recommended to avoid proper names where possible because the knowledge of even the most famous names varies greatly from culture to culture and from individual to individual. 
A pilot analysis of current ESL course books for adults and young adults shows that as far as dealing with proper names is concerned, learners are largely left to their own devices. Textbook developers pride themselves on the authenticity of the language samples they employ, thus a large number of (most likely unfamiliar) names is found in reading and listening passages. However, no explanation on how to deal with proper names is provided either in pre-listening, pronunciation or vocabulary support sections.

A number of textbooks were reviewed at each of the target proficiency levels, beginner, intermediate and advanced. In the majority of textbooks, guided 'focus on form' (Doughty and Williams, 1998; Ellis, 1999) does not cover proper names at all. A few (mainly intermediate level) series briefly mention place names as part of grammar work on the use/non-use of articles. Very few sporadic tasks were found that explicitly draw learners' attention to proper names while maintaining a communicative focus.

Haines and Stewart (2000b: 46) incorporated a number of brand names into a listening passage about teenagers' obsessions with famous brands as a reflection of the need for creating an identity. Comprehension was skilfully facilitated via:

- a pre-listening task (discussing what brands students already know and like);

- visual aids (logos of various companies).

Baker et al. (2003: 240) devised a task to show students how to write an effective title for a newspaper article. Although not communicative per se, this task could be easily developed into a discussion of names of local newspapers as well as journals, books and other publications.

In my view, the most appropriate approach to proper names in ESL or EFL classrooms is language awareness work, i.e. (i) explaining what proper names are and what objects normally have names; (ii) making learners aware of the fact that names are peculiar semantically and require a different kind of processing compared to common vocabulary while listening; (iii) emphasizing their position at the interface between purely linguistic and encyclopaedic knowledge domains; (iv) encouraging students to familiarize themselves with the proper names frequently used in the area where they live and study (in ESL contexts); and (v) possibly illustrating the most common structural patterns of English proper names. 
Here are a few classroom activities through which awareness of proper names can be promoted:

- Prepare a short passage where all proper names are typed up as ordinary words (i.e. start with small letters instead of capitals). Ask students to read it and underline all the words they don't know. Get students to read the passage a second time and tick those underlined words which they think are proper names. Check in pairs or as a whole class and discuss what clues helped them decide which words might be names.

- The same can be done with a listening passage. Get students to listen and jot down the words that they feel they don't know. Get them to listen a second time and tick the words they think are proper names. Discuss what clues helped them decide. Ask students if it was easier to recognize the names in the reading passage or in the listening passage.

- Divide the class into teams and get each team to write up a list of all the objects they can think of that can have a name. Set up a fun competition. Teams take turns at writing one category from their list on the board and giving an example. The team which puts up the last category wins. After the game, compare the list on the board with Zelinsky's taxonomy (2002) or with a list of your own.

- For homework, ask students to collect as many personal names as they can (family, host family, flatmates/friends, other lecturers etc.). In class get them to share the names in small groups. Their peers have to decide if the name is a man's name or a woman's name. Is it always easy to tell?

- Give students a list of $15-20$ proper names and ask them to put each name under one of the two headings: 'Easy to tell what it is' (i.e. what the name refers to) and 'Hard to tell what it is'. Names with transparent classifiers should end up under the first heading. Ask students if they can see any similarities/differences between the easy-to-tell's and the hard-to-tell's. Get students to add their own examples under each heading.

- Encourage students to find out as much as they can about the area where they live. Ask them to keep a log of proper names they come across out of class. 


\subsection{Limitations of the study and suggestions for future research}

'If we knew what it was we were doing, it wouldn't be called research, would it?' (quote attributed to Albert Einstein)

The present study has a number of limitations. As far as the theoretical part goes, there have been so many thinkers interested in proper names throughout the centuries that - it should be admitted - it was impossible to discuss every position. For example, I have not included an analysis of arguments put forward by those scholars who hold an alternative view that proper names have senses. I am also aware of two more areas relevant for ESL learning contexts that had been raised in the literature but not dealt with here, and that require further research: (i) the problem of proper name translatability (Bhat, 1979: 102-106; Clankie, 2002: 50; Coates, 2006: 373-378); and (ii) the challenges proper names pose in lexicography (Mufwene, 1988; Möller, 1996; Nicolaisen, 1996; Napoli, 1997).

As for the empirical part, some critical remarks on the data gathering method can be anticipated. First, the participants' attention in my experiments was overly focused on proper names, which is not what happens in natural listening. Second, the impact of unknown common vocabulary was controlled, which is again not the case in a normally occurring comprehension process. Controlling variables in an experimental design inevitably detracts from the generalizability of findings, however it can be argued that if the effect of unfamiliar proper names manifests itself even under such supportive experimental conditions it would definitely be present in a more strenuous real life listening situation.

Another limitation of the last two experiments is that only a single text was used. An important avenue for future research is to assess the impact of proper names on comprehension involving various types of listening input. This can be done by manipulating the text length, genre and structure as well as the percentage of unfamiliar proper names and low-frequency common vocabulary. For instance, the burden of unfamiliar proper names could decrease in a longer text in which the core set of names would be encountered many times.

There is a lot of room for improving comprehension testing instruments, both in the context of this research and in general. The test format in the last two experiments was mostly focused on the final product as opposed to the process of comprehension. For advanced ESL learners, interesting qualitative data could be 
obtained with a more process-oriented methodology such as think-alouds (Pressley and Afflerbach, 1995; Cohen, 1999).

The present study looked at proper names mainly from an adult ESL learner's point of view. There is also a need for classroom-based research that would explore another perspective, specifically: (i) what do teachers currently do about proper names, and (ii) what kind of communicative tasks and focus on form activities can teachers devise in order to facilitate comprehension in light of the experimental findings?

This study has demonstrated that unfamiliar proper names hinder ESL learners' comprehension of a spoken text and raise vocabulary threshold in listening. Better second language learning outcomes can be achieved if the findings are incorporated into successful ESL teaching methodology. 


\section{Appendix A}

Experiment 1. Text topics, origin and speakers.

\begin{tabular}{|c|c|c|c|}
\hline Topic & Text & Source & $\begin{array}{l}\text { Speaker, gender and } \\
\text { accent }\end{array}$ \\
\hline \multirow[t]{2}{*}{ Crime (2) } & Rachel's murder & WSC & S1 (M, New Zealand) \\
\hline & Random killer & WSC & S1 (M, New Zealand) \\
\hline \multirow[t]{2}{*}{ Business (2) } & Sky expansion & WSC & S1 (M, New Zealand) \\
\hline & Pasific fisheries & WSC & S3 (F, Australia) \\
\hline \multirow[t]{4}{*}{ Politics (4) } & President runs & WSC & S1 (M, New Zealand) \\
\hline & Deadly garland & WSC & S7 (F, New Zealand) \\
\hline & Opinion poll & $\begin{array}{l}\text { Radio NZ news } \\
\text { bulletin transcript } \\
(5.09 .2005)\end{array}$ & $\begin{array}{l}\text { S8 (F, New Zealand) + } \\
\text { S9 (F, Russia) }\end{array}$ \\
\hline & $\begin{array}{l}\text { Anti-Japanese } \\
\text { protests }\end{array}$ & $\begin{array}{l}\text { Radio NZ news } \\
\text { bulletin transcript } \\
(11.04 .2005)\end{array}$ & $\begin{array}{l}\text { S2 (F, New Zealand) + } \\
\text { S9 (F, Russia) }\end{array}$ \\
\hline \multirow[t]{3}{*}{ History (3) } & $\begin{array}{l}\text { Gulf victory } \\
\text { parade }\end{array}$ & WSC & S1 (M, New Zealand) \\
\hline & Vikings & WSC & S1 (M, New Zealand) \\
\hline & $\begin{array}{l}\text { Spanish before } \\
\text { Cook }\end{array}$ & WSC & S1 (M, New Zeland) \\
\hline \multirow[t]{3}{*}{ Medicine (3) } & Flu vaccine & $\begin{array}{l}\text { Radio NZ news } \\
\text { bulletin transcript } \\
(14.03 .2005)\end{array}$ & $\begin{array}{l}\text { S8 (F, New Zealand) + } \\
\text { S9 (F, Russia) }\end{array}$ \\
\hline & Skin cancer rates & WSC & S2 (F, New Zealand) \\
\hline & $\begin{array}{l}\text { Underwater } \\
\text { births }\end{array}$ & $\mathrm{BNC}$ & S6 (F, United States) \\
\hline \multirow{3}{*}{$\begin{array}{l}\text { Emergen- } \\
\text { cies (3) }\end{array}$} & NZ tornado & WSC & S1 (M, New Zealand) \\
\hline & Barge sinking & WSC & S1 (M, New Zealand) \\
\hline & Rock throwing & $\begin{array}{l}\text { Radio NZ news } \\
\text { bulletin transcript } \\
(22.08 .2005)\end{array}$ & $\begin{array}{l}\text { S8 (F, New Zealand) + } \\
\text { S9 (F, Russia) }\end{array}$ \\
\hline \multirow[t]{3}{*}{ Sport (3) } & New team & WSC & $\begin{array}{l}\text { S1 (M, New Zealand) + } \\
\text { S9 (F, Russia) }\end{array}$ \\
\hline & Tennis & WSC & S3 (F, Australia) \\
\hline & Rude test & WSC & S6 (F, United States) \\
\hline \multirow{4}{*}{$\begin{array}{l}\text { Miscella- } \\
\text { neous (4) }\end{array}$} & Importing dogs & WSC & S7 (F, New Zealand) \\
\hline & Invalid bet & $\mathrm{BNC}$ & S3 (F, Australia) \\
\hline & $\begin{array}{l}\text { Christmas too } \\
\text { early }\end{array}$ & $\mathrm{BNC}$ & $\begin{array}{l}\text { S4 (M, Britain) + S5 } \\
(\mathrm{M}, \text { New Zealand })\end{array}$ \\
\hline & $\begin{array}{l}\text { Across the } \\
\text { Channel }\end{array}$ & $\mathrm{BNC}$ & $\begin{array}{l}\text { S4 (M, Britain) + S5 } \\
\text { (M, New Zealand) }\end{array}$ \\
\hline
\end{tabular}




\section{Appendix B}

Experiment 1. Number of proper names and text length.

\begin{tabular}{|c|c|c|c|c|}
\hline Text & $\begin{array}{l}\text { Number } \\
\text { of PN } \\
\text { types }\end{array}$ & $\begin{array}{l}\text { Number } \\
\text { of PN } \\
\text { tokens }\end{array}$ & $\begin{array}{l}\text { Length, } S \\
\text { version }\end{array}$ & $\begin{array}{l}\text { Length, C } \\
\text { version }\end{array}$ \\
\hline 1.Rachel's murder & 10 & $17(\mathrm{~S}) / 15(\mathrm{C})^{*}$ & 149 & 153 \\
\hline 2.Random killer & 10 & 13 & 146 & 149 \\
\hline 3.Sky expansion & 11 & 20 & 153 & 152 \\
\hline 4.Pasific fisheries & 10 & 19 & 148 & 156 \\
\hline 5.President runs & 10 & $17(\mathrm{~S}) / 18(\mathrm{C})$ & 154 & 153 \\
\hline 6.Deadly garland & 10 & $15(\mathrm{~S}) / 14(\mathrm{C})$ & 148 & 154 \\
\hline 7.Opinion poll & 10 & 21 & 154 & 148 \\
\hline $\begin{array}{l}\text { 8.Anti-Japanese } \\
\text { protests }\end{array}$ & 10 & 22 & 152 & 152 \\
\hline $\begin{array}{l}\text { 9.Gulf victory } \\
\text { parade }\end{array}$ & 10 & 17 & 152 & 150 \\
\hline 10.Vikings & 10 & $19(\mathrm{~S}) / 18(\mathrm{C})$ & 153 & 155 \\
\hline $\begin{array}{l}\text { 11.Spanish before } \\
\text { Cook }\end{array}$ & 10 & 19 & 150 & 151 \\
\hline 12.Flu vaccine & 10 & 16 & 149 & 153 \\
\hline $\begin{array}{l}\text { 13.Skin cancer } \\
\text { rates }\end{array}$ & 10 & 13 & 153 & 152 \\
\hline $\begin{array}{l}\text { 14.Underwater } \\
\text { births }\end{array}$ & 10 & 10 & 151 & 152 \\
\hline 15.NZ tornado & 10 & 11 & 152 & 160 \\
\hline 16.Barge sinking & 10 & 12 & 149 & 147 \\
\hline 17.Rock throwing & 10 & 11 & 150 & 153 \\
\hline 18.New team & 10 & 14 & 157 & 155 \\
\hline 19.Tennis & 10 & 15 & 149 & 151 \\
\hline 20.Rude test & 10 & 20 & 150 & 151 \\
\hline 21.Importing dogs & 10 & 16 & 153 & 148 \\
\hline 22.Invalid bet & 10 & 14 & 147 & 147 \\
\hline $\begin{array}{l}\text { 23.Christmas too } \\
\text { early }\end{array}$ & 10 & 13 & 155 & 155 \\
\hline $\begin{array}{l}\text { 24.Across the } \\
\text { Channel }\end{array}$ & 10 & 13 & 151 & 160 \\
\hline
\end{tabular}

\footnotetext{
* In 4 texts the number of proper name tokens differed in the simplified and complicated versions due to structural modifications that the originals had undergone.
} 


\section{Appendix C}

Experiment 1 information sheet.

What is a proper name?

A proper name is a word or a group of words that refers to a specific individual or object. The main function of a proper name is to identify a particular person or thing and to distinguish it from others.

Examples: Polly, China, Wellington, Victoria University, the Golden Gate Bridge.

Proper names can be simple (consist of one word) or complex (multi-word). Examples of simple proper names: Frodo, Salient, Mars, Matrix, Telecom.

Examples of complex proper names: the Lord of the Rings, Dominion Post, New World, Courtenay Place, New Zealand Idol.

In principle, any object can have a proper name. But most commonly, we use proper names to point to:

- Gods and goddesses, e.g. Amen-Ra, Allah, Jesus Christ

- Persons, e.g. Mr Bush, Helen Clark, Aristotle

- Pets and other animals, e.g. Bugs Bunny, Fluffy, King Kong

- Geographical locations (natural and constructed), e.g. the Pacific Ocean, Australia, Kelburn Parade, Lake Geneva, Hong Kong, Porirua, Kennedy Airport

- Organizations, e.g. Duxton Hotel, BBC, the National Bank, Broyden Lilies Ltd, Air New Zealand, Readings (Cinema), MacDonalds

- Special events, e.g. the Wellington Film Festival, Christmas, World War II, the Olympic Games

- Publications and works of art, e.g. Romeo and Juliet, Daily Telegraph, Forrest Gump, Mona Lisa, the Statue of Liberty

- Social groups, e.g. VUW Tennis Club, Russians, Catholics, Aborigines, the French, Labour (Party), All Blacks [sports team]

- Product brands, e.g. Panasonic, Milo, Cadbury, Levi's 


\section{Appendix D}

$\mathrm{D}$ [a]. Experiment 1 listening instructions.

You will hear a short news story 2 times: first time the whole story, second time the same story with pauses ( 3 clicks) after each sentence.

Although you may not know all the words in the text, try to be attentive and to understand as much as you can.

While listening to the whole story, pay attention both to the main ideas and the details. Try to understand as much as you can even if you miss something at times.

When listening to the story sentence by sentence, press the Insert button every time you hear a proper name. It doesn't matter if you hear the name only once or 2-3 times. Please press the Insert button each time you think there is a proper name in the text.

$\mathrm{D}[\mathrm{b}]$. Sequence of text presentation.

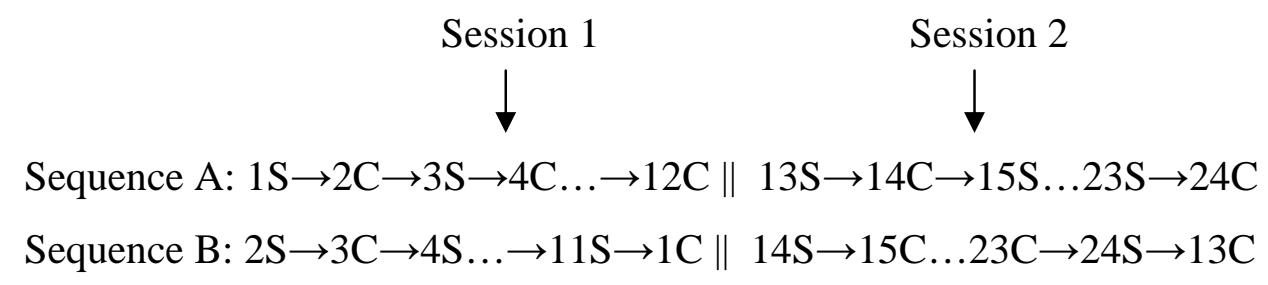




\section{Appendix E}

Experiment 1 participants and their VLT test results.

\begin{tabular}{|c|c|c|c|c|c|c|c|}
\hline Class ${ }^{*}$ & Name & Gender & Age & L1 & $\begin{array}{l}\text { VLT } \\
2000^{* *}\end{array}$ & $\begin{array}{l}\text { VLT } \\
3000\end{array}$ & $\begin{array}{l}\text { VLT } \\
5000\end{array}$ \\
\hline 1 & Amshi & $\mathrm{f}$ & 27 & Japanese & 23 & 22 & 19 \\
\hline 1 & Yuali & $\mathrm{f}$ & 31 & Chinese & 24 & 24 & 17 \\
\hline 1 & Mekuga & $\mathrm{f}$ & 25 & Japanese & 21 & 23 & 20 \\
\hline 1 & Linmea & $\mathrm{f}$ & 19 & Samoan & 22 & 19 & 15 \\
\hline 1 & Zhyunji & $\mathrm{f}$ & 21 & Chinese & 23 & 22 & 20 \\
\hline 1 & Palaipa & $\mathrm{f}$ & 18 & Thai & 24 & 23 & 20 \\
\hline 2 & Klinyan & $\mathrm{m}$ & 18 & Dutch & 30 & 28 & 26 \\
\hline 2 & Joa & $\mathrm{f}$ & 22 & Korean & 30 & 30 & 23 \\
\hline 2 & Sieko & $\mathrm{f}$ & 20 & Mandarin & 30 & 26 & 16 \\
\hline 2 & Souzi & $\mathrm{m}$ & 22 & Mandarin & 30 & 27 & 21 \\
\hline 2 & Kanisa & $\mathrm{m}$ & 24 & Thai & 29 & 25 & 24 \\
\hline 2 & Kanitka & $\mathrm{f}$ & 26 & Thai & 27 & 20 & 19 \\
\hline 2 & Rodem & $\mathrm{m}$ & 26 & Spanish & 29 & 26 & 21 \\
\hline 2 & Iryaka & $\mathrm{f}$ & 18 & Indonesian & 29 & 26 & 24 \\
\hline 3 & Gisu & $\mathrm{f}$ & 22 & Mandarin & 26 & 21 & 18 \\
\hline 3 & Sujong & $\mathrm{m}$ & 24 & Korean & 25 & 21 & 19 \\
\hline 3 & Yoncha & $\mathrm{f}$ & 22 & Chinese & 24 & 18 & 11 \\
\hline 3 & Nisna & $\mathrm{f}$ & 20 & Japanese & $\mathrm{n} / \mathrm{a}^{* * * *}$ & $\mathrm{n} / \mathrm{a}$ & $\mathrm{n} / \mathrm{a}$ \\
\hline
\end{tabular}

\footnotetext{
"Proficiency levels were as follows: Class 1 - higher intermediate, Class 2 - advanced, Class 3 - lower intermediate.

** Vocabulary Levels Test results at the 2000, 3000 and 5000 word level.

**** This participant did not attend the test.
} 


\section{Appendix F}

Experiment 1. Number of errors of different types by participant.

\begin{tabular}{|c|c|c|c|c|c|c|c|c|c|c|c|c|c|}
\hline $\begin{array}{l}\frac{w}{0} \\
\frac{\tilde{J}}{0}\end{array}$ & 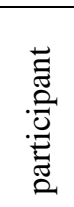 & $\begin{array}{l}\mathrm{S} \\
\text { total }\end{array}$ & $\begin{array}{l}\mathrm{C} \\
\text { total }\end{array}$ & S UW & $\begin{array}{l}\text { S } \\
\text { IP }\end{array}$ & S R & $\begin{array}{l}\mathrm{S} \\
\mathrm{M}\end{array}$ & $\begin{array}{l}\text { C } \\
\text { UW }\end{array}$ & $\begin{array}{l}\text { C } \\
\text { IP }\end{array}$ & C R & $\begin{array}{l}\mathrm{C} \\
\mathrm{M}\end{array}$ & $\begin{array}{l}\text { S non- } \\
\text { random }\end{array}$ & $\begin{array}{l}\text { C non- } \\
\text { random }\end{array}$ \\
\hline 1 & 1 & 4 & 9 & 0 & 2 & 2 & 0 & 8 & 1 & 0 & 0 & 2 & 9 \\
\hline 1 & 2 & 6 & 29 & 1 & 0 & 5 & 0 & 17 & 7 & 2 & 3 & 1 & 27 \\
\hline 1 & 3 & 6 & 7 & 1 & 2 & 1 & 2 & 2 & 4 & 1 & 0 & 5 & 6 \\
\hline 1 & 4 & 1 & 7 & 0 & 1 & 0 & 0 & 3 & 4 & 0 & 0 & 1 & 7 \\
\hline 1 & 5 & 8 & 27 & 1 & 2 & 4 & 1 & 12 & 7 & 6 & 2 & 4 & 21 \\
\hline 1 & 6 & 3 & 14 & 0 & 1 & 2 & 0 & 11 & 1 & 1 & 1 & 1 & 13 \\
\hline 2 & 1 & 1 & 1 & 0 & 1 & 0 & 0 & 1 & 0 & 0 & 0 & 1 & 1 \\
\hline 2 & 2 & 9 & 13 & 0 & 6 & 3 & 0 & 7 & 1 & 3 & 2 & 6 & 10 \\
\hline 2 & 3 & 3 & 11 & 0 & 1 & 2 & 0 & 2 & 4 & 3 & 2 & 1 & 8 \\
\hline 2 & 4 & 4 & 12 & 0 & 1 & 2 & 1 & 4 & 1 & 7 & 0 & 2 & 5 \\
\hline 2 & 5 & 13 & 9 & 0 & 2 & 11 & 0 & 5 & 0 & 4 & 0 & 2 & 5 \\
\hline 2 & 6 & 3 & 23 & 0 & 2 & 1 & 0 & 13 & 5 & 2 & 3 & 2 & 21 \\
\hline 2 & 7 & 5 & 17 & 0 & 2 & 3 & 0 & 5 & 6 & 5 & 1 & 2 & 12 \\
\hline 2 & 8 & 5 & 8 & 0 & 4 & 1 & 0 & 2 & 4 & 1 & 1 & 4 & 7 \\
\hline 3 & 1 & 9 & 19 & 0 & 4 & 3 & 2 & 8 & 4 & 5 & 2 & 6 & 14 \\
\hline 3 & 2 & 4 & 14 & 1 & 1 & 1 & 1 & 5 & 3 & 2 & 4 & 3 & 12 \\
\hline 3 & 3 & 6 & 13 & 0 & 3 & 2 & 1 & 7 & 3 & 2 & 1 & 4 & 11 \\
\hline 3 & 4 & 18 & 29 & 1 & 1 & 15 & 1 & 11 & 6 & 1 & 11 & 3 & 28 \\
\hline \multicolumn{2}{|c|}{ totals -> } & 108 & 262 & 5 & 36 & 58 & 9 & 123 & 61 & 45 & 33 & 50 & 217 \\
\hline
\end{tabular}




\section{Appendix G}

Experiment 2 listening passage.

The Nangatuo boyfriend of a nineteen-year-old Milton University student has been charged with her murder.

Jase Tanner, a twenty two year old student, was charged in court with killing Rati Maclean. Before his arrest Tanner told the police that he last saw Rati when she saw him off on a train to Loottingrey in April. He was arrested in Loottingrey after hours of police questioning. He does not have to appear in court personally until May. The police have described the case as most unusual and are waiting till all the facts become known.

Rati's body was found in the evening at her home in Argyle Street, Dowley, Milton. Taiton Valley police looked under the floor in Rati Maclean's home which she shared with three other students. Rati's mother Rean says Tanner had asked her daughter to marry him but she told him that she wasn't ready. 


\section{Appendix H}

Experiment 2 open-ended questions.

Please write your answers clearly in English. Try hard to answer all questions.

1 . Who were the main characters in the story?

2. How did they know each other?

3. What happened to the girl?

4. Who was arrested and why?

5. He told the police that the last time they met was...

6. What will happen to him next?

7. What does the police think about this case?

8. What did the police find at the student flat?

9. Who lived in this flat?

10. What could be the murderer's motive (=the reason to kill)?

11. Who told the police about this motive? 


\section{Appendix I}

Experiment 2 multiple choice questions.

Please circle the right answer like this a. If you make a mistake please cross the wrong answer out like this and circle the right answer. If you are not sure - please guess. Only one answer is correct!

\section{The two students were}

a - flatmates

$\mathrm{b}-$ boyfriend and girlfriend

$\mathrm{c}$ - murderers

2. The guy was years old.

$a-22$

$b-19$

$c-25$

3. was murdered.

$\mathrm{a}-$ The guy $\quad \mathrm{b}-$ Her mother $\quad \mathrm{c}-$ The girl

4. was charged with murder in court.

a-The guy $\quad b-$ The flatmate $\quad c-$ The girl

5. The last time they saw each other was at

$\mathrm{a}$-her home $\quad \mathrm{b}$ - his home $\quad \mathrm{c}$ - the railway station

\section{The police spent hours}

a - calming the students down

$\mathrm{b}$ - questioning the guy

$\mathrm{c}-$ searching the train

7. The police spoke to the guy and he

a - was arrested

$\mathrm{b}$ - didn't describe all the facts

$\mathrm{c}-$ appeared in court

\section{The body was found}

$\mathrm{a}-$ in the girl's flat $\mathrm{b}-$ in the guy's flat $\mathrm{c}-$ in the street

9. The girl a flat with 3 other students.

$\mathrm{a}$ - was looking for $\quad \mathrm{b}$-lived in $\quad \mathrm{c}$-just moved into 
10. The guy wanted to

$a$ - get married $b$ - appear in court soon $c-$ share the flat

11. The girl was not ready to

$\mathrm{a}$-study $\quad \mathrm{b}$ - live with her mother $\mathrm{c}$ - get married

12. Before the murder, the guy and the girl

a - hated their home

b - didn't want to meet

$\mathrm{c}-$ spent some time together

13. The police

that the guy was the murderer.

$\mathrm{a}-$ knew $\quad \mathrm{b}$ - suspected $\quad \mathrm{c}$-didn't believe

14. The police say this murder case is

$a-$ unusual $\quad b-$ too sad $\quad c-$ endless

15. It looked as if the dead body was

$\mathrm{a}$-hidden $\quad \mathrm{b}$ - unchanged $\quad \mathrm{c}$ - most unusual

16. The girl's mother seems to think that the guy

a - was charged unfairly by mistake

$\mathrm{b}$ - was the real murderer

c - was upset to hear 'no' 


\section{Appendix J}

Experiment 2 proper names related statements (true-false-don't know).

1. F Nangatuo is part of Milton University.

2. T Jase Tanner comes from the Nangatuo region.

3. DN Rati Maclean and her mother have travelled to Nangatuo before.

4. T Jase Tanner was arrested in Loottingrey.

5. F Rati Maclean's home was in Loottingrey.

6. T Rati lived in Argyle Street, Milton.

7. F Dowley is one of Rati's three flatmates.

8. T Argyle Street is in Dowley.

9. T Rati's body was discovered by Taiton Valley Police.

10. DN Taiton Valley Police building is very close to Rati's flat.

11. T Rean and Rati Maclean were relatives.

12. $\mathrm{T}$ Rean was interviewed by the police.

13. DN Rean often visited Rati's flat in the evenings.

14. F Jase Tanner and Rati Maclean were relatives.

Participants' answer sheet.

Please circle the right answer. If you make a mistake please cross the wrong answer out like this and then circle the right answer. Only one answer is correct!

$\mathrm{T}=$ True $\quad \mathrm{F}=$ False $\quad \mathrm{DN}=$ Don't know

1. $\mathrm{T} \quad \mathrm{F}$ DN

2. T $\mathrm{F}$ DN

3. T $\mathrm{F}$ DN

4. T $\mathrm{F} \quad \mathrm{DN}$

5. etc. 


\section{Appendix K}

Experiment 2. Difficulty ratings of the experimental tasks, participants' answer sheet. Please circle ONE number .

1. How well do you think you understood the story?

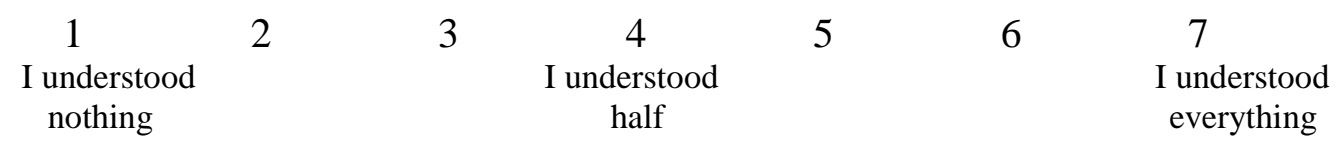

2. How difficult was it for you to retell the story?

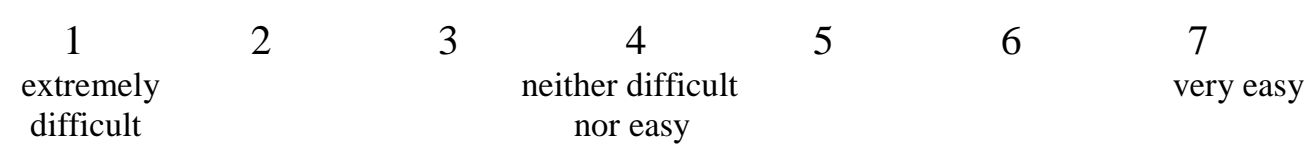

3. How difficult was it for you to answer multiple choice questions?

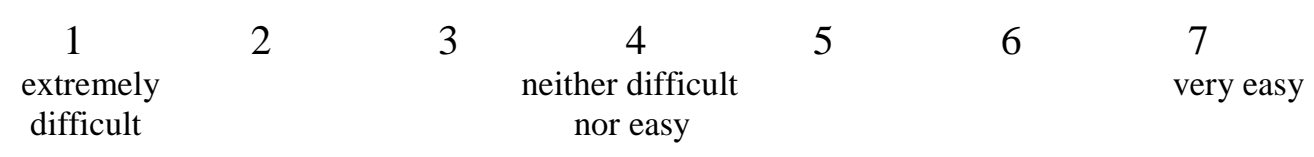

4. How difficult was it for you to answer True/False/Don't Know questions?

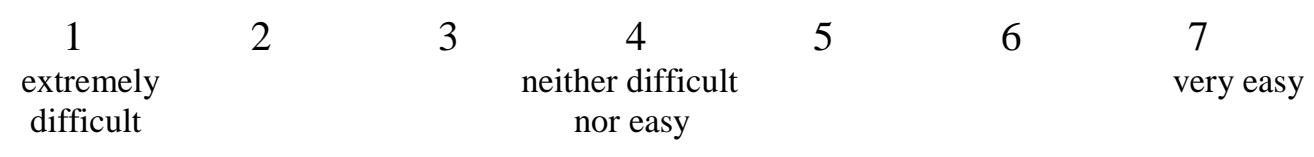

5. How difficult was it for you to do the computer test at the end?

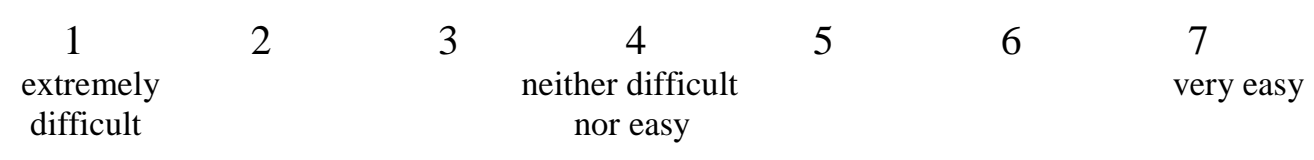




\section{Appendix L}

Experiment 2. Participants' scores on open-ended questions (out of 33).

\begin{tabular}{|l|r|l|r|}
\hline Names Known & \multicolumn{2}{l|}{ Names Unknown } \\
\hline Participant & OE score & Participant & OE score \\
\hline ANV & 18 & FZH & 11 \\
\hline CMN & 11 & XNL & 5 \\
\hline MRC & 14 & WUT & 20 \\
\hline SMT & 13 & YNJ & 8 \\
\hline STB & 21 & KRS & 23 \\
\hline LSG & 24 & RTM & 16 \\
\hline TUM & 9 & THH & 6 \\
\hline BSY & 10 & PLA & 6 \\
\hline DVA & 26 & MLD & 0 \\
\hline VRS & 8 & MQD & 27 \\
\hline VHM & 29 & NHQ & 8 \\
\hline BAR & 6 & TKRF & 12 \\
\hline EUM & 14 & GZM & 24 \\
\hline HUN & 9 & TVM & 17 \\
\hline ALL & 23 & JOL & 21 \\
\hline IEO & 12 & NAT & 14 \\
\hline NRB & & AGS & 21 \\
\hline NSA & & SCP & 19 \\
\hline TWL & & & 26 \\
\hline & & NBH & \\
\hline & & & 21 \\
\hline
\end{tabular}




\section{Appendix M}

Experiment 2. Participants' scores on multiple choice questions (out of 16).

\begin{tabular}{|l|r|l|l|}
\hline \multicolumn{2}{|l|}{ Names Known } & \multicolumn{2}{l|}{} \\
\hline Participant & MC score & Participant & MC score \\
\hline YML & 11 & GZF & 7 \\
\hline CNX & 13 & KTS & 8 \\
\hline KKN & 11 & LOE & 8 \\
\hline KJW & 10 & CRG & 6 \\
\hline ANV & 10 & FZH & 9 \\
\hline CMN & 8 & XNL & 9 \\
\hline MRC & 10 & WUT & 13 \\
\hline SMT & 12 & YNJ & 12 \\
\hline STB & 15 & KRS & 13 \\
\hline LSG & 13 & RTM & 7 \\
\hline TUM & 7 & THH & 9 \\
\hline BSY & 11 & PLA & 11 \\
\hline DVA & 13 & MLD & 5 \\
\hline VRS & 9 & MQD & 11 \\
\hline VHM & 15 & NHQ & 13 \\
\hline PKP & 11 & TKRF & 10 \\
\hline MSM & 7 & GZM & 14 \\
\hline BAR & 5 & TVM & 14 \\
\hline EUM & 13 & JOL & 13 \\
\hline HUN & 6 & NAT & 15 \\
\hline ALL & 10 & AGS & 13 \\
\hline IEO & 9 & LCP & 7 \\
\hline NRB & 14 & NBH & 10 \\
\hline NSA & 13 & YKA & 13 \\
\hline TWL & 13 & SAS & 13 \\
\hline & & & 13 \\
\hline
\end{tabular}




\section{Appendix N}

Experiment 2. Participants' scores on proper names related statements (true-falsedon't-know, out of 14).

\begin{tabular}{|c|c|c|c|}
\hline \multicolumn{2}{|c|}{ Names Known } & \multicolumn{2}{|c|}{ Names Unknown } \\
\hline Participant & TFDN score & Participant & TFDN score \\
\hline YML & 10 & GZF & 4 \\
\hline CNX & 9 & KTS & 3 \\
\hline $\mathrm{KKN}$ & 8 & LOE & 5 \\
\hline KJW & 7 & CRG & 4 \\
\hline ANV & 8 & FZH & 4 \\
\hline CMN & 8 & XNL & 6 \\
\hline MRC & 9 & WUT & 6 \\
\hline SMT & 12 & YNJ & 9 \\
\hline STB & 12 & KRS & 7 \\
\hline LSG & 10 & RTM & 1 \\
\hline TUM & 13 & $\mathrm{THH}$ & 8 \\
\hline BSY & 10 & PLA & 9 \\
\hline DVA & 13 & MLD & 6 \\
\hline VRS & 7 & MQD & 8 \\
\hline VHM & 10 & NHQ & 6 \\
\hline PKP & 9 & TKRF & 6 \\
\hline MSM & 7 & GZM & 10 \\
\hline BAR & 11 & TVM & 10 \\
\hline EUM & 11 & $\mathrm{JOL}$ & 2 \\
\hline HUN & 7 & NAT & 5 \\
\hline ALL & 10 & AGS & 6 \\
\hline IEO & 9 & LCP & 7 \\
\hline NRB & 10 & $\mathrm{NBH}$ & 4 \\
\hline NSA & 11 & YKA & 8 \\
\hline TWL & 11 & SAS & 8 \\
\hline
\end{tabular}




\section{Appendix P}

Experiment 2. Participants' difficulty ratings of experimental tasks.

Names Known Group.

\begin{tabular}{|l|r|r|r|r|r|r|}
\hline Participant & DR $_{\text {compeh }}$ & Retell & MC & TFDN & PNT & Total \\
\hline YML & 4 & 3 & 4 & 5 & 7 & 23 \\
\hline CNX & 4 & 4 & 4 & 4 & 4 & 20 \\
\hline KKN & 4 & 5 & 2 & 4 & 4 & 19 \\
\hline KJW & 4 & 4 & 3 & 3 & 4 & 18 \\
\hline ANV & 5 & 3 & 6 & 3 & 5 & 22 \\
\hline CMN & 4 & 4 & 5 & 3 & 5 & 21 \\
\hline MRC & 5 & 4 & 5 & 6 & 6 & 26 \\
\hline SMT & 5 & 4 & 7 & 6 & 7 & 29 \\
\hline STB & 5 & 5 & 5 & 6 & 6 & 27 \\
\hline LSG & 5 & 5 & 5 & 3 & 3 & 21 \\
\hline TUM & 4 & 4 & 5 & 7 & 6 & 26 \\
\hline BSY & 4 & 4 & 4 & 4 & 4 & 20 \\
\hline DVA & 5 & 5 & 6 & 6 & 4 & 26 \\
\hline VRS & 4 & 4 & 4 & 4 & 4 & 20 \\
\hline VHM & 4 & 4 & 5 & 3 & 5 & 21 \\
\hline PKP & 2 & 1 & 2 & 2 & 4 & 11 \\
\hline MSM & 2 & 1 & 2 & 2 & 2 & 9 \\
\hline BAR & 4 & 3 & 5 & 5 & 7 & 24 \\
\hline EUM & 4 & 3 & 4 & 4 & 5 & 20 \\
\hline HUN & 3 & 3 & 3 & 3 & 4 & 16 \\
\hline ALL & 5 & 5 & 6 & 6 & 5 & 27 \\
\hline IEO & 5 & 5 & 4 & 5 & 6 & 25 \\
\hline NRB & 5 & 5 & 5 & 5 & 6 & 26 \\
\hline NSA & 6 & 6 & 6 & 6 & 6 & 30 \\
\hline TWL & 6 & 4 & 7 & 7 & 5 & 29 \\
\hline
\end{tabular}


Names Unknown Group.

\begin{tabular}{|l|r|r|r|r|r|r|}
\hline Participant & DR $_{\text {compeh }}$ & Retell & MC & TFDN & PNT & Total \\
\hline GZF & 2 & 1 & 2 & 1 & 3 & 9 \\
\hline KTS & 2 & 1 & 3 & 1 & 1 & 8 \\
\hline LOE & 3 & 3 & 3 & 2 & 1 & 12 \\
\hline CRG & 2 & 3 & 2 & 2 & 1 & 10 \\
\hline FZH & 3 & 2 & 3 & 3 & 3 & 14 \\
\hline XNL & 2 & 2 & 3 & 1 & 3 & 11 \\
\hline WUT & 5 & 5 & 6 & 2 & 6 & 24 \\
\hline YNJ & 4 & 2 & 5 & 3 & 2 & 16 \\
\hline KRS & 5 & 3 & 3 & 2 & 4 & 17 \\
\hline RTM & 4 & 5 & 3 & 4 & 4 & 20 \\
\hline THH & 3 & 2 & 3 & 2 & 3 & 13 \\
\hline PLA & 3 & 4 & 5 & 4 & 6 & 22 \\
\hline MLD & 2 & 2 & 4 & 4 & 4 & 16 \\
\hline MQD & 5 & 5 & 5 & 3 & 4 & 22 \\
\hline NHQ & 3 & 3 & 4 & 4 & 4 & 18 \\
\hline TKRF & 2 & 2 & 5 & 5 & 3 & 17 \\
\hline GZM & 4 & 3 & 3 & 3 & 2 & 15 \\
\hline TVM & 4 & 4 & 5 & 5 & 5 & 23 \\
\hline JOL & 4 & 5 & 6 & 1 & 2 & 18 \\
\hline NAT & 4 & 4 & 4 & 3 & 3 & 18 \\
\hline AGS & 5 & 4 & 6 & 3 & 3 & 21 \\
\hline LCP & 3 & 3 & 4 & 4 & 4 & 18 \\
\hline NBH & 3 & 2 & 4 & 3 & 3 & 15 \\
\hline YKA & 4 & 3 & 6 & 2 & 3 & 18 \\
\hline SAS & 3 & 4 & 2 & 2 & 3 & 14 \\
\hline
\end{tabular}




\section{Appendix Q}

Experiment 3. Participants' scores on proper names related statements (true-falsedon't know, out of 14).

\begin{tabular}{|c|c|c|c|}
\hline \multicolumn{2}{|c|}{ Names Known } & \multicolumn{2}{|c|}{ Names Unknown } \\
\hline Participant & TFDN score & Participant & TFDN score \\
\hline NBT & 9 & SNE & 5 \\
\hline MDP & 7 & CRD & 9 \\
\hline PTH & 4 & VIC & 4 \\
\hline TTH & 9 & AHD & 2 \\
\hline HKK & 8 & UNG & 4 \\
\hline KAT & 13 & PEG & 5 \\
\hline PIL & 10 & $\mathrm{JJC}$ & 7 \\
\hline DIG & 11 & CEO & 7 \\
\hline MHT & 8 & JDM & 5 \\
\hline LZT & 10 & AID & 6 \\
\hline $\mathrm{VCZ}$ & 4 & LUM & 7 \\
\hline NAR & 10 & WEI & 8 \\
\hline SIV & 8 & $\mathrm{OKZ}$ & 4 \\
\hline DRA & 6 & MHY & 4 \\
\hline FAT & 11 & PAN & 3 \\
\hline FAB & 7 & THI & 8 \\
\hline $\mathrm{CAN}$ & 10 & $\mathrm{BPH}$ & 2 \\
\hline ALB & 10 & $\mathrm{HOM}$ & 4 \\
\hline $\mathrm{JOO}$ & 11 & KNS & 7 \\
\hline FYU & 9 & DMR & 5 \\
\hline WYX & 10 & GLY & 11 \\
\hline XRU & 9 & JUN & 7 \\
\hline CLP & 8 & WAG & 7 \\
\hline NOR & 10 & AAS & 5 \\
\hline KAW & 9 & DAL & 3 \\
\hline SAO & 7 & THE & 7 \\
\hline AMY & 9 & RUI & 6 \\
\hline KHA & 11 & LEV & 2 \\
\hline MIY & 10 & YKA & 9 \\
\hline ITT & 11 & UMI & 9 \\
\hline ZED & 12 & NAC & 9 \\
\hline LIW & 9 & KOB & 8 \\
\hline TOU & 11 & YJY & 5 \\
\hline MAH & 7 & PAS & 4 \\
\hline OMA & 5 & ENG & 7 \\
\hline DAY & 8 & BIR & 6 \\
\hline ESU & 9 & SHE & 5 \\
\hline JOA & 9 & ARO & 6 \\
\hline FIK & 11 & LKS & 8 \\
\hline GEL & 8 & NAF & 4 \\
\hline
\end{tabular}




\begin{tabular}{|l|r|l|r|}
\hline \multicolumn{2}{|l|}{ Names Known } & \multicolumn{2}{l|}{ Names Unknown } \\
\hline Participant & TFDN score & Participant & TFDN score \\
\hline OVL & 12 & KEA & 5 \\
\hline NID & 12 & ITA & 9 \\
\hline LMT & 9 & CIS & 8 \\
\hline YFA & 7 & ROD & 5 \\
\hline EMR & 11 & KWE & 5 \\
\hline SUN & 9 & RAT & 6 \\
\hline MAZ & 8 & AYE & 3 \\
\hline LIN & 10 & HAL & 7 \\
\hline EID & 11 & PCW & 9 \\
\hline ELL & 6 & JIN & 8 \\
\hline VIN & 6 & VET & 5 \\
\hline ADA & 7 & MUJ & 7 \\
\hline DNT & 10 & IQB & 5 \\
\hline BRM & 11 & FAN & 4 \\
\hline JIT & 8 & HUO & 5 \\
\hline
\end{tabular}




\section{Appendix R.}

Experiment 3. Participants' scores on open-ended questions (out of 33).

\begin{tabular}{|c|c|c|c|}
\hline \multicolumn{2}{|c|}{ Names Known } & \multicolumn{2}{|c|}{ Names Unknown } \\
\hline Participant & OE score & Participant & OE score \\
\hline NBT & 4 & SNE & 6 \\
\hline MDP & 3 & CRD & 14 \\
\hline PTH & 7 & VIC & 3 \\
\hline TTH & 11 & AHD & 0 \\
\hline HKK & 22 & UNG & 14 \\
\hline KAT & 28 & PEG & 14 \\
\hline PIL & 7 & JJC & 8 \\
\hline DIG & 5 & CEO & 10 \\
\hline MHT & 13 & JDM & 26 \\
\hline LZT & 23 & AID & 7 \\
\hline VCZ & 1 & LUM & 9 \\
\hline NAR & 9 & WEI & 17 \\
\hline SIV & 22 & $\mathrm{OKZ}$ & 8 \\
\hline DRA & 2 & MHY & 6 \\
\hline FAT & 26 & PAN & 6 \\
\hline FAB & 25 & THI & 12 \\
\hline $\mathrm{CAN}$ & 12 & $\mathrm{BPH}$ & 12 \\
\hline ALB & 16 & HOM & 11 \\
\hline JOO & 7 & KNS & 8 \\
\hline FYU & 8 & DMR & 5 \\
\hline WYX & 14 & GLY & 9 \\
\hline XRU & 7 & JUN & 3 \\
\hline CLP & 13 & WAG & 6 \\
\hline NOR & 12 & AAS & 12 \\
\hline KAW & 18 & DAL & 7 \\
\hline SAO & 15 & THE & 12 \\
\hline AMY & 23 & RUI & 6 \\
\hline KHA & 26 & LEV & 4 \\
\hline MIY & 17 & YKA & 8 \\
\hline ITT & 18 & UMI & 15 \\
\hline ZED & 16 & NAC & 5 \\
\hline LIW & 20 & KOB & 1 \\
\hline TOU & 11 & YJY & 12 \\
\hline MAH & 10 & PAS & 5 \\
\hline OMA & 10 & ENG & 6 \\
\hline DAY & 20 & BIR & 9 \\
\hline ESU & 10 & SHE & 14 \\
\hline JOA & 15 & ARO & 3 \\
\hline FIK & 16 & LKS & 16 \\
\hline GEL & 19 & NAF & 5 \\
\hline
\end{tabular}




\begin{tabular}{|l|r|l|r|}
\hline \multicolumn{2}{|l|}{ Names Known } & \multicolumn{2}{l|}{ Names Unknown } \\
\hline Participant & OE score & Participant & OE score \\
\hline OVL & 30 & KEA & 5 \\
\hline NID & 29 & ITA & 10 \\
\hline LMT & 10 & CIS & 25 \\
\hline YFA & 17 & ROD & 5 \\
\hline EMR & 6 & KWE & 10 \\
\hline SUN & 8 & RAT & 5 \\
\hline MAZ & 17 & AYE & 6 \\
\hline LIN & 6 & HAL & 8 \\
\hline EID & 12 & PCW & 15 \\
\hline ELL & 6 & JIN & 7 \\
\hline VIN & 11 & VET & 5 \\
\hline ADA & 11 & MUJ & 13 \\
\hline DNT & 14 & IQB & 2 \\
\hline BRM & 17 & FAN & 0 \\
\hline JIT & 6 & HUO & 5 \\
\hline
\end{tabular}




\section{Appendix S}

Experiment 2. Computerized proper names test (PNT). Correct options and distractors for questions 2 and 3.

Section 1. Participant hears: 'Nangatuo'

2. In this text this expression refers to (tick as many options as you think are correct):
(c) geographical area*
( ) boyfriend
( ) mountain in New Zealand
( ) North Island boundary
(c) region in New Zealand
( ) New Zealand students

3. In this text this expression refers to (choose one option only):
( ) student group
(c) geographical location
( ) political party

Section 2. Participant hears: 'Milton University'

2. In this text this expression refers to (tick as many options as you think are correct):

( ) train timetable

( ) police department

( ) Victoria campus

( ) university in New Zealand

(c) university in Britain

( ) city of contrasts

3. In this text this expression refers to (choose one option only):
(c) university
( ) police
( ) court

Section 3. Participant hears: 'Jase Tanner'

2. In this text this expression refers to (tick as many options as you think are correct):
( ) getting a tan
(c) person charged with murder
(c) university student
( ) young girl with her mother
( ) elderly woman
(c) young guy

3. In this text this expression refers to (choose one option only):
( ) place
(c) person
( ) train

\footnotetext{
" ' $\mathrm{C}$ ' indicates correct options.
} 
Section 4. Participant hears: 'Milton'

2. In this text this expression refers to (tick as many options as you think are correct):

( ) military ton

( ) part of the university

(c) city in Britain

( ) bridge over the Milton River

(c) city where the victim studied

( ) part of the police search

3. In this text this expression refers to (choose one option only):
( ) building
( ) person
(c) city

Section 5. Participant hears: 'Rati Maclean'

2. In this text this expression refers to (tick as many options as you think are correct):

(c) 19-year-old girl

(c) girl who was killed

( ) 19-year-old guy

( ) 22-year-old girl

( ) 22-year-old guy

( ) girl's mother

3. In this text this expression refers to (choose one option only):
( ) $\operatorname{dog}$
( ) floor
(c) person

Section 6. Participant hears: 'Taiton Valley'

2. In this text this expression refers to (tick as many options as you think are correct):
( ) 19-year-old girl
(c) geographical area in Britain
( ) valley where taitons live
( ) train station
(c) region where the girl was killed
( ) geographical area in New Zealand

3. In this text this expression refers to (choose one option only):

(c) region

( ) person

( ) holiday

Section 7. Participant hears: 'Argyle Street'

2. In this text this expression refers to (tick as many options as you think are correct):

( ) police department

( ) floor argyle

(c) street where the victim lived

( ) street where the police didn't go

( ) train depot 
( ) British newspaper

3. In this text this expression refers to (choose one option only):

(c) street

( ) war

( ) marriage

Section 8. Participant hears: 'Dowley'

2. In this text this expression refers to (tick as many options as you think are correct):
(c) suburb in Milton
( ) suburb in Nangatuo
( ) boyfriend's address
(c) suburb where the victim lived
( ) boyfriend's home town
( ) dough

3. In this text this expression refers to (choose one option only):
( ) dough
( ) parent
(c) suburb

Section 9. Participant hears: 'Rean'

2. In this text this expression refers to (tick as many options as you think are correct):

( ) marine animal

( ) the boyfriend's friend

( ) the boyfriend's lawyer

(c) the girl's mother

( ) the girl's death

( ) something green

3. In this text this expression refers to (choose one option only):

( ) student

( ) police

(c) mother

Section 10. Participant hears: 'Loottingrey'

2. In this text this expression refers to (tick as many options as you think are correct):

(c) city in Britain

( ) city where the university was

( ) train station

( ) looting

(c) Jase Tanner was going there before his arrest

( ) suburb where Rati Maclean lived

3. In this text this expression refers to (choose one option only):

(c) city

( ) train

( ) loot 


\section{Appendix T}

Experiments 2 and 3. Cards used in preteaching.

\begin{tabular}{|l|l|}
\hline $\begin{array}{l}\text { Front of card } \\
\text { (proper names) }\end{array}$ & $\begin{array}{l}\text { Reverse of card } \\
\text { (descriptions of referents) }\end{array}$ \\
\hline Nangatuo & region in New Zealand \\
\hline Milton University & university in Britain \\
\hline Jase Tanner & guy \\
\hline Milton & city in Britain \\
\hline Rati Maclean & girl \\
\hline Taiton Valley & $\begin{array}{l}\text { region in Britain } \\
\text { (where Milton is) }\end{array}$ \\
\hline Argyle Street & street in Milton \\
\hline Dowley & suburb in Milton \\
\hline Rean & woman \\
\hline Loottingrey & town in Britain \\
\hline
\end{tabular}




\section{List of textbooks}

Abbs, Brian, Chris Barker, and Ingrid Freebairn. 1997. Snapshot: starter students' book. Harlow: Longman.

Abbs, Brian, Ingrid Freebairn, and Chris Barker. 1998. Snapshot: elementary students' book. Harlow: Longman.

2000. Snapshot: intermediate students' book. Harlow: Longman.

Acklam, Richard, and Araminta Crace. 2005. Total English: pre-intermediate students' book. Harlow: Longman.

Baker, Lida R., Mary Mitchell Church, Pamela Hartmann, Keesia Hyzer, Elaine Kirn, John P. Nelson, Cheryl Pavlik, Margaret Keenan Segal, Judith Tanka, and Patricia K. Werner. 2003. Interactions 2, integrated skills edition: intermediate. New York: McGraw-Hill Contemporary.

Bell, Jan, and Roger Gower. 1988. Matters: advanced students' book. Harlow: Longman.

. 1992. Matters: upper intermediate students' book. Harlow: Longman.

— 1995. Matters: pre-intermediate students' book. Harlow: Longman.

— 1997. Matters: elementary students' book. Harlow: Longman.

Brawn, Pornsawan. 2003. Listening to New Zealand: intermediate. Sydney: NSW AMES [Adult Migrant English Service].

Butterworth, Anthony, and Patti Nicholson. 2003. Listening to New Zealand: postbeginner. Sydney: NSW AMES [Adult Migrant English Service].

Clare, Antonia, and JJ Wilson. 2002. Language to go: upper intermediate students' book. Edited by S. Greenall. Harlow: Longman.

Crace, Araminta, and Robin Wileman. 2002. Language to go: intermediate students' book. Edited by S. Greenall. Harlow: Longman.

Cunningham, Gillie, and Sue Mohamed. 2002. Language to go: pre-intermediate students' book. Edited by S. Greenall. Harlow: Longman.

Cunningham, Sarah, and Peter Moor. 2005. New cutting edge: upper intermediate students' book. Harlow: Pearson Education Limited, Longman.

Doff, Adrian, and Christopher Jones. 2000. Language in use new edition: preintermediate classroom book. Cambridge: Cambridge University Press. 
Foley, Barbara, and Howard Pomann. 1992. Lifelines 1 coping skills in English: entry. Englewood Cliffs: Regents/Prentice Hall.

1993. Lifelines 2 coping skills in English: beginning. Englewood Cliffs: Regents/Prentice Hall.

- 1993. Lifelines 3 coping skills in English: low intermediate. Englewood Cliffs: Prentice Hall Regents.

1995. Lifelines 4 coping skills in English: intermediate. Englewood Cliffs: Prentice Hall Regents.

Foley, Mark, and Diane Hall. 2005. Total English elementary: students' book. Harlow: Longman.

Haines, Simon, and Barbara Stewart. 2000a. Landmark: intermediate student's book. Oxford: Oxford University Press.

- 2000b. Landmark: upper intermediate student's book. Oxford: Oxford University Press.

Harris, Michael, and David Mower. 2002. Opportunities: beginner students' book. Harlow: Longman.

Jeffries, Amanda. 2001. Clockwise: advanced classbook. Oxford: Oxford University Press.

Jones, Ceri, Tania Bastow, and Jon Hird. 2001. Inside out: advanced student's book Oxford: Macmillan Heinemann.

Kay, Sue, Vaughan Jones, Jon Hird, and Philip Kerr. 2001. Inside out: upper intermediate student's book. Oxford: Macmillan.

le Maistre, Simon, and Carina Lewis. 2002. Language to go: elementary students' book. Edited by S. Greenall. Harlow: Longman.

Mattson, Lyn. 2007. Listen up: listening activities for adult ESOL beginners. Christchurch: ESOL Home Tutors Christchurch Inc.

McKinlay, Stuart, and Bob Hastings. 2007. Success: intermediate students' book. Harlow: Pearson Education Limited.

Nicholson, Patti, and Anthony Butterworth. 2003. Listening to New Zealand: beginner. Sydney: NSW AMES [Adult Migrant English Service].

Radley, Paul, and Kathy Burke. 1999. Workout: advanced students' book. Harlow: Longman.

Richards, Jack C., Jonathan Hull, and Susan Proctor. 2005. Interchange third edition: student's book 2. Cambridge: Cambridge University Press. 
Richards, Jack C., and Chuck Sandy. 2000. Passages, an upper-level multi-skills course: student's book 2. Cambridge: Cambridge University Press.

Saslow, Joan M., and Allen Ascher. 2006. Summit 1: English for today's world. White Plains: Pearson Education Inc.

Walton, Richard, and Mark Bartram. 2000. Initiative, a course for advanced learners: student's book. Cambridge: Cambridge University Press.

Wilson, JJ, and Antonia Clare. 2007. Total English: advanced students' book. Harlow: Longman. 


\section{References}

IELTS Specimen Materials 2003 (updated October 2003). University of Cambridge ESOL Examinations, the British Council, IDP: IELTS Australia.

IELTS Specimen Materials April 1995 (updated November 1997). UCLES [University of Cambridge Local Examinations Syndicate], the British Council, IDP Education Australia.

The new encyclopaedia Britannica. 2002. 15th ed. Vol. 24. Chicago: Encyclopædia Britannica, Inc.

The Chicago Manual of Style. 2003. 15th ed. Chicago: University of Chicago Press.

Alford, Richard D. 1988. Naming and identity: a cross-cultural study of personal naming practices. New Haven: HRAF Press.

Algeo, John. 1973. On defining the proper name. Gainesville: University of Florida Press.

Allan, Keith. 1986. Linguistic meaning. Vol. 1. London, New York: Routledge and Kegan Paul.

—. 2001. Natural language semantics. Malden: Blackwell.

Allerton, David J. 1987. The linguistic and sociolinguistic status of proper names. Journal of pragmatics 11 (1): p 61-92.

Ames, Wilbur S. 1966. The development of a classification scheme of contextual aids. Reading research quarterly 2 (1): p 57-82.

Anderson, John Mathieson. 2003. On the structure of names. Folia linguistica 37 (34): p 347-98.

-2004. On the grammatical status of names. Language 80 (3): p 435-74.

— 2007. The grammar of names. New York: Oxford University Press.

Anderson-Hsieh, Janet, and Kenneth Koehler. 1988. The effects of foreign accent and speaking rate on native speaker comprehension. Language learning 38 (4): p 561-613.

Arcario, Paul. 1990. Criteria for selecting video materials. In Video in second language teaching: using, selecting and producing video for the classroom, edited by S. Stempleski and P. Arcario. p 109-21: Teachers of English to Speakers of Other Languages, Inc.

Arnaud, Pierre J.L., and Henri Béjoint, eds. 1992. Vocabulary and applied linguistics. London: Macmillan. 
Asher, R.E., and J.M.Y. Simpson, eds. 1994. The encyclopedia of language and linguistics. Vol.6. Oxford: Pergamon Press.

Austin, John Langshaw. 1962. How to do things with words: the William James Lectures delivered at Harvard University in 1955. Oxford: Clarendon Press.

Bauer, Laurie. 1983. English word-formation. Cambridge: Cambridge University Press.

Baxter, James Keir. 1972. Stonegut sugar works; Junkies \& the fuzz; Ode to Auckland, \& other poems. Dunedin: Caveman Press.

Beglar, David, and Alan Hunt. 1999. Revising and validating the 2000 Word Level and University Word Level Vocabulary Tests Language testing 16 (2): p 131-62.

Berezowski, Leszek. 2001. Articles and proper names. Wrocław: Wydaw. Uniwersytetu Wrocławskiego.

Berkemeyer, Victoria C. 1989. Qualitative analysis of immediate recall protocol data: some classroom implications. Die Unterrichtspraxis/Teaching German 22 (2): p 1317.

Berne, Jane E. 1993. The role of text type, assessment task, and target language experience in L2 listening comprehension assessment. Paper presented at the Annual Meetings of the American Association for Applied Linguistics and the American Association of Teachers of Spanish and Portuguese. Atlanta, USA, March 1993, and Cancun, Mexico, August 1992. Available from ERIC, accession number ED 358737.

1995. How does varying pre-listening activities affect second language listening comprehension? Hispania 78 (2): p 316-29.

Bernhardt, Elizabeth B. 1983. Testing foreign language reading comprehension: the immediate recall protocol. Die Unterrichtspraxis/Teaching German 16 (1): p 27-33.

- 1991. Reading development in a second language: theoretical, empirical, and classroom perspectives. Norwood: Ablex Publishing Corporation.

Bernhardt, Elizabeth B., and Charles J. James. 1987. The teaching and testing of comprehension in foreign language learning. In Proficiency, policy and professionalism in foreign language education, edited by D. W. Birckbichler. p 65-81. Lincolnwood: National Textbook Company.

Bhat, D.N.S. 1979. The referents of noun phrases. Pune: Deccan College Postgraduate and Research Institute.

Birckbichler, Diane W., ed. 1987. Proficiency, policy and professionalism in foreign language education. Lincolnwood: National Textbook Company.

Bjørge, Anne Kari. 2003. The explicitation of proper names in expository news texts. International journal of applied linguistics 13 (1): p 115-38. 
Blau, Eileen K. 1982. The effect of syntax on readability for ESL students in Puerto Rico. TESOL quarterly 16 (4): p 517-28.

. 1990. The effect of syntax, speed and pauses on listening comprehension. TESOL quarterly 24 (4): p 746-53.

Bonk, William J. 2000. Second language lexical knowledge and listening comprehension. International journal of listening 14: p 14-31.

Brindley, Geoff. 1998. Assessing listening abilities. Annual review of applied linguistics 18: p 171-91.

Buck, Gary. 2001. Assessing listening. Cambridge: Cambridge University Press.

Burns, Matthew K., Vincent J. Dean, and Sarah Foley. 2004. Preteaching unknown key words with incremental rehearsal to improve reading fluency and comprehension with children identified as reading disabled. Journal of school psychology 42 (4): p 303-14.

Bussmann, Hadumod. 1996. Routledge dictionary of language and linguistics. Translated by G. Trauth and K. Kazzazi. London, New York: Routledge.

Carney, Edward. 1994. A survey of English spelling. London, New York: Routledge.

Carroll, John M. 1985. What's in a name?: an essay in the psychology of reference. New York: W.H. Freeman.

Carver, Ronald P. 1994. Percentage of unknown vocabulary words in text as a function of the relative difficulty of the text: implications for instruction. Journal of reading behaviour 26 (4): p 413-37.

Chang, Yuh-Fang. 2006. On the use of the immediate recall task as a measure of second language reading comprehension. Language testing 23 (4): p 520-43.

Chiang, Chung Shing, and Patricia Dunkel. 1992. The effect of speech modification, prior knowledge, and listening proficiency on EFL lecture learning. TESOL quarterly 26 (2): p 345-74.

Chomsky, Noam. 1965. Aspects of the theory of syntax. Cambridge: M.I.T. Press.

Chung, Teresa Mihwa. 2003. Identifying technical terms: a thesis submitted to the Victoria University of Wellington in fulfilment of the requirements for the degree of Doctor of Philosophy in Applied Linguistics. Wellington: Victoria University of Wellington.

Cinque, Guglielmo. 2003. Predication. In International encyclopedia of linguistics, edited by W.J. Frawley. p 399-400. New York: Oxford University Press.

Clankie, Shawn M. 2002. A theory of genericization on brand name change.

Lewiston: Edwin Mellen Press. 
Clark, Herbert H., and Richard J. Gerrig. 1983. Understanding old words with new meanings. Journal of verbal learning and verbal behaviour 22: p 591-608.

Coady, James, and Thomas N. Huckin. 1997. Second language vocabulary acquisition: a rationale for pedagogy. Cambridge, New York: Cambridge University Press.

Coates, Richard. 1994. Proper names: change of form. In The encyclopedia of language and linguistics, edited by R. E. Asher and J. M. Y. Simpson. p 3369-72. Oxford: Pergamon Press.

2000. Singular definite expressions with a unique denotatum and the limits of properhood. Linguistics 38 (6): p 1161-74.

- 2004. A speculative psycholinguistic model of onymization. Paper presented at the International Onomastic Symposium, 2-4 September 2004, Zadar, Croatia.

—. 2006. Properhood. Language 82 (2): p 356-82.

Cohen, Andrew D. 1999. Exploring strategies in test-taking: fine-tuning verbal reports from respondents. In Learner-directed assessment in ESL, edited by G. Ekbatani and H. Pierson. p 127-50. Mahwah: Lawrence Erlbaum Associates.

Coxhead, Averil Jean. 1998. The development and evaluation of an academic word list: a thesis submitted to the Victoria University of Wellington in fulfilment of the requirements for the degree of Master of Arts in Applied Linguistics. Wellington: Victoria University of Wellington.

Croft, William. 2003. Typology and universals. 2nd ed. Cambridge, New York: Cambridge University Press.

Cutler, Anne, James McQueen, and Ken Robinson. 1990. Elizabeth and John: sound patterns of men's and women's names. Journal of linguistics 26: p 471-82.

Dalberg, Vibeke. 1985. On homonymy between proper name and appelative. Names 33 (3): p 127-35.

Davis, Hayley G., and Talbot J. Taylor, eds. 1990. Redefining linguistics. London, New York: Routledge.

Doughty, Catherine, and Jessica Williams, eds. 1998. Focus on form in classroom second language acquisition. New York: Cambridge University Press.

Eichler, Ernst, Gerold Hilty, Heinrich Löffler, Hugo Steger, and Ladislav Zgusta, eds. 1996. Namenforschung: ein internationales Handbuch zur Onomastik. Name studies: an international handbook of onomastics. Vol. 2. Berlin: Mouton de Gruyter.

Ekbatani, Glayol , and Herbert Pierson, eds. 1999. Learner-directed assessment in ESL. Mahwah: Lawrence Erlbaum Associates. 
Elkhafaifi, Hussein. 2005. Listening comprehension and anxiety in the Arabic language classroom. The modern language journal 89 (2): p 206-20.

Ellis, Rod. 1999. The place of grammar instruction in the second/foreign language curriculum. New Zealand studies in applied linguistics 5: p 1-21.

Engelbart, Silke Maria, and Beate Theuerkauf. 1999. Defining context within vocabulary acquisition. Language teaching research 3 (1): p 57-69.

Francis, Winthrop Nelson, and Henry Kučera. 1982. Frequency analysis of English usage: lexicon and grammar. Boston: Houghton Mifflin Company.

Frawley, William J., ed. 2003. International encyclopedia of linguistics. 2nd ed. Vol.3. New York: Oxford University Press.

Freedle, Roy, and Irene Kostin. 1999. Does text matter in a multiple-choice test of comprehension? The case for the construct validity of TOEFL's minitalks. Language testing 16 (1): p 2-32.

Gardiner, Alan Henderson. 1957. The theory of proper names: a controversial essay. London: Oxford University Press.

Gary-Prieur, Marie-Noëlle, ed. 1994. Grammaire du nom propre. Paris: Presses universitaires de France.

Gleason, Henry Allan. 1965. Linguistics and English grammar. New York: Holt, Rinehart and Winston.

Greenberg, Joseph Harold, ed. 1963. Universals of language: report of a conference held at Dobbs Ferry, New York, April 13-15, 1961. Cambridge: M.I.T. Press.

Griffiths, Roger. 1992. Speech rate and listening comprehension: Further evidence of the relationship. TESOL quarterly 26 (2): p 385-91.

Grodzinski, Eugeniusz. 1980. Proper names, common names and singular descriptions. Onoma 24: p 10-5.

Hall, Geoffrey D. 1996. Preschoolers' default assumptions about word meaning: Proper names designate unique individuals. Developmental psychology 32 (1): p 17786.

Hall, Geoffrey D., Barbara C. Veltkamp, and William J. Turkel. 2004. Children's and adults' understanding of proper namable things. First language 24 (1): p 5-32.

Hatch, Evelyn, and Anne Lazaraton. 1991. The research manual: design and statistics for applied linguistics. Boston: Heinle and Heinle Publishers.

Heatley, A., I.S.P. Nation, and Averil Coxhead. 2002. RANGE and FREQUENCY programmes. Available at http://www.victoria.ac.nz/lals/staff/paul-nation/nation.aspx [accessed 14 March 2008]. 
Heinz, Peter J. 2004. Towards enhanced second language reading comprehension assessment: Computerized versus manual scoring of written recall protocols. Reading in a foreign language 16 (2): p 97-124.

Hirai, Akiyo. 1999. The relationship between listening and reading rates of Japanese EFL learners. The modern language journal 83 (3): p 367-84.

Hirsh, David, and Paul Nation. 1992. What vocabulary size is needed to read unsimplified texts for pleasure? Reading in a foreign language 8 (2): p 689-96.

Hockett, Charles Francis. 1958. A course in modern linguistics. New York: Macmillan.

1963. The problem of universals in language. In Universals of language edited by J. H. Greenberg. p 1-22. Cambridge: M.I.T. Press.

Hopper, Paul. 1990. The emergence of the category 'proper name' in discourse. In Redefining linguistics, edited by H. G. Davis and T. J. Taylor. p 149-63. London, New York: Routledge.

Hornblower, Simon, and Elaine Matthews, eds. 2000. Greek personal names: Their value as evidence. Oxford: Oxford University Press.

Hough, Carole. 2000. Towards an explanation of phonetic differentiation in masculine and feminine personal names. Journal of linguistics 36 (1): p 1-11.

$\mathrm{Hu}$, Marcella Hsueh-chao, and Paul Nation. 2000. Unknown vocabulary density and reading comprehension. Reading in a foreign language 13 (1): p 403-30.

Huddlleston, Rodney D. 1988. English grammar: an outline. Cambridge: Cambridge University Press.

Huddlleston, Rodney D., and Geoffrey K. Pullum, eds. 2002. The Cambridge grammar of the English language. New York: Cambridge University Press.

Hung, Huynh Cong Minh. 2007. Split attention in reading comprehension: a case of English as a second/foreign language. Master's thesis. Sydney: The University of New South Wales.

Johnson, Ronald E. 1970. Recall of prose as a function of the structural importance of the linguistic units. Journal of verbal learning and verbal behaviour 9: p 12-20.

Jung, Euen Hyuk (Sarah). 2003. The role of discourse signalling cues in second language listening comprehension. The modern language journal 87 (4): p 562-77.

Kameenui, Edward J., Douglas W. Carnine, and Roger Freschi. 1982. Effects of text construction and instructional procedures for teaching word meanings on comprehension and recall. Reading research quarterly 27 (3): p 367-88. 
Kelly, Peter. 1991. Lexical ignorance: the main obstacle to listening comprehension with advanced foreign language learners. IRAL 29 (2): p 135-49.

Kendall, Martha B. 1980. Exegesis and translation: Northern Yuman names as texts. Journal of anthropological research 36 (3): p 261-73.

Kintsch, Walter, and Ely Kozminsky. 1977. Summarizing stories after reading and listening. Journal of educational psychology 69 (5): p 491-9.

Kneale, William. 1962. Modality, de dicto and de re. In Logic, methodology and philosophy of science, edited by E. Nagel, P. Suppes and A. Tarski. p 622-33. Stanford: Stanford University Press.

Kripke, Saul A. 1980. Naming and necessity. Oxford: Blackwell.

Künne, Wolfgang, Albert Newen, and Martin Anduschus, eds. 1997. Direct reference, indexicality, and propositional attitudes. Stanford: Center for the Study of Language and Information.

Lass, Roger. 1973. Review of P.H.Reaney (1967). Foundations of language: International journal of language and philosophy 9: p 392-402.

Laufer, Batia. 1989. What percentage of text-lexis is essential for comprehension? In Special language: from humans thinking to thinking machines, edited by C. Laurén and M. Nordman. p 316-23. Clevedon: Multilingual Matters.

- 1992. How much lexis is necessary for reading comprehension? In Vocabulary and applied linguistics, edited by P. J. L. Arnaud and H. Bejoint. p 12632. London: MacMillan.

Laufer, Batia, and Paul Nation. 1995. Vocabulary size and use: lexical richness in L2 written production. Applied linguistics 16 (3): p 307-22.

Laufer, Batia, and Donald Sim. 1985a. Taking the easy way out: non-use and misuse of clues in EFL reading. English teaching forum 23 (2): p 7-10, 20.

Laufer, Batia, and Donald Sim. 1985b. Measuring and explaining the reading threshold needed to English for Academic Purposes texts. Foreign language annals 18 (5): p 405-411.

Laurén, Christer, and Marianne Nordman, eds. 1989. Special language: from humans thinking to thinking machines. Clevedon: Multilingual Matters.

Lee, James F. 1986. On the use of the recall task to measure L2 reading comprehension. Studies in second language acquisition 8: p 201-12.

Leech, Geoffrey, Paul Rayson, and Andrew Wilson. 2001. Word frequencies in written and spoken English: based on the British National Corpus. Harlow: Longman. 
Lehrer, Adrienne. 1992. Names and naming: Why we need fields and frames. In Frames, fields, and contrasts: new essays in semantic and lexical organization, edited by A. Lehrer and E. F. Kittay. p 123-42. Hillsdale: Lawrence Erlbaum Associates.

1994. Proper names: linguistic aspects. In The encyclopedia of language and linguistics, edited by R. E. Asher and J. M. Y. Simpson. p 3372-4. Oxford: Pergamon Press.

Lehrer, Adrienne, and Eva Feder Kittay, eds. 1992. Frames, fields, and contrasts: new essays in semantic and lexical organization. Hillsdale: Lawrence Erlbaum Associates.

Lieberson, Stanley. 1984. What's in a name? ... some sociolinguistic possibilities. International journal of the sociology of language 45: $\mathrm{p}$ 77-87.

Lipka, Leonhard, and J.M.Y. Simpson. 1994. Lexicalization and institutionalization. In The encyclopedia of language and linguistics, edited by R. E. Asher. p 2164-7. Oxford: Pergamon Press.

Liu, JeeLoo. 1996. The two-component theory of proper names and Kripke's puzzle. Paper presented at the American Philosophical Association Central Division Meeting, April 1996, Chicago. Available at http://faculty.fullerton.edu/jeelooliu/Kripke\%20Puzzle.pdf [accessed 14 March 2008].

Liu, Na and I.S.P. Nation. 1985. Factors affecting guessing vocabulary in context. RECL journal 16 (1): $\mathrm{p} 33-42$.

Long, Donna Reseigh. 1990. What you don't know can't help you: an exploratory study of background knowledge and second language listening comprehension. Studies in second language acquisition 12: p 65-80.

Lund, Randall J. 1991. A comparison of second language listening and reading comprehension. The modern language journal 75 (2): p 196-204.

Lyons, Christopher. 1999. Definiteness. Cambridge, New York: Cambridge University Press.

Lyons, John. 1977. Semantics. Vol. 1. Cambridge, New York: Cambridge University Press.

Markham, Paul, and Michael Latham. 1987. The influence of religion-specific background knowledge on the listening comprehension of adult second-language students. Language learning 37 (2): p 157-70.

Marmaridou, A. Sophia S. 1989. Proper names in communication. Journal of linguistics 25: p 355-72.

Matsuura, Hiroko. 2007. Intelligibility and individual learner differences in the EIL context. System 35 (3): p 293-304. 
Matthews, Peter Hugoe. 1997. The concise Oxford dictionary of linguistics. New York: Oxford University Press.

Möller, Lucie A. 1996. Methods and problems in proper name lexicography. In Namenforschung: ein internationales Handbuch zur Onomastik. Name studies: an international handbook of onomastics, edited by E. Eichler, G. Hilty, H. Löffler, H. Steger and L. Zgusta. p 324-8. Berlin: Mouton de Gruyter.

Morpurgo Davies, Anna. 2000. Greek personal names and linguistic continuity. In Greek personal names: Their value as evidence, edited by S. Hornblower and E. Matthews. p 15-39. Oxford: Oxford University Press.

Mufwene, Salikoko S. 1988. Dictionaries and proper names. International journal of lexicography 1 (3): p 268-83.

Nagel, Ernest, Patrick Suppes, and Alfred Tarski, eds. 1962. Logic, methodology and philosophy of science. Stanford: Stanford University Press.

Nagy, William E., Patricia A. Herman, and Richard C. Anderson. 1985. Learning words from context. Reading research quarterly 20 (2): p 233-53.

Napoli, Ernesto. 1997. Names, indexicals, and identity statements. In Direct reference, indexicality, and propositional attitudes, edited by W. Künne, A. Newen and M. Anduschus. p 185-211. Stanford: Center for the Study of Language and Information.

Nation, I.S.P. 2001. Learning vocabulary in another language. Cambridge: Cambridge University Press.

Nation, I.S.P. 2006. How large a vocabulary is needed for reading and listening? The Canadian Modern Language Review/La revue canadienne des langues vivantes 63 (1): p 59-82.

Nation, I.S.P., and Peter Yongqi Gu. 2007. Focus on vocabulary. Sydney: NCELTR [National Centre for English Language Teaching and Research].

Nicolaisen, Wilhelm F.H. 1996. Name and appellative. In Namenforschung: ein internationales Handbuch zur Onomastik. Name studies: an international handbook of onomastics, edited by E. Eichler, G. Hilty, H. Löffler, H. Steger and L. Zgusta. p 384-93. Berlin: Mouton de Gruyter.

Nuessel, Frank H. 1992. The study of names: a guide to principles and topics. Westport: Greenwood Press.

Nuttall, Christine Elizabeth, and Charles J. Alderson. 1996. Teaching reading skills in a foreign language. Oxford: Heinemann English Language Teaching.

Olsen, Leslie A., and Thomas N. Huckin. 1990. Point-driven understanding in engineering lecture comprehension. English for specific purposes 9 (1): p 33-47. 
Pamp, Bengt. 1985. Ten theses on proper names. Names 33 (3): p 111-8.

Paribakht, T. Sima, and Marjorie Wesche. 1997. Vocabulary enhancement activities and reading for meaning in second language vocabulary acquisition. In Second language vocabulary acquisition: a rationale for pedagogy, edited by J. Coady and T. Huckin. p 174-202. Cambridge, New York: Cambridge University Press.

Payne, John, and Rodney D. Huddleston. 2002. Nouns and noun phrases. In The Cambridge grammar of the English language, edited by R. D. Huddleston and G. K. Pullum. p 323-524. New York: Cambridge University Press.

Peters, Pam. 2004. The Cambridge guide to English usage. Cambridge: Cambridge University Press.

Pitkänen, Ritva Liisa, and Kaija Mallat, eds. 1997. You name it: perspectives on onomastic research. Helsinki: Finnish Literature Society.

Pressley, Michael, and Peter Afflerbach. 1995. Verbal protocols of reading: the nature of constructively responsive reading. Hillsdale: Lawrence Erlbaum Associates.

Pulgram, Ernst. 1954. Theory of names. Berkeley: American Name Society.

Quirk, Randolph, Sidney Greenbaum, Geoffrey Leech, and Jan Svartvik. 1985. A

Comprehensive grammar of the English language. London, New York: Longman.

Read, John A.S. 2000. Assessing vocabulary. Cambridge: Cambridge University Press.

Récanati, François. 1993. Direct reference: from language to thought. Oxford, UK, and Cambridge, USA: Blackwell.

Riley, Gail L., and James F. Lee. 1996. A comparison of recall and summary protocols as measures of second language reading comprehension. Language testing 13 (2): p 173-89.

Robertson, William A. 1996. Name studies in New Zealand. In Namenforschung: ein internationales Handbuch zur Onomastik. Name studies: an international handbook of onomastics, edited by E. Eichler, G. Hilty, H. Löffler, H. Steger and L. Zgusta. p 274-6. Berlin: Mouton de Gruyter.

Rosch, Eleanor. 1978. Principles of categorization. In Cognition and categorization, edited by E. Rosch and B. B. Lloyd. p 27-48. Hillsdale: Lawrence Erlbaum.

Rosch, Eleanor, and Barbara Bloom Lloyd, eds. 1978. Cognition and categorization. Hillsdale: Lawrence Erlbaum.

Ruddell, Martha Rapp. 1994. Vocabulary knowledge and comprehension: a comprehension-process view of complex literacy relationships. In Theoretical models and processes of reading, edited by R. B. Ruddell, M. R. Ruddell and H. Singer. p 414-47. Newark: International Reading Association. 
Ruddell, Robert B., Martha Rapp Ruddell, and Harry Singer, eds. 1994. Theoretical models and processes of reading. Newark: International Reading Association

Sanders, James R. 1973. Retention effects of adjunct questions in written and aural discourse. Journal of educational psychology 65 (2): p 181-6.

Sarig, Gissi. 1989. Testing meaning construction: can we do it fairly? Language testing 6 (1): p 77-94.

Schmidt-Rinehart, Barbara C. 1994. The effects of topic familiarity on second language listening comprehension. The modern language journal 78 (2): p 179-89.

Schmitt, Norbert, Diane Schmitt, and Caroline Clapham. 2001. Developing and exploring the behaviour of two new versions of the Vocabulary Levels Test. Language testing 18 (1): p 55-88.

Seuren, Pieter A.M. 1998. Western Linguistics. An historical introduction. Oxford, Malden: Blackwell.

Sherman, Jane. 1997. The effect of question preview in listening comprehension tests. Language testing 14 (2): p 185-213.

Shohamy, Elana. 1984. Does the testing method make a difference? The case of reading comprehension. Language testing 1 (2): p 147-70.

Shohamy, Elana, and Ofra Inbar. 1991. Validation of listening comprehension tests: the effect of text and question type. Language testing 8 (1): p 23-40.

Sloat, Clarence. 1969. Proper nouns in English. Language 45: p 26-30.

Stahl, Steven A., and Marilyn M. Fairbanks. 1986. The effects of vocabulary instruction: a model-based meta-analysis. Review of educational research 56 (1): p $72-110$.

Taglieber, Loni K., Linda L. Johnson, and Donald B. Yarbrough. 1988. Effects of prereading activities on EFL reading by Brazilian college students. TESOL quarterly 22 (3): p 455-72.

Tatsuki, Donna Hurst. 1998. Comprehension hot spots in movies: scenes and dialogs that are difficult for ESL/EFL students to understand. The internet TESL journal 4 (11). Available at http://iteslj.org/Articles/Tatsuki-HotSpots.html [accessed 14 March 2008].

Thrane, Torben. 1980. Referential-semantic analysis: aspects of a theory of linguistic reference. Cambridge, New York: Cambridge University Press.

Trask, Robert Lawrence. 1997. A student's dictionary of language and linguistics. London: Arnold. 
Tse, Yuen Wah Grace. 2000. Pedagogical implications of prototype theory for the writing of English grammar textbooks: the case of proper names. In Proceedings of the 13th International Symposium on Theoretical and Applied Linguistics (22-24 April 1999), edited by K. Nicolaidis and M. Mattheoudakis. p 490-500. Thessaloniki: Aristotle University of Thessaloniki.

- 2004. A grammatical study of personal names in present-day English: with special reference to the usage of the definite article. English studies 3: p 241-59.

Valentine, Tim, Tim Brennen, and Serge Brédart. 1996. The cognitive psychology of proper names: on the importance of being Ernest. London, New York: Routledge.

Van Langendonck, Willy. 1997. Proper names and their categorical presupposition. In You name it: perspectives on onomastic research edited by R. L. Pitkänen and K. Mallat. p 37-46. Helsinki: Finnish Literature Society.

- 1999. Neurolinguistic and syntactic evidence for basic level meaning in proper names. Functions of language 6 (1): p 95-138.

- 2007. Theory and typology of proper names. Berlin, New York: Mouton de Gruyter.

Walker, Laurence. 1976. Comprehending writing and spontaneous speech. Reading research quarterly 11 (2): p 144-67.

Waring, Rob, and Misako Takaki. 2003. At what rate do learners learn and retain new vocabulary from reading a graded reader? Reading in a foreign language 15 (2): $\mathrm{p}$ 130-63.

Wee, Lionel. 2006. Proper names and the theory of metaphor. Journal of linguistics 42 (2): p 355-71.

Weir, Cyril J. 1988. Communicative language testing with special reference to English as a foreign language. Exeter: A. Wheaton \& Co. Ltd.

—. 1990. Communicative language testing. New York: Prentice Hall. 1993. Understanding and developing language tests. London: Prentice Hall International.

Wells, Daniel R. 1986. The assessment of foreign language reading comprehension: Refining the task. Die Unterrichtspraxis/Teaching German 19 (2): p 178-84.

Whitson, V. 1972. The correlation of auditory comprehension with general language proficiency. Audio-visual language journal 10 (2): p 89-91.

Willems, Klaas. 2000. Form, meaning, and reference in natural language: A phenomenological account of proper names. Onoma 35: p 85-119. 
Wixson, Karen K. 1986. Vocabulary instruction and children's comprehension of basal stories. Reading research quarterly 21 (3): p 317-29.

Wu, Yi'an. 1998. What do tests of listening comprehension test? - A retrospection study of EFL test-takers performing a multiple-choice task. Language testing 15 (1): p $21-44$.

Zelinsky, Wilbur. 2002. Slouching toward a theory of names: A tentative taxonomic fix. Names 50 (4): p 243-62.

Zgusta, Ladislav. 2002. Names. In The new encyclopaedia Britannica. p 733-8.

Chicago: Encyclopædia Britannica, Inc.

Ziff, Paul. 1960. Semantic analysis. Ithaca: Cornell University Press. 